CAMILA MOLENA DE ASSIS

ESTUDO DO COMPORTAMENTO DE CORROSÃO DE LIGAS DE ALUMÍNIO SOLDADAS POR FRICÇÃO (FSW) UTILIZANDO TÉCNICAS ELETROQUÍMICAS GLOBAIS E LOCAIS

SÃO PAULO 
CAMILA MOLENA DE ASSIS

\section{ESTUDO DO COMPORTAMENTO DE CORROSÃO DE LIGAS DE ALUMÍNIO SOLDADAS POR FRICÇÃO (FSW) UTILIZANDO TÉCNICAS ELETROQUÍMICAS GLOBAIS E LOCAIS}

Tese apresentada à Escola Politécnica da Universidade de São Paulo como prérequisito para obtenção do título de Doutora em Ciências 
CAMILA MOLENA DE ASSIS

\section{ESTUDO DO COMPORTAMENTO DE CORROSÃO DE LIGAS DE ALUMÍNIO SOLDADAS POR FRICÇÃO (FSW) UTILIZANDO TÉCNICAS ELETROQUÍMICAS GLOBAIS E LOCAIS}

Tese apresentada à Escola Politécnica da Universidade de São Paulo como prérequisito para obtenção do título de Doutora em Ciências

Área de concentração: Engenharia Química

Orientador

Prof. Dr. Hercílio Gomes de Melo

SÃO PAULO 
Este exemplar foi revisado e corrigido em relação à versão original, sob responsabilidade única do autor e com a anuência de seu orientador.

São Paulo, $\underline{06}$ de janeiro de 2017

Assinatura do autor:

Assinatura do orientador:

\section{Catalogação-na-publicação}

Molena de Assis, Camila

Estudo do comportamento de corrosão de ligas de alumínio soldadas por fricção (FSW) utilizando técnicas eletroquímicas globais e locais / C. Molena de Assis -- versão corr. -- São Paulo, 2017. 164 p.

Tese (Doutorado) - Escola Politécnica da Universidade de São Paulo. Departamento de Engenharia Química.

1.FSW 2.LEIS 3.Ângulo de contato I.Universidade de São Paulo. Escola Politécnica. Departamento de Engenharia Química II.t. 


\section{AGRADECIMENTOS}

Aos orientadores Vincent e Hercílio pela oportunidade e auxílio no desenvolvimento do trabalho.

A professora Mireille por me acolher também no seu laboratório e com toda paciência passar seu conhecimento.

Aos envolvidos nesta pesquisa que contribuíram com conhecimento e experiência: Rocio, Patrícia, Nadine, Isolda e Caio.

À capes pelo financiamento da bolsa do Brasil e do exterior.

Aos amigos pelo apoio: Caio, Rocio, Adriana e Fernando.

Aos meus amigos de Paris: Bea, Larbi, Pierlucca, Nour, Stephane et Sara

À minha mulher por todo apoio psicológico para eu conseguir concretizar este trabalho, sem você eu nada seria.

À minha mãe e irmã pelo incentivo sempre.

Porque, Tu, ó senhor, És meu refúgio 


\section{RESUMO}

A redução de peso é uma questão tecnológica fundamental para a indústria aeroespacial, uma vez que diminui o consumo de combustível, resultando em redução de custos e contribuindo para a redução da emissão de gases de efeito estufa. Devido à relação favorável entre resistência mecânica e peso, as ligas de alumínio de elevada resistência mecânica contribuem favoravelmente para este aspecto. Entretanto, como estas ligas são dificilmente soldáveis pelos processos tradicionais envolvendo fusão, o procedimento de junção utilizado em aeronaves é a rebitagem, resultando em ganho de peso. O processo de soldagem por fricção (friction stir welding-FSW), desenvolvido no início dos anos noventa pelo The Welding Institute (TWI) do Reino Unido, se constituiu em um grande avanço para a soldagem das ligas de alumínio utilizadas na indústria aeroespacial, pois permite a produção de soldas mais confiáveis e virtualmente livres de defeitos. Entretanto, o aquecimento das peças e a deformação mecânica durante a FSW geram zonas com diferentes características microestruturais que, de acordo com a literatura, apresentam resistências à corrosão diferentes. Por oferecerem elevada resolução lateral, as técnicas eletroquímicas locais são úteis para elucidar as diferenças de reatividade local de eletrodos heterogêneos, como no caso de metais soldados. No presente trabalho técnicas eletroquímicas locais foram empregadas para caracterização da resistência à corrosão em meio contendo cloreto das diferentes zonas geradas pela soldagem de topo da liga de alumínio 2024-T3 por FSW, comparando-a com a exibida pelo metal base. O estudo foi complementado com a caracterização microestrutural destas regiões e também por ensaios macroscópicos de corrosão. Os resultados dos procedimentos de caracterização microestrutural confirmaram que a FSW provoca modificações na microestrutura das regiões afetadas pelo processo, principalmente no que concerne à distribuição das nanopartículas precipitadas durante o envelhecimento natural da liga. Por sua vez, os resultados dos ensaios macroscópicos de corrosão e eletroquímicos locais mostraram-se concordantes na determinação da região mais sensível à corrosão, que foi verificada como sendo as zonas termicamente afetada (Heat Affected Zone - HAZ) e termomecanicamente afetada (Thermomechanically Affected Zone TMAZ) do lado do avanço da ferramenta de soldagem, mostrando também que as regiões afetadas pelo processo de soldagem apresentam resistência à corrosão inferior à do metal base. Através do uso da espectroscopia de impedância eletroquímica local (Local Electrochemical Impedance Spectroscopy - LEIS) foi evidenciado que o acoplamento galvânico entre as diferentes zonas geradas durante o processo de soldagem não desempenha um papel relevante na aceleração do processo corrosivo, o que está em desacordo com os resultados publicados em diversos estudos realizados com esta liga soldada por FSW. O trabalho apresenta ainda uma contribuição teórica original demonstrando que medidas de ângulo de contato e de espectroscopia de impedância eletroquímica em uma gota séssil podem ser usadas simultaneamente para a determinação da capacitância da dupla camada elétrica. As previsões do modelo teórico foram confirmadas tanto através de resultados obtidos com um sistema modelo como também em determinações realizadas nas diferentes regiões geradas pela soldagem por FSW da liga 2024-T3.

Palavras-chave: FSW, AA 2024, Espectroscopia de impedância eletroquímica, Espectroscopia de impedância eletroquímica local, ângulo de contato. 


\begin{abstract}
Weight reduction is a fundamental technological issue for the aerospace industry, as it decreases the fuel consumption, resulting in reduced both costs and greenhouse gases emission. Due to the favorable relation between strength and weight, high strength aluminum alloys favorably contribute to this aspect, but they remain difficult to weld by conventional processes involving fusion, and, therefore, the junction procedure used in aircraft is riveting, resulting in weight gain. The friction stir welding (FSW) process, developed in the early nineties by the "The Welding Institute" (TWI), United Kingdom, is a major breakthrough for the welding of aluminum alloys as it allows the production of more reliable and virtually defect-free welds. However, the heating of the parts and the mechanical deformation during FSW generate zones with different microstructures with different corrosion resistances. As they offer high lateral resolution, local electrochemical techniques are useful for elucidating differences in local reactivity of heterogeneous electrodes, as the case of welded metals. In the present work, local electrochemical techniques were employed to characterize the corrosion resistance in chloride environment of the different zones generated by butt welding the 2024-T3 aluminum alloy by FSW, and to compare this response with that displayed by the base metal. The study was complemented with the microstructural characterization of these regions and also by macroscopic corrosion tests. The results of the microstructural characterization confirmed that FSW causes changes in the microstructure of the regions affected by the process, especially with regard to the distribution of the precipitated nanoparticles during the natural aging of the alloy. The results of the macroscopic corrosion and of the local electrochemical tests showed good agreement in the determination of the most sensitive regions to corrosion, which were found to be the heat affected (HAZ) and the thermomechanically affected (TMAZ) zones of the advancing side of the weld tool. They also showed that the regions affected by the welding procedure have a lower corrosion resistance than the base metal. By using Local Electrochemical Impedance Spectroscopy (LEIS), it was shown that the galvanic coupling between the different areas generated during the welding process does not need to be taken into account in the description of the corrosion process, which is at odds with the results published in several studies of this alloy welded by FSW. The work also present an original theoretical contribution, demonstrating that contact-angle measurements and electrochemical impedance spectroscopy in a sessile drop can be used simultaneously to determine the capacity of the interface. The theoretical model predictions were confirmed by the experimental results obtained both with a model system and in the different regions generated by FSW of aluminum alloy 2024-T3.
\end{abstract}

Keywords: FSW, AA 2024, Electrochemical impedance spectroscopy, Local electrochemical impedance spectroscopy, Contact Angle 


\section{RÉSUMÉ}

La réduction de la masse est une question technologique fondamentale pour l'industrie aérospatiale car elle diminue la consommation de carburant, et entraine ainsi une réduction des coûts et des émissions de gaz à effet de serre. Les alliages d'aluminium à haute résistance contribuent favorablement à cet aspect en raison du rapport favorable masse / tenue mécanique, mais ils restent difficiles à souder par des procédés classiques impliquant la fusion. Ainsi, le procédé classique de jonction utilisé pour les avions est le rivetage, ce qui entraîne un gain de masse significatif. Le soudage par friction (FSW pour friction stir welding), mis au point au début des années 90 par le "The Welding Institute" au Royaume-Uni, est une percée majeure pour le soudage des alliages d'aluminium, car il permet la production plus fiable et pratiquement sans défaut de soudures. Cependant, le chauffage des pièces et de la déformation mécanique pendant la FSW génèrent des zones de microstructures ayant des résistances différentes à la corrosion. Grâce à leur résolution latérale élevée, les techniques électrochimiques locales sont utiles pour élucider les différences de réactivité locale des électrodes hétérogènes. Dans ce travail, les techniques électrochimiques locales ont été utilisées pour caractériser la résistance à la corrosion dans un environnement contenant des chlorures, des différentes zones générées par le soudage bout à bout de l'alliage d'aluminium 2024-T3 par FSW, et comparer cette réponse avec celle du métal de base. L'étude a été complétée par la caractérisation de la microstructure de ces régions, ainsi que par des essais de corrosion à une échelle macroscopique. Les résultats de la caractérisation microstructurale ont confirmé que la FSW provoque des modifications des régions touchées par le processus de soudage, en particulier en ce qui concerne la distribution des nanoparticules précipitées au cours du vieillissement naturel de l'alliage. Les résultats de corrosion macroscopique et des tests électrochimiques locaux sont en bon accord pour la détermination des régions les plus sensibles à la corrosion, qui se sont révélés être les zones affectées thermiquement (ZAT) et thermomécaniquement (TMAZ) du côté « avance » de l'outil de soudure. Ces mesures ont également montré que les régions affectées par le procédé de soudage ont une résistance à la corrosion inférieure à celle du métal de base. En utilisant la spectroscopie d'impédance électrochimique locale (SIEL), il a été démontré que le couplage galvanique entre les différentes zones générées pendant le processus de soudage ne doit pas être pris en compte dans la description du processus de corrosion, ce qui est en contradiction avec les résultats publiés dans plusieurs études pour cet alliage soudé par FSW. Le travail présente également une contribution originale sur le couplage des mesures d'angle de contact et de la spectroscopie d'impédance électrochimique dans une goutte sessile qui peuvent être utilisés en même temps pour déterminer la capacité de l'interface. Les prédictions du modèle théorique ont été confirmées par des résultats expérimentaux obtenus dans un premier temps avec un système de modèle puis sur les différentes régions générées par le soudage FSW de l'alliage d'aluminium 2024-T3.

Mots-clés: Soudage par FSW, Alliage AA 2024, Spectroscopie d'impédance électrochimique, Spectroscopie d'impédance électrochimique locale, Angle de contact 


\section{LISTA DE ILUSTRAÇÕES}

Figura 2-1: Esquema ilustrativo das designações dos tratamentos térmicos e mecânicos aplicados às ligas de alumínio (TRUJILLO, 2015)

Figura 2-2: Diagrama de fases hipotético para ligas endurecidas por precipitação com composição $\mathrm{C}_{0}$ (CALLISTER \& WILLIAN, 1994).

Figura 2-3: Esquema de precipitação dos precipitados de endurecimento durante o envelhecimento da liga 2024-T3. O último precipitado da sequência representa a fase de equilíbrio que não é coerente com a matriz.

Figura 2-4: Diagrama de Pourbaix do Alumínio, potencial (V,EPH) versus $\mathrm{pH}$ a $25^{\circ} \mathrm{C}$, aAl3+, aAl2O $-=10^{-6} \mathrm{~mol} . \mathrm{L}^{-1}$,com o domínio de estabilidade da água apresentada pelas linhas pontilhadas (BARDAL, 1933).

Figura 2-5: Ilustração do processo de soldagem por fricção (Friction Stir Welding -FSW) (MOROZ, ALCÂNTARA, \& SANTOS, 2012).

Figura 2-6: Microestrutura com a classificação das zonas geradas na FSW para um liga de Al 2024. A: Base não afetada do material, B: Zona afetada pelo calor (Heat Affected Zone - HAZ), C: Zona termomecanicamente afetada (Thermomechanically Affected Zone - TMAZ). A região central representa o nugget ou "zona misturada" (THREADGILL P. L., LEONARD, SHERCLIFF, \& WITHERS, 2009)

Figura 2-7: Distribuição de precipitados nas diferentes regiões da liga de alumínio 7050-T651 soldada por FSW: (a) metal base, (b) HAZ, (c) TMAZ próxima à HAZ e (d) TMAZ próxima ao nugget, (e) nugget. (SU J. , NELSON, MISHRA, \& MAHONEY, 2003).

Figura 3-1: Esquema representativo das regiões onde foram realizados os ensaios eletroquímicos nas diferentes zonas da solda FSW.

Figura 3-2: Representação esquemática da metodologia do eletrodo vibratório de varredura -SVET. 59

Figura 3-3: Esquematização da ponta de um bi eletrodo

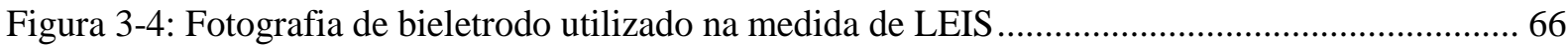

Figura 3-5: Esquema do sistema para medida de LEIS...

Figura 3-6: Célula eletroquímica composta por 5 eletrodos - montagem clássica dos três eletrodos e o bieletrodo.

Figura 3-7: Célula eletroquímica composta por 5 eletrodos - montagem clássica dos três eletrodos e o bieletrodo (a) posicionamento da rede de platina na célula eletroquímica (b)

Figura 3-8: Impedâncias global $(\mathrm{Z})$ e local $(\mathrm{z})$ do eletrodo de platina com a solução de trabalho $\mathrm{NaCl}$ $0,1 \mathrm{~mol} \cdot \mathrm{L}^{-1}$

Figura 3-9: Medida global (Z) e local (z) de impedância feitas em um eletrodo de platina em meio de

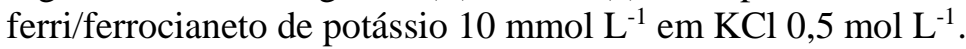

Figura 3-10: Representação esquemática de uma gota sobre uma superfície sólida onde $\mathrm{A}^{\mathrm{SL}}$ é a área sólido- líquido e $\mathrm{A}^{\mathrm{LV}}$ é a área líquido-vapor.

Figura 3-11: Variação de $\tau^{\mathrm{SL}}$ em função do potencial de acordo com a Eq. 31 supondo uma superfície onde foi depositada uma gota de água destilada formando uma calota esférica. Simulação realizada de acordo com as propriedades apresentadas na própria Figura. Observar que uma variação de $100 \mathrm{mV}$ em potencial acarreta em uma mudança entre 1 e $2^{\circ}$ no ângulo de contato. 76

Figura 3-12: Imagem da célula utilizada para os ensaios eletroquímicos sobre a gota, equipamento Krüss, DSA 100 (a); suporte porta amostra (b), contraeletrodo sobre uma gota de 2,5 $\mu \mathrm{L}$ (c) e conexões elétricas entre o suporte da amostra e os equipamentos eletrodo de referência (d). 
Figura 3-13: Representação esquemática do acoplamento entre as medidas de ângulo de contato e de potencial de circuito aberto (Krüss, DSA 100 e Autolab PGSTAT 100) e a medida de impedância (potenciostato SOTELEM-PG-STAT.Z1 acoplado a um gerador/analisador de frequência Solartron 1254)

Figura 3-14: Imagem ótica da gota séssil sobre o eletrodo de trabalho, platina envelhecida, com o eletrodo de referência e o contra eletrodo inseridos em seu interior.

Figura 3-15: Representação esquemática da divisão das regiões da solda e como procedeu-se o experimento para avaliar a reprodutibilidade do experimento.

Figura 4-1: Imagens obtidas em microscópio eletrônico de varredura, da superfície da liga AA2024-T3: metal base, região não afetada pela soldagem (a), região do nugget (b) e junção TMAZ-nugget (c)... 82

Figura 4-2: Imagens obtidas por MEV da superfície da liga AA2024: metal base (a), região do nugget (b). Círculos pretos: IMs Al-Cu-Mg; círculo vermelho: grupo de IMs Al-Cu-Fe-Mn-Si.

Figura 4-3: Imagem obtida em microscópio eletrônico de varredura da região TMAZ, com mapeamento EDS da região.

Figura 4-4: Imagem obtida em microscópio eletrônico de varredura da região do nugget, com mapeamento EDS da região.

Figura 4-5: Micrografias obtidas em microscópio eletrônico de varredura da superfície da liga AA2024T3: metal base (a), HAZ (b), TMAZ (c) e nugget (d).

Figura 4-6: Micrografias obtidas por TEM das diferentes regiões da solda. Metal-base (a) e (b); HAZ (c), (d) e (e), TMAZ (f), (g) e (h), nugget (i) e (j). As micrografias (e), (h) e (j) mostram detalhes de precipitados poligonais atribuídos por Wang e Starink à fase S (WANG \& STARINK, 2007).......... 90

Figura 4-7: Perfil de dureza através das regiões afetadas pela soldagem por FSW.

Figura 4-8: Imagem por microscopia ótica da seção transversal após ataque com reagente Keller (a). Detalhes das regiões do metal base (b); do nugget (c); do nugget e das zonas termicamente afetadas do lado do avanço (d) e (e), do nugget e das zona termomecanicamente afetadas do lado do retrocesso (f).

Figura 4-9: Micrografias obtidas por FE-SEM de zona não afetada pelo calor da liga AA 2024-T3 após ataque com reagente de Keller.

Figura 4-10: Micrografias obtidas por FE-SEM da TMAZ da liga AA 2024-T3 soldada por FSW após ataque com reagente de Keller. Em evidência, nanopartículas precipitadas ao longo dos contornos de grão.

Figura 4-11: Micrografias obtidas por FE-SEM do nugget da liga AA 2024-T3 soldada por FSW após ataque com reagente de Keller.

Figura 4-12: Diagrama esquemático mostrando detalhes da evolução da microestrutura na HAZ para a liga de alumínio endurecível por precipitação AA 7108-T6 (FRIGAARD, GRONG, \& MIDLING, 2001).

Figura 4-13: Imagens obtidas por microscopia eletrônica de varredura da região do metal base (a) e do nugget (b) após 3 horas de imersão em solução de $\mathrm{NaCl}$ 0,1 $\mathrm{mol} \mathrm{L}^{-1}$. Imagens obtidas sobre um mesmo corpo de prova contendo toda a região de solda. 102

Figura 4-14: Detalhe da corrosão de um IM Al-Cu-Fe-Mn-(Si) no metal base (a) e no nugget (b). Imagens obtidas em um mesmo corpo de prova contendo toda a região de solda.

Figura 4-15: Resultado do teste de corrosão em solução de $\mathrm{NaCl} 0,7 \mathrm{~mol} \mathrm{~L}^{-1}$ contendo ágar-ágar e indicador universal de $\mathrm{pH}$ sobre a superfície da liga de alumínio 2024-T3 soldada por FSW "A" e "R" se referem, respectivamente, ao lado do avanço e do retrocesso.

Figura 4-16: Imagem de topo por microscopia ótica da superfície da liga AA 2024-T3 soldada por FSW após o término do ensaio de corrosão por esfoliação. 
Figura 4-17: Imagem por microscopia ótica da seção transversal da liga de Al 2024 soldada por FSW após ensaio de corrosão por esfoliação realizado de acordo com a norma ASTM G-34 e limpeza dos produtos de corrosão. Detalhes do: lado do avanço (a)) e lado do retrocesso (b). 105

Figura 4-18: Micrografia ótica da seção transversal da região de solda após ensaio de corrosão intergranular de acordo com a norma ASTM G110-97 (a). Detalhes com maiores aumentos: das regiões HAZ-TMAZ (avanço) (b), (c), (d); da região do nugget (e), (f), (g); das regiões TMAZ-HAZ (retrocesso) (h), (i), (j).

Figura 4-19: Seção transversal do metal base após ensaio de corrosão intergranular de acordo com os procedimentos da norma ASTM G110-97.

Figura 4-20: Monitoramento do potencial de circuito aberto para as regiões do metal base, HAZ e nugget em solução de $\mathrm{NaCl}$ 0,1 mol.L $\mathrm{L}^{-1}$ durante 1 hora.

Figura 4-21: Curvas de polarização potenciodinâmica anódica em meio de $\mathrm{NaCl}$ 0,1 mol.L $\mathrm{L}^{-1}$ das regiões da liga de alumínio 2024-T3 soldada por FSW: metal base, HAZ e nugget. 113

Figura 4-22: Curvas de polarização potenciodinâmica catódica em meio de $\mathrm{NaCl} 0,1$ mol.L $\mathrm{L}^{-1}$ das regiões da liga de alumínio 2024-T3 soldada por FSW: metal base, HAZ e nugget. 114

Figura 4-23: Diagramas de impedância em meio de $\mathrm{NaCl}$ 0,1 mol.L-1 para Liga de alumínio 2024 soldada por FSW (a) Diagrama de Nyquist e (b) Diagramas de Bode

Figura 4-24: Diagramas de Nyquist (a) e de ângulo de fases (b) para a liga AA2024-T3 soldada por FSW......

Figura 4-25: Fotografia do microeletrodo de referência de $\mathrm{Ag} / \mathrm{AgCl}_{\text {sat }}$.

Figura 4-26: Comparação entre voltamogramas obtidos com o microeletrodo de referência de $\mathrm{Ag} / \mathrm{AgCl}$ e eletrodo comercial de $\mathrm{Ag} / \mathrm{AgCl}$. Pt em solução de $\mathrm{K}_{3}\left[\mathrm{Fe}(\mathrm{CN})_{6}\right]$. 117

Figura 4-27: Monitoramento do potencial de circuito aberto em solução de $\mathrm{NaCl} 0,1$ mol.L ${ }^{-1}$ para as diferentes regiões de solda da liga de alumínio 2024-T3 soldada por FSW. BM - base metálica; HAZ A - zona termicamente afetada no lado do avanço; TMAZ A - zona termomecanicamente afetada lado do avanço; nugget; TMAZ - R zona termomecanicamente afetada no lado do retrocesso; HAZ - R - zona termicamente afetada no lado do retrocesso. 118

Figura 4-28: Diagramas de impedância em solução de $\mathrm{NaCl} 0,1$ mol.L $\mathrm{L}^{-1}$ para as diferentes regiões de solda da liga de alumínio 2024-T3 soldada por FSW. BM - base metálica; HAZ - A - zona termicamente afetada no lado do avanço; TMAZ - A - zona termomecanicamente afetada lado do avanço; nugget; TMAZ - R zona termomecanicamente afetada no lado do retrocesso; HAZ - R - zona termicamente afetada no lado do retrocesso.

Figura 4-29: Mapas de densidade corrente, obtidos por SVET com as imagens do eletrodo de trabalho (Nugget) após 0h (a), 3h (b), 6h (c), de imersão em $\mathrm{NaCl}$ 0,05 mol.L-1.

Figura 4-30: Mapas de densidade corrente, obtidos por SVET com as imagens do eletrodo de trabalho (Nugget) após $12 \mathrm{~h}(\mathrm{a}), 20 \mathrm{~h}$ (b) e $24 \mathrm{~h}$ (c) de imersão em $\mathrm{NaCl} 0,05$ mol.L. $\mathrm{L}^{-1}$. 124

Figura 4-31: Mapas de densidade de corrente, obtidos por SVET com as imagens do eletrodo de trabalho (HAZ, TMAZr e do nugget) após 0h (a), 3h (b) e 24h (c) de imersão em $\mathrm{NaCl}$ 0,05 mol.L-1.......... 125

Figura 4-32: Mapas de densidade de corrente, obtidos por SVET com as imagens do eletrodo de trabalho (HAZ, TMAZa e do nugget) após 0h (a), 3h (b) e 24h (c) de imersão em $\mathrm{NaCl}$ 0,05 mol.L - $^{-1}$.......... 126

Figura 4-33: Diagramas de Nyquist das medidas de impedância global (a), local (b), realizadas sobre AA 2024-T3 soldada por FSW em meio $\mathrm{NaCl} 0,1$ mol. $\mathrm{L}^{-1}$ e a região em $\mathrm{AF}$ da impedância local (c)

Figura 4-34:Distribuições de potencial e corrente na solução devido ao acoplamento galvânico entre eletrodos modelos de $\mathrm{Al}$ e $\mathrm{Mg}$. Em branco as linhas equipotenciais e em vermelho a distribuição de corrente em solução. Adaptado de Lacroix et al (2009). 
Figura 4-35: Esboços das configurações utilizadas para modelagem numérica

Figura 4-36: Diagrama de Nyquist da simulação FEM (círculos abertos) para um eletrodo de $5 \mathrm{~mm}$ de diâmetro em uma célula convencional de 3 eletrodos. A linha sólida foi obtida a partir da expressão analítica (Eq. 10) correspondendo ao circuito Randles. As simulações foram feitas com k $\mathrm{k}_{0}=10^{-3} \mathrm{~cm} \mathrm{~s}^{-1}$, $\mathrm{D}=510^{-6} \mathrm{~cm}^{2} \mathrm{~s}^{-1}, \alpha=0,5, \sigma=10 \mathrm{mS} \mathrm{cm}{ }^{-1}$ 135

Figura 4-37: A. Diagramas de Nyquist obtidos por simulação FEM (círculos abertos) para uma célula gota (configuração a). A linha sólida foi calculada com a expressão analítica (Eq. 10) correspondendo ao circuito Randles. Os detalhes para altas frequências são apresentados na figura B. As simulações foram feitas com $\mathrm{D}=510^{-6} \mathrm{~cm}^{2} \mathrm{~s}^{-1}, \alpha=0,5, \sigma=62 \mathrm{mS} \mathrm{cm}$. 137

Figura 4-38: Diagramas de Nyquist obtidos por simulação FEM (círculos abertos) para uma célula gota (configuração b). A linha sólida foi calculada com a expressão analítica (Eq. 10) correspondendo ao circuito Randles. Os detalhes para a alta frequência são apresentados na figura B. As simulações foram conduzidas com $\mathrm{D}=510^{-6} \mathrm{~cm}^{2} \mathrm{~s}^{-1}, \alpha=0,5, \sigma=10 \mathrm{mS} \mathrm{cm}$. 139

Figura 4-39:Diagramas de Nyquist obtidos por simulação FEM (círculos abertos) para uma célula gota (configuração b). A linha sólida foi calculada com a expressão analítica (Eq. 10) correspondendo ao circuito de Randles. As simulações foram realizadas com $\mathrm{k}_{0}=10^{-3} \mathrm{~cm} \mathrm{~s}^{-1}, \mathrm{D}=510^{-6} \mathrm{~cm}^{2} \mathrm{~s}^{-1}, \alpha=0,5$, (A) e (C) foram plotadas usando todos os valores de frequência $(100 \mathrm{kHz}-10 \mathrm{mHz}$ ); Figuras (B) e (D) com um intervalo menor $(1,6 \mathrm{kHz}-10 \mathrm{mHz})$

Figura 4-40: Diagramas de Nyquist obtidos por simulação FEM (símbolos abertos) para uma célula gota (configuração b) em função da distância entre o WE e da relação RE/CE. A linha sólida foi calculada com a expressão analítica (Eq. 10) correspondendo ao circuito de Randles cujos parâmetros foram obtidos por ajuste descartando os resultados nas frequências mais elevadas. A simulação foi feita com $\mathrm{D}=510^{-6} \mathrm{~cm}^{2} \mathrm{~s}^{-1}, \alpha=0,5, \mathrm{e}(7 \mathrm{~A}) \mathrm{k}^{0}=10^{-3} \mathrm{~cm} \mathrm{~s}^{-1}$ ou (7B) $\mathrm{k}^{0}=210^{-2} \mathrm{~cm} \mathrm{~s}^{-1}$. 142

Figura 4-41: Comparação dos diagramas de Nyquist obtidos com a célula eletroquímica convencional de 3 eletrodos e com a célula gota com configuração para dois tamanhos do CE (A) $0,1 \mathrm{~mm}$ e (B) 0,2 $\mathrm{mm}$ de diâmetro. As linhas sólidas correspondem ao ajuste utilizando circuito de Randles com as características especificadas na Tabela 2. 143

Figura 4-42: Voltamograma cíclico para as três configurações (célula eletroquímica convencional e duas células gota) a $50 \mathrm{mV} \mathrm{s}^{-1}$.

Figura 4-43: Variação do ângulo de contato da gota $\mathrm{Fe}(\mathrm{CN})_{6}{ }^{3-} / \mathrm{Fe}(\mathrm{CN})_{6}{ }^{4-}$ em $0.1 \mathrm{~mol} \mathrm{~L}^{-1} \mathrm{KCl}$ (configuração b)durante as medidas de impedância. As variações devem-se à evaporação da água como mostrado nas figuras. 146

Figura 4-44: Avaliação da reprodutibilidade, com repetições de 4 gotas, acompanhando o potencial de circuito aberto em função do tempo (A) e o ângulo de contato (B) na região do metal em solução de $\mathrm{NaCl} 0,1$ mol. $\mathrm{L}^{-1}$. 146

Figura 4-45: Variação do OCP para as regiões do metal base, HAZ+TMAZ e nugget em solução NaCl $0,1 \mathrm{~mol} . \mathrm{L}^{-1}$

Figura 4-46: Simulação da interpretação dos dados experimentais com os valores estabelecidos pela Figura 3-11.

Figura 4-47: Diagramas de Nyquist das medidas de impedância sobre a gota, realizadas sobre AA 2024T3 soldada por FSW nas diferentes regiões da solda em meio $\mathrm{NaCl} 0,1$ mol. $\mathrm{L}^{-1}$. 


\section{LISTA DE ABREVIATURAS E SIGLAS}

AA Aluminum Association

Al Alumínio

Cu Cobre

EDS Espectroscopia de Energia Dispersiva (Energy Dispersive Spectroscopy)

EIS Espectroscopia de impedância eletroquímica (Electrochemical Impedance Spectroscopy)

ET Eletrodo de trabalho

ER Eletrodo de referência

Fe Ferro

FSW Soldagem por Fricção (Friction Stir Welding)

GP Guinier-Preston

GPB Guinier-Preston-Bagaryatsky

HAZ Zona afetada pelo calor (Heat affected zone)

IMs Intermetálicos

LEC Laboratório de Eletroquímica e corrosão

LEIS Espectroscopia de Impedância Eletroquímica Localizada (Local Electrochemical Impedance Spectroscopy)

LISE Laboratoire Interfaces et Systèmes Électrochimiques

Mg Magnésio

MEV Microscopia Eletrônica de Varredura

MIG/MAG Metal Inert Gas e Metal Active Gas

MO Microscopia Óptica

PCA Potencial de Circuito Aberto

PFZ Precipitate free zone

Si Silício

SVET Técnica do eletrodo vibratório de varredura (Scanning Vibrating Electrode Technique)

TEM Transmission Electron Microscopy

TIG Tungsten Inert Gas

TMAZ Zona termomecanicamente afetada (Thermomechanically affected zone)

TWI The Welding Institute 


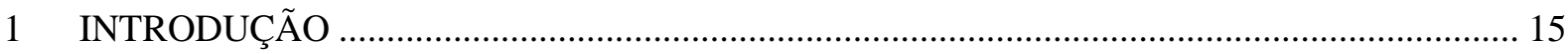

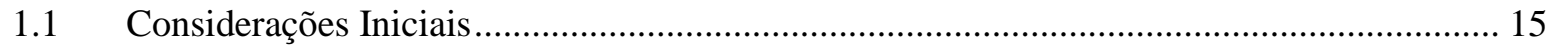

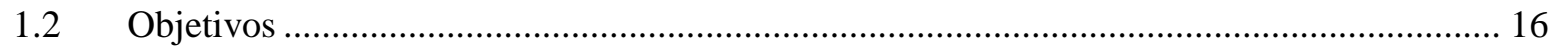

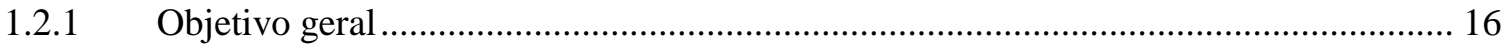

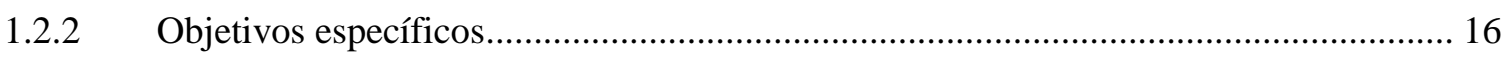

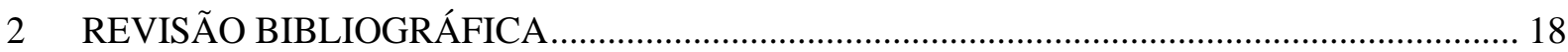

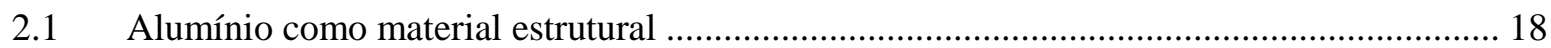

2.2 Sistema de classificação das ligas de alumínio ...................................................................... 19

2.2.1 Sistema de classificação para as ligas de alumínio fundidas (casting compositions).... 19

2.2.2 Sistema de classificação para as ligas de alumínio trabalháveis mecanicamente

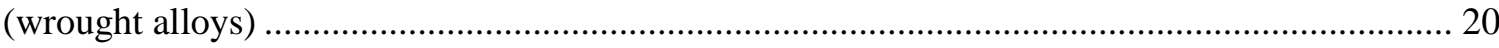

2.2.3 Designação do tratamento térmico para as ligas de alumínio ........................................ 21

2.3 Microestrutura da liga alumínio 2024-T3 .......................................................................... 28

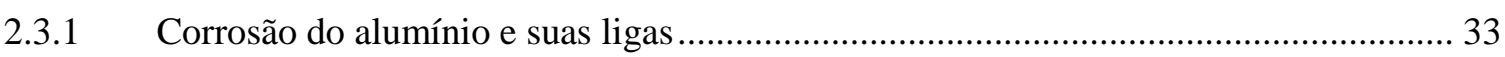

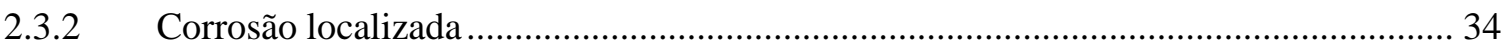

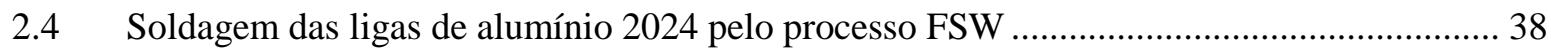

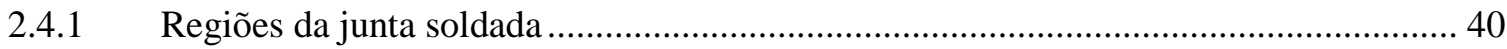

2.4.2 Modificações microestruturais nas diferentes regiões da solda ..................................... 42

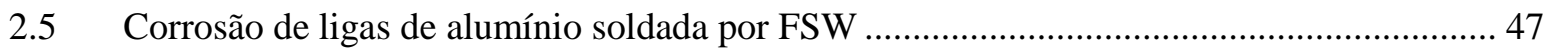

2.5.1 Uso de técnicas locais para avaliação de corrosão da liga de alumínio 2024 soldada por FSW $\quad 51$

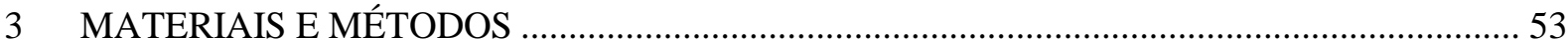

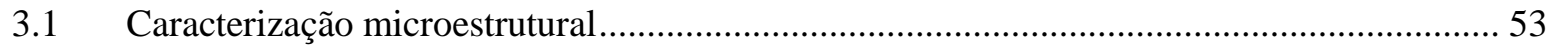

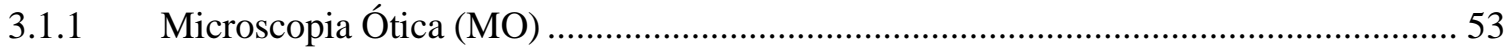

3.1.2 Microscopia Eletrônica de Varredura com análise por Energia Dispersiva de Raio-X

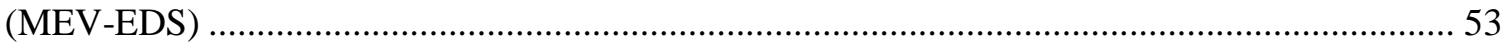

3.1.3 Microscopia Eletrônica de Transmissão (TEM) ........................................................... 54

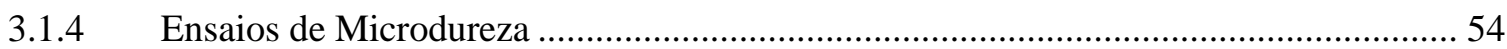

3.1.5 Ensaio de corrosão utilizando solução de $\mathrm{NaCl} 0,7 \mathrm{~mol} \mathrm{~L}^{-1}$ contendo ágar-ágar e

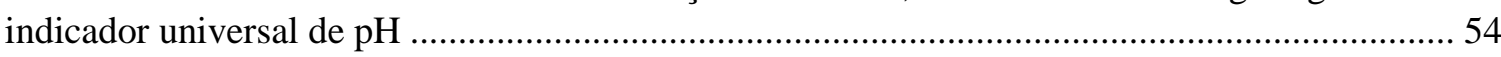

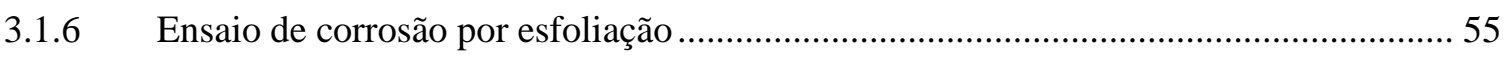

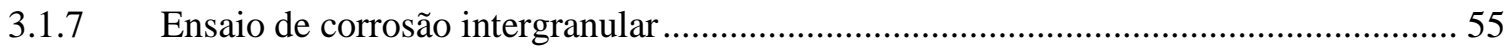

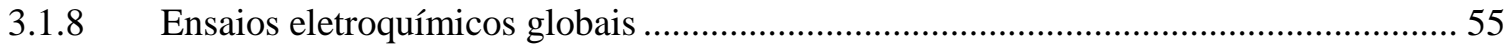

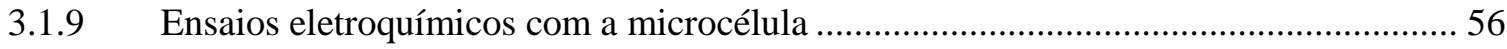

3.1.10 Eletrodo Vibratório de Varredura (Scanning Vibrating Electrode Technique - SVET)57

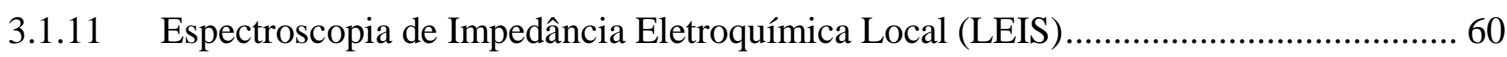

3.1.12 Ensaios com a gota séssil (Acoplamento EIS/ângulo de contato) ................................... 70

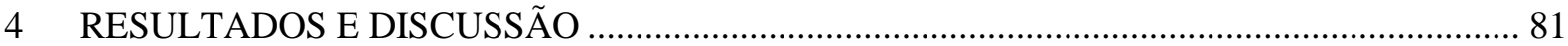


4.1 Caracterização microestrutural da liga de alumínio 2024 soldada por FSW

4.1.1 Caracterização por MEV de amostras polidas............................................................... 81

4.1.2 Caracterização por Microscopia Eletrônica de Transmissão (TEM) das diferentes

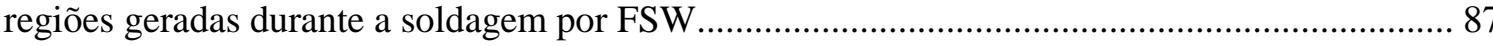

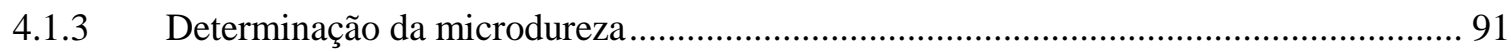

4.1.4 Caracterização por MEV de amostras polidas atacadas por Keller ................................ 93

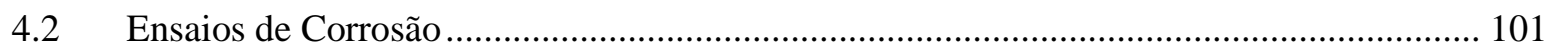

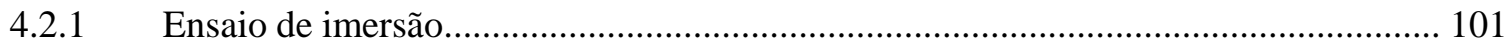

4.2.2 Ensaio em solução de $\mathrm{NaCl} 0,7 \mathrm{~mol} \mathrm{~L}^{-1}$ contendo ágar-ágar e indicador universal de $\mathrm{pH}$

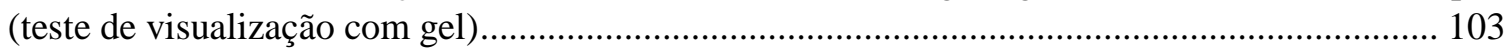

4.2.3 Ensaio de corrosão por esfoliação (ASTM G-34) ......................................................... 104

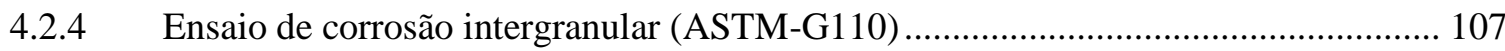

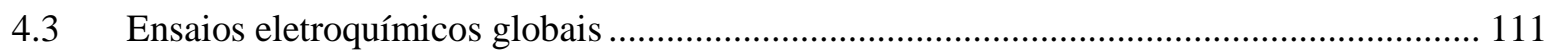

4.4 Ensaios eletroquímicos utilizando a microcélula .................................................................... 116

4.5 Ensaios com Eletrodo Vibratório de Varredura (SVET) ................................................. 121

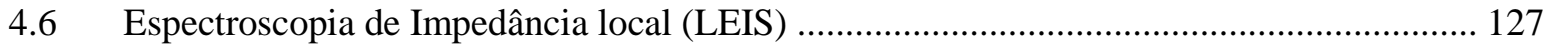

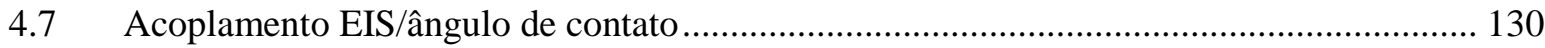

4.7.1 Modelização das linhas de corrente e potencial em uma gota..................................... 130

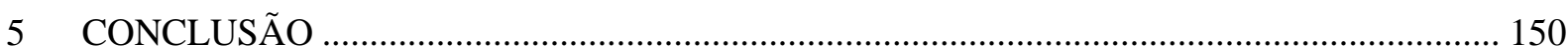

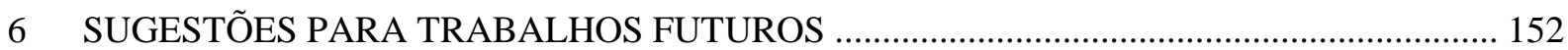

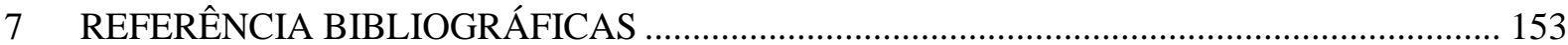




\section{INTRODUÇÃ̃o}

\subsection{CONSIDERAÇÕES INICIAIS}

As ligas de alumínio ( $\mathrm{Al}$ ) da série $2 \mathrm{XXX}$ têm como principais elementos de liga o cobre $(\mathrm{Cu})$ e o magnésio $(\mathrm{Mg})$, apresentando como características mais relevantes: elevada resistência mecânica, reduzida taxa de propagação de trinca, elevada condutividade térmica e facilidade de usinagem. É largamente utilizada na indústria aeroespacial, na fabricação de moldes para conformação de termoplásticos e em estruturas onde se necessita de leveza e alta resistência mecânica. Entretanto, apresentam limitações nos processos de soldagem utilizando técnicas de fusão convencional como plasma, Tungsten Inert Gas (TIG), Metal Inert Gas e Metal Active Gas (MIG/MAG) ou eletrodo revestido, por apresentarem defeitos decorrentes da fusão envolvida no processo como porosidades, trincas de solidificação e fusão no contorno do grão (ASTM METALS HANDBOOK, 1990) (JARIYABOON, et al., 2007) (MOROZ, ALCÂNTARA, \& SANTOS, 2012), o que é um inconveniente para a construção de estruturas de grande porte, como as aeronaves, onde, frequentemente, é necessária a junção de diferentes partes. Desta maneira, atualmente, utiliza-se a rebitagem para a junção de partes de aeronave, o que acarreta em um ganho de peso na estrutura.

Com o objetivo de não utilizar os processos convencionais no estado líquido, na década de 90, o The Welding Institute (TWI), no Reino Unido, desenvolveu um procedimento inovador denominado soldagem por fricção ( $F S W$ - Friction Stir Welding) (EUA Patente $\mathrm{N}^{\circ}$ PCT/GB92/02203, 1991). Este processo não envolve fusão, nem introduz outro metal na estrutura obtendo-se soldas mais resistentes e virtualmente livres de defeitos. A união no estado sólido na região de solda ocorre devido à energia térmica gerada a partir da fricção e da deformação plástica gerada pelo deslocamento e movimento rotativo de uma ferramenta, composta por um pino e uma base não consumíveis, na junção das peças a serem unidas combinadas com a força aplicada para alinhamento das mesmas (MOROZ, ALCÂNTARA, \& SANTOS, 2012).

Entretanto, como em todo processo de soldagem, o aumento da temperatura durante o procedimento provoca mudanças na microestrutura do material base, criando regiões distintas, com propriedades microestruturais diferentes (BOUSQUET, POULONQUINTIN, PUIGGALI, DEVOS, \& TOUZET, 2011). De acordo com a American Welding Society Standard D17-3M, macroscopicamente, as zonas de fusão das ligas de 
alumínio soldadas por fricção podem ser classificadas como: base não afetada do material, zona afetada pelo calor (Heat affected zone - HAZ) e zona termomecanicamente afetada (Thermomechanically affected zone - TMAZ), que inclui uma região com uma microestrutura cristalizada, de granulação fina, a qual é denominada nugget (BOUSQUET, POULON-QUINTIN, PUIGGALI, DEVOS, \& TOUZET, 2011) (JARIYABOON, et al., 2007). As diferenças entre as microestruturas dessas regiões e as modificações introduzidas pelo processo de soldagem podem provocar variações no desempenho anticorrosivo entre as diferentes regiões de solda e entre estas e o metal base, levando ao desenvolvimento de células galvânicas tanto entre as diferentes regiões da solda como no interior de uma mesma região, aspecto que ainda não se encontra estudado de maneira adequada na literatura.

\subsection{OBJETIVOS}

\subsubsection{Objetivo geral}

O objetivo do presente trabalho foi empregar técnicas eletroquímicas globais e locais para estudar o comportamento de corrosão de chapas da liga de alumínio AA 2024T3 soldadas por FSW em meio contendo cloreto, focando na investigação do comportamento eletroquímico de cada região individual da solda FSW e nos efeitos do acoplamento galvânico entre as diferentes regiões sobre o processo corrosivo.

\subsubsection{Objetivos específicos}

- Utilizar uma microcélula para avaliar a tendência à corrosão de cada região individual da solda através de técnicas eletroquímicas convencionais: curvas de polarização e espectroscopia de impedância eletroquímica (Electrochemical Impedance Spectroscopy - EIS).

○ Utilizar técnicas eletroquímicas locais como: espectroscopia de impedância eletroquímica local (Local Electrochemical Impedance Spectroscopy - LEIS), técnica do eletrodo vibratório de varredura (Scanning Vibrating Electrode Technique - SVET) e o método eletroquímico de eletromolhabilidade (gota séssil) para avaliar a reatividade local das diferentes regiões de solda. 
- Identificar a região mais reativa do cordão de solda, comparando esta resistência com a do metal base.

- Identificar a existência de acoplamento galvânico entre as diferentes zonas geradas durante a soldagem e sua influência no comportamento eletroquímico das diferentes regiões. 


\section{REVISÃO BIBLIOGRÁFICA}

\subsection{ALUMÍNIO COMO MATERIAL ESTRUTURAL}

O alumínio é o segundo elemento metálico mais abundante na crosta terrestre, possuindo a interessante propriedade de apresentar baixo peso específico: $2,70 \mathrm{~g} / \mathrm{cm}^{3}, \mathrm{o}$ que corresponde a aproximadamente $35 \%$ do peso do aço e $30 \%$ do peso do cobre, dois dos metais estruturais mais utilizados industrialmente. Para uma visão mais completa da importância desta propriedade, a Tabela 2-1 apresenta a densidade de alguns dos principais materiais metálicos (ATKINS \& JONES, 2001). Verifica-se que o Al é mais denso apenas do que o $\mathrm{Be}$ e o $\mathrm{Mg}$. Materiais com menores densidades permitem a construção de estruturas mais leves, o que é uma característica particularmente desejada na indústria aeroespacial devido à necessidade de redução do consumo de combustível (ABAL - Associação Brasileira do Alumínio, 2007). Daí o fato de que $70 \%$ da maioria das aeronaves comerciais serem fabricadas usando ligas de alumínio como matéria prima (TOBER \& SCHILLER, 2000).

Tabela 2-1: Comparação entre a densidade do alumínio e alguns dos principais materiais metálicos (ATKINS \& JONES, 2001)

\begin{tabular}{cccccccccccccc}
\hline Metal & Al & Be & $\mathbf{C u}$ & Sn & $\mathbf{F e}$ & $\mathbf{M g}$ & $\mathbf{M n}$ & $\mathbf{N i}$ & $\mathbf{A u}$ & $\mathbf{P t}$ & $\mathbf{A g}$ & $\mathbf{T i}$ & $\mathbf{W}$ \\
\hline $\begin{array}{c}\text { densidade } \\
\mathbf{g} / \mathbf{c m}^{3}\end{array}$ & 2,70 & 1,85 & 8,93 & 7,29 & 7,87 & 1,74 & 7,47 & 8,91 & 19,28 & 21,45 & 10,50 & 4,55 & 19,30 \\
\hline
\end{tabular}

Inicialmente utilizado para a produção de elementos decorativos e de cozinha, o alumínio passou a ser um competidor econômico na área de engenharia a partir das primeiras décadas do século 20, quando foi descoberto o processo de envelhecimento (ABAL - Associação Brasileira do Alumínio, 2007). Sob a forma comercialmente pura, devido à baixa resistência mecânica (resistência à tração de $90 \mathrm{MPa}$ que pode ser praticamente dobrada por trabalho a frio) (ABAL - Associação Brasileira do Alumínio, 2007), o metal apresenta pouco interesse para uso estrutural. Entretanto sua resistência mecânica pode ser aumentada significativamente com a adição de pequenas quantidades de elementos de liga, com especial destaque para o cobre, zinco e magnésio, de forma que, atualmente, algumas das ligas de $\mathrm{Al}$ produzidas são tão resistentes quanto alguns aços estruturais. Devido a isto, hoje em dia, o alumínio é utilizado em diversos setores 
industriais como: transporte, embalagens, construção e bens de consumo, comprovando a versatilidade deste metal.

\subsection{SISTEMA DE CLASSIFICAÇÃO DAS LIGAS DE ALUMÍNIO}

O sistema de classificação das ligas de alumínio registrado pela The Aluminum Association $(A A)$ utiliza os principais elementos de liga e o processo empregado para obtenção de produtos semiacabados como parâmetros, ou seja, ligas destinadas à fabricação de componentes fundidos (cast alloys) ou ligas destinadas à fabricação de produtos semiacabados (wrought alloys). Estas últimas podem ser trabalhadas mecanicamente como laminados planos (placas, chapas e folhas), laminados não planos (tarugos, barras e arames) perfis extrusados e componentes forjados (ASM Specialty Handbook, 1993), (HANDBOOK, 1966), (KAUFMAN \& ROOY, 2004) (GLOBAL ADVISORY GROUP, 2011).

\subsubsection{Sistema de classificação para as ligas de alumínio fundidas (casting compositions)}

$\mathrm{Na}$ designação da AA as ligas designadas como Cast, ligas fundidas, são identificadas por 3 (três) dígitos seguidos de um valor decimal (ASM Specialty Handbook, 1993). A Tabela 2-2 apresenta um sistema de identificação simplificado para estas ligas.

Tabela 2-2: Sistema de identificação das ligas de alumínio fundidas (ASM Specialty Handbook, 1993)

\begin{tabular}{lcc}
\hline Série & Elemento Principal & Outros elementos \\
\hline 1 xx.x & Alumínio Puro & - \\
$2 x x . x$ & Cobre & Podem estar presentes \\
3xx.x & Silício & Cobre, Magnésio \\
$4 x x . x$ & Silício & - \\
$5 x x . x$ & Magnésio & - \\
$6 x x . x$ & & Não utilizada \\
$7 x x . x$ & Zinco & Cobre, Magnésio \\
$8 x x . x$ & Estanho & \\
$9 x x . x$ & & Não utilizada \\
\hline
\end{tabular}

O primeiro dígito corresponde ao constituinte principal da liga, o segundo e o terceiro dígito é uma designação específica da liga. O decimal .0 (ponto zero) em todos 
os casos representa os limites da liga fundida, ou seja, a composição das peças fundidas 0.1 (ponto um) lingotamento e 0.2 (ponto dois), lingotamento com composição diferente do 0.1 .

No Brasil, a norma ABNT NBR 15975 determina a composição química das Ligas de alumínio de fundição. (ABNT NBR15975:2011, 2015)

\subsubsection{Sistema de classificação para as ligas de alumínio trabalháveis mecanicamente (wrought alloys)}

Na designação da AA as ligas wrought, ligas trabalháveis mecanicamente, são identificadas por 4 (quatro) dígitos. A Tabela 2-3 apresenta um sistema de identificação simplificado (ASM Specialty Handbook, 1993).

Tabela 2-3: Sistema de identificação das ligas de alumínio trabalháveis mecanicamente (ASM Specialty Handbook, 1993).

\begin{tabular}{lcc}
\hline Série & Elemento Principal & Outros elementos \\
\hline 1xxx & Alumínio Puro & - \\
$2 \times x x$ & Cobre & Magnésio, Lítio \\
3xxx & Manganês & Magnésio \\
4xxx & Silício & - \\
$5 \times x x$ & Magnésio & - \\
$6 \times x x$ & Silício, Magnésio & Cobre, Magnésio, Crômio, \\
$7 \times x x$ & Zinco & Zircônio \\
& & Composição Mista \\
$8 \times x x$ & Estanho e Lítio & Reservado para uso futuro \\
$9 \times$
\end{tabular}

Essas ligas são utilizadas nas mais diversas áreas, de acordo com sua composição e características como (ASM Specialty Handbook, 1993):

Liga 1xxx: Indústrias química e elétrica.

Liga 2xxx: Aeronaves (graças a sua elevada resistência mecânica).

Liga 3xxx: Aplicações arquitetônicas e produtos de uso geral.

Liga 4xxx: Varetas ou eletrodos de solda e chapas para brasagem.

Liga 5xxx: Produtos expostos à atmosfera marinha como cascos de barcos.

Liga 6xxx: Produtos de extrusão de uso arquitetônico. 
Liga 7xxx: Componentes estruturais de aeronaves e outras aplicações que necessitam de elevados requisitos de resistência. Esta liga é a que possui a maior resistência mecânica entre todas as ligas de alumínio.

Liga 8xxx: Envolve um grande número de composições com uma miscelânea de elementos de liga, foram desenvolvidas para uso aeroespacial e criogenia.

No Brasil, a norma ABNT NBR ISO209 determina a composição química do alumínio e suas ligas, que são expressas em porcentagem, abrangendo sistemas de classificação das ligas trabalháveis mecanicamente e as para fundição, como também peças, lingotes além de densidade nominal das ligas trabalháveis de alumínio (ABNT, 2010).

\subsubsection{Designação do tratamento térmico para as ligas de alumínio}

Os tratamentos térmicos podem ser aplicados em ligas de alumínio específicas, tanto fundidas como tratáveis termicamente, e visam melhorar a microestrutura e/ou controlar algumas características metalúrgicas, tais como propriedades mecânicas, tamanho de grãos, etc (ABAL - Associação Brasileira do Alumínio, 2007).

As ligas de alumínio trabalháveis mecanicamente podem ser divididas em duas classes: as não tratáveis termicamente (séries 1000, 3000, 4000, 5000 e 8000) e aquelas que podem ser tratadas termicamente (séries 2000, 6000 e 7000). As primeiras podem ter suas propriedades mecânicas alteradas apenas por meio de tratamento mecânico, enquanto as segundas podem ter suas propriedades mecânicas alteradas por tratamento térmico de solubilização e posterior envelhecimento, sendo que este segundo processo pode ocorrer tanto a temperatura ambiente como em temperaturas relativamente elevadas e pode ser precedido de trabalho mecânico.

A designação do tratamento sucede o número que determina a composição da liga e é separado por um hífen (2024-T351). Ela é composta por uma letra que indica o tratamento básico seguida de números que indicam as condições desse tratamento. A Figura 2-1 (TRUJILLO, 2015) apresenta um esquema das designações para os tratamentos térmicos e mecânicos que são aplicados às ligas de alumínio. Vargel (1999) apresenta na Tabela 2-4, a composição das ligas trabalhadas mecanicamente e seus aditivos. 


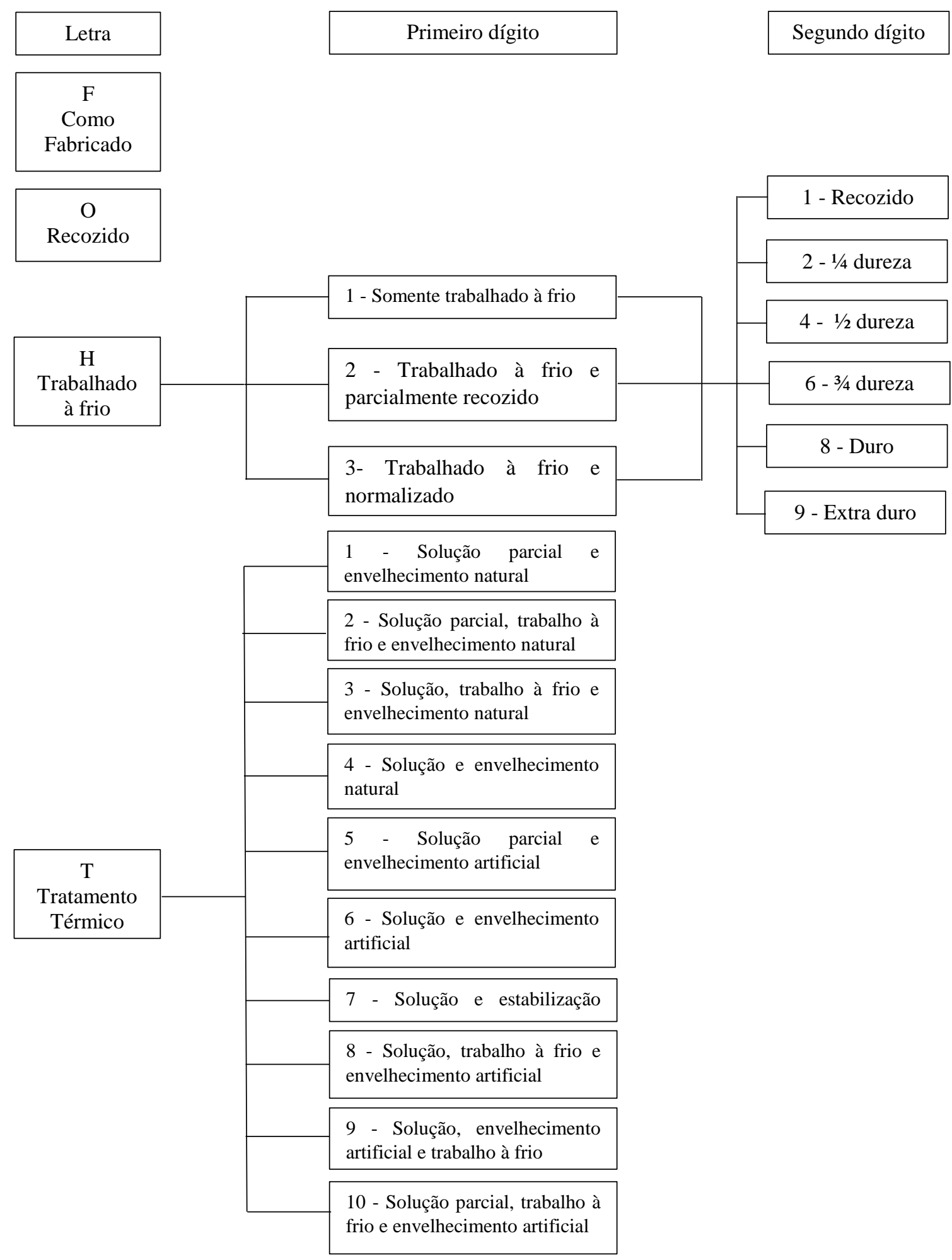

Figura 2-1: Esquema ilustrativo das designações dos tratamentos térmicos e mecânicos aplicados às ligas de alumínio (TRUJILLO, 2015)

No presente trabalho a liga estudada foi a 2024-T3. Esta é uma liga do sistema Al$\mathrm{Cu}$, endurecível por precipitação, e com adição de magnésio como elemento de liga 
secundário. O teor de cobre varia entre 2 e $6 \%$ em peso (HANDBOOK, 1966), e para atingir as propriedades mecânicas desejadas a liga é solubilizada, trabalhada a frio e envelhecida até uma condição estável. As aplicações da liga 2024-T3 incluem chapas e painéis automotivos, blindagens leves, componentes forjados e usinados (VARGEL, 1999). Na indústria aeroespacial ela é utilizada em estruturas da fuselagem, nos denominados shear webs, que correspondem aos membros das asas submetidos a tensões extremas e em áreas estruturais onde a tenacidade, resistência mecânica e à fadiga sejam necessárias (WANG \& STARINK, 2007). A Tabela 2-4, apresenta a composição das ligas trabalhadas mecanicamente e seus aditivos (VARGEL, 1999).

Tabela 2-4: Designação das ligas trabalhadas mecanicamente (VARGEL, 1999)

\begin{tabular}{ccccc}
\hline Tipo de endurecimento & Séries & Elementos de liga & Concentração (\%) & Aditivos \\
\hline \multirow{4}{*}{ Encruado } & 1000 & Ausente & - & $\mathrm{Cu}$ \\
& 3000 & Manganês & $0,5-1,5$ & $\mathrm{Mg}, \mathrm{Cu}$ \\
& 5000 & Magnésio & $0,5-5$ & $\mathrm{Mn}, \mathrm{Cr}$ \\
& 8000 & Ferro e silício & $\mathrm{Si}: 0,3-1$ & - \\
& & & $\mathrm{Fe}: 0,6-2$ & \\
\hline \multirow{2}{*}{ Precipitação } & 6000 & Magnésio e silício & $\mathrm{Mg}: 0,5-1,5 ; \mathrm{Si}: 0,5-$ & $\mathrm{Cu}, \mathrm{Cr}$ \\
& 2000 & Cobre & 1,5 & $\mathrm{Si}, \mathrm{Mg}$ \\
& 7000 & Zinco e magnésio & $\mathrm{Zn}: 5-7$ & $\mathrm{Cu}$ \\
& & & $\mathrm{Mg}: 1-2$ & \\
\hline
\end{tabular}

A etapa da solubilização consiste em aquecer a liga a uma temperatura tal que todos os átomos (elementos de liga e de adição) permaneçam em solução sólida. Por exemplo, considere uma liga de composição $\mathrm{C}_{0}$ na Figura 2-2. O tratamento consiste em aquecer o material até a temperatura $\mathrm{T}_{0}$, campo de estabilidade da fase $\alpha$, mantendo-o nesta temperatura durante tempo suficiente para que todos os precipitados da fase $\beta$ sejam dissolvidos, obtendo assim uma solução sólida homogênea $\alpha$. (CALLISTER \& WILLIAN, 1994). Para a liga de alumínio 2024-T3 esta temperatura é de cerca de $495^{\circ}$ C (VARGEL, 1999). 


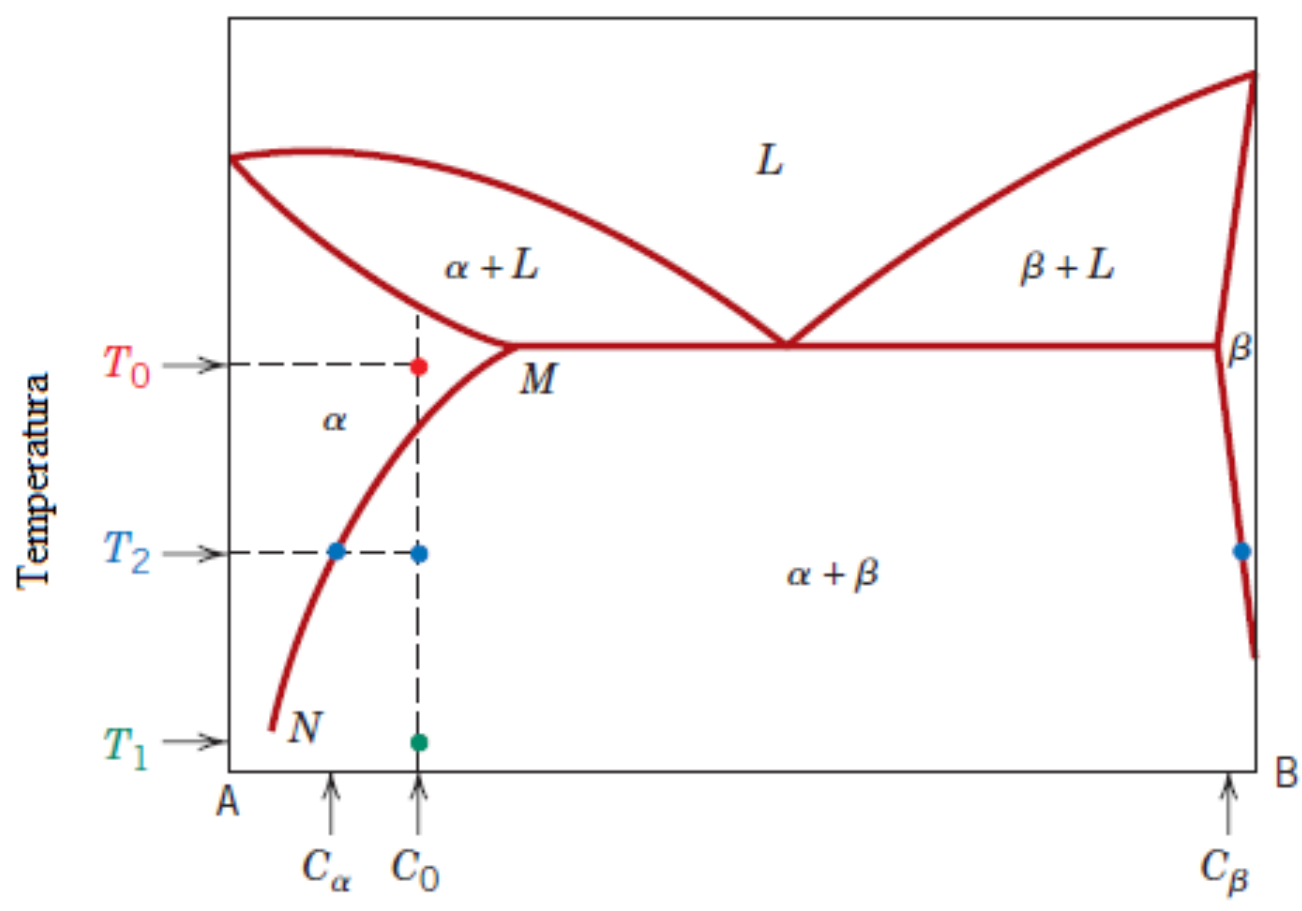

Composição (\%B)

Figura 2-2: Diagrama de fases hipotético para ligas endurecidas por precipitação com composição $\mathrm{C}_{0}$ (CALLISTER \& WILLIAN, 1994).

A têmpera consiste em um resfriamento rápido da liga a partir da temperatura de solubilização até uma temperatura na qual os átomos de soluto fiquem em condição instável na solução sólida. Assim, uma solução sólida supersaturada é obtida, onde os átomos do soluto são posicionados nos nós da rede cúbica de face centrada do alumínio. Este tipo de procedimento impede temporariamente a precipitação dos elementos de liga e mantém a concentração de lacunas na microestrutura igual àquela existente em alta temperatura. Entretanto, como esta condição é instável, posteriormente, os elementos de liga difundirão e precipitarão na microestrutura do material com cinéticas variáveis, dando origem a novas fases. Estes fenômenos são acelerados pelo elevado número de lacunas presentes na liga temperada (VARGEL, 1999), e, no caso da liga 2024, também pela deformação mecânica à qual a mesma é submetida após esta etapa do tratamento térmico, que aumenta o número de discordâncias na microestrutura, os quais também servem de sítios para nucleação para as novas fases. Reportando-se à Figura 2-2, o resfriamento rápido da liga da temperatura $T_{0}$, após a solubilização, até a temperatura $T_{1}$ gera uma solução sólida supersaturada com concentração de soluto $\mathrm{C}_{0}$ superior à composição de equilíbrio. (CALLISTER \& WILLIAN, 1994). 
A última etapa do tratamento térmico da liga 2024-T3 é o envelhecimento. Este fenômeno foi observado pela primeira vez em 1906 pelo alemão, Alfred Wilm, em uma liga de $\mathrm{Al}-\mathrm{Cu}-\mathrm{Mg}$, cuja dureza aumentava com o tempo à temperatura ambiente (DUBOIT \& SAINFORT, 1991), e no caso das ligas leves, resultou na primeira liga industrial, o duraluminum (2017-T4), em 1916. Genericamente, o procedimento consiste em manter a liga em uma determinada temperatura que permitirá a difusão controlada dos átomos de soluto que se encontram retidos na solução sólida supersaturada. Estes átomos irão se aglomerar e precipitar de maneira extremamente fina em defeitos da microestrutura (lacunas, discordâncias, etc.) potencializando o efeito de endurecimento (ABAL - Associação Brasileira do Alumínio, 2007). Na sequência do processo de envelhecimento da liga 2024, inicialmente surgem as zonas de Guinier-Preston (GP), para as ligas $\mathrm{Al}-\mathrm{Cu}$ ou $\mathrm{Al}-\mathrm{Cu}-\mathrm{Mg}$ com elevada relação $\mathrm{Cu} / \mathrm{Mg}$ ou de Guinier-PrestonBagaryatsky (GPB) para as ligas $\mathrm{Al}-\mathrm{Cu}-\mathrm{Mg}$. Estas zonas consistem em monocamadas de átomos de soluto de dimensões nanométricas (RINGER \& HONO, 2000) que, de acordo com o documentado na literatura, são insuficientes para garantir um endurecimento substancial, pois podem ser facilmente cisalhadas por discordâncias em movimento. A diferença entre as zonas GP e GPB é que na primeira existem interações apenas entre os átomos de $\mathrm{Cu}$ e na segunda átomos de $\mathrm{Cu}$ e $\mathrm{Mg}$ estão envolvidos (RINGER \& HONO, 2000) (CHARAI, WALTHER, ALFONSO, ZAHRA, \& ZAHRA, 2000).

Com o prosseguimento do envelhecimento (aumento do tempo em temperatura ambiente ou então aquecimento por qualquer processo), a partir das zonas GP e GPB, formam-se os precipitados metaestáveis. Nestes existe a presença de Al, e eles são coerentes ou semicoerentes com a matriz da liga (CHARAI, WALTHER, ALFONSO, ZAHRA, \& ZAHRA, 2000) (WANG \& STARINK, 2007) dependendo do grau de envelhecimento (o grau de coerência diminui com o tempo ou temperatura de envelhecimento). De acordo com a literatura, as pequenas diferenças de parâmetro de rede entre estes precipitados e a matriz gera um campo de tensões que dificulta a movimentação de discordâncias e provoca o endurecimento, sendo este processo o grande responsável pelo endurecimento e pela melhoria das propriedades mecânicas das ligas de alumínio de elevada resistência mecânica (ASTM METALS HANDBOOK, 1990). O prolongamento excessivo do envelhecimento provoca um amolecimento significativo da liga devido à perda total de coerência entre o precipitado e a matriz, formando uma interface, o que alivia totalmente as tensões (ASTM METALS HANDBOOK, 1990). Este processo coincide com a formação das fases $\mathrm{S}\left(\mathrm{Al}_{2} \mathrm{CuMg}\right)$ ou $\theta\left(\mathrm{Al}_{2} \mathrm{Cu}\right)$ que não são 
coerentes com a matriz da liga (CHARAI, WALTHER, ALFONSO, ZAHRA, \& ZAHRA, 2000).

O fluxograma da Figura 2-3, mostra as sequências propostas para a precipitação das fases de endurecimento da liga 2024-T3 durante o envelhecimento (RINGER \& HONO, 2000) (WANG \& STARINK, 2007). Neste, os sobrescritos (") e (') representam, respectivamente, os precipitados coerentes e semi-coerentes com a matriz. No caso da sequência $\mathrm{GP}$ o precipitado de equilíbrio $(\theta)$ é a fase $\mathrm{Al}_{2} \mathrm{Cu}$, enquanto para a GPB a fase de equilíbrio é o $\mathrm{Al}_{2} \mathrm{CuMg}$ (fase $\mathrm{S}$ ). À formação das zonas GP e/ou GPB geralmente é relacionada ao primeiro aumento de dureza observado durante o envelhecimento das ligas $\mathrm{Al}-\mathrm{Cu}$ ou $\mathrm{Al}-\mathrm{Cu}-\mathrm{Mg}$, e que acontece após tempos relativamente curtos de envelhecimento, enquanto um segundo aumento de dureza, que ocorre após períodos mais longos de envelhecimento, estaria associado à formação das demais fases coerentes ou semicoerentes com a matriz (RINGER \& HONO, 2000) (ZAHRA \& ZAHRA, 2001).

Destaca-se que ambos os processos podem ser acelerados com a temperatura, resultando, porém, em propriedades mecânicas reduzidas devido ao engrossamento das partículas e/ou sua precipitação de modo menos homogêneo e em locais preferenciais, tais como, contornos de grão.

Solução Sólida Supersaturada (SSSS) $\left\{\begin{array}{l}\mathrm{GP} \longrightarrow \theta^{\prime \prime} \longrightarrow \theta^{\prime} \longrightarrow \theta\left(\mathrm{Al}_{2} \mathrm{Cu}\right) \\ \mathrm{GPB} \longrightarrow \mathrm{S}^{\prime \prime} \longrightarrow \mathrm{S}^{\prime} \longrightarrow \mathrm{S}\left(\mathrm{Al}_{2} \mathrm{CuMg}\right)\end{array}\right.$

Figura 2-3: Esquema de precipitação dos precipitados de endurecimento durante o envelhecimento da liga 2024-T3. O último precipitado da sequência representa a fase de equilíbrio que não é coerente com a matriz.

Com relação às sequências de precipitação apresentadas na Figura 2-3, alguns aspectos devem ser destacados:

i. as zonas GP e GPB não são consideradas como fases pois carecem de estrutura cristalina organizada. Têm sido identificadas como cilíndricas ou sob formas de bastão possuindo dimensões típicas entre 1 e $2 \mathrm{~nm}$ de diâmetro e 4 a $8 \mathrm{~nm}$ de comprimento (RINGER S. , HONO, POLMEAR, \& SAKURAI, 1996) (SILCOCK, 1960-1961)

ii. alguns autores propõem que a formação das zonas GP e GPB é precedida pelo agrupamento (clustering) ou co-agrupamento (co-clustering - quando envolve 
mais de uma espécie química) de átomos de soluto (MATSUBARA \& COHEN, 1983) (RINGER S., HONO, POLMEAR, \& SAKURAI, 1996). Estes teriam, formas, tamanho, composição, grau de ordenamento e orientação menos definidos que uma zona (RINGER S. P., HONO, SAKSAI, \& POLMEAR, 1997). Nestes casos, o primeiro aumento de dureza observado durante o envelhecimento da liga 2024 estaria relacionado à formação destes aglomerados e não à formação das zonas GP e GPB (RINGER S. , HONO, POLMEAR, \& SAKURAI, 1996). A quantidade de átomos contidas em um cluster é de apenas algumas dezenas (RINGER S. P., HONO, SAKSAI, \& POLMEAR, 1997) (STARINK, GAO, \& YAN, 2004)

iii. alguns autores rejeitam a existência das zonas GPB, justificando que as evidências experimentais de sua formação são muito fracas (STARINK, GAO, \& YAN, 2004). Nestes trabalhos o aumento de dureza que ocorre à temperatura ambiente nas ligas $\mathrm{Al}-\mathrm{Cu}-\mathrm{Mg}$ também é atribuído à formação dos co-precipitados (co-clusters);

iv. algumas ou várias das etapas propostas na Figura 2-3 podem estar ausentes na sequência de precipitação, sendo este fator altamente dependente da temperatura de envelhecimento (RINGER \& HONO, 2000). Ringer e Hono (2000) reportam que a sequência completa de precipitação ocorre apenas quando o envelhecimento da liga ocorre em temperaturas abaixo da linha solvus correspondente às zonas GP e GPB, e que algumas etapas da sequência podem ser suprimidas se o envelhecimento ocorrer em temperaturas próximas ou superiores às mesmas. Deste modo, dependendo da condição de envelhecimento, pode haver a nucleação de uma determinada fase diretamente a partir de um sítio propício na matriz, sem que anteriormente as zonas GP ou GPB tenham sido formadas;

v. é possível a coexistência de mais de uma fase em uma mesma condição de envelhecimento (SILCOCK, 1960-1961) (RINGER \& HONO, 2000) (CHARAI, WALTHER, ALFONSO, ZAHRA, \& ZAHRA, 2000)

vi. para a sequência de precipitação que termina com a formação da fase $S$ $\left(\mathrm{Al}_{2} \mathrm{CuMg}\right)$ diversos autores propõem sequências diferentes daquela apresentada na Figura 2-3, com o início da precipitação ocorrendo a partir do agrupamento (clustering) e/ou co-agrupamento (co-clustering) de átomos de $\mathrm{Cu}$ e $\mathrm{Mg}$ e/ou a ausência de uma ou mais das fases de não equilíbrio (S” e S') 
(RINGER \& HONO, 2000) (RINGER S. , HONO, POLMEAR, \& SAKURAI, 1996) (ZAHRA \& ZAHRA, 2001) (CHARAI, WALTHER, ALFONSO, ZAHRA, \& ZAHRA, 2000)

vii. em função da dificuldade em diferenciar suas estruturas cristalográficas, diversos autores questionam a existências das fases S" e também consideram que as fases S' e S são as mesmas, variando apenas o grau de coerência com a matriz (RINGER \& HONO, 2000) (RINGER S. , HONO, POLMEAR, \& SAKURAI, 1996)

A partir da literatura consultada para a revisão de literatura apresentada neste item, é possível afirmar que ainda existem muitas discussões e incertezas na literatura sobre a sequência de precipitação e até existência de alguns dos precipitados de endurecimento presentes na microestrutura da liga 2024, pelo menos no que concerne à sequência iniciada com as zonas GPB (Figura 2-3), a mais importante para as ligas 2024. Porém, para efeito da apresentação dos resultados e discussão será admitido que a sequência de precipitação dos precipitados de endurecimento corresponde àquela apresentada na Figura 2-3.

\subsection{MICROESTRUTURA DA LIGA ALUMÍNIO 2024-T3}

A composição complexa e os tratamentos termomecânicos realizados na liga 2024-T3 resultam em uma microestrutura complexa, composta por diversos tipos de partículas e de intermetálicos, os quais podem ser classificados em três categorias principais (DUBOIT \& SAINFORT, 1991): precipitados de endurecimento, dispersoides e partículas intermetálicas. Entretanto, é importante destacar que na literatura científica, não existe consenso de como denomina-las, por exemplo, Birbilis e Buchheit (2005), classificam como intermetálicos todas as fases de equilíbrio e de não equilíbrio presentes na microestrutura de ligas de alumínio de elevada resistência mecânica, ou seja, todas as fases precipitadas na microestrutura. Estes autores denominam simplesmente precipitados, as partículas que, no presente trabalho e em outros (DUBOIT \& SAINFORT, 1991) são denominadas precipitados de endurecimento, e de partículas constituintes, o que aqui será denominado intermetálico, a denominação dispersoides é comum aos dois trabalhos (BIRBILIS \& BUCHHEIT, 2005). Por outro lado, Starke e 
Staley (1996), chamam de partículas intermetálicas constituintes àquelas que, no presente trabalho, são denominadas simplesmente intermetálicos (STARKE \& STALEY, 1996)

Partículas Intermetálicas (IMs): este grupo de precipitados não contribui para o endurecimento da matriz, e é constituído por partículas irregulares e com dimensões tipicamente acima de alguns micrômetros (BUCHHEIT, GRANT, HLAVA, MCKENZIE, \& ZENDER, 1997) (LIAO, OLIVE, GAO, \& WEI, 1988) (STARKE \& STALEY, 1996) que, no entanto, podem atingir algumas dezenas de micrômetros em algumas amostras (GUILLAUMIN \& MANKOWSKI, 1999) (STARKE \& STALEY, 1996). Esta variabilidade pode estar associada tanto a diferenças no tratamento de homogeneização de amostras com diferentes origens (HUGHES, et al., 2011), como às diferentes composições das ligas estudadas (ZHOU, LUO, HASHIMOTO, HUGHES, \& THOMPSON, 2012), uma vez que as solubilidades sólidas dos elementos de liga e impurezas são interdependentes, assim como ao histórico termomecânico do material (STARKE \& STALEY, 1996) (ZHOU, LUO, HASHIMOTO, HUGHES, \& THOMPSON, 2012). Assim, o tamanho dos IMs decresce com o aumento da velocidade de solidificação, com a diminuição do teor de Fe e/ou Si e com o nível de deformação (STARKE \& STALEY, 1996). Estas partículas são formadas durante a solidificação da liga (BIRBILIS \& BUCHHEIT, 2005) (STARKE \& STALEY, 1996), e praticamente não são dissolvidas mesmo em temperaturas tão elevadas quando às de solubilização (aproximadamente $495^{\circ} \mathrm{C}$ ) (ZHANG \& FRANKEL, 2003)

No que concerne à composição dos IMs, a literatura reporta informações divergentes (STARKE \& STALEY, 1996) (BUCHHEIT, GRANT, HLAVA, MCKENZIE, \& ZENDER, 1997), e é reportado que, frequentemente, uma mesma partícula pode exibir composição heterogênea com diferentes domínios composicionais coexistindo no interior de um mesmo IM (BOAG, et al., 2009) (CAMPESTRINI, VAN WESTING, VAN ROOIJEN, \& de WIT, 2000) (HUGHES, et al., 2010) (ILEVBARE, SCHNEIDER, KELLY, \& SCULLY, 2004). Por exemplo, em estudos recentes publicados por Boag et al. (2009) e por Hughes et. al. (2010) foi reportada a presença de nove fases distintas em uma amostra da liga 2024-T3, e a frequente associação entre as fases $\mathrm{Al}_{2} \mathrm{CuMg}$ e $\mathrm{Al}_{2} \mathrm{Cu}$ em uma mesma partícula (BOAG, et al., 2009) (HUGHES, et al., Corrosion of AA2024-T3 Part II, 2011). Por outro lado, Hughes et al. (2010) reportam a existência de aproximadamente 324.000 domínios composicionais diferentes para 271.000 IMs presentes por $\mathrm{cm}^{2}$ de amostra, isto sem levar em conta as áreas periféricas, que geralmente possuem composição diferente em relação ao núcleo do IM e à matriz da 
liga, e que foram consideradas simplesmente como "áreas com diferentes composições ao redor das partículas intermetálicas". A heterogeneidade intrínseca dos IMs, assim como a diversidade de composição que estes apresentam podem ser os principais motivos da reatividade heterogênea frequentemente reportada para estas partículas na literatura (BLANC, LAVELLE, \& MANKOWSKI, 1997) (QUEIROZ, MAGNANI, COSTA, \& de MELO, 2008). Embora não seja o objetivo do presente trabalho apresentar uma discussão exaustiva sobre a composição dos IMs encontrados nas ligas 2024, algumas considerações gerais podem ser apresentadas: i) o elemento $\mathrm{Cu}$ está presente na grande maioria dos IMs identificados na literatura; ii) em quase todos os trabalhos consultados foi identificada a presença de intermetálicos com a composição $\mathrm{Al}_{2} \mathrm{CuMg}$, com o $\mathrm{Al}_{2} \mathrm{Cu}$ em menor percentual; iii) os demais IMs são constituídos por $\mathrm{Al}, \mathrm{Cu}, \mathrm{Fe}, \mathrm{Mn}$ com diferentes proporções entre os elementos, podendo um ou mais dentre eles estar ausente em uma determinada partícula; iv) em ligas com teores mais elevados de $\mathrm{Si}$, este elemento também pode estar presente na composição dos IMs agrupados no item iii).

Outro aspecto a ser destacado relativamente aos IMs é a sua distribuição e densidade superficial na microestrutura das ligas. De acordo com Starke e Staley (1996) eles têm a tendência a se distribuir heterogeneamente e serem mais grosseiros em chapas espessas, entretanto, em chapas finas, como a estudada no presente trabalho, a distribuição tende a ser mais homogênea, como verificado por Buchheit et al. (1997) e as partículas são menores. Ilevbare et al. (2004) e Zhuo et al (2012) relatam a tendência à aglomeração entre partículas da mesma natureza, enquanto Boag et al. (2009) reportam tendência de aglomeração (clustering) tanto entre partículas com a mesma composição como entre partículas com composições diferentes, embora estes autores não tenham observado esta tendência entre partículas ricas em $\mathrm{Mg}$ e ricas em Fe e Mn. Este aspecto (aglomeração) parece ser determinante para a existência de áreas com diferentes atividades eletroquímicas em uma mesma amostra e para o desenvolvimento da corrosão localizada (HUGHES, et al., Corrosion of AA2024-T3 Part II, 2011) (CHEN, GAO, \& WEI, 1996) (ZHOU, LUO, HASHIMOTO, HUGHES, \& THOMPSON, 2012) com formação de pites estáveis e posterior progressão para corrosão intergranular (ZHOU, LUO, HASHIMOTO, HUGHES, \& THOMPSON, 2012). Estudos recentes têm mostrado que, embora macroscopicamente a distribuição superficial dos IMs possa ser considerada como relativamente uniforme, quando a área analisada é dividida em regiões cada vez menores, estas tendem a mostrar grandes desvios em relação ao número médio de partículas determinado para a amostra global, sendo este um fator indicativo da tendência 
para agrupamento e que explicaria a falta de homogeneidade na reatividade superficial de uma mesma amostra, uma vez que regiões com maior densidade de partículas tendem a ser eletroquimicamente mais reativas (HUGHES, et al., 2010).

No que se refere à densidade superficial dos IMs, as informações disponíveis na literatura reportam que esta pode atingir a centenas de milhares de partículas por $\mathrm{cm}^{2}$ : 271.000 no trabalho de Boag et al.(2009) e 323.000, segundo o reportado por Chen, Gao e Wei (1996). Por sua vez, em seu estudo, Boag et al. relatam que os IMs cobrem 2,71\% da área superficial (BOAG, et al., 2009) enquanto que a área recoberta por estas partículas na liga investigada por Buchheit et al correspondeu a 4,19\% (BUCHHEIT, GRANT, HLAVA, MCKENZIE, \& ZENDER, 1997). No que diz respeito à divisão percentual entre as diferentes classes de IMs, Buchheit et al (1997) relatam que cerca de $60 \%$ dos IMs encontrados em sua amostra correspondiam à fase $\mathrm{Al}_{2} \mathrm{CuMg}$ (anódicas-fase $\mathrm{S}$ ), sendo o restante constituído por fases catódicas ricas em Al, $\mathrm{Cu}, \mathrm{Fe}, \mathrm{Mn}$ (aproximadamente 22\%, considerando todos os IMs deste tipo e levando em conta que nem todos os elementos estão presentes em um determinado IM) e por fases com composições indeterminadas (17\%). Por sua vez, Hughes et al. indicam que $77 \%$ dos IMs (HUGHES, et al., 2010) analisados em suas amostras são catódicos em relação à matriz (o restante sendo constituído basicamente de $\mathrm{Al}_{2} \mathrm{CuMg}$ ), enquanto Boag et al.(2009) fazem um balanço de $40 \%$ de partículas anódicas (aquelas que contém Al, $\mathrm{Cu}, \mathrm{Mg}$ ) e 60\% de catódicas, embora fique claro na discussão realizada por estes autores que se os domínios correspondentes e $\mathrm{Al}_{2} \mathrm{Cu}$ (fase- $\theta$ ) encontrados nos $\mathrm{IMs} \mathrm{Al}_{2} \mathrm{CuMg}$ forem considerados como regiões catódicas a razão entre partículas catódicas e anódicas aumentaria.

A consolidação das informações consultadas sobre os IMs, não apenas nos trabalhos mencionados nesta revisão de literatura, mas em outros que não foram referenciados, indica que os resultados experimentais publicados em um determinado estudo são fortemente dependentes tanto da composição da liga estudada como de seu histórico termomecânico, o que justifica a diversidade de interpretação no que concerne ao comportamento de corrosão das ligas de alumínio de elevada resistência mecânica.

Dispersóides: São formados durante o pré-aquecimento do lingote a partir da precipitação dos elementos de transição $\mathrm{Cr}$, Mn ou $\mathrm{Zr}$, insolúveis no alumínio (STARKE \& STALEY, 1996) possuindo tamanhos que variam de 0,2 e 0,8 $\mu \mathrm{m}$ (PAREL, WANG, \& STARINK, 2010). Podem ser desde parcialmente coerentes como completamente coerentes com a matriz (STARKE \& STALEY, 1996). Não participam diretamente como fase de endurecimento, estando presentes na microestrutura para controle da estrutura do 
grão, atrasando a recristalização e o aumento do tamanho do grão. Mediante aquecimento moderado não são dissolvidos (ZHANG \& FRANKEL, 2003), porém podem apresentar tendência a engrossar (STARKE \& STALEY, 1996). Na liga 2024 sua composição mais comum é $\mathrm{Al}_{20} \mathrm{Cu}_{2} \mathrm{Mn}_{3}$ (STARKE \& STALEY, 1996). Apresentam-se sob forma de bastão.

Precipitados de endurecimento (strengthening precipitates) (não serão abordadas as zonas GPB e GP, dificilmente detectáveis mesmo por microscopia eletrônica de transmissão (Transmission Electron Microscopy - TEM), e já abordadas na parte sob tratamentos térmicos) - são partículas formadas, em sua grande maioria durante o envelhecimento controlado da matriz (STARKE \& STALEY, 1996), correspondendo no esquema apresentado na Figura 2-3 às fases S”, S', $\theta$ ” e $\theta$ '. Como já destacado anteriormente, são coerentes ou semicoerentes com a matriz (CHARAI, WALTHER, ALFONSO, ZAHRA, \& ZAHRA, 2000) (WANG \& STARINK, 2007) (WANG \& STARINK T, 2004), e desempenham o papel de impedir o movimento de discordâncias, em parte responsáveis pela deformação plástica, sendo os grandes responsáveis pelo aumento da resistência mecânica nas ligas de alumínio endurecíveis por precipitação.

De acordo com a literatura, os precipitados da fase $\theta$ se apresentam sob a forma de plaquetas octogonais (RINGER \& HONO, 2000), enquanto os da fase S ocorrem sob a forma de ripas (RINGER S. , HONO, POLMEAR, \& SAKURAI, 1996); (GAO, DAVIN, WANG, CEREZO, \& STARINK, 2002) (WILSON \& PARTRIDGE, 1965).

É importante destacar, que, na literatura consultada, existem grandes controvérsias a respeito da denominação e mesmo da existência dos precipitados S” e S'. Assim, em sua revisão de literatura, Ringer e Hono (2000) indicam que existem dúvidas a respeito da existência das fases S" e S', e Charai et al.(2000), na introdução de seu artigo mencionam que, devido à grande semelhança, muitos autores não diferenciam as fases $\mathrm{S}$ ' e S, sendo a primeira considerada apenas uma fase ligeiramente distorcida da segunda (CHARAI, WALTHER, ALFONSO, ZAHRA, \& ZAHRA, 2000) corroborando as considerações de Wang e Starink (2007). Já Ringer et al. (1996) afirmam em seu artigo não terem conseguido identificar as fases S" e S', propondo, em função disto, uma nova sequência para a precipitação das partículas de endurecimento (RINGER S. , HONO, POLMEAR, \& SAKURAI, 1996). Em virtude destas controvérsias, no presente trabalho, os precipitados de endurecimento serão denominados coletivamente como fase $S^{\prime}(S)$ ou simplesmente $\mathrm{S}$, sem que, no entanto, isto venha a comprometer a clareza do texto, pois estarão sempre associados ao aumento das propriedades mecânicas da liga. 
Para finalizar este tópico, menciona-se que os precipitados de endurecimento, incluindo as zonas GPB, são bastante sensíveis à temperatura, apresentando reversão (dissolução), precipitação e coalescimento nas faixas de temperaturas tipicamente empregadas na FSW. Porém este aspecto específico será tratado posteriormente nesta revisão de literatura.

\subsubsection{Corrosão do alumínio e suas ligas}

\subsubsection{Aspectos Gerais}

Para o alumínio puro, a resistência à corrosão diminui consideravelmente à medida que as impurezas e elementos de liga aumentam de 0,01 para $1 \%$ na composição da liga, no entanto, até $99 \%$ de pureza este metal resiste muito bem a atmosferas neutras e à água isenta de cloretos. Na água do mar, há ocorrência de pites, porém estes são predominantemente rasos (BARDAL, 1933). Em atmosfera industrial severa (ácida), ocorre uma mistura de corrosão por pites e localizada, pois o filme óxido pode ser dissolvido diante de certas condições, como pode ser visto no diagrama de Pourbaix (BARDAL, 1933).

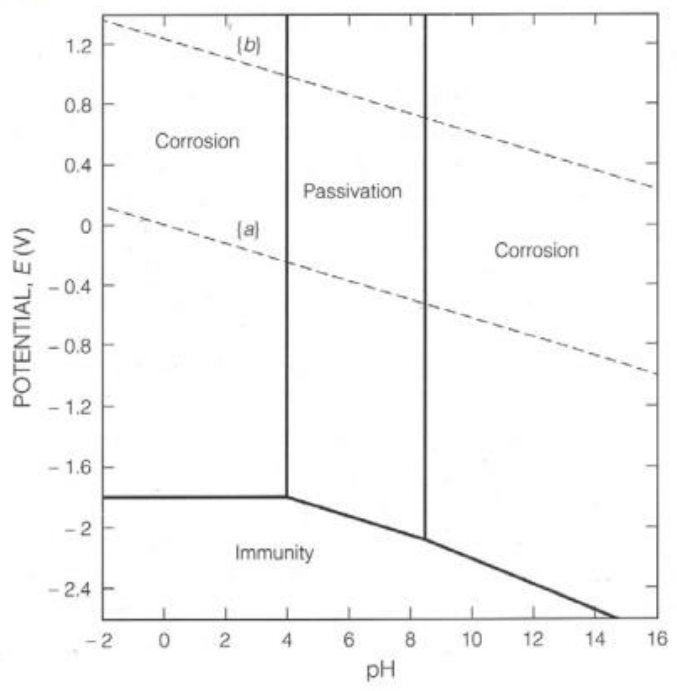

Figura 2-4: Diagrama de Pourbaix do Alumínio, potencial (V,EPH) versus $\mathrm{pH}$ a $25^{\circ} \mathrm{C}$, $a_{A l^{3+}}, a_{A l_{2} O^{-}}=10^{-6} \mathrm{~mol} . \mathrm{L}^{-1}$,com o domínio de estabilidade da água apresentada pelas linhas pontilhadas (BARDAL, 1933).

A corrosão ou dissolução do alumínio em meio ácido, ocorre de acordo com a reação (2-1), representada pela linha horizontal que se estende até $\mathrm{pH}=4$. 


$$
A l_{(a q)}^{3+}+3 e^{-} \rightarrow A l_{(s)}^{0}
$$

Observa-se também, a importância da concentração de $\mathrm{H}^{+}$e $\mathrm{OH}^{-}$. Na presença destes íons a oxidação ocorre segundo as equações 2-2 e 2-3:

$$
\begin{aligned}
& p H<4: A l_{(s)}^{0}+3 H_{(a q)}^{+} \rightarrow A l_{(a q)}^{3+}+\frac{3}{2} H_{2(g)} \\
& p H>9: A l_{(s)}^{0}+H_{2} O_{(l)}+O H_{(a q)}^{-} \rightarrow A l O_{2(a q)}^{-}+\frac{3}{2} H_{2}(g)
\end{aligned}
$$

O domínio termodinâmico de passivação se situa entre os $\mathrm{pHs} 4$ e 9 , e é determinado pela estabilidade do óxido ou hidróxido de alumínio com número de oxidação 3+ (Eq. 2-4), que dificulta a ocorrência das reações apresentadas nas Equações 2-1, 2-2 e 2-3. Deste modo, na ausência de espécies agressivas, o metal resiste de modo adequado à corrosão.

$$
4 A l_{(s)}^{0}+3 H_{2} O_{(l)}+\frac{3}{2} O_{2(g)} \rightarrow 2 \mathrm{Al}_{2} \mathrm{O}_{3(s)}+3 \mathrm{H}_{2(g)}
$$

O potencial de equilíbrio do metal, número oxidação zero, corresponde a potenciais extremamente negativos $\left(\mathrm{E}^{\mathrm{o}}=-1,662 \mathrm{~V} / \mathrm{EPH}\right)$, impossíveis de serem atingidos em soluções aquosas. Portanto, o uso industrial do alumínio é completamente dependente da estabilidade da camada de óxido e de sua proteção por diferentes metodologias.

\subsubsection{Corrosão localizada}

As ligas de alumínio da série 2XXX apresentam propriedades mecânicas superiores, e, por este motivo consistem o material estrutural utilizado a mais tempo na indústria aeronáutica, com especial destaque para a 2024. Entretanto, a composição complexa desta liga, juntamente com os tratamentos termomecânicos aos quais é submetida, além da presença de impurezas em sua composição, aumentam a susceptibilidade à corrosão localizada, principalmente corrosão intergranular e por pites, pois formam-se precipitados de diversas naturezas (vide item 2.3) que possuem atividade eletroquímica diferente da matriz, provocando o aparecimento de células galvânicas que iniciam o processo de corrosão localizada. Está amplamente documentado na literatura que o início da corrosão localizada em ligas de alumínio de elevada resistência mecânica 
está associado aos intermetálicos grosseiros (BUCHHEIT, GRANT, HLAVA, MCKENZIE, \& ZENDER, 1997) (BIRBILIS \& BUCHHEIT, 2005). Revisões de literatura sobre o papel destas partículas na corrosão localizada do alumínio podem ser encontradas em outros trabalhos realizados no LEC (PALOMINO, 2007) (FERRARI, 2011) Apesar de bastante investigado, o mecanismo exato de iniciação e de propagação da corrosão localizada ainda não se encontra determinado, sendo ainda um assunto de grande interesse científico. Entretanto, nos últimos anos, o aumento do poder de resolução espacial e de análise das técnicas de caracterização superficial tem melhorado de maneira efetiva a compreensão sobre este fenômeno. No que concerne à corrosão por pites e intergranular, os resultados mais recentes publicados na literatura indicam que o agrupamento (clustering) de IMs possui papel determinante no estabelecimento de pites estáveis nas ligas de alumínio 2024-T3, que criam condições adequadas para o desenvolvimento da corrosão intergranular.

Boag et al. (2010) estudaram a corrosão localizada da liga de alumínio 2024-T3 em solução de $\mathrm{NaCl} 0,1 \mathrm{~mol} \mathrm{~L}^{-1}$ pela técnica do eletrodo vibratório de varredura (Scanning Vibrating Electrode Technique - SVET), e as técnicas eletroquímicas de polarização potenciodinâmica e potenciostática, denominadas pelos autores como padrão. Foi verificado que o desenvolvimento de pites estáveis está frequentemente relacionado à associação (proximidade) entre partículas com atividades catódicas (tipicamente IMs ricos em $\mathrm{Cu}$ e $\mathrm{Fe}$ ) e anódicas (IMs contendo $\mathrm{Mg}$ ), levando os autores a sugerirem que o acoplamento local de IMs tem um papel importante na iniciação do processo de corrosão por pites. Os autores também realizaram estudos de densidade de correntes por meio de curvas de polarização em IMs modelo e através da técnica de SVET (BOAG, et al., 2010). Foi verificado que altas densidades de corrente podem ser desenvolvidas nos IMs ricos em cobre e magnésio (anódicos), e que a atividade eletroquímica dos IMs catódicos está fortemente relacionada à presença do cobre, devido à capacidade deste metal em sustentar a reação catódica de redução do oxigênio, sendo estes os IMs mais importantes para o início da corrosão localizada na liga 2024-T3. Conclusões semelhantes foram apresentadas no trabalho publicado por Hughes et al. (2010) onde foi verificado que a presença de agrupamentos de IMs com comportamento catódico ativa os sítios da superfície mais sensíveis à corrosão. No trabalho, Hughes et al. (2010) reportam a formação de anéis de produtos de corrosão em torno das regiões anodicamente ativas, sendo que no interior destes anéis domos de produtos de corrosão ricos em cloreto foram encontrados, correspondendo às regiões anódicas, enquanto no restante da região interior 
destes anéis não houve a formação de produtos de corrosão. Estudos realizados em soluções com diferentes $\mathrm{pHs}$, e onde também não foi verificada a formação de produtos de corrosão no interior dos anéis, levaram os autores a proporem que estas regiões estavam protegidas catodicamente pelos anodos ativos no interior dos anéis (HUGHES, et al., 2010). Os autores observaram ainda o desenvolvimento de corrosão intergranular no interior dos anéis de corrosão, os quais atingiam profundidade de até $50 \mu \mathrm{m}$, no intervalo de duas horas em que os estudos foram efetuados, o que foi atribuído ao ataque local dos contornos de grão na região catodicamente protegida (HUGHES, et al., 2010)

Em uma série de trabalhos dedicados ao estudo da corrosão localizada e o efeito de agrupamentos de partículas sobre a progressão deste tipo de corrosão em ligas de alumínio 2024-T3, Hughes e diversos colaboradores verificaram que a etapa inicial da corrosão localizada nestas ligas envolve o ataque de intermetálicos isolados com a formação de trincheiras ao redor destas partículas, como proposto classicamente por Boag et al. (2011), porém o progresso da corrosão com o estabelecimento de pites estáveis e posterior aparecimento da corrosão intergranular está associado à presença de agrupamentos de IMs, o que os autores denominaram de corrosão cooperativa (HUGHES, et al., 2011). Como no trabalho publicado em 2010 e já referenciado anteriormente por Hughes et al.(2010), os autores verificaram a presença dos anéis de produtos de corrosão com regiões anódicas em seu interior, caracterizadas pela presença de domos de produtos de corrosão, e ausência de produtos de corrosão nas demais áreas do interior dos anéis, que funcionariam como delimitadores entre áreas com e sem corrosão acentuada, porém, o modelo de corrosão cooperativa foi desenvolvido de maneira mais aprofundada (HUGHES, et al., 2011). De acordo com Hughes et al. (2011) o desenvolvimento da corrosão cooperativa envolve cinco processos: (i) a formação de $\mathrm{H}_{2}$; (ii) o aparecimento e o desenvolvimento dos anéis de corrosão; (iii) ataque intergranular na superfície assim como nas regiões subsuperficiais; (iv) a formação de domos de produtos de corrosão no interior dos anéis; (v) o ataque dos grãos tanto na região superficial como subsuperficial. No que se refere especificamente ao desenvolvimento da corrosão intergranular, os autores propõem que dentro dos anéis de corrosão a superfície se transforma em um local com corrente catódica líquida, levando ao desenvolvimento de atividade anódica nas regiões mais suscetíveis da superfície, que correspondem à rede de contornos de grão, sendo este, segundo os autores, o principal papel dos agrupamentos de IMs catódicos (HUGHES, et al., 2011). No artigo, os autores apresentam um modelo para o desenvolvimento da corrosão intergranular a partir da atividade dos IMs que leva em 
conta o confinamento do eletrólito agressivo nas trincheiras formadas em volta destas partículas (HUGHES, et al., 2011). Deste modo, o ataque dos contornos de grão seria iniciado em torno dos IMs em situação de corrosão, progredindo posteriormente para o interior do metal. Este modelo foi consolidado no terceiro artigo da série, onde foram realizadas observações microscópicas e análises por EBSD de cortes transversais de amostras submetidas a ensaios de imersão, tendo sido constatado o estabelecimento de extensa corrosão intergranular sob os sítios de corrosão localizada estáveis, e que são localizados sob os agrupamentos de IMs (GLENN, et al., 2011).

O estabelecimento de pites estáveis, com posterior indução ao desenvolvimento de corrosão intergranular, a partir de agrupamentos (clusters) de IMs da fase $\mathrm{S}\left(\mathrm{Al}_{2} \mathrm{CuMg}\right)$ enterrados sob a superfície da liga de alumínio 2024-T3 foi demonstrado por Zhuo et al. (2012). Os autores (Zhuo et al., 2012) empregaram a microscopia eletrônica de varredura baseada em tomografia para gerar análises tridimensionais de regiões corroídas da liga em questão, e nas quais houve o desenvolvimento de pites estáveis. As imagens apresentadas com contrastes de cores mostram claramente o desenvolvimento de pites profundos a partir das trincheiras formadas em volta dos agrupamentos de IMs e a propagação da corrosão intergranular em todas as direções a partir da rede de contornos de grão da matriz. De acordo com os autores (Zhuo et al., 2012), a oxidação e posterior hidrólise dos íons de Al na região confinada formada sob os IMs cria um ambiente agressivo e enriquecido em cloretos, necessário para a progressão do processo corrosivo. Quando este front de corrosão encontra um contorno de grão a corrosão passa a se desenvolver preferencialmente através desta região, dando início à corrosão intergranular (Zhuo et al., 2012). Os autores sugerem ainda que a corrosão intergranular ocorre preferencialmente através dos contornos de grãos com alta concentração de discordâncias, que são mais energéticos, e que o enriquecimento superficial da matriz em cobre ao longo da região de propagação da corrosão intergranular impede que os grãos sejam corroídos (Zhuo et al., 2012).

Luo et al (2012) estudaram a corrosão intergranular de AA 2024-T351 utilizando Microscopia eletrônica e difração de elétrons retro-espalhados (EBSD), os mesmos, observaram que a corrosão intergranular se propagou pela liga com a formação de pites. Ao avaliarem o contorno dos grãos do metal base e no material corroído observaram uma quantidade de fase $\theta$ nos contornos dos grãos do metal base e a mesma não foi observada nos produtos de corrosão intergranular. $\mathrm{O}$ ataque preferencialmente ao longo do contorno dos grãos foi observado nos grãos com alta energia estocada, justificada pelos autores, 
onde esta reflete no deslocamento da densidade causando maior susceptibilidade ao ataque do contorno de grãos, explicando o progresso da corrosão intergranular ao longo de um grão, no contorno de grão. Referente à energia dos grãos, este resultado foi discutido por Zhou et al (2013), os quais utilizaram Microscopia eletrônica de Varredura e Transmissão para avaliar os passos de propagação da corrosão intergranular. Utilizando difração de elétrons retro-espalhados investigaram a estrutura do grão e susceptibilidade à corrosão. Observaram então, que a corrosão intergranular ocorre nos contornos de grãos onde há ausência da fase 2 dos precipitados. Concluíram também que a corrosão intergranular ocorre nos grãos que rodeiam grão com alta energia estocada, e a corrosão não necessariamente ocorre na região adjacente ao contorno do grão mas desenvolve nos grãos com alta energia estocada, relacionando esses grãos com grãos com níveis maiores de defeitos.

\section{FSW \\ 2.4 SOLDAGEM DAS LIGAS DE ALUMÍNIO 2024 PELO PROCESSO}

Para os processos de soldagem, a principal limitação do alumínio é a sua baixa temperatura de fusão $\left(660^{\circ} \mathrm{C}\right)$, o que limita a temperatura que pode ser empregada na soldagem de suas ligas (ASM Specialty Handbook, 1993), dificultando o uso de técnicas de fusão convencional como plasma, Tungsten Inert Gas (TIG), Metal Inert Gas e Metal Active Gas (MIG/MAG) ou eletrodo revestido, por apresentarem defeito decorrentes da fusão envolvida no processo como porosidades, trincas de solidificação e fusão no contorno do grão (ASTM METALS HANDBOOK, 1990) (JARIYABOON, et al., 2007) (MOROZ, ALCÂNTARA, \& SANTOS, 2012). Isto se constitui em um inconveniente para a construção de estruturas de grande porte, como as aeronaves, onde, frequentemente, é necessária a junção de diferentes partes. O processo denominado soldagem por fricção ( $F S W$ - Friction Stir Welding), não envolve fusão, nem introduz outro metal na estrutura, permitindo a obtenção soldas mais resistentes e virtualmente livres de defeitos.

A soldagem por fricção (FSW) foi inventada por Thomas Wayne no TWI (The Welding Institute), Reino Unido, e patenteada no ano de 1991 (EUA Patente $\mathrm{N}^{\circ}$ PCT/GB92/02203, 1991). O processo ocorre no estado sólido, não produzindo porosidades ou trincas de solidificação associadas à composição química da liga, ganhando grande relevância na soldagem de ligas de alumínio das séries 2XXX e 7XXX, 
com elevado teor de cobre e empregadas na indústria aeronáutica, que não são soldáveis através de processos de fusão convencionais (JARIYABOON, et al., 2009). Desde a sua invenção o grande interesse científico e tecnológico despertados por este novo processo levaram o TWI a emitir, até o ano de 2007, 200 licenças para a utilização do processo, e 1900 pedidos de patentes relativos ao processo foram preenchidos (THREADGILL P. L., LEONARD, SHERCLIFF, \& WITHERS, 2009).

Na soldagem por FSW, as peças a serem unidas são inicialmente fixadas em um dispositivo de apoio e mantidas unidas pela aplicação de uma pressão de forjamento. Para a realização da soldagem, utiliza-se uma ferramenta não consumível composta de uma base de formato cilíndrico, chamada de shoulder (ombro), e de um pino protuberante de perfil especial e rotativo que penetra na linha da junta e realiza um furo na peça (RADISAVLJEVIC, ZIVKOVIC, RADOVIC, \& GRABULOV, 2013). O aumento de temperatura gerado pela elevada pressão de forjamento normal às peças e pela ação de cisalhamento do ombro rotatório da ferramenta contra as peças a serem soldadas em seu deslocamento pela superfície é suficiente para causar a formação de uma zona de metal "amolecido" (plasticized metal) (MOROZ, ALCÂNTARA, \& SANTOS, 2012). O movimento rotacional do pino provoca a extrusão do material amolecido em torno de seu eixo para a parte posterior da ferramenta, proporcionando a junção em estado sólido, conforme apresentado na Figura 2-5. O lado da solda para o qual a rotação da ferramenta ocorre na mesma direção de seu movimento de deslocamento sobre as peças é denominado "lado do avanço" (advancing side), enquanto denomina-se "lado do retrocesso" (retreating side) o outro lado, onde a rotação da ferramenta se opõe à sua direção de deslocamento (THREADGILL P. L., LEONARD, SHERCLIFF, \& WITHERS, 2009) (FONDA, et al., 2009). Estes aspectos operacionais fazem com que a junta soldada por FSW tenha características assimétricas, já que a maior parte do material é extrudado a partir do lado do retrocesso da ferramenta.

As propriedades das soldas dependem de fatores como as velocidades de rotação e de deslocamento da ferramenta, as geometrias do pino e da base (shoulder) da ferramenta, assim como da pressão exercida pela ferramenta sobre a peça. Revisões recentes abordando estes aspectos, assim como os principais ramos de aplicação da FSW, defeitos e propriedades mecânicas das solda e comparação com outros processos de soldagem, foram publicadas recentemente por Threadgill (2009) e por Gibson et al.(2013). 


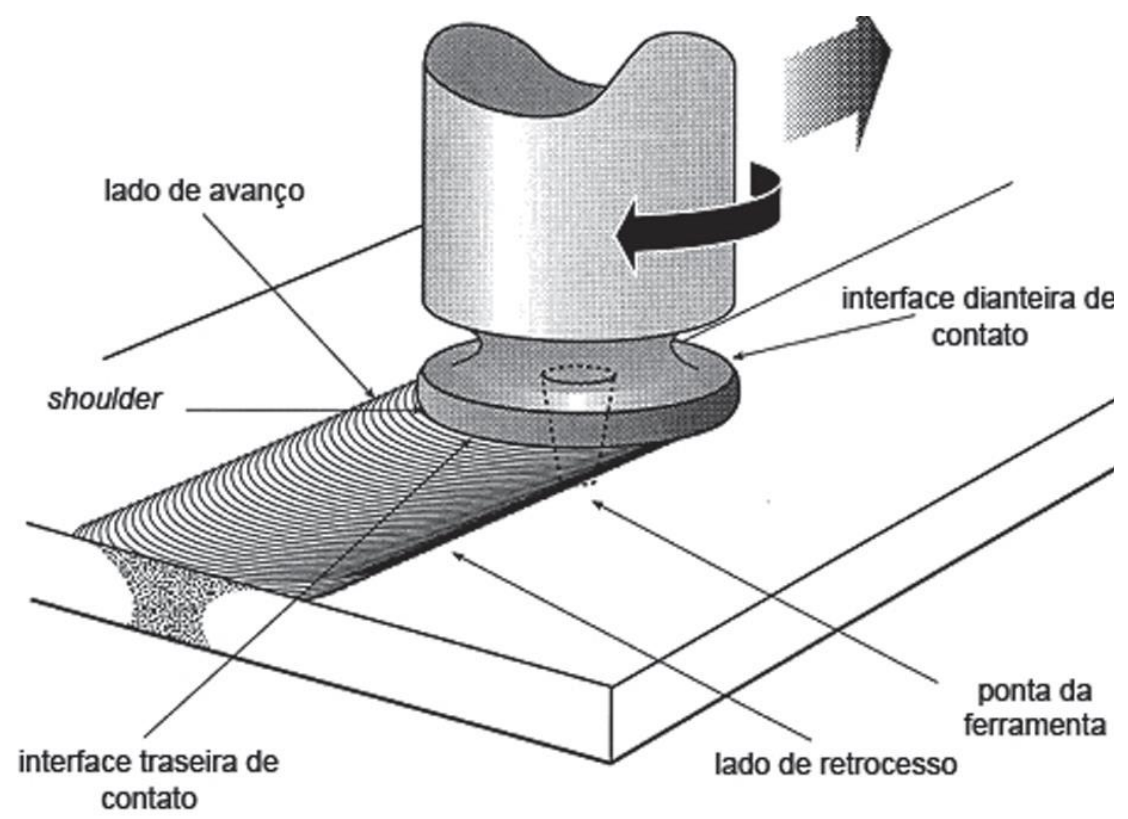

Figura 2-5: Ilustração do processo de soldagem por fricção (Friction Stir Welding -FSW) (MOROZ, ALCÂNTARA, \& SANTOS, 2012).

\subsubsection{Regiões da junta soldada}

De acordo com a American Welding Society Standard D17-3M, macroscopicamente, diferentes zonas são geradas durante o processo de FSW como descritas a seguir:

○ Base não afetada do material - material inalterado ou o chamado metal original, não deformado, que, embora possa ter sofrido um ciclo térmico na soldagem, não é afetado pelo calor a ponto de sofrer alterações detectáveis na microestrutura ou nas suas propriedades.

○ Zona afetada pelo calor (Heat Affected Zone - HAZ) - região perto o suficiente da solda para sofrer modificações na microestrutura e/ou propriedades mecânicas pelo ciclo térmico do processo, mas sem deformação plástica aparente pela luz do microscópio, normalmente chamada de zona afetada termicamente.

$\circ \quad$ Zona termomecanicamente afetada (Thermomechanically Affected Zone - TMAZ) - região onde, além de ser submetido a ciclos térmicos capazes de modificar sua microestrutura, o material também sofre deformação plástica pela ação do ombro da ferramenta. No caso do alumínio é possível considerar a existência de duas regiões distintas nesta zona: uma com deformação plástica sem recristalização, e outra recristalizada, denominada nugget (BOUSQUET, POULON-QUINTIN, PUIGGALI, 
DEVOS, \& TOUZET, 2011) (JARIYABOON, et al., 2007) (THREADGILL P. L., LEONARD, SHERCLIFF, \& WITHERS, 2009) (PROTON, et al., 2011).

A Figura 2-6 apresenta o corte transversal de uma liga de Al 2024 soldada por FSW com a identificação das diferentes zonas mencionadas nos parágrafos precedentes. Como pode ser verificado, devido às características operacionais da FSW (que faz uso de um pino penetrante e de uma base giratória que exerce pressão a partir da superfície das peças sem, no entanto, penetrá-la) o perfil da zona de solda ao longo da espessura é cônico. Além do mais, devido à assimetria do processo, existem diferenças no perfil térmico e na intensidade da deformação entre os lados do avanço e do retrocesso (THREADGILL P. L., LEONARD, SHERCLIFF, \& WITHERS, 2009).

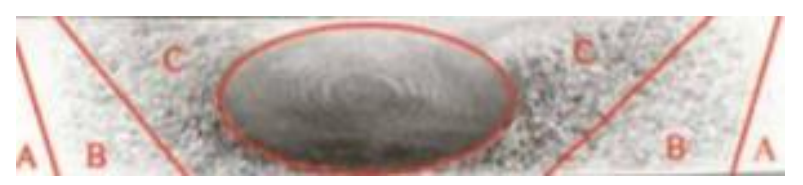

Figura 2-6: Microestrutura com a classificação das zonas geradas na FSW para um liga de Al 2024. A: Base não afetada do material, B: Zona afetada pelo calor (Heat Affected Zone - HAZ), C: Zona termomecanicamente afetada (Thermomechanically Affected Zone - TMAZ). A região central representa o nugget ou "zona misturada" (THREADGILL P. L., LEONARD, SHERCLIFF, \& WITHERS, 2009)

A rotação do pino da ferramenta na região do nugget, juntamente com o aquecimento, provoca um processo de extrusão do material em torno de seu eixo de rotação pelo lado do retrocesso. Este movimento resulta em uma estrutura em faixas dentro da região de solda, a qual é denominada de onion rings. De acordo com alguns autores cada uma das faixas desta estrutura é originada pelo material extrudado em cada ciclo de rotação da ferramenta (SCHNEIDER J., 2006) (M.W. MAHONEY, 1998). Já outros autores afirmam que os padrões na forma de anéis visualizados na região do nugget são resultantes das diferenças na intensidade do ataque em grãos com tamanhos diferentes (ZHANG \& FRANKEL, 2003). Embora esta afirmação não possa ser completamente generalizada, o aumento da temperatura da região do nugget durante a FSW é suficiente para gerar uma microestrutura recristalizada, de granulação fina e com grãos equiaxiais. As características desta região, assim como o grau de recristalização, dependem de diversos parâmetros, dentre os quais os mais importantes são a velocidade de rotação e de translação da ferramenta de soldagem, assim como a geometria da mesma (DUDZIK, 
2011) (MOHAMMADTAHERI, HADDAD_SABZEVAR, MAZINANI, \& BAHRAMI MOTLAGH, 2013).

\subsubsection{Modificações microestruturais nas diferentes regiões da solda}

A intensa deformação plástica do material associada às altas temperaturas desenvolvidas durante a soldagem resultam em modificações microestruturais importantes tanto na região de passagem do pino (nugget) como na TMAZ e HAZ. A intensidade das modificações, assim como as extensões das zonas afetadas, depende das variáveis do processo, tais como tamanho e tipo de ferramenta de soldagem e velocidade de deslocamento e de rotação desta última, que afetam diretamente a temperatura e as taxas de deformação atingidas na região da solda (NANDAN, DEBROY, \& BHADESHIA, 2008).

Na zona do nugget, está relativamente bem estabelecido que, devido às elevadas temperaturas desenvolvidas nesta região, que podem atingir até $80 \%$ do ponto de fusão (LI, MURR, \& MCCLURE, 1999), ocorre um processo de recristalização dinâmica durante a FSW resultando na geração de grãos finos e equiaxiais (BENAVIDES, LI, \& MURR, 1999); (JATA \& SEMIATIN, 2000) (MURR, LI, FLORES, \& TRILLO, 1998), embora alguns autores sugiram a ocorrência de um processo de recuperação dinâmica (FONDA, BINGERT, \& COLLIGAN, 2004). Os parâmetros do processo, a geometria da ferramenta, a composição química do material, a temperatura e a pressão vertical exercem influência significativa no tamanho destes grãos recristalizados (MISHRA \& MA.Z.Y., 2005). Pesquisadores que avaliaram a influência dos parâmetros de processo sobre o tamanho dos grãos recristalizados mostraram que o tamanho destes pode ser reduzido pela diminuição da taxa de rotação da ferramenta mantendo-se uma velocidade de deslocamento constante, ou seja, diminuindo a relação velocidade de rotação/velocidade de deslocamento da ferramenta, o que diminui o aporte térmico para a região (LI, MURR, \& MCCLURE, 1999); (KWON \& SAITO, 2002).

O aumento da velocidade de rotação da ferramenta ou da relação velocidade de rotação/velocidade de deslocamento da ferramenta eleva tanto o grau de deformação como a temperatura de pico do ciclo térmico. $\mathrm{O}$ aumento no grau de deformação durante o FSW resulta na redução no tamanho de grão recristalizado de acordo com os princípios gerais de recristalização (HATHERLY \& HUMPHREYS, 1995). Por outro lado, o aumento da temperatura de pico do ciclo térmico para soldagem FSW conduz a um 
notável crescimento dos grãos, tornando-os mais grosseiros (MISHRA \& MA.Z.Y., 2005). As pesquisas sobre a soldagem FSW do alumínio 1050 e da liga 7075-T651 parecem indicar que a temperatura de pico do ciclo térmico é o fator predominante em determinar o tamanho do grão recristalizado. Desse modo, em ligas de alumínio, este aumenta com a velocidade de rotação da ferramenta ou com o aumento da relação da velocidade de rotação/velocidade de deslocamento (MURR, TRILLO, FLORES, \& MCCLURE, 1998a)

Outro aspecto microestrutural frequentemente observado na região do nugget é a presença de padrões com características elípticas ou circulares, visíveis em amostras atacadas metalograficamente, denominados anéis de cebola (onion rings), e que são originados devido aos fenômenos complexos de fluxo de matéria estabelecidos pela rotação do pino e por sua geometria (GUERRA, SCHIMIDT, MCCLURE, MURR, \& NUNES, 2003) (THREADGILL P. L., LEONARD, SHERCLIFF, \& WITHERS, 2009). Também no nugget verifica-se a presença de intermetálicos micrométricos fraturados, e que são originados pela ação mecânica de rotação da ferramenta (BOUSQUET, 2011a) (JARIYABOON, et al., 2007)

A HAZ consiste na região da solda que sofre os efeitos dos ciclos térmicos, mas não é submetida a nenhum tipo de deformação plástica. Está documentado na literatura que as temperaturas desenvolvidas nesta região durante a FSW não são suficientes para causar modificações nas estruturas dos grãos, que se apresenta semelhante à do metal base (SU J., NELSON, MISHRA, \& MAHONEY, 2003). Para a TMAZ, região que sofre picos de temperatura mais importantes que a HAZ e também é submetida a severa deformação plástica pela rotação do ombro da ferramenta, Su et al. (2003) reportam que a estrutura de grão depende da posição em relação ao centro da solda. Assim na região vizinha à HAZ (com temperaturas mais baixas) a estrutura de grãos da matriz é preservada, embora tenha sido observado um aumento na densidade de discordâncias, enquanto na região próxima ao nugget (submetida a temperaturas mais elevadas) ocorre um processo de recuperação dinâmica dos grãos que exibem uma elevada densidade de sub-grãos, sendo caracterizada por uma baixa densidade de discordâncias (SU J. , NELSON, MISHRA, \& MAHONEY, 2003). Bousquet et al. (2011b) avaliaram através de microscopia óptica a distribuição dos grãos em cada região da solda da liga Al 2024, e observaram microestruturas semelhantes na região do metal base e na HAZ, compostos por grãos recristalizados e alongados paralelos à direção da solda. Na TMAZ observaram grãos mais arredondados, devido à deformação plástica, sem modificação no tamanho do 
grão. Já na região do nugget, além de mais arredondados, os grãos são menores devido à constante recristalização gerada pelas temperaturas relativamente elevadas atingidas nesta região. Radisavljevic et al. (2013) utilizaram microscopia óptica e verificaram estrutura de grãos semelhantes para o mesmo tipo de liga: assim, devido à recristalização, a região do nugget apresentou grãos finamente divididos, na TMAZ os grãos se apresentaram alongados e deformados enquanto na HAZ e no metal base os grãos se mostraram alongados.

As temperaturas atingidas durante a FSW não são suficientemente elevadas para dissolver os intermetálicos grosseiros, com dimensões micrométricas, presentes na microestrutura das ligas de alumínio de elevada resistência mecânica. Entretanto, a literatura documenta que estas são suficientes para dissolver, ativar a precipitação ou provocar a coalescência dos precipitados responsáveis pelo aumento da resistência mecânica destas ligas, afetando também os dispersóides (JARIYABOON, et al., 2007) (FRIGAARD, GRONG, \& MIDLING, 2001).

O perfil de temperatura que se estabelece na chapa durante a FSW faz com que, em algumas regiões, os processos de precipitação e/ou coalescência dos precipitados submicrométricos sejam favorecidos (temperaturas menos elevadas atingidas tipicamente na HAZ e na TMAZ nas vizinhanças da HAZ), enquanto em outras os processos de dissolução são predominantes (temperaturas mais elevadas tipicamente atingidas no nugget e na TMAZ muito próxima deste). Estes processos são particularmente intensos na região dos contornos de grão o que pode gerar zonas de depleção, levando ao desenvolvimento de corrosão intergranular (THREADGILL P. L., LEONARD, SHERCLIFF, \& WITHERS, 2009) (PAGLIA \& BUCHHEIT, 2008) (PAGLIA \& BUCHHEIT, 2006).

$\mathrm{Na}$ região do nugget, onde as temperaturas mais elevadas são atingidas, os precipitados com dimensões submicrométricas presentes na microestrutura da matriz podem engrossar ou dissolver na matriz dependo do tipo de liga e da temperatura (MISHRA \& MA, 2005) (RHODES, MAHONEY, BINGEL, SPURLING, \& BAMPTON, 1997). Liu et al. (1997) investigaram a microestrutura de uma liga 6061AlT6 após soldagem FSW, e relataram que os precipitados distribuídos homogeneamente são geralmente menores e mais numerosos no metal base que na zona do nugget, o que implica na ocorrência tanto da dissolução quanto de engrossamento de precipitados durante a soldagem por FSW. Por sua vez, Sato et al. (1999) examinaram a evolução microestrutural de uma liga 6063Al-T5 soldada por FSW usando microscopia eletrônica 
de transmissão (TEM), onde não foram observados precipitados submicrométricos dentro da zona de núcleo, o que indica que todos foram dissolvidos na matriz de alumínio durante a soldagem. Heinz e Skrotzki (2002) também relataram a completa dissolução dos precipitados nas ligas 6013Al-T6 e 6013Al-T4 com uma taxa de rotação da ferramenta de $1400 \mathrm{rpm}$ e uma velocidade transversal de 400-500 $\mathrm{mm} / \mathrm{min}$. Entretanto também existem trabalhos onde é relatada a existência de precipitados no interior da região de solda os quais possuem papel decisivo na resposta de corrosão, dureza e resistência mecânica desta região. (BOUSQUET, POULON-QUINTIN, PUIGGALI, DEVOS, \& TOUZET, 2011) (HU \& MELETIS, 2000).

Su et al. (2003) realizaram uma detalhada caracterização por microscopia eletrônica de transmissão da distribuição dos precipitados de fortalecimento nas diferentes regiões originadas pela FSW em uma liga de alumínio 7050-T651. Foi verificado que o metal base (Figura 2-7 (a)) apresentava precipitados intragranulares (< $50 \mathrm{~nm}$ ) uniformemente distribuídos, e a presença de uma fina zona ( 25 nm) livre de precipitados (precipitate free zone - PFZ) na região dos contornos de grão, onde também se concentravam precipitados ligeiramente mais grosseiros. Na HAZ (Figura 2-7(b)) foi verificado que os precipitados intragranulares continuavam uniformemente distribuídos, embora um forte coalescimento tenha sido observado, um aumento de um fator de cinco na extensão da PFZ e a presença de precipitados grosseiros nos contornos de grão. $\mathrm{Na}$ TMAZ duas regiões puderam ser distinguidas, na zona mais fria (próxima da HAZ) (Figura 2-7(c)) nos contornos de grão foi observada a presença de precipitados muito grosseiros, enquanto intragranularmente foi constatada uma distribuição não homogênea e duplex (dois tamanhos diferentes) de precipitados com as seguintes características: grosseiros, formados a partir do coalescimento dos precipitados menores, e pequenos, resultantes da precipitação heterogênea nas discordâncias durante o resfriamento, indicando que nesta região houve dissolução e crescimento dos precipitados. Já na zona mais aquecida da TMAZ (próxima ao nugget) (Figura 2-7(d)) observou-se a presença de precipitados muito finos $(10-20 \mathrm{~nm})$ distribuídos não uniformemente no interior dos grãos, enquanto nos contornos de grão os mesmos se encontravam pouco espaçados, levando os autores a proporem que nesta região os precipitados foram completamente dissolvidos durante a soldagem e, posteriormente, reprecipitaram nos contornos de grão e em locais com concentrações de discordâncias durante o resfriamento. Já na região do nugget (Figura 2-7(e)) os autores verificaram a existência de precipitados grosseiros nos contornos de grão com a formação de PFZ, e que a distribuição dos precipitados é 
fortemente dependente da concentração de discordâncias no interior dos grãos. Assim em grãos contendo elevada densidade de discordâncias foi observada uma alta densidade de precipitados (60-100 $\mathrm{nm})$ dispersos de modo relativamente uniforme, levando à proposição de que nesta região os precipitados haviam sido completamente dissolvidos durante a soldagem e que reprecipitam posteriormente durante o envelhecimento da liga.
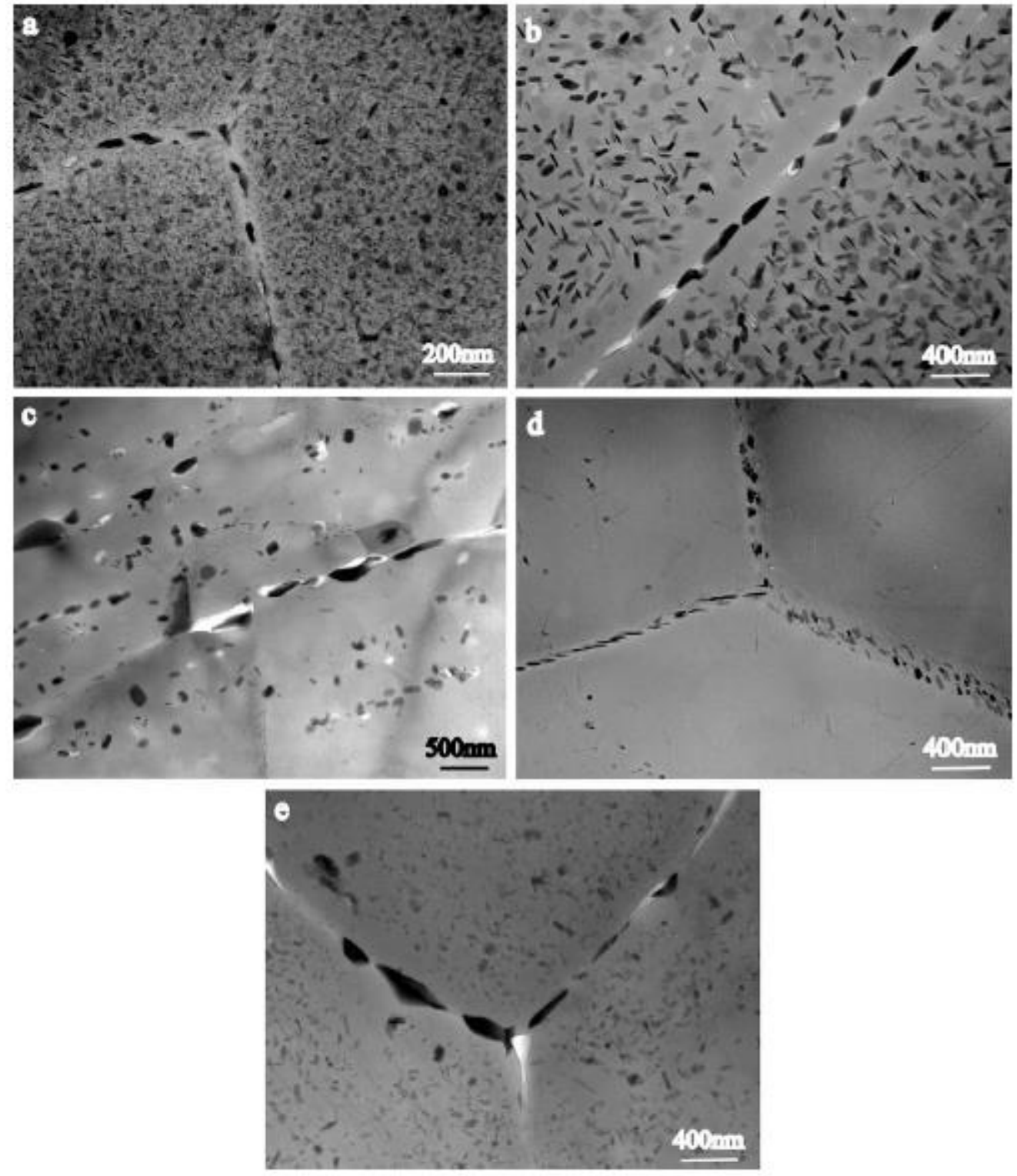

Figura 2-7: Distribuição de precipitados nas diferentes regiões da liga de alumínio 7050T651 soldada por FSW: (a) metal base, (b) HAZ, (c) TMAZ próxima à HAZ e (d) TMAZ próxima ao nugget, (e) nugget. (SU J., NELSON, MISHRA, \& MAHONEY, 2003).

O estudo desenvolvido por Su et al. (2003) exemplifica e discute de modo bastante claro um processo característico dos materiais envelhecíveis ou endurecíveis por precipitação, como as ligas de alumínio de elevada resistência mecânica: a possibilidade 
de reprecipitação a partir da solução sólida da matriz de partículas de endurecimento dissolvidas nas regiões aquecidas durante o processo de FSW. Este fenômeno pode ocorrer tanto após exposição do material à temperatura ambiente ou então após aplicação de tratamento térmico, recuperando parcialmente algumas das propriedades como observado nos estudos realizados por Jariyaboon et al. (2009), Proton et al. (2011) e Proton et al. (2013) no que se refere à corrosão e por Zheng e Zhang (2015) relativamente às propriedades mecânicas desta classe de materiais.

\subsection{CORROSÃO DE LIGAS DE ALUMÍNIO SOLDADA POR FSW}

Na literatura científica existem vários trabalhos dedicados ao estudo da corrosão das ligas de alumínio soldadas por FSW, e os mesmos utilizam como substrato, principalmente, as ligas de elevada resistência mecânica utilizadas na indústria aeroespacial. Os resultados são conflitantes. Assim, vários autores relatam diminuição da resistência à corrosão na região de solda quando comparada com a matriz não afetada pelo processo de soldagem (BOUSQUET, POULON-QUINTIN, PUIGGALI, DEVOS, \& TOUZET, 2011) (JARIYABOON, et al., 2009) (FONDA, et al., 2009). Outros mostram que a região de solda apresenta comportamento mais nobre que o metal base (HU \& MELETIS, 2000) (LIU, MURR, NIOU, MCCLURE, \& VEGA, 1997) (PROTON, et al., 2011), existindo também indicações de que não há diferenças entre o comportamento de corrosão do metal base e da região de solda (CORRAL, TRILLO, YING, \& MURR, 2000).

Diferenças de comportamento eletroquímico ao longo da seção transversal da região soldada também têm sido verificadas (HEINS \& SKROTZKI, 2002) (SU J. , NELSON, MISHRA, \& MAHONEY, 2003) (PROTON, et al., 2011), bem como devido à posição da solda em relação ao avanço da ferramenta. Estas diferenças de comportamento podem ter origem nas diferentes condições experimentais empregadas na obtenção da FSW, que são parâmetros importantes para a quantidade de deformação aplicada e geração de calor na região soldada, e, consequentemente, na microestrutura desta região (SU J. , NELSON, MISHRA, \& MAHONEY, 2003). Podendo também ter origem nos diferentes tipos de liga utilizados na investigação e também nos pré e póstratamentos aplicados às peças soldadas.

É de se esperar também que diferenças microestruturais existam dentro de uma mesma região da solda, uma vez que a ausência de fusão não propicia a mistura dos 
constituintes em escala atômica, e existem gradientes térmicos na região de soldagem que podem gerar diferenças na microestrutura. Bousquet et al. (2011b) identificaram variações na microdureza dentro de uma mesma região da solda, a qual foi relacionada com diferenças na distribuição e densidade de precipitados de endurecimento nestas regiões.

Proton et al. (2011) investigaram o comportamento de corrosão em $\mathrm{NaCl}$ 1,0 mo; $\mathrm{L}^{-1}$ de uma liga de alumínio 2050 soldada por FSW, antes e após a aplicação do tratamento térmico T8. Os testes foram realizados na seção transversal do material, tendo sido empregadas técnicas eletroquímicas e observações microestruturais além de um teste de acoplamento galvânico. Os resultados das curvas de polarização mostraram comportamento ativo para o metal base e para todas as regiões de solda, independentemente da aplicação do tratamento térmico após a soldagem. Entretanto, este último procedimento tornou o potencial da região de solda mais nobre que o do metal base, particularmente no que concerne à HAZ, o que foi comprovado por testes de acoplamento galvânico que mostraram que, após o tratamento T8, esta região apresentava comportamento catódico em relação ao nugget e ao metal base, enquanto sem o tratamento térmico a mesma era anódica. No que concerne ao tipo de corrosão, foi observado que o metal base era suscetível à corrosão por pites enquanto a região de solda não tratada termicamente apresentou corrosão intergranular e inter e intragranular após a aplicação do tratamento térmico.

Em outro trabalho Proton et al. (2013) caracterizaram o comportamento de corrosão do nugget da liga 2050 soldada por FSW e submetida a um tratamento térmico T8. Foram usados testes de imersão, eletroquímicos e um teste de visualização por gel. Os resultados dos testes eletroquímicos e de corrosão mostraram que o nugget não tratado termicamente era suscetível à corrosão intergranular e o tratado termicamente às corrosões inter e intragranular. Já o teste de visualização por gel evidenciou um comportamento heterogêneo da seção transversal do nugget, com a região inferior sendo mais anódica que a superior, independentemente da aplicação do tratamento térmico. As observações microestruturais revelaram também que as morfologias dos processos de corrosão eram diferentes para o nugget com e sem tratamento térmico, o que foi correlacionado com os diferentes estados de precipitação das partículas na microestrutura desta região.

Fahimpour et al. (2012) compararam o comportamento eletroquímico da liga de Al 6061 soldada por FSW (800 rpm e $200 \mathrm{~mm} / \mathrm{min}$ ) e por TIG. Os autores observaram a 
seguinte gradação da resistência à corrosão para a liga como soldada: metal base > FSW > TIG. A menor resistência à corrosão da região da solda FSW em relação ao metal base foi explicada pela maior quantidade de contornos de grão (grãos menores) presentes nesta região tornando-a termodinamicamente mais suscetível à corrosão. Já para o processo TIG, de acordo com os autores, a formação de estruturas dendríticas com distribuição de concentração heterogênea é a responsável pela baixa resistência à corrosão. Para ambos os tipos de soldagem a aplicação de um tratamento térmico T6 tornou a resistência à corrosão similar à do metal base.

Um resultado oposto ao de Fahimpour et al. (2012) foi obtido por Xu et al. (2011), onde a base metálica apresentou maior suscetibilidade à corrosão por pites comparada com a região do nugget. No entanto, a solução utilizada por estes autores continha tampão de $\mathrm{NaOH}$ para o $\mathrm{pH}$ ficar estabilizado em 12, o que pode ter diferenciado os resultados. Os autores observaram a formação de uma fase $\mathrm{Al}_{2} \mathrm{Cu}$ em maior quantidade na base do metal, dificultando a formação de uma camada de óxido protetora e a ação dos íons cloretos passou a ser maior nesta região, causando uma propensão à corrosão por pites.

Com o objetivo de reduzir o aumento da temperatura durante a soldagem, Jaryiaboon et al. (2009) investigaram o efeito do resfriamento criogênico com dióxido de carbono, aplicado durante a realização da soldagem por FSW, no comportamento de corrosão da liga de alumínio 2024-T351 soldada por FSW. Foi verificado que a aplicação do tratamento térmico não modifica o mecanismo de corrosão, mas reduz de maneira efetiva a extensão da zona suscetível a este fenômeno. Deste modo, para as duas condições a HAZ apresentou-se anódica em relação ao metal base e ao nugget, apesar deste último também ter apresentado alguma atividade anódica. Observações por MEV realizadas após testes de imersão com a seção transversal da solda mostraram a ocorrência de corrosão intergranular na HAZ e no nugget, atribuída à formação de zonas de depleção nos contornos de grão, e de corrosão por pites em torno dos intermetálicos no metal base. Foi verificado também que o nugget apresenta atividade eletroquímica heterogênea, sendo mais anódico na região inferior (raiz da solda) na amostra soldada sem refrigeração e perto da extremidade do nugget, no lado do retrocesso, na amostra soldada com refrigeração. Foi observado ainda que a densidade de locais catódicos observadas na região do nugget é maior do que no metal base, isto ocorre devido à precipitação de partículas da fase-S nesta região, que agem como catodos.

Squillace et al. (2004) além de apresentar as curvas de polarização da liga de Alumínio AA2024-T3 também realizaram ensaios de impedância eletroquímica para 
avaliar a suscetibilidade à corrosão das regiões da solda feita pelo processo de FSW. Verificaram que tanto as curvas de polarização como os testes de EIS apresentaram o metal base com maior tendência à corrosão, enquanto o nugget e HAZ mostraram comportamento passivo.

Na literatura são poucos os trabalhos que reportam a os efeitos dos parâmetros de soldagem, mais especificamente velocidade de deslocamento e de rotação sobre as propriedades mecânicas e de corrosão de ligas de alumínio soldadas por FSW. Jariyaboon et al. (2007) verificaram que a região de solda (HAZ + TMAZ + nugget) se comporta anodicamente em relação à matriz, e que a região preferencialmente anódica se desloca do nugget para a região afetada termicamente (HAZ) quando a velocidade de rotação da ferramenta aumenta, sendo este comportamento relacionado à dissolução e reprecipitação de partículas dispersóides e de endurecimento devido aos ciclos térmicos impostos pela soldagem. No que concerne ao comportamento de corrosão das regiões individuais, investigada por meio de ensaios de polarização utilizando uma microcélula, foi verificado que o potencial de pites aumenta tanto com o aumento da velocidade de deslocamento, mantendo-se constante a velocidade de rotação da ferramenta, como com a velocidade de rotação, mantendo-se constante a velocidade de deslocamento, sendo que o efeito da velocidade de rotação parece exercer um papel mais importante neste parâmetro. Por sua vez, os resultados das curvas catódicas não permitiram nenhuma correlação direta entre a variação dos parâmetros de soldagem e a intensidade da reação de redução.

Gupta et al. (2012) estudaram a resistência à corrosão de uma liga de Al da série 7000 soldada por FSW em função da velocidade de rotação da ferramenta, que foi variada entre 300 e 1000 rpm, mantendo constante a velocidade de deslocamento (avanço). Foi verificado, através de ensaios de polarização realizados com as diferentes zonas originadas na soldagem, que a resistência à corrosão aumenta com o aumento da velocidade de rotação. Entretanto, no que concerne às propriedades mecânicas, foi observado que as maiores resistências à tração foram exibidas pelas soldas obtidas com menores velocidades de rotação (400 rpm foi a melhor), o que correspondeu às amostras que apresentaram maior dureza e maiores extensões de zonas recristalizadas no nugget (GUPTA, DAS, \& PAL, 2012).

No estudo de Patil e Soman (2013) foi avaliada a influência da velocidade de deslocamento (avanço) sobre as propriedades mecânicas e de resistência à corrosão de duas ligas diferentes da série $6 \mathrm{XXX}$ soldadas por FSW, mantendo a constante a velocidade de rotação. Verificou-se que as propriedades mecânicas dos materiais 
soldados variam consideravelmente de acordo com o posicionamento das ligas em relação ao deslocamento e rotação da ferramenta durante o processo de produção (lado do avanço ou do retrocesso), não permitindo uma generalização do efeito da velocidade de deslocamento sobre estas variáveis. Por exemplo, constatou-se que quando a liga 6061 era posicionada no lado do avanço da ferramenta a microdureza da região de solda variava inversamente com o aumento da velocidade de deslocamento, enquanto quando a liga 6082 foi posicionada nesta condição a dureza aumentou com a velocidade de deslocamento. Já no que se refere ao limite de resistência à tração, foi observado uma diminuição deste parâmetro com o aumento da velocidade de deslocamento, independentemente de qual liga foi posicionada no lado do avanço da ferramenta. No que se refere ao comportamento de corrosão, verificou-se que a velocidade de corrosão (determinada pela corrente de corrosão) diminuiu com a velocidade de deslocamento quando a liga 6082 foi posicionada no lado do avanço e aumentou com a liga 6061 nesta posição (PATIL \& SOMAN, 2013).

\subsubsection{Uso de técnicas locais para avaliação de corrosão da liga de alumínio 2024 soldada por FSW}

O controle dos parâmetros do processo de soldagem foi estudado por Jaryiaboon et al. que avaliaram a influência desta variável na resistência à corrosão da liga AA 2024T351. Os autores verificaram que o potencial de degradação se apresentava mais eletronegativo na solda do que no material base. Observaram predominantemente ataques intergranular na região do nugget em baixas velocidades de rotação (215 rpm$154 \mathrm{~mm} / \mathrm{mim}$ e $215 \mathrm{rpm}-75 \mathrm{~mm} / \mathrm{mim}$ ) enquanto para alta velocidade de rotação (350 rpm95mm/mim, $468 \mathrm{rpm}-154 \mathrm{~mm} / \mathrm{mim}$ e $468 \mathrm{rpm}-75 \mathrm{~mm} / \mathrm{mim}$ ), o ataque ocorreu predominantemente na zona afetada termicamente (HAZ). Concluíram que o comportamento anódico na região da solda ocorreu devido à sensitização dos contornos dos grãos, conduzindo a ataques intergranulares e, em contrapartida, a melhoria na resposta anódica foi encontrada na região do nugget para maiores velocidades de rotação devido à precipitação da fase-S (Al2 $\mathrm{CuMg})$, o que é consequência da maior geração de calor durante o processo7. Utilizando uma microcélula estes autores verificaram que o potencial de quebra da película passiva das diferentes regiões de solda variava com os parâmetros de soldagem, sendo tanto mais positivo quanto maior a geração de calor durante o processo, traduzida, principalmente, por uma maior velocidade de rotação da 
ferramenta.Bousquet et al. (2011b) avaliaram a sensibilidade à corrosão da liga de alumínio AA2024-T3 soldada por FSW através do teste de corrosão intergranular normalizado (ASTM-G110) e de uma microcélula eletroquímica para medida de potencial de circuito aberto. O teste de corrosão intergranular mostrou que tanto o metal base como as diferentes regiões de solda são suscetíveis à corrosão intergranular, sendo que o processo foi mais intenso na HAZ nas proximidades da TMAZ. Por sua vez as observações micrográficas mostraram que no metal base e no nugget o principal tipo de corrosão foi por pites. O registro do potencial de circuito aberto com a microcélula mostrou grandes flutuações na região do metal base e na HAZ nas proximidades com este, o que foi atribuído à característica estocástica da corrosão por pites predominante nestas regiões; estabilidade entre a HAZ e a TMAZ, devido ao estabelecimento de um processo de corrosão intergranular uniforme através de linha contínua de precipitados na região de contornos de grãos; e estabilidade entre a TMAZ e o nugget devido à distribuição uniforme de partículas de intermetálicos fraturados pelo movimento da ferramenta, originando uma grande quantidade de pequenos pites distribuídos em toda a superfície. No que se refere a possíveis efeitos galvânicos foi verificado que o potencial de circuito aberto do metal base é superior ao das demais regiões de solda.

Sidane et al (2015) estudaram uma solda FSW dissimilar de AA 2050-T8 e 7449T79 utilizando técnicas eletroquímicas locais, Microscopia Eletroquímica de varredura (SECM) e espectroscopia de impedância eletroquímica (LEIS). Através da cartografia SECM os autores mostraram que a cinética eletroquímica muda na camada passiva entre os dois materiais nas diferentes regiões da solda. Esta variação foi atribuída à existência de um par galvânico entre as ligas 2050 e 7449. Os ensaios de SECM foram acompanhados por LEIS, a qual confirmou a existência de uma alta corrente local na região de ligação entre a liga 2050 e a 7449, ou duas diferentes zonas microestruturais.

O uso da técnica do eletrodo vibratório de varredura (SVET) foi reportado por Bertoncello, Manhabosco e Dick (2015), os quais, avaliaram o comportamento de corrosão de uma solda FSW dissimilar de AA7050-T76511 e AA2024-T3 em solução $\mathrm{NaCl}$ 0,1 mol.L $\mathrm{L}^{-1}$. Observaram a ocorrência de corrosão por pites na região do nugget da AA 7050, próxima a interface AA 7050 com AA 2024, devido ao par galvânico formado, como também a alta estabilidade de nucleação dos pites na região do nugget da AA 7050. Na liga AA 2024 os autores observaram que a região HAZ era mais susceptível à corrosão intergranular, entretanto a corrosão intergranular é menos intensa que no material base devido o para galvânico formado com a liga mais nobre AA 7050. 


\section{MATERIAIS E MÉTODOS}

O material utilizado neste trabalho foi a liga de alumínio 2024-T3, fornecida pela EMBRAER já na condição soldada, cuja composição nominal está apresentada na Tabela 3-1.

Tabela 3-1: Composição química nominal da liga AA2024 T3 (\% em massa dos elementos) (ASTM METALS HANDBOOK, 1990)

\begin{tabular}{llllllllll}
\hline Al & $\mathbf{S i}$ & $\mathbf{F e}$ & $\mathbf{C u}$ & $\mathbf{M n}$ & $\mathbf{M g}$ & $\mathbf{C r}$ & $\mathbf{Z n}$ & $\mathbf{T i}$ & Outros \\
\hline Restante & $0,5-1,2$ & 0,7 & $3,9-5,0$ & $0,4-1,2$ & $02-0,8$ & 01 & 0,25 & 0,15 & 0,15 \\
\hline
\end{tabular}

\subsection{CARACTERIZAÇÃO MICROESTRUTURAL}

\subsubsection{Microscopia Ótica (MO)}

Para análise da microestrutura das diferentes zonas da solda por microscopia ótica utilizou-se ataque metalográfico de Keller ( $1 \mathrm{ml}$ de ácido fluorídrico 40 \%p/p, 1,5ml ácido clorídrico $35 \%$ p/p, $2,5 \mathrm{ml}$ de ácido nítrico $68 \%$ p/p e $95 \mathrm{ml}$ de água destilada).

Para esta avaliação utilizou-se um microscópio óptico Olympus 60M. Antes do ataque com o reagente de Keller, os corpos de prova tiveram as superfícies tratadas em uma politriz com lixas d’água de carbeto de silício (granas \#600, \#800, \#1200, \#2400 e \#4000) e, posteriormente, foram polidos com pasta de diamante de 3 e $1 \mu \mathrm{m}$. Em seguida um algodão foi embebido com a solução Keller e passado na superfície por 10s, a superfície foi lavada com água deionizada e seca ao ar antes de ser analisada no microscópio.

\subsubsection{Microscopia Eletrônica de Varredura com análise por Energia Dispersiva de Raio-X (MEV-EDS)}

As observações foram realizadas utilizando um microscópio eletrônico JEOLJBM-7401F. Foram analisadas amostras polidas sem e após imersão em solução de $\mathrm{NaCl}$ 0,1 mol. $L^{-1}$, e amostras atacada com o reagente de Keller. 


\subsubsection{Microscopia Eletrônica de Transmissão (TEM)}

As observações foram realizadas utilizando um microscópio eletrônico JEOLJEM-2100 - 200kV. Foram analisados discos de 2,0 mm de diâmetro e $100 \mu \mathrm{m}$ de espessura de cada região da solda polidos pelo processo eletrolítico utilizando o equipamento Tenupol-Struers.

\subsubsection{Ensaios de Microdureza}

Os perfis de microdureza Hv 0,3 (carga de $300 \mathrm{~g}$ ) foram obtidos na superfície da amostra através de toda a região de solda utilizando o equipamento Micro Hardness tester HMV Shimadzu com um passo de 0,5 mm em uma extensão de $15 \mathrm{~mm}$ para cada lado do ponto central do nugget.

Os perfis foram obtidos sobre amostras polidas segundo o procedimento descrito no item 3.1.1.

\subsubsection{Ensaio de corrosão utilizando solução de $\mathrm{NaCl} 0,7 \mathrm{~mol} \mathrm{~L}^{-1}$ contendo ágar-ágar e indicador universal de $\mathrm{pH}$}

Este procedimento foi empregado com o objetivo de identificar macroscopicamente a suscetibilidade à corrosão do metal base e das diferentes regiões de solda e seguir sua evolução em função do tempo de exposição a um ambiente corrosivo.

A solução de ágar-ágar foi preparada misturando-se 2,5 $\mathrm{g}$ deste componente em $100 \mathrm{ml}$ de solução de $\mathrm{NaCl}$ 0,7 mol.L $\mathrm{L}^{-1}$ contendo $7 \mathrm{ml}$ indicador universal de $\mathrm{pH}$.

Para a realização do ensaio, amostras polidas contendo todas as regiões da solda eram colocadas em uma placa de Petri. Em seguida a solução com ágar-ágar era colocada no recipiente até recobri-las com uma lâmina de eletrólito com espessura entre 1 e $2 \mathrm{~mm}$.

As modificações na coloração da solução sobre a superfície da liga foram registradas fotograficamente em função do tempo de imersão. 


\subsubsection{Ensaio de corrosão por esfoliação}

Para avaliação da corrosão por esfoliação seguiu-se a metodologia descrita na norma ASTM G34-01. A limpeza das peças brutas foi inicialmente realizada em solução contendo $945 \mathrm{~mL}$ de água, $50 \mathrm{~mL}$ de ácido nítrico $\left(\mathrm{HNO}_{3}\right) 70 \%$ p/p e $4 \mathrm{~mL}$ de ácido fluorídrico $(\mathrm{HF}) 48 \%$, deixando-as imersas por 1 minuto a $93^{\circ} \mathrm{C}$. Em seguida estas permaneciam por mais 1 minuto imersas em $\mathrm{HNO}_{3} 70 \% \mathrm{p} / \mathrm{p}$ à temperatura ambiente. As peças eram então lavadas e secas ao ar e imersas durante 6 horas, a temperatura ambiente, em uma solução com $57 \mathrm{~g}$ de cloreto de sódio $(\mathrm{NaCl})$, contendo $10 \mathrm{~mL}$ de água oxigenada $\left(\mathrm{H}_{2} \mathrm{O}_{2}\right) 30 \%$ p/p diluídos em 1L de água. Após o ensaio as amostras foram lavadas com água, secas ao ar e analisadas por microscopia ótica na superfície e seção transversal.

\subsubsection{Ensaio de corrosão intergranular}

Para avaliação da corrosão intergranular seguiu-se a metodologia descrita na norma ASTM G110-97. Após serem limpas com água e secas ao ar as amostras brutas foram imersas em uma solução contendo 4 mol. $\mathrm{L}^{-1}$ de cloreto de sódio $(\mathrm{NaCl})$ com 0,5 mol. $\mathrm{L}^{-1}$ de nitrato de potássio $\left(\mathrm{KNO}_{3}\right)$ e $0,1 \mathrm{~mol} . \mathrm{L}^{-1}$ de ácido nítrico $\left(\mathrm{HNO}_{3}\right)$ por 48 horas à temperatura ambiente. Após o ensaio as amostras foram lavadas com água, secas ao ar e analisadas por microscopia ótica na superfície e seção transversal

\subsubsection{Ensaios eletroquímicos globais}

Para o estudo do comportamento eletroquímico de cada zona individual da solda FSW da liga de alumínio AA 2024-T3, corpos de prova de $0,36 \mathrm{~cm}^{2}$, representativos das regiões metal base, HAZ, TMAZ + nugget, foram cortados separadamente, providos de contato elétrico com fio de cobre, e embutidos em baquelite.

Os eletrodos de trabalho assim obtidos, foram embutidos em baquelite, tiveram as superfícies tratadas em uma politriz com lixas d’água de carbeto de silício (granas \#600, \#800, \#1200) e, posteriormente, polidas com lixas de grana \#2400 e \#4000, em sequência. Para os ensaios eletroquímicos utilizou-se uma célula eletroquímica convencional de três eletrodos: referência $\mathrm{Ag}, \mathrm{AgCl} / \mathrm{KCl}$ sat e uma folha de platina de $6 \mathrm{~cm}^{2}$ de área como contra eletrodo. Foram realizados ensaios de impedância eletroquímica no potencial de circuito aberto, após 1 hora de estabilização, em meio de $\mathrm{NaCl} 0,1 \mathrm{~mol} \mathrm{~L}^{-1}$. O intervalo de 
frequência de todas as medidas foi de $10^{4} \mathrm{~Hz}$ a $10^{-2} \mathrm{~Hz}$ com 10 medidas por década logarítmica, com amplitude de perturbação de $10 \mathrm{mV}$ utilizando um potenciostato ( $\mu$ AUTOLAB Type III) acoplado a um analisador de resposta em frequência (FRA2). Os dados foram obtidos pelo programa NOVA 1.9 e tratados utilizando o software OriginPro 8.

As curvas de polarização anódica e catódica foram obtidas utilizando eletrodos independentes. Os ensaios foram realizados após uma hora de estabilização do potencial de circuito aberto. A varredura anódica foi de $-0,03 \mathrm{~V}$ à $1,5 \mathrm{~V}$ vs. PCA com varredura de $0,5 \mathrm{mV} / \mathrm{s}$ e a catódica de $0,03 \mathrm{~V}$ à $-1,5 \mathrm{~V} v s$. PCA com velocidade de varredura de $0,5 \mathrm{mV} / \mathrm{s}$ utilizando um potenciostato ( $\mu$ AUTOLAB Type III).

Foram utilizados três condições pra AA 2024 o metal base, em influência das soldas, peças inteiras (contendo o metal base e as diferentes regiões afetadas pela soldagem) e somente as regiões afetadas pela solda (HAZ e TMAZ + nugget).

\subsubsection{Ensaios eletroquímicos com a microcélula}

O comportamento eletroquímico de cada uma das regiões individuais foi avaliado utilizando uma microcélula, que permitia separar de modo mais preciso cada uma das diferentes regiões afetadas pelo processo de soldagem.

Para estes ensaios, os eletrodos de trabalho tiveram as superfícies tratadas com lixa d’água de carbeto de silício (granas \#600) em uma politriz, sendo deixados expostos ao ar por um período de 24 horas para estabilização da camada passiva.

Para isolar as diferentes regiões de solda foram construídas inicialmente duas microcélulas eletroquímicas, uma com área exposta de $0,041 \mathrm{~cm}^{2}$ e outra com área de $0,031 \mathrm{~cm}^{2}$. Após a realização dos ensaios preliminares optou-se por usar a célula com menor área que permitia uma seleção mais precisa da região de solda a ser ensaiada sem interferência das regiões adjacentes.

Todos os ensaios eletroquímicos foram realizados em triplicata no metal base e em cada uma das diferentes regiões da solda, a saber: zona afetada termicamente (Heat Affected Zone - HAZ), zona afetada termomecanicamente (Thermomechanically Affected Zone - TMAZ) e nugget. Na HAZ e na TMAZ foram avaliados os lados do avanço e do retrocesso. A Figura 3-1 apresenta uma imagem da região de solda com a marcação de todas as regiões ensaiadas 


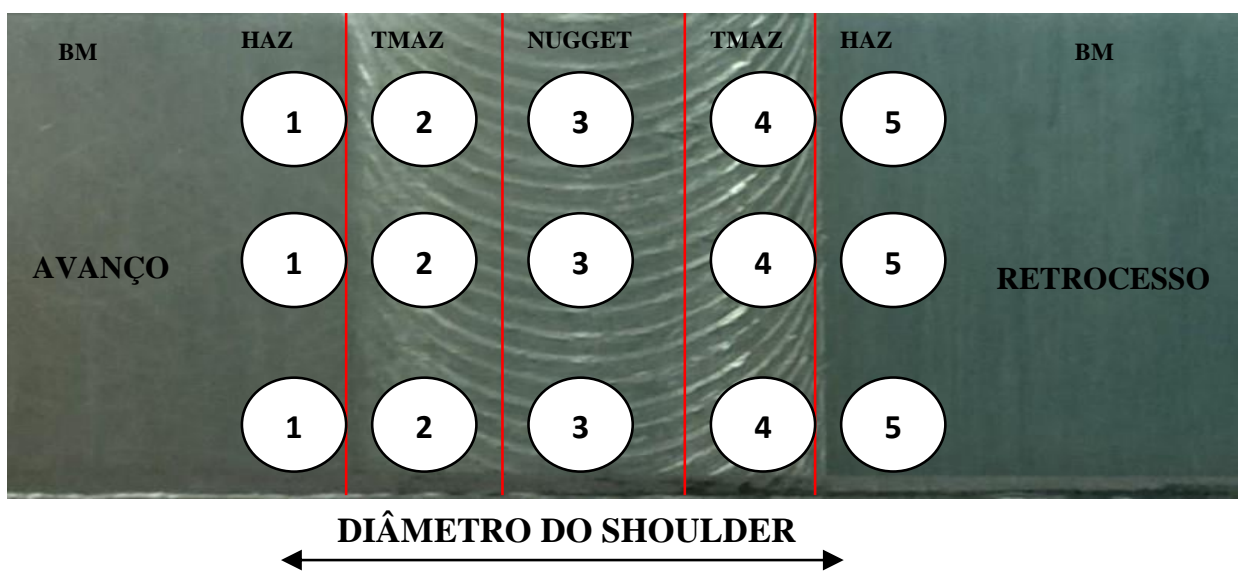

Figura 3-1: Esquema representativo das regiões onde foram realizados os ensaios eletroquímicos nas diferentes zonas da solda FSW.

Os ensaios eletroquímicos foram realizados utilizando um sistema com três eletrodos constando de um microeletrodo de referência de $\mathrm{Ag} / \mathrm{AgCl}(\mathrm{KCl}$ sat. $)$ e de uma folha de Pt como contra eletrodo.

Os ensaios de espectroscopia de impedância eletroquímica (EIS) foram realizados no potencial de circuito aberto (PCA) utilizando um potenciostato (AUTOLAB 70896) acoplado a um analisador de resposta em frequência (FRA2). Os diagramas foram adquiridos após 1 hora de estabilização do PCA, em meio de $\mathrm{NaCl}$ 0,1 mol.L $\mathrm{L}^{-1}$ O intervalo de frequência foi de $10^{4} \mathrm{~Hz}$ a $10^{-2} \mathrm{~Hz}$ com aquisição de 10 pontos por década logarítmica, e amplitude de perturbação de $10 \mathrm{mV}$ (rms). Para controle dos experimentos e aquisição dos dados foi utilizado o programa NOVA®

As curvas de polarização anódica foram obtidas em um potenciostato AUTOLAB 70896 após uma hora de estabilização do PCA. A varredura foi realizada no intervalo entre $-0,03 \mathrm{~V}$ a $+1,5 \mathrm{~V} v s$. PCA com velocidade de varredura de $0,5 \mathrm{mV} / \mathrm{s}$.

\subsubsection{Eletrodo Vibratório de Varredura (Scanning Vibrating Electrode Technique - SVET)}

O objetivo desta parte é avaliar as atividades eletroquímicas sobre as diferentes regiões da solda quando em contato entre si e expostas a um mesmo eletrólito através das medidas das densidades de corrente anódicas e catódicas que se desenvolvem sobre o eletrodo em virtude da atividade eletroquímica. Nesta parte do trabalho será apresentada inicialmente uma breve introdução sobre a técnica, e, em seguida, a montagem 
experimental utilizada para a realização dos experimentos realizados com a liga de alumínio 2024-T3 soldada por FSW.

\subsubsection{Princípio da metodologia}

Desenvolvida e utilizada por biólogos para estudos de fluxos iônicos em sistemas biológicos (JAFFE e NUCCITELLI, 1974), a técnica do eletrodo vibratório de varredura, denominada em inglês de Scanning Vibrating Electrode Technique (SVET), teve seu início na área de corrosão nos anos 70 com o pioneiro trabalho de (ISAACS \& KISSEL, 1972) (ISAACS H. , 1987) A partir de então, começou-se os estudos para avaliar superfícies revestidas (ISAACS, ALDYKIEWICZ, THIERRY, \& SYMPSON, 1996), pares galvânicos (ISAACS H. , 1988).

O sistema completo está esquematizado na Figura 3-2 onde o eletrodo de trabalho é colocado no porta amostra, posicionado em uma mesa anti-vibração, uma gaiola de Faraday e uma unidade de alimentação ininterrupta com filtragem da corrente de alimentação. Através de uma câmara de vídeo, pode-se fazer o controle da posição do eletrodo e obter imagens da amostra. Um sistema de motores é utilizado para posicionar e movimentar o microeletrodo com $1 \mu \mathrm{m}$ de precisão, e um pré-amplificador e um amplificador IPA-2 integram dois amplificadores lock-in, um para cada vibração. A medida é realizada utilizando-se uma sonda dotada de um microeletrodo (Pt-Ir) colocado em sua extremidade, o qual possui duas pontos, uma fixa e outra ligada a dois osciladores piezo eletrônicos que são responsáveis pelas vibrações x e z (frequências selecionáveis entre 40 e $1000 \mathrm{~Hz}$ ). Todo o processo é controlado pelo software ASET desenvolvido pela empresa Sciencewares (BASTOS, DIAS, DIAMANTINO, \& FERREIRA, 2013) (BASTOS \& SIMÕES, 2003)

O sistema mede variações extremamente pequenas de potencial existentes em uma solução devidas aos fluxos de corrente originados em uma reação eletroquímica em uma superfície ativa. Em superfície que sofre corrosão, a oxidação e a redução ocorrem em regiões separadas e íons são formados e distribuídos na solução, então, o gradiente de concentração cria um campo elétrico, que pode ser detectado usando um microeletrodo que mede a diferença de potencial entre dois pontos na solução localizada sobre a superfície do eletrodo de trabalho. Geralmente, é obtido um mapa de distribuição de correntes com todos os pontos medidos através de uma varredura da superfície. O potencial (V) medido em cada ponto, pode ser relacionado com as intensidades de 
corrente (I) do processo através da Lei de Ohm (BASTOS, DIAS, DIAMANTINO, \& FERREIRA, 2013) (BASTOS \& SIMÕES, 2003)

$$
V=\frac{I \rho}{2 \pi d}
$$

Onde $\rho$ é a resistividade da solução e d é a distância entre o ponto de medição e o local da corrente.

A Figura 3.2 apresenta uma representação esquemática de um sistema de medição por SVET.

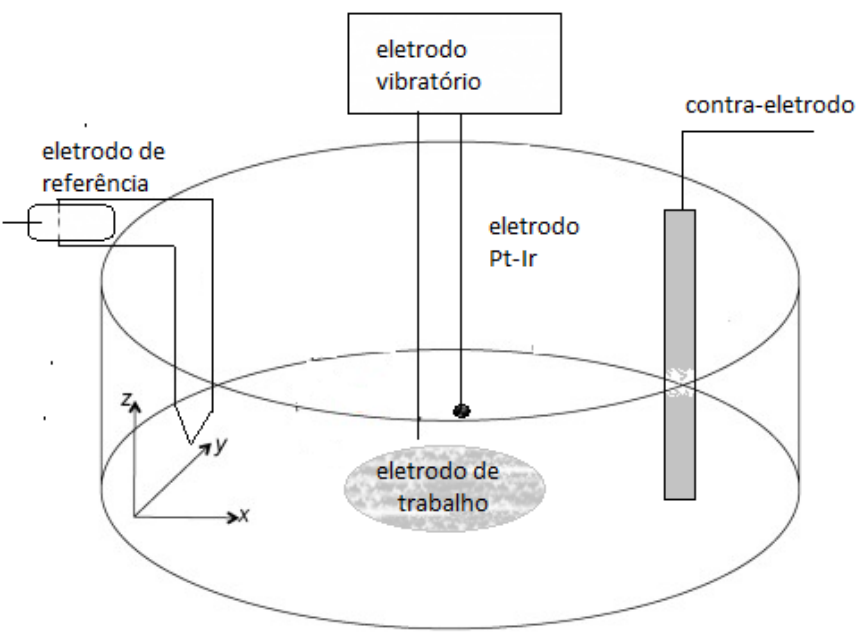

Figura 3-2: Representação esquemática da metodologia do eletrodo vibratório de varredura - SVET.

\subsubsection{Montagem experimental}

Como destacado na introdução deste item, estes ensaios foram realizados para avaliar as atividades eletroquímicas sobre as diferentes regiões da solda quando em contato entre si e expostas a um mesmo eletrólito. Devido à extensão do cordão de solda (incluindo o metal base e a HAZ do lado do avanço e do retrocesso), que tornava extremamente longa a varredura através de toda a região, os mapas de SVET foram adquiridos sobre amostras construídas a partir de partes do cordão de solda. Estas partes foram separadas e as regiões foram isoladas e separadas da seguinte maneira:

$$
\begin{aligned}
& \circ \text { amostra 1: TMAZ(a) + Nugget + TMAZ(r); } \\
& \circ \text { amostra 2: Nugget +TMAZ(a) + HAZ; } \\
& \circ \text { amostra 3: Nugget + TMAZ(r) + HAZ, }
\end{aligned}
$$


onde (a) e (r) se referem, respectivamente, ao lado do avanço e do retrocesso da solda. Para a realização das medidas, estas amostras foram colocadas embutidas em baquelite.

Todas as amostras foram expostas à solução $\mathrm{NaCl} 0,05$ mol.L ${ }^{-1}$ por 24 horas, e os mapas foram adquiridos a cada hora usando um equipamento SVET (Applicable Electronics) controlado pelo programa ASET (Sciencewares). Na sonda Pt-Ir (Microprobe, Inc) foi depositado negro de platina como uma gota de $15 \mu \mathrm{m}$ de diâmetro. A sonda foi posicionada à $150 \pm 5 \mu \mathrm{m}$ acima da superfície, vibrando nas direções normal (Z) e paralela (X) à superfície da amostra. A amplitude de vibração foi $30 \mu \mathrm{m}$ (pico à pico) e a frequência de vibração de $77 \mathrm{~Hz}(\mathrm{Z})$ e $263 \mathrm{~Hz}$ (X).

Somente a componente normal da corrente foi utilizada para a construção dos mapas de densidade de corrente e para os cálculos. As dimensões das amostras variaram de 5,3 x 5,5 a 7.0 x $7.0 \mathrm{~mm}$ e a janela de medida teve uma área de 8,0 x 9,0 mm. Após o posicionamento da sonda em cada ponto um tempo de espera fixo foi atribuído antes da aquisição de cada valor de corrente. Cerca de 5000 pontos de medição foram adquiridos por cada mapa com duração de varredura de aproximadamente 50 minutos.

\subsubsection{Espectroscopia de Impedância Eletroquímica Local (LEIS)}

Embora inicialmente proposta por Isaacs e Kendig (1980) com objetivo de avaliar a reatividade local em eletrodos heterogêneos a espectroscopia de impedância eletroquímica localizada (Local Electrochemical Impedance Spectroscopy - LEIS) com a configuração de cinco eletrodos utilizada no presente trabalho foi proposta por Lillard, Moran e Isaacs (1992) tendo sido empregada para o estudo da impedância local de um eletrodo de Al no centro do qual foi implantado um disco de Molibdênio (LILLARD, MOARAN, \& ISAACS, 1992 ). A técnica possui a vantagem da resolução espacial característica de técnicas que utilizam microssondas, associada à possibilidade de obter informações sobre os mecanismos de corrosão que caracteriza a EIS. A sonda mede a diferença de potencial elétrico na solução e que é proveniente das reações eletroquímicas que ocorrem na superfície do eletrodo submetido a uma excitação em corrente alternada.

\subsubsection{Princípio da metodologia}

As medidas de LEIS foram realizadas utilizando uma sonda, à qual será denominada bi eletrodo, que permite a medição da diferença de potencial ac na solução 
nas proximidades da superfície do eletrodo de trabalho (ET). O sistema experimental, assim como as considerações teóricas envolvidas no cálculo da impedância local, será descrito detalhadamente neste item.

As denominações utilizadas para descrever a técnica seguirão as notações proposta por Huang et al (2007). Chamaremos a letra "Z", em maiúsculo de impedância global, e a "z”, em minúsculo de impedância local.

A Figura 3-3 apresenta a esquematização da ponta de um bi eletrodo constituído de dois fios condutores, da ordem de micrômetros $(150 \mu \mathrm{m})$, colocados dentro de um bicapilar e selados para não terem contato entre si. Essas pontas agem como eletrodos de referência e medem o potencial ac em solução. Para a realização da medida de LEIS é de extrema importância saber a distância (d) entre os dois fios utilizados para a construção da microssonda, bem como o diâmetro dos fios utilizados para construí-la. Através dessas informações obtém-se a corrente local que é calculada pela equação 3-2 .

$$
\Delta_{i l o c}=\frac{\Delta V . k}{d}
$$

onde $\Delta \mathrm{V}$ é a diferença de potencial entre as duas pontas do bi eletrodo e é dada por $\Delta \mathrm{V}=\mathrm{E}_{1}-\mathrm{E}_{2}(\mathrm{~V})$, " $\mathrm{k}$ " é a condutividade específica do eletrólito $\left(\Omega^{-1} \mathrm{~cm}^{-1}\right)$ e "d" é a distância entre as duas pontas (cm). Substituindo as unidades na Eq. 3-2, obtém-se a unidade de A.cm ${ }^{-2}$. A Figura 3-3 apresenta um esquema da ponta de um bi-eletrodo.

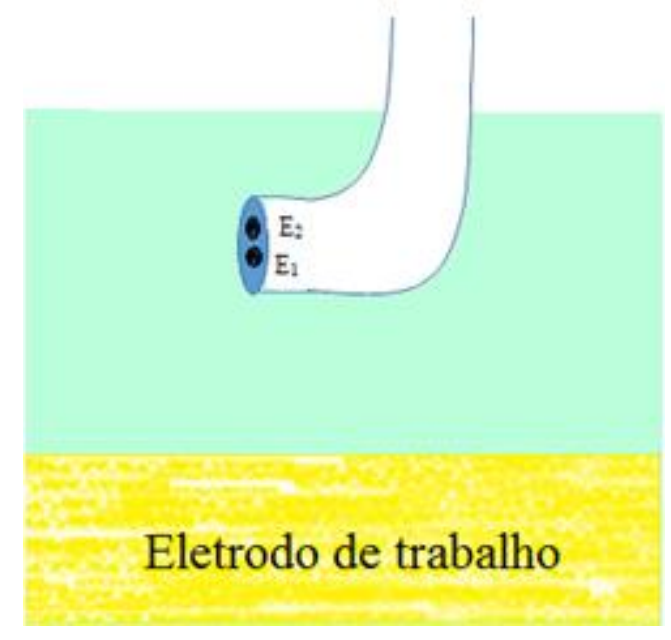

Figura 3-3: Esquematização da ponta de um bi eletrodo

Através dos resultados da corrente local consegue-se então calcular o valor da impedância local ( $\mathrm{Z}_{\mathrm{loc}}$ ) que é dada pela equação 3-3. 


$$
z_{\text {loc }}=\frac{\widetilde{\Delta E}}{\Delta_{\text {iloc }}}
$$

Onde $\widetilde{\Delta E}$ é a diferença de potencial ac entre o eletrodo de trabalho e o eletrodo de referência imersos na solução. Esta impedância local, pode ser comparada com a impedância global (Z), que é a impedância conhecida e determinada em EIS.

$$
Z=\frac{\widetilde{\Delta E}}{\widetilde{\Delta I}}
$$

Como na metodologia clássica EIS na LEIS ocorre uma perturbação senoidal da diferença de potencial entre o eletrodo de trabalho e o eletrodo de referência com objetivo de receber o sinal de corrente entre o eletrodo de trabalho e a distância do contraeletrodo com o potenciostato, mas no caso da impedância local além desses parâmetros obtém-se uma razão deste potencial aplicado em função da densidade de corrente local da solução, onde a densidade de corrente local é obtida pela diferença de potencial medida próxima da superfície utilizando dois microeletrodos. Através da medida da diferença de potencial entre os microeletrodos, conhecendo a distância que os separa e a condutividade da solução, obtém-se a densidade de corrente local. Lillard, Moaran e Isaacs (1992) utilizaram dois modelos para investigar a precisão desta densidade de corrente local. $\mathrm{O}$ primeiro modelo consistiu em um eletrodo homogêneo, o que permitiu a comparação entre a impedância global (EIS) e a impedância local (LEIS), e o segundo sistema utilizando um eletrodo heterogêneo onde conhecia-se o tamanho e a localização dos quais os componentes poderiam ser facilmente caracterizados pela técnica tradicional. Utilizando um eletrodo de trabalho de alumínio puro, os autores observaram que a medida de impedância local foi semelhante aos resultados clássicos EIS, também observaram uma resposta de impedância local maior no centro do eletrodo quando comparada com a impedância local obtida nas bordas, justificando este fenômeno pela distribuição de corrente primária de um eletrodo de disco plano isolado em um plano infinito. No eletrodo heterogêneo conseguiram observar facilmente com LEIS a heterogeneidade da amostra enquanto com EIS uma pequena indicação do fenômeno foi detectada. A limitação da técnica é discutida comentando-se sobre o tamanho do microeletrodo e a distância deste com o eletrodo de trabalho, bem como os erros que podem estar induzidos no diagrama devido o LEIS ser obtido pela componente normal à superfície do ET (NEWMAN, 1996) 
(LILLARD, MOARAN, \& ISAACS, A Novel Method for Generating Quantitative Local Electrochemical Impedance Spectroscopy, 1992 )

Com objetivo de avaliar as propriedades eletroquímicas de um recobrimento de epóxi modificado utilizado para proteger o revestimento de estanho em latas de aço soldadas por soldagem por resistência Lillard et al (1995) examinaram amostras com recobrimento, amostras sem recobrimento e uma amostra com defeito artificial em solução de $\mathrm{NaCl}$ 0,1 mol.L $\mathrm{L}^{-1} \mathrm{com} \mathrm{pH}$ tamponado em 7,2. O mapeamento LEIS evidenciou que a falha no recobrimento ocorria preferencialmente em cima da solda a uma velocidade maior que no defeito artificial. A falha no recobrimento foi detectada por LEIS antes da observação visual. Nos resultados de EIS, os autores conseguiram fazer construir o modelo convencional de penetração de poro com duas constantes de tempo, enquanto com LEIS os resultados mostraram três constantes de tempo (recobrimento, defeito e cordão de solda), indicando que a técnica LEIS é mais sensível (LILLARD, KRUGER, TAIT, \& MORAN, 1995).

Thierry e Zou (1997) utilizaram LEIS para avaliar a corrosão em aço inoxidável, os autores contaminaram a superfície do aço com gotas de $0,3 \mathrm{~mm}^{2}$ de $\mathrm{NaCl} 0,1$ mol.L $\mathrm{L}^{-1}$ e em seguida pintaram a superfície com tinta epóxi. A impedância foi obtida em solução 10mmol. $\mathrm{L}^{-1}$ de $\mathrm{NaCl}$ cuja condutividade estava na ordem de $1,1 \mathrm{mS} . \mathrm{cm}^{-1}$. Com o microeletrodo posicionado em cima de um dos defeitos do recobrimento, os autores obtiveram as impedâncias EIS e LEIS e concluíram que LEIS pode ser utilizada com sucesso para detectar a formação de bolhas na superfície de aço pintado a partir de gráfico da capacitância em função do tempo pois a vantagem é a realização de medidas locais e obtém-se um valor quantitativo mais pronunciado em LEIS do que EIS. Na observação do espectro de impedância local os autores observaram nas regiões de baixa frequência a evolução de um arco de resistência negativa, que aumenta com o aumento do tempo de exposição atribuindo o comportamento ao processo de repassivação. (ZOU \& THIERRY, 1997).

Baril e colaboradores (2003) utilizaram LEIS para avaliar a corrosão da liga de magnésio AZ91. Observaram a partir dos resultados uma semelhança nos diagramas de impedância global e local entretanto devido ao tamanho do microeletrodo, não conseguiram diferenciar as atividades eletroquímicas das diferentes regiões devido resolução espacial baixa. Obtiveram uma resposta esperada referente à impedância local, que decrescia a medida que o microeltrodo se deslocava saia do centro para as bordas (BARIL, BLANC, KEDDAM, \& PÉBÈRE, 2003). Em 2009, Galícia et al (2009) também 
avaliaram a mesma liga de magnésio AZ91 em meio sulfato. A primeira avaliação foi feita em um eletrodo de magnésio puro posicionando o bieletrodo no centro da amostra e e a 100 e $200 \mu \mathrm{m}$ a partir do centro da amostra. Os espectros apresentaram-se similares e sobrepostos nas três posições, apresentaram em alta frequência o arco indutivo já observado por outros autores e foi atribuído à geometria de célula e não à um comportamento eletroquímico da liga. Quando o eletrodo foi posicionado sobre a liga AZ91 os autores observaram uma forma semelhante na impedância global e local, entretanto quando o bieletrodo foi posicionado sobre a fase $\beta$, o arco capacitivo foi três vezes maior quando comparado com o da fase $\alpha$ e o arco capacitivo da constante de tempo em altas frequência foi dez vezes menor que na fase $\alpha$, indicando que a velocidade de corrosão da fase $\beta$ é menor que da fase $\alpha$ (GALICIA, PÉBÈRE, TRIBOLLET, \& VIVIER, 2009).

A utilização de LEIS e a importância da técnica para avaliar acoplamento galvânico foi apresentada por Lacroix et al (2012) apresentando o estudo entre o acoplamento galvânico entre as partículas da fase $\mathrm{S}-\mathrm{Al}_{2} \mathrm{CuMg}$ e a matrix $\mathrm{Al}$ 2024. Para representar a liga $\mathrm{Al} 2024$, utilizaram um modelo $\mathrm{Al}-\mathrm{Cu}$ e representando a fase $\mathrm{S}$ $\mathrm{Al}_{2} \mathrm{CuMg}$, utilizaram um modelo $\mathrm{Al}-\mathrm{Cu}-\mathrm{Mg}$ sintetizados por pulverização catódica (magnetron sputtering) sobre alumínio puro. A medida LEIS foi feita após 60 minutos período de imersão em solução de sulfato de sódio $10^{-3}$ mol.L $\mathrm{L}^{-1}$, (60 minutos) e um longo perído (600 minutos). Os autores observaram que no curto período de imersão $\mathrm{Al}-\mathrm{Cu}$, no par galvânico, estava polarizado catodicamente e em longos período $\mathrm{Al}-\mathrm{Cu}$ estava polarizado anodicamente. A partir do par galvânico (região central), seguindo para as bordas na direção do $\mathrm{Al}-\mathrm{Cu}-\mathrm{Mg}$, em alta frequência os autores observaram, um arco indutivo maior próximo à região central que foi diminuindo à medida que o microeletrodo era conduzido para as bordas, comportamento relacionado ao efeito geométrico devido às linhas de distribuição de potencial acima da superfície de um eletrodo. Já o espectro na interface $\mathrm{Al}-\mathrm{Cu}$ apresentou na posição $(\mathrm{x}=+1)$ próximo a interface $\mathrm{Al}-\mathrm{Cu} / \mathrm{Al}-\mathrm{Cu}-\mathrm{Mg}$ um comportamento capacitivo com duas constantes de tempo atribuída à reação de redução do oxigênio (processo de transferência de carga e difusão semi-infinita), concordando com o resultado que em curto tempo de imersão $\mathrm{Al}-\mathrm{Cu}$ se comporta com um cátodo. A medida que o microeletrodo é deslocado para as bordas $(\mathrm{x}=+4)$, a resposta da impedância é similar à resposta do eletrodo sozinho atribuindo este comportamento à um acoplamento galvânico entre as duas ligas.Em baixas frequências os valores de impedância foram maiores para $\mathrm{Al}-\mathrm{Cu}$ quando comparados com $\mathrm{Al}-\mathrm{Cu}-\mathrm{Mg}$, revelando o 
comportamento capacitivo da liga $\mathrm{Al}-\mathrm{Cu}$ e um comportamento reativo da liga $\mathrm{Al}-\mathrm{Cu}-\mathrm{Mg}$. (LACROIX, et al., 2012).

Mouanga et al (2013) chama a atenção para relevância do tema, acoplamento galvânico para as indústrias automotivas e aeroespaciais. A investigação ocorreu entre o acoplamento de aço e zinco em solução $0,06 \mathrm{~g} \mathrm{~L}^{-1}$ de $\mathrm{NaCl}$. O eletrodo modelo consistiu em uma haste de zinco de $6 \mathrm{~mm}$ de diâmetro colocado no centro de uma haste de aço de 20mm. As medidas de LEIS foram feitas acima de cada metal no acoplamento com a posição radial de bieletrodo com parâmetro. Quando o microeletrodo é colocado sobre o aço, observou-se em alta frequência um arco indutivo com baixa amplitude quando comparado ao arco capacitivo em baixa frequência. A resposta indutiva foi atribuída à impedância ôhmica local explicada pela dispersão associada à geometria dos eletrodos de disco e pela distribuição de correntes e potenciais na superfície dos dois metais. $\mathrm{O}$ arco capacitivo foi atribuído à transferência de carga e ao processo de redução do oxigênio na superfície do aço. Conforme observado pelos outros autores mencionados, à medida que o microeletrodo se aproxima do centro da interface, a amplitude do arco diminui e a corrente local na vizinhança da interface aumenta. Quando o microeletrodo é posicionado na superfície do zinco, o espectro é totalmente diferente, em alta frequência um pequeno arco capacitivo é observado seguido de um grande arco indutivo. A impedância correspondente à transferência de carga de dissolução de zinco (comportamento capacitivo) foi quase insignificante em comparação com a resposta indutiva. A $1 \mathrm{~Hz}$, a fase foi positiva sobre o aço (circular capacitivo) ao mesmo tempo que foi negativo sobre o zinco (laço indutivo). Assim, o arco capacitivo observado no diagrama de impedância local sobre o par aço/zinco foi atribuído ao processo de redução do oxigênio dissolvido, enquanto o circuito indutivo, no diagrama local observado acima da superfície do zinco, caracterizou o processo de adsorção no mecanismo de dissolução de zinco (MOUANGAA, et al., 2013).

Existe na literatura um artigo utilizando LEIS para avaliação de FSW, entretanto, feita sobre uma liga dissimilar AA 2050-T8 e AA 7449-T79. A medida de LEIS foi utilizada para avaliar a distribuição local da admitância, uma vez que esta já foi utilizada no acoplamento galvânico entre alumínio e magnésio através de eletrodos modelos (LACROIX, et al., 2012). Já foi evidenciado que a alta admitância, ou densidade de corrente local, foi medida na interface de ambos os metais e estiveram de acordo com a resolução de Laplace. Através da avaliação do módulo da impedância em função da posição pode-se concluir comparativamente com o gráfico de SECM que baixos valores 
do módulo da impedância caracterizaram alta atividade eletroquímica local, justificada pelos altos valores de distribuição da corrente na interface entre os dois metais em um acoplamento galvânico. Os diagramas apresentaram uma resposta capacitiva característica da transferência de carga devido à corrosão galvânica que ocorre na região da solda em paralelo com a capacitância do file de óxido formado na interface. Os autores observaram que a amplitude do arco diminui quando o bieletrodo é posicionada acima do nugget, correspondendo às altas densidades de corrente, portanto, um domínio onde a atividade eletroquímica é reforçada, enquanto longe do nugget, o limite de baixa frequência aumenta drasticamente, de acordo com o comportamento passivo local da interface. Os resultados confirmaram a existência de uma corrente local mais elevada na região interfaciais que caracterizam a fronteira entre as ligas 2xxx e ligas 7xxx ou duas zonas microestruturais diferentes.

\subsubsection{Montagem experimental}

O procedimento experimental começou com a preparação do bi eletrodo que consistiu em um fio de prata de $150 \mu \mathrm{m}$ inserido em um capilar e isolado com resina. Em volta deste capilar foi feita uma argola com outro fio de prata de $150 \mu \mathrm{m}$, e este foi grudado por fora do capilar e isolado também, conforme apresentado na Figura 3-4 (a).

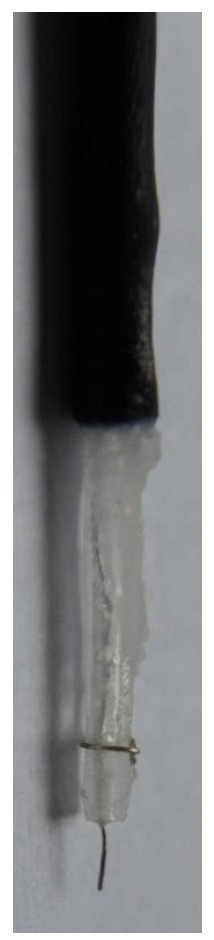

Figura 3-4: Fotografia de bieletrodo utilizado na medida de LEIS 
As medidas foram realizadas em uma montagem apresentada na Figura 3-5 onde o analisador de resposta de frequência é constituído por um FRA de quatro canais da marca Solartron, modelo 1254, acoplado a um potenciostato de baixo ruído fabricado no Laboratoire Interfaces et Systèmes Électrochimiques - LISE (home-made). Este último permite medidas de correntes extremamente baixas devido à sua alta impedância de entrada. O sistema é complementado por um amplificador diferencial de ganho variável (10x - 1000x), também de alta impedância, utilizado para amplificar simultaneamente as variações locais de corrente e potencial. Para a aquisição dos dados de impedância foi utilizado um programa desenvolvido no LISE e não disponível comercialmente.

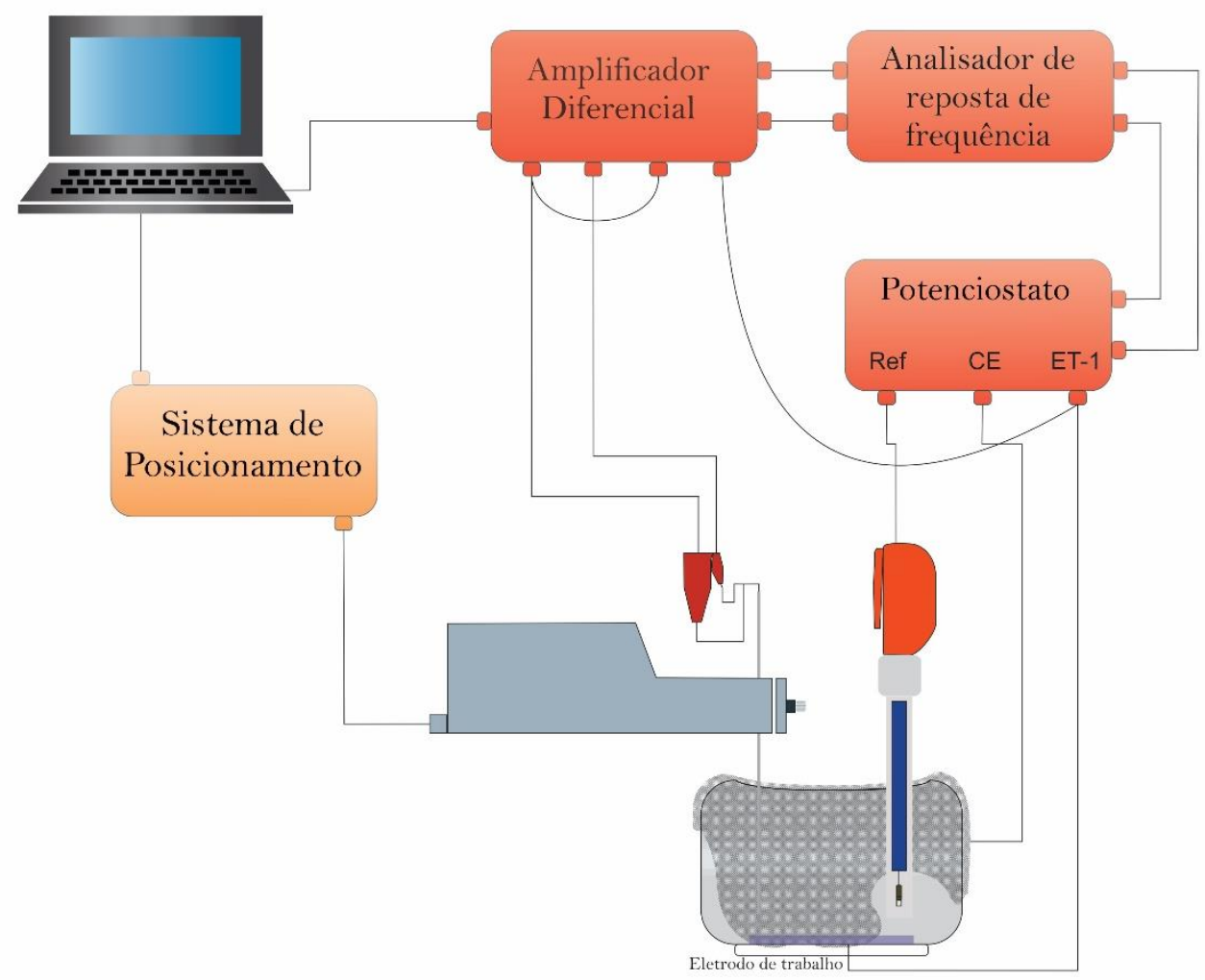

Figura 3-5: Esquema do sistema para medida de LEIS

A célula eletroquímica (Figura 3-6) consistiu na montagem clássica de três eletrodos para obter a impedância global $(Z)$ e simultaneamente o bieletrodo é colocado acima do eletrodo de trabalho para obtenção da impedância local (z), compondo um sistema de cinco eletrodos. O contraeletrodo consistiu em uma rede de platina de tamanho suficiente para envolver simetricamente todo o ET, com objetivo de uma distribuição mais homogênea das linhas de potencial (figura 3-7 (a) e (b)). O eletrodo de referência foi Eletrodo de Calomelano Saturado (ECS). Todas as medidas foram feitas após 24 horas 
o eletrodo ficar 24 horas exposto ao ar, na faixa de frequência de $63 \mathrm{kHz}$ a $0,1 \mathrm{~Hz}$ com 7 pontos por década, com amplitude de perturbação de $30 \mathrm{mV}$ e amplificação do sinal das correntes locais de 100. Com o motor do aparelho foi possível o deslocamento do bieletrodo sobre a superfície do ET.

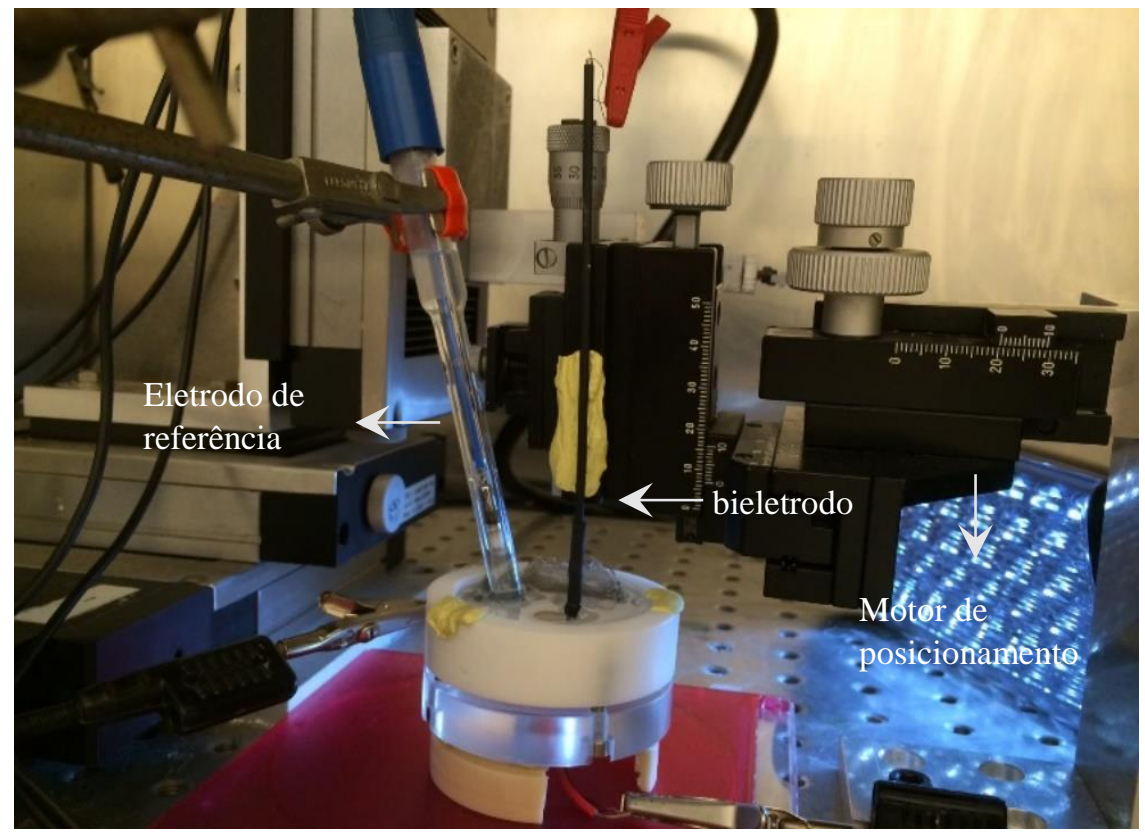

Figura 3-6: Célula eletroquímica composta por 5 eletrodos - montagem clássica dos três eletrodos e o bieletrodo
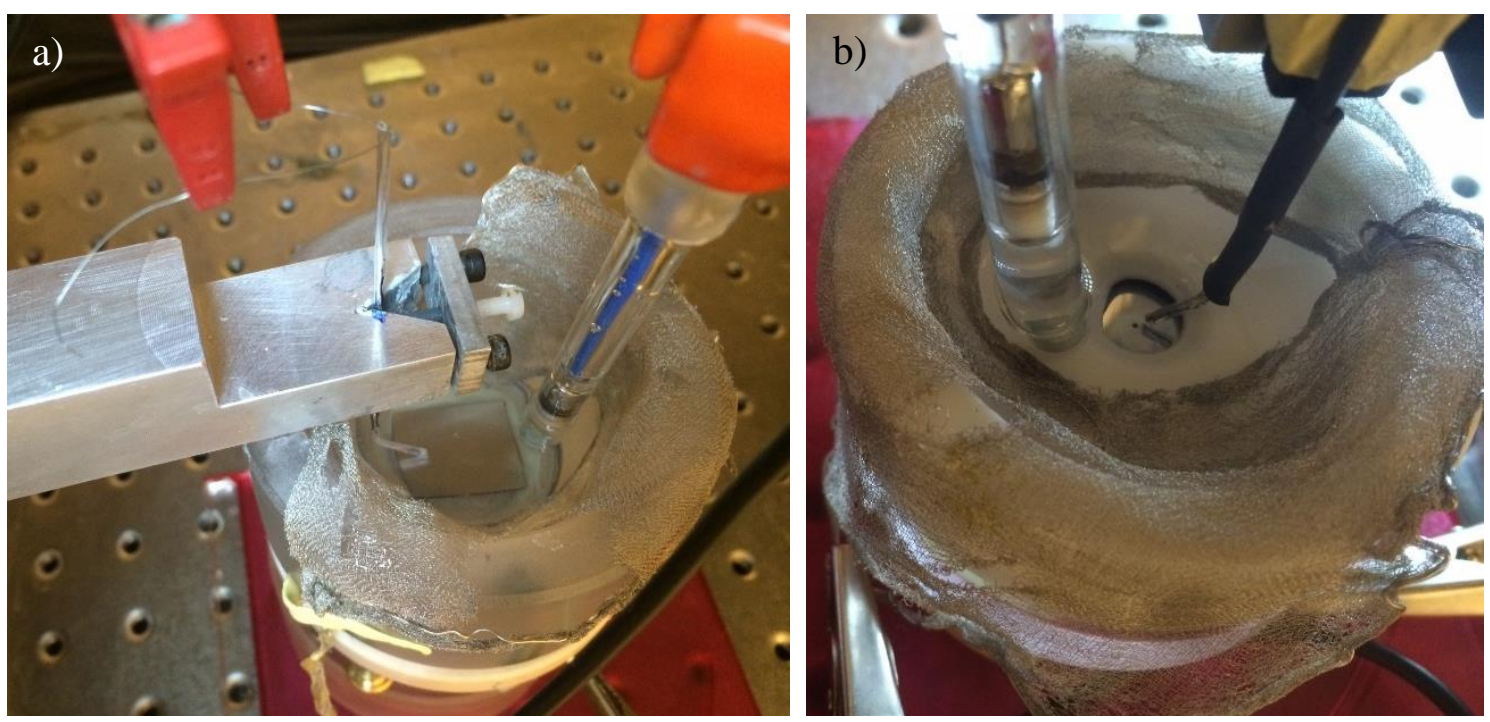

Figura 3-7: Célula eletroquímica composta por 5 eletrodos - montagem clássica dos três eletrodos e o bieletrodo (a) posicionamento da rede de platina na célula eletroquímica (b) 
Antes de começar as medidas com o bi eletrodo é necessária uma correção dos dados obtidos pelo fator $\mathrm{d} / \mathrm{k}$, sendo " $\mathrm{k}$ ", a condutividade específica do eletrólito em $\Omega^{-1}$ $\mathrm{cm}^{-1}$, e "d" a distância entre as pontas. Para isso utiliza-se um eletrodo de platina de $5 \mathrm{~mm}$ de diâmetro como ET e utilizando a solução de trabalho $\mathrm{NaCl}$ 0,1 mol.L $\mathrm{L}^{-1}$ obtém-se a impedância global (Z) e a impedância local (z). A Figura 3-8 apresenta as impedâncias global (Z) e local (z) do eletrodo de platina com a solução de trabalho $\mathrm{NaCl}$ 0,1 mol.L $\mathrm{L}^{-1}$. Para determinar o valor $\mathrm{d} / \mathrm{k}$ escolhe-se, para um mesmo valor de frequência, tanto da impedância global $(Z)$ como da impedância local (z) os valores reais e imaginários. Através da Figura 3-8, na frequência de 0,6 Hz tem-se Z' sendo 3403 e z' sendo 346,6 ao dividir Z' por z' obtém-se um fator de 9,8. Para a solução $\mathrm{NaCl}$ 0,1 mol.L ${ }^{-1}$, obteve-se um $\mathrm{k}$ de $0,086 \mathrm{~S} / \mathrm{cm}$ e sendo a distância entre dos bi eletrodos de $1 \mathrm{~cm}$ obtém-se um d/k de $11.63 \Omega \mathrm{cm}^{2}$, ou seja, este será o fator utilizado para correção das impedâncias locais.
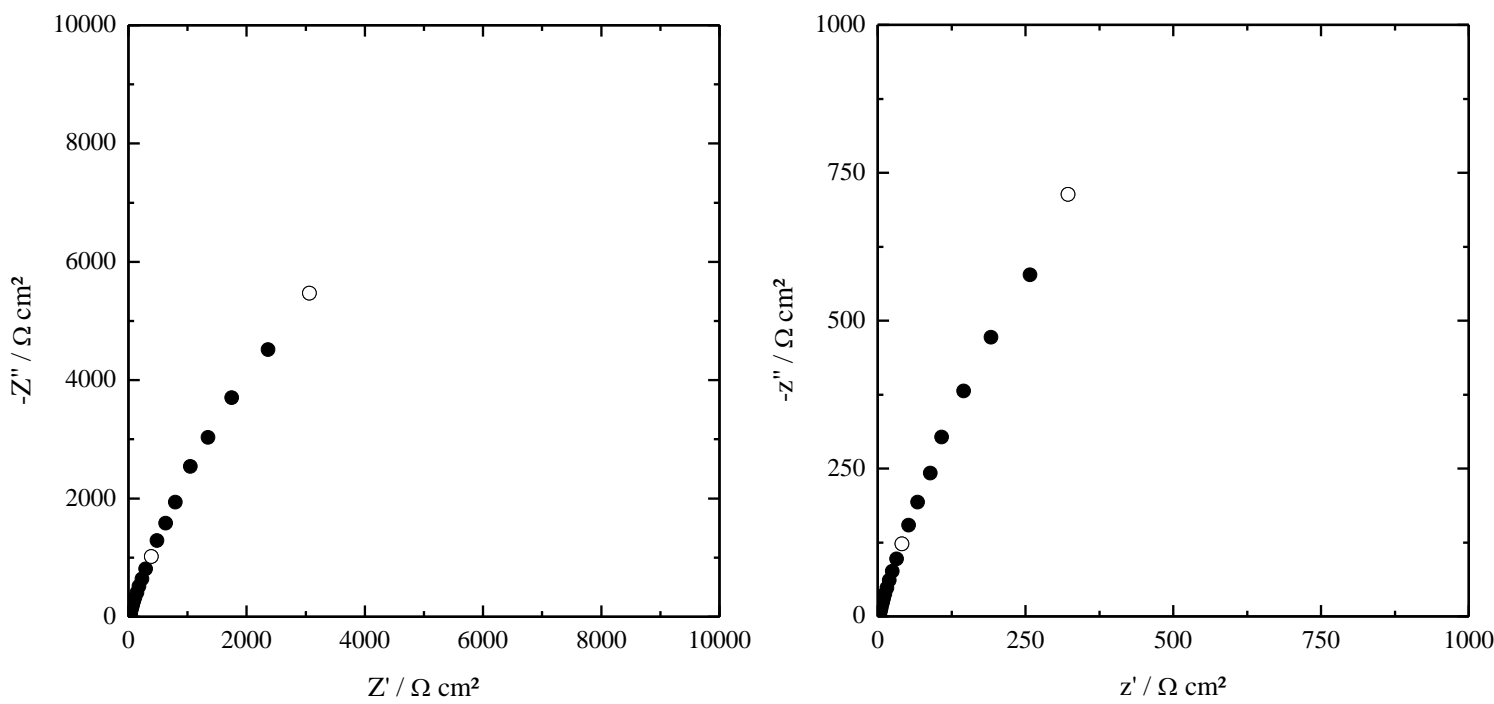

Figura 3-8: Impedâncias global $(Z)$ e local $(z)$ do eletrodo de platina com a solução de trabalho $\mathrm{NaCl} 0,1$ mol.L ${ }^{-1}$

\subsubsection{Validação do sistema de medida LEIS}

Para validação do sistema de medida LEIS foi utilizada a solução ferri/ferro cianeto de potássio $\left(\mathrm{K}_{3} \mathrm{Fe}(\mathrm{CN})_{6} / \mathrm{K}_{4} \mathrm{Fe}(\mathrm{CN})_{6}\right)$ no eletrodo de platina de $5 \mathrm{~mm}$ de diâmetro utilizando o bieletrodo produzido conforme item 3.1.11.2. A montagem do sistema no modelo clássico de 3 eletrodos sendo a platina o ET, uma grade de platina como $\mathrm{CE}$, o ER foi calomelano e completou-se esta montagem com o bieletrodo para configuração como exemplificado na Figura 3-5. 
A solução $\mathrm{K}_{3} \mathrm{Fe}(\mathrm{CN})_{6} / \mathrm{K}_{4} \mathrm{Fe}(\mathrm{CN})_{6}$ de $10 \mathrm{mmol} . \mathrm{L}^{-1} \mathrm{em} \mathrm{KCl}$ 0,5 mol.L $\mathrm{L}^{-1}$ foi utilizada pois esta apresenta um par redox, conforme apresentada no equação 3-5, e esta é controlado por difusão.

$F e_{(a q)}^{3+}+e^{-} \rightarrow F e_{(a q)}^{2+}$

Conforme apresentado na Figura 3-9, obtém-se os diagramas de impedância global (Z) e local (z), onde pode-se observar que em alta frequência, o diagrama local apresentou um arco indutivo em alta frequência, o qual não aparece no diagrama local, onde verifica-se o controle por difusão habitual neste sistema.
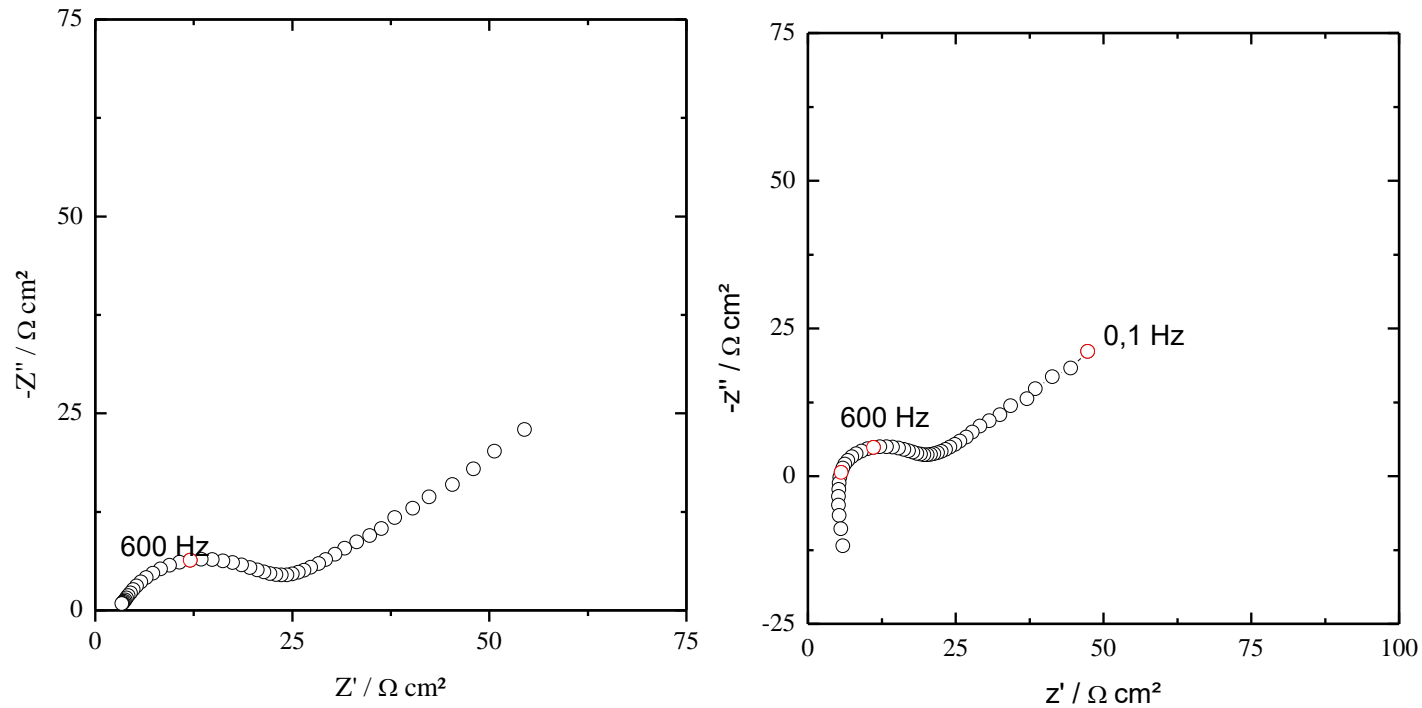

Figura 3-9: Medida global (Z) e local (z) de impedância feitas em um eletrodo de platina em meio de ferri/ferrocianeto de potássio $10 \mathrm{mmol} \mathrm{L}^{-1} \mathrm{em} \mathrm{KCl} \mathrm{0,5} \mathrm{mol} \mathrm{L}^{-1}$

\subsubsection{Ensaios com a gota séssil (Acoplamento EIS/ângulo de contato)}

O objetivo desta parte é realizar simultaneamente medidas de impedância e de ângulo de contato. Nesta parte do trabalho serão inicialmente apresentadas uma breve revisão bibliográfica, o desenvolvimento matemático para obtenção do modelo e a montagem experimental utilizada para a realização dos experimentos. Posteriormente, no capítulo de 4.6, será apresentada a validação do método utilizando um sistema eletroquímico modelo e, em seguida, a mesma metodologia experimental será utilizada para as medidas realizadas com a liga de alumínio 2024-T3 soldada por FSW. 


\subsubsection{Princípio da metodologia}

Ao longo dos anos o interesse por medidas eletroquímicas utilizando pequenos volumes ou domínios confinados cresceu, particularmente devido à necessidade de redução de resíduos químicos em processo analíticos (MILANI \& CARDOSO, 2003) (KANYANEE, FUEKHAD, \& GRUDPAN, 2013), pelo interesse no acoplamento de diferentes técnicas de investigação (WILMANN \& MURRAY, 1983) (WANG \& MURRAY, 2007) ou então para diminuir o tamanho dos domínios a serem investigados (PILASKI, HAMELMANN, MOEHRING, \& LOHRENGEL, 2004) (SÁNCHEZ, et al., 2012) com a finalidade de estudar, especificamente, materiais com estruturas nãohomogêneas, como apresentado no trabalho pioneiro desenvolvido na década de 40 por Dix para investigação da corrosão utilizando uma gota como célula eletroquímica (DIX, 1940). Recentemente, Unwin et al. revisitou o uso de microcapilares para investigar as respostas eletroquímicas de interfaces apresentando reatividade distribuída, tendo alcançado resolução espacial na faixa sub-micrométrica (PATEL, et al., 2012) (O'CONNELL, et al., 2014). Em todos estes experimentos, as técnicas eletroquímicas apresentaram-se sensíveis para a caracterização da interface formada entre a solução eletrolítica e o material. Entretanto, na maioria dos estudos envolvendo eletroquímica em pequenos volumes, e, especificamente, quando se utiliza uma gota séssil, a cronopotenciometria e a voltametria foram as principais técnicas utilizadas, e poucos trabalhos relatam o uso de espectroscopia de impedância eletroquímica (EIS) (KRAWIEC, VIGNAL, AMAR, \& PEYRE, 2011) (MENNUCCI, et al., 2012), que é uma técnica bastante adequada para estudos sobre mecanismos, especialmente quando intermediários adsorvidos estão envolvidos. Isso pode estar associado à geometria não convencional da célula eletroquímica. Neste tipo de ensaio, a gota com a solução eletroquímica é colocada diretamente sobre o eletrodo de trabalho, enquanto o eletrodo de referência e o contra-eletrodo são introduzidos no interior da própria gota séssil. Este último é, em geral, bem menor que o eletrodo de trabalho, cuja superfície é definida pela interface eletrodo/eletrólito formada pela calota esférica da gota, enquanto que as linhas de corrente e potencial ficam restritas no pequeno volume da gota, tipicamente de alguns $\mu \mathrm{L}$ (geralmente entre 2 e $4 \mu \mathrm{L}$ ). Estes últimos valores são importantes, uma vez que controlam o tamanho do sistema eletroquímico.

O acoplamento de técnicas eletroquímicas e medidas de ângulo de contato é interessante para obter informações complementares. Por exemplo, durante a polarização 
de uma superfície sólida condutora, a natureza química desta superfície pode ser alterada ou ajustada, modificando assim a energia da superfície, e, portanto, a molhabilidade, a qual pode ser estimada pelo ângulo de contato. O conhecimento deste parâmetro é importante para muitas aplicações, tais como incrustações biológicas (MIKHAYLIN \& BAZINET, 2016) bateria de fluxo redox (RABBOW, TRAMPERT, POKORNY, BINDER, \& WHITEHEAD, 2015). Além disso, qualquer mudança de molhabilidade com a polarização da interface pode ser utilizada como um gatilho eletroquímico (BALOGH, TEL-VERED, RISKIN, ORBACH, \& WILLNER, 2011) (TEL-VERED, KAHN, \& WILLNER, 2016).

A molhabilidade é consequência da facilidade com a qual uma gota de líquido interage com a superfície de um sólido, sendo caracterizada pelo ângulo de contato $(\theta)$. Este depende de três tensões interfaciais: sólido-líquido ( $\gamma \mathrm{sl})$, sólido-vapor ( $\gamma \mathrm{sv})$ e líquido-vapor $(\gamma \mathrm{lv})$. Sendo que, no equilíbrio, a somatória dessas tensões é igual a zero, de acordo com Young-Dupre (DUBOIS, FOURNÉE, THIEL, \& BELIN-FERRÉ, 2008), (SCHREDER, 1999). Considerando um sistema onde se tem uma solução em contato com um sólido, e supondo que esta solução seja uma gota. Esta assume a geometria de uma calota esférica onde a área sólido-líquido $\left(\mathrm{A}^{\mathrm{SL}}\right)$ e a área líquido-vapor $\left(\mathrm{A}^{\mathrm{LV}}\right)$ podem ser expressas através do ângulo de contato entre o líquido e o sólido, conforme as equações 3-6 e 3-7. A Figura 3-10 apresenta uma representação esquemática da situação descrita.

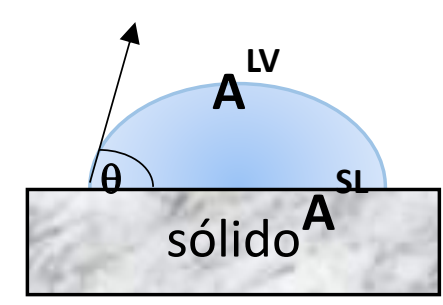

Figura 3-10: Representação esquemática de uma gota sobre uma superfície sólida onde $\mathrm{A}^{\mathrm{SL}}$ é a área sólido- líquido e $\mathrm{A}^{\mathrm{LV}}$ é a área líquido-vapor.

$\mathrm{A}^{\mathrm{LV}}=2 \pi \mathrm{r}^{2}(1-\cos \theta)$

$A^{S L}=\pi r^{2} \operatorname{sen}^{2} \theta$ 
onde, $\mathrm{r}$ é o raio da esfera na qual se localiza a calota esférica. Este pode ser relacionado com o raio de contato sólido-líquido $\left(R^{S L V}\right)$, que corresponde ao diâmetro da gota, através de relação expressa na equação 3-8.

$R^{S L V}=r \operatorname{sen} \theta$

A energia livre deste sistema pode ser escrita por meio da equação 3-9:

$d G=V d P-S d T+\phi d q+\gamma^{L V} d A^{L V}+\gamma^{S L} d A^{S L}+\gamma^{S V} d A^{S V}$

O produto $\phi d q$ corresponde à contribuição elétrica. Sabendo-se que:

$d E^{\sigma}=\gamma^{L V} d A^{L V}+\gamma^{S L} d A^{S L}+\gamma^{S V} d A^{S V}$

A energia interfacial resulta das interações nas três interfaces. Nota-se então que as variações das áreas interfaciais $\mathrm{A}^{\mathrm{SL}} \mathrm{e} \mathrm{A}^{\mathrm{SV}}$ podem ser escritas conforme a equação 311:

$d A^{S L}=-d A^{S V}$

Então tem-se que:

$d E^{\sigma}=\gamma^{L V} d A^{L V}+\left(\gamma^{S L}-\gamma^{S V}\right) d A^{S L}$

A relação de Young relaciona as três tensões interfaciais entre si de acordo com a equação 3-13:

$\gamma^{L V} \cos \theta=\gamma^{S V}-\gamma^{S L}$

Então é possível estabelecer a relação apresentada na equação 3-14:

$d E^{\sigma}=\gamma^{L V} d A^{L V}-\left(\gamma^{L V} \cos \theta\right) d A^{S L}$ 
Esta energia interfacial pode ser expressa a partir de uma única energia, por exemplo:

$d E^{\sigma}=\left[\gamma^{L V} \frac{d A^{L V}}{d A^{S L}}-\gamma^{L V} \cos \theta\right] d A^{S L}$

Esta, após a derivação das expressões das áreas, a $\theta$ constante, resulta na equação 3-16:

$d E^{\sigma}=\left[\frac{2}{1+\cos \theta}-\cos \theta\right] \gamma^{L V} d A^{S L}=\frac{(2+\cos \theta)(1-\cos \theta)}{1+\cos \theta} \gamma^{L V} d A^{S L}=\tau^{S L} d A^{S L}$

Então pode-se escrever a equação da energia livre (Eq. 3-9) como a equação 3-17:

$d G=V d P-S d T+\phi d q+\tau^{S L} d A^{S L}$

Onde G é uma função de estado e suas propriedades matemáticas implicam na igualdade das derivadas segundas, conforme a equação 3-18:

$\left(\frac{\partial \tau^{S L}}{\partial q}\right)_{T, P, A^{S L}}=\left(\frac{\partial \phi}{\partial A^{S L}}\right)_{T, P, q}$

Como a forma apresentada não é interessante, utiliza-se a matriz jacobiana para realizar uma mudança de variáveis, tornando a equação mais facilmente explorável. Podese assim escrever as derivadas parciais sob uma forma diferente, mas equivalente:

$\left(\frac{\partial\left(\tau^{\mathrm{SL}}, \mathrm{A}^{\mathrm{SL}}\right)}{\partial\left(\mathrm{q}, \mathrm{A}^{\mathrm{SL}}\right)}\right)_{\mathrm{T}, \mathrm{P}}=\left(\frac{\partial(\phi, \mathrm{q})}{\partial\left(\mathrm{A}^{\mathrm{SL}}, \mathrm{q}\right)}\right)_{\mathrm{T}, \mathrm{P}}$

$\left(\frac{\partial\left(\tau^{\left.\mathrm{SL}, \mathrm{A}^{\mathrm{SL}}\right)}\right.}{\partial\left(\mathrm{q}, \mathrm{A}^{\mathrm{SL}}\right)}\right)_{\mathrm{T}, \mathrm{P}} \times\left(\frac{\partial\left(\phi, \mathrm{A}^{\mathrm{SL}}\right)}{\partial\left(\phi, \mathrm{A}^{\mathrm{SL}}\right)}\right)_{\mathrm{T}, \mathrm{P}}=\left(\frac{\partial(\phi, \mathrm{q})}{\partial\left(\mathrm{A}^{\mathrm{SL}}, \mathrm{q}\right)}\right)_{\mathrm{T}, \mathrm{P}} \times\left(\frac{\partial\left(\phi, \mathrm{A}^{\mathrm{SL}}\right)}{\partial\left(\phi, \mathrm{A}^{\mathrm{SL}}\right)}\right)_{\mathrm{T}, \mathrm{P}}$

$\left(\frac{\partial\left(\tau^{\left.\mathrm{SL}, \mathrm{A}^{\mathrm{SL}}\right)}\right.}{\partial\left(\phi, \mathrm{A}^{\mathrm{SL}}\right)}\right)_{\mathrm{T}, \mathrm{P}} \times\left(\frac{\partial\left(\phi, \mathrm{A}^{\mathrm{SL}}\right)}{\partial\left(\mathrm{q}, \mathrm{A}^{\mathrm{SL}}\right)}\right)_{\mathrm{T}, \mathrm{P}}=\left(\frac{\partial(\phi, \mathrm{q})}{\partial\left(\phi, \mathrm{A}^{\mathrm{SL}}\right)}\right)_{\mathrm{T}, \mathrm{P}} \times\left(\frac{\partial\left(\phi, \mathrm{A}^{\mathrm{SL}}\right)}{\partial\left(\mathrm{A}^{\mathrm{SL}}, \mathrm{q}\right)}\right)_{\mathrm{T}, \mathrm{P}}$

O tratamento matemático das relações acima permite escrever a forma derivada apresentada a seguir: 
$\left(\frac{\partial \tau^{S L}}{\partial \phi}\right)_{T, P, A^{S L}}=-\left(\frac{\partial q}{\partial A^{S L}}\right)_{T, P, \phi}$

A T e P constantes, temos que $d \tau^{s l}=-C^{\sigma}-\emptyset d \emptyset$, sendo que $C^{\sigma}$ é a capacitância interfacial por unidade de área. Ao integrá-la se obtém:

$\tau^{S L}=-\frac{1}{2} C^{\sigma} \phi^{2}+c t e$

Esta relação é semelhante àquela estabelecida por Lippmann para uma interface líquido-líquido (mercúrio-solução) (HOLLY, 1977), podendo ser utilizada para a determinação da capacitância interfacial a partir da medida de ângulo de contato:

$\gamma^{l v}=-\frac{1}{2} C^{\sigma} \phi^{2}+\gamma_{0}^{l v}$

Como exemplo de aplicação da equação 3-24, supondo uma superfície onde seja depositada uma gota de água destilada, cuja tensão superficial teórica é $72 \mathrm{mN} \mathrm{m}^{-1}$, e que seja formada uma calota esférica com ângulo de contato de $70^{\circ}$. Considerando uma capacitância interfacial de $40 \mu \mathrm{F} \mathrm{cm}^{-2}$ (típica para uma dupla camada elétrica), as variações de $\tau^{\mathrm{SL}}$ em função do potencial estão representadas na Figura 3-11. Observa-se, portanto, que, sob estas condições, uma variação de potencial de $100 \mathrm{mV}$, implicará em uma variação do ângulo de contato de 1 a $2^{\circ}$ (Figura 3-11). 


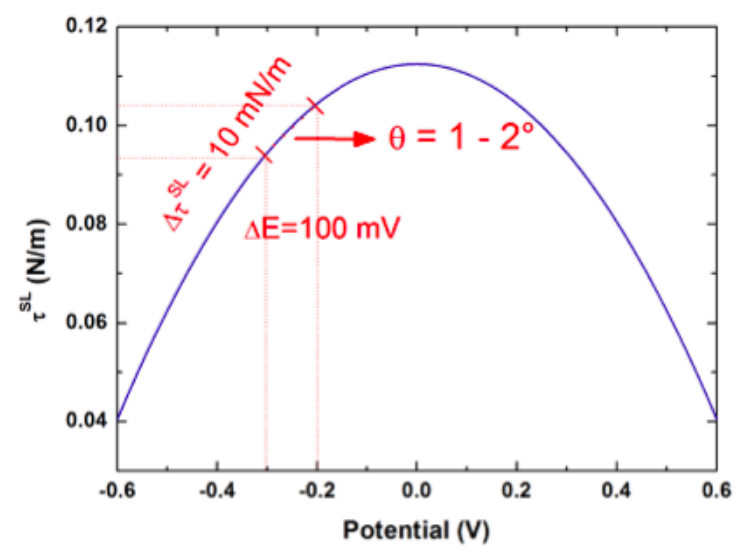

Figura 3-11: Variação de $\tau^{\mathrm{SL}}$ em função do potencial de acordo com a Eq. 31 supondo uma superfície onde foi depositada uma gota de água destilada formando uma calota esférica. Simulação realizada de acordo com as propriedades apresentadas na própria Figura. Observar que uma variação de $100 \mathrm{mV}$ em potencial acarreta em uma mudança entre 1 e $2^{\circ}$ no ângulo de contato.

\subsubsection{Montagem experimental}

Neste trabalho serão apresentados os resultados experimentais e de simulação numérica, a fim de investigar a resposta de EIS simultaneamente com a medida de ângulo de contato para um sistema confinado, o qual consiste em uma gota séssil com volume na ordem de $\mu \mathrm{L}$ (basicamente entre 2 e $4 \mu \mathrm{L}$ ). Para isto, com auxílio de uma micropipeta, uma gota com volume de aproximadamente $2,5 \mu \mathrm{l}$ foi depositada sobre a superfície polida da amostra (ET), que se encontrava fixada sobre um que permitia a realização dos contatos elétricos da região molhada com todos os equipamentos. Sobre o suporte do aparelho de ângulo de contato, utilizou-se uma seringa de 1,0 mL como suporte para o eletrodo de referência (ER) e para o contraeletrodo (CE), constituídos, respectivamente, de um fio de prata de $0,16 \mathrm{~mm}$ de diâmetro, recoberto com uma fina camada de cloreto de prata eletrodepositado e de um fio de platina de 0,2 $\mathrm{mm}$ de diâmetro. Com o motor do aparelho de ângulo de contato foi possível controlar a introdução dos eletrodos dentro da gota e seu posicionamento perto da superfície a ser estudada (ET). Na sequência da montagem, inicialmente, uma gota da solução é colocada sobre o ET posicionado sobre o porta-amostras, e, em seguida, os demais eletrodos são inseridos e posicionados dentro da gota. A Figura 3-12 apresenta imagens das diferentes etapas de montagem do sistema. Com o objetivo de controlar a evaporação da solução durante o experimento uma câmara de acrílico com 12x12 cm foi utilizada para cobrir a amostra. Além do mais, o ER e o CE (constituídos por microfios) foram inseridos em um tubo microcapilar duplo (suportado 
mecanicamente pela seringa anteriormente descrita) e as extremidades de ambos foram colocadas no interior gota séssil, como apresentado esquematicamente. Com esta configuração, evita-se a infiltração de líquido no capilar, diminuindo assim alguns problemas como distribuição de correntes e potenciais, comuns quando experimentos em pequenos volumes são utilizados.
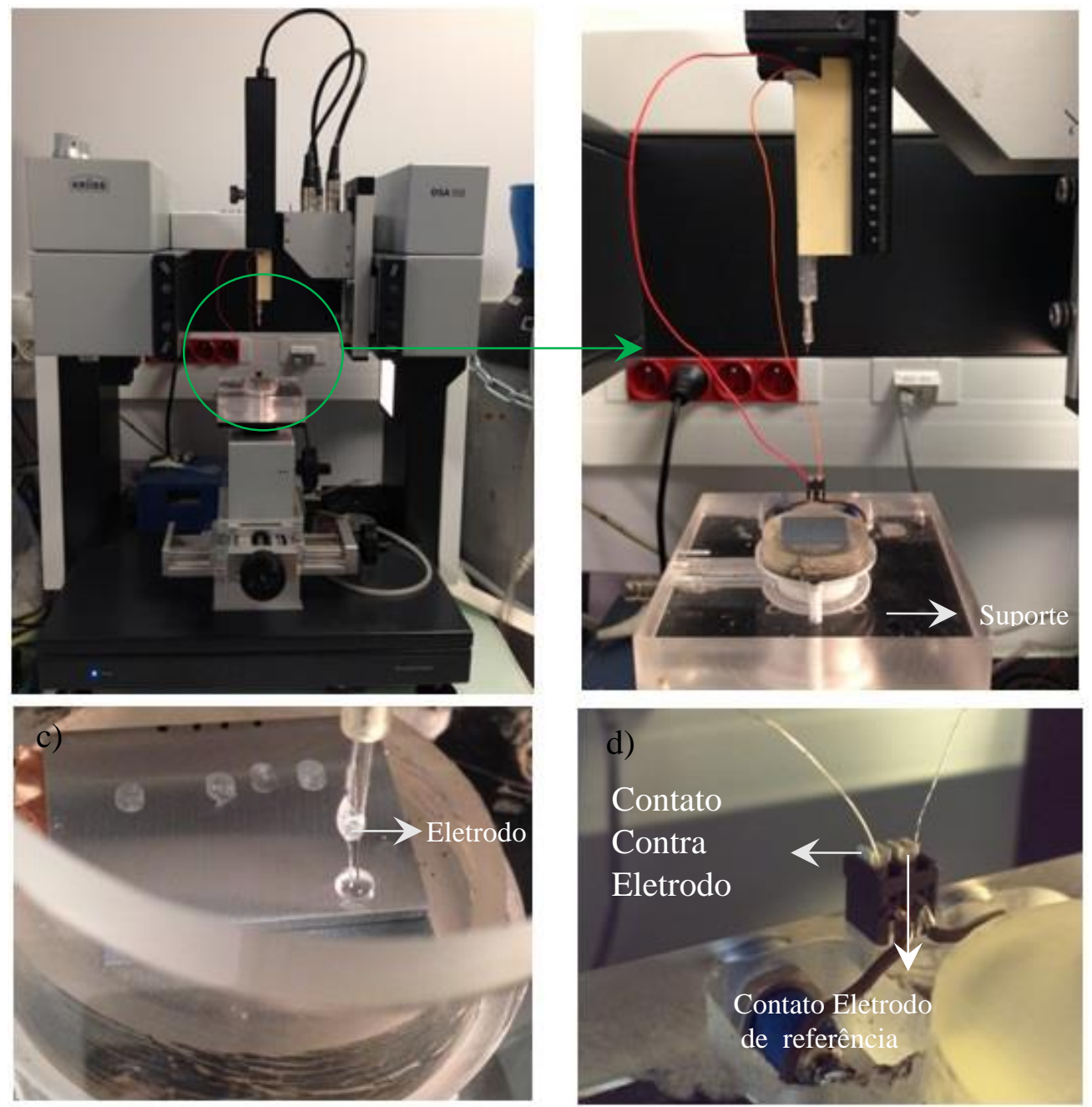

Figura 3-12: Imagem da célula utilizada para os ensaios eletroquímicos sobre a gota, equipamento Krüss, DSA 100 (a); suporte porta amostra (b), contraeletrodo sobre uma gota de $2,5 \mu \mathrm{L}$ (c) e conexões elétricas entre o suporte da amostra e os equipamentos eletrodo de referência $(\mathrm{d})$.

A Figura 3-13 apresenta o esquema do acoplamento entre a medida de ângulo de contato e de potencial de circuito aberto composta por: aparelho de ângulo de contato (Krüss, DSA 100), célula eletroquímica composta por três eletrodos, equipamento para 
medida do potencial de circuito aberto (Autolab PGSTAT 100, potenciostato galvanostato) e da impedância eletroquímica: potenciostato SOTELEM-PG-STAT.Z1 acoplado a um gerador/analisador de frequência Solartron 1254 de 4 canais.

As medidas de impedância foram feitas via software FRACOM desenvolvido no LISE, o qual permite um controle mais preciso sobre os ensaios de impedância em relação aos filtros utilizados nos ensaios eletroquímicos, bem como o controle da resistência aplicada, pois o mesmo possui um controle de até $1 \mathrm{M} \Omega$.

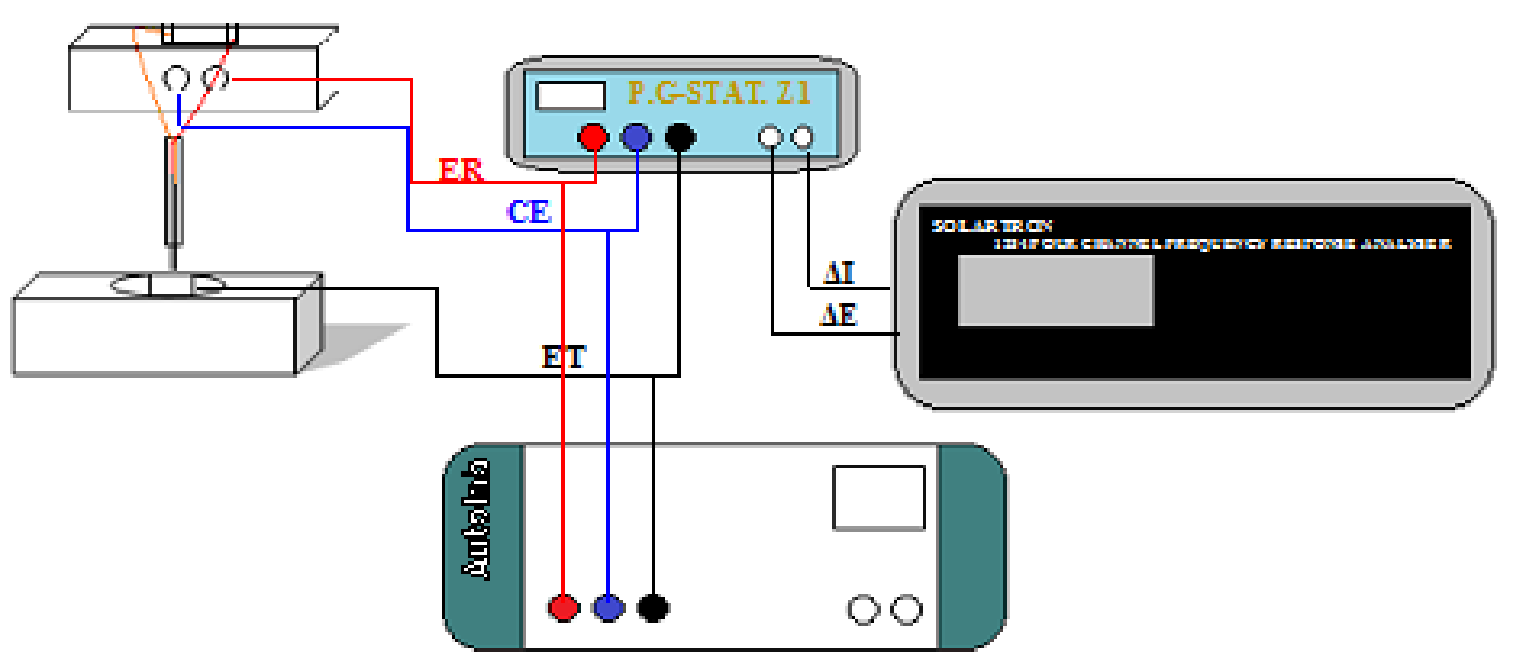

Figura 3-13: Representação esquemática do acoplamento entre as medidas de ângulo de contato e de potencial de circuito aberto (Krüss, DSA 100 e Autolab PGSTAT 100) e a medida de impedância (potenciostato SOTELEM-PG-STAT.Z1 acoplado a um gerador/analisador de frequência Solartron 1254)

Para a validação do sistema de medida, o eletrodo de trabalho (ET) consistiu em uma folha de platina $(\mathrm{Pt})$ plana que foi deixada pelo menos 24 horas em atmosfera ambiente, a fim de obter uma superfície envelhecida e poluída pelo ambiente, na qual a cinética da reação de transferência de elétrons é reduzida quando em comparação com uma superfície recém-preparada. O eletrólito consistiu em uma solução equimolar de $\mathrm{K}_{3} \mathrm{Fe}(\mathrm{CN})_{6}$ e $\mathrm{K}_{4} \mathrm{Fe}(\mathrm{CN})_{6}\left(10^{-2} \mathrm{~mol} \mathrm{~L}^{-1}\right)$ em uma solução $0,1 \mathrm{~mol} \mathrm{~L}^{-1}$ de $\mathrm{KCl}$, cuja condutividade medida foi de $17 \mathrm{mS} \mathrm{cm}^{-1}$. Como já descrito anteriormente, uma gota desta solução (entre 2,5 e $3 \mu \mathrm{L}$ ) foi depositada sobre o ET e, em seguida, o ER (fio de $\mathrm{Ag} / \mathrm{AgCl}$ com 0,16 mm de diâmetro) e o CE (fio de Pt pura de 0,1 ou 0,2 mm de diâmetro) inseridos no microcapilar duplo foram posicionados no interior da gota (Figura 3-14). Todas as medidas foram conduzidas utilizando esta configuração de 3 eletrodos. $\mathrm{O}$ tamanho do CE foi selecionado de forma a poder comparar os resultados experimentais com os resultados 
dos cálculos numéricos desenvolvidos utilizando o método dos elementos finitos (FEM) do software COMSOL Multiphysics® (vide infra). Nas próximas descrições, esta configuração será referenciada como célula gota. A Figura 3-14 apresenta uma imagem da gota posicionada sobre a superfície do ET com os demais eletrodos inseridos em seu interior. O diâmetro e a área superficial do ET, que corresponde à interface Pt-gota, foram determinados a partir de análise de imagem utilizando software ImageJ. O tamanho das diferentes interfaces formadas variou entre $5-7 \mathrm{~mm}^{2}$.

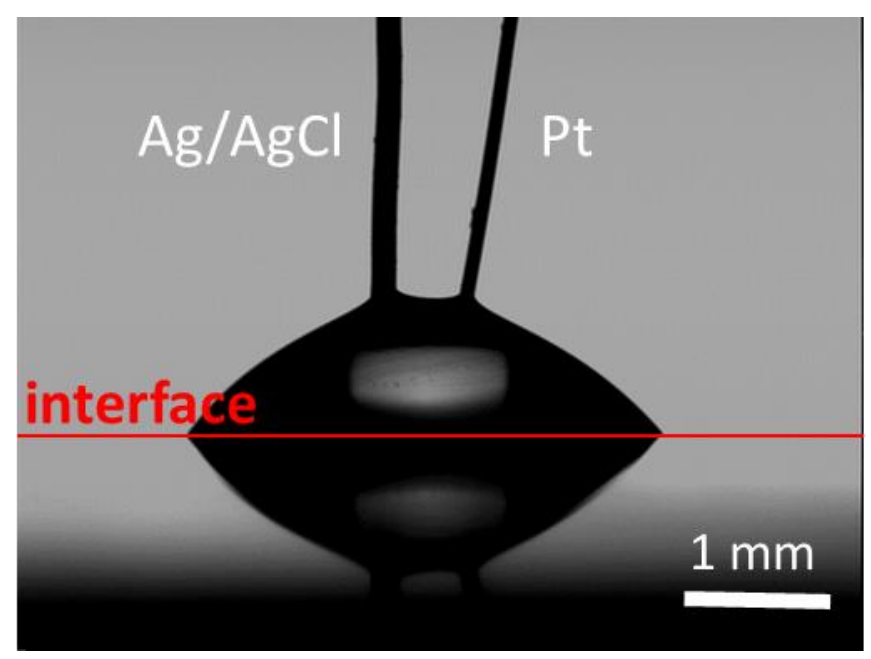

Figura 3-14: Imagem ótica da gota séssil sobre o eletrodo de trabalho, platina envelhecida, com o eletrodo de referência e o contra eletrodo inseridos em seu interior.

As respostas eletroquímicas das células gota também foram comparadas com aquelas obtidas utilizando uma célula eletroquímica clássica com a mesma Pt envelhecida como ET, um ER de $\mathrm{Ag} / \mathrm{AgCl}$ e uma grande rede de platina $\left(20\right.$ x $\left.20 \mathrm{~mm}^{2}\right)$ como CE.

Medidas de ângulo de contato (molhabilidade) e de espectroscopia de impedância eletroquímica utilizando a metodologia da gota séssil foram realizadas simultaneamente nas diferentes regiões da liga de alumínio soldada por FSW. Para isto, dividiu-se as regiões geradas pela solda, e em cada uma delas realizou-se o ensaio sobre a gota (2-3 $\mu \mathrm{L})$ em 4 pontos diferentes. A Figura 3-15 apresenta a divisão das regiões e os locais das repetições dos experimentos. Na Figura, é possível observar que devido ao raio das gotas (aproximadamente $3 \mathrm{~mm}$ ) e às dimensões da ferramenta utilizada para realizar a soldagem, as regiões da TMAZ e da HAZ não puderam ser separadas. Assim as medidas relativas a estas duas regiões foram realizadas em um só experimento. 
Todas as medidas de impedância eletroquímica foram realizadas no potencial de corrosão. A amplitude da perturbação de onda senoidal foi de $10 \mathrm{mV}$ pico-a-pico e a variação de frequência foi de $63 \mathrm{kHz}$ a $0,1 \mathrm{~Hz}$, com 7 pontos por década de frequência.

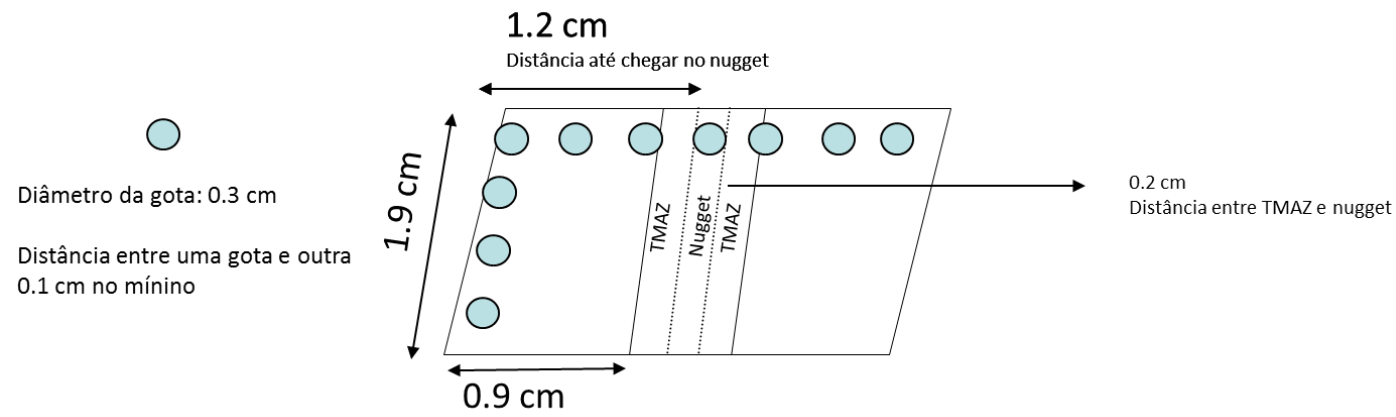

Figura 3-15: Representação esquemática da divisão das regiões da solda e como procedeu-se o experimento para avaliar a reprodutibilidade do experimento. 


\section{RESULTADOS E DISCUSSÃO}

\subsection{CARACTERIZAÇÃO MICROESTRUTURAL DA LIGA DE ALUMÍNIO 2024 SOLDADA POR FSW}

\subsubsection{Caracterização por MEV de amostras polidas}

A Figura 4-1 apresenta micrografias obtidas por MEV, com baixo aumento, do metal base e das diferentes zonas criadas durante a soldagem. O metal base (Figura 4-1 (a)) apresenta uma grande quantidade de pontos brancos, que são os intermetálicos (IMs), distribuídos por toda a superfície. Na região do nugget (Figura 4-1 (b)) os IMs se alinham em uma distribuição circular, correspondendo ao movimento rotatório do pino da solda que arrasta a liga plasticizada em torno de seu eixo de rotação. Na Figura 4-1 (c) é apresentada a fronteira entre a TMAZ e o nugget. Nesta é possível verificar, mesmo com aumento de baixa magnitude, que os IMs da região do nugget apresentam menores dimensões que na TMAZ, o que é consequência do efeito mecânico de rotação do pino, que fratura os IMs mais frágeis. A comparação entre a região esquerda da Figura 4-1 (c) com a Figura 4-1 (a) permite verificar que na TMAZ os IMs apresentam as mesmas características do metal base. Como na TMAZ a deformação mecânica é imposta apenas pela pressão e movimento de fricção do ombro (shoulder) da ferramenta contra a superfície do material que está sendo soldado, não há fratura dos IMs presentes na microestrutura do material.

A Figura 4-2 apresenta micrografias com maiores magnificações do metal base e da região do nugget. Para o metal base, Figura 4-2 (a), é possível distinguir os dois principais tipos de IMs grosseiros, com dimensões superiores ao micrômetro. Os IMs com forma regular e arredondada (círculos pretos) correspondem à fase-S, e são ricos em Al$\mathrm{Cu}-\mathrm{Mg}$, e os IMs irregulares (círculo vermelho) são ricos em $\mathrm{Al}, \mathrm{Cu}, \mathrm{Fe}, \mathrm{Mn}$ e $\mathrm{Si}$ (QUEIROZ, MAGNANI, COSTA, \& DE MELO, 2008). Na região do nugget (Figura 4-2 (b)), a ação mecânica e de rotação da ferramenta sobre os IMs mais frágeis fica evidenciada. Assim estes se encontram alinhados de acordo com a direção de rotação da ferramenta, e vários deles foram fraturados, estando dispostos na microestrutura como se fossem "cometas". 

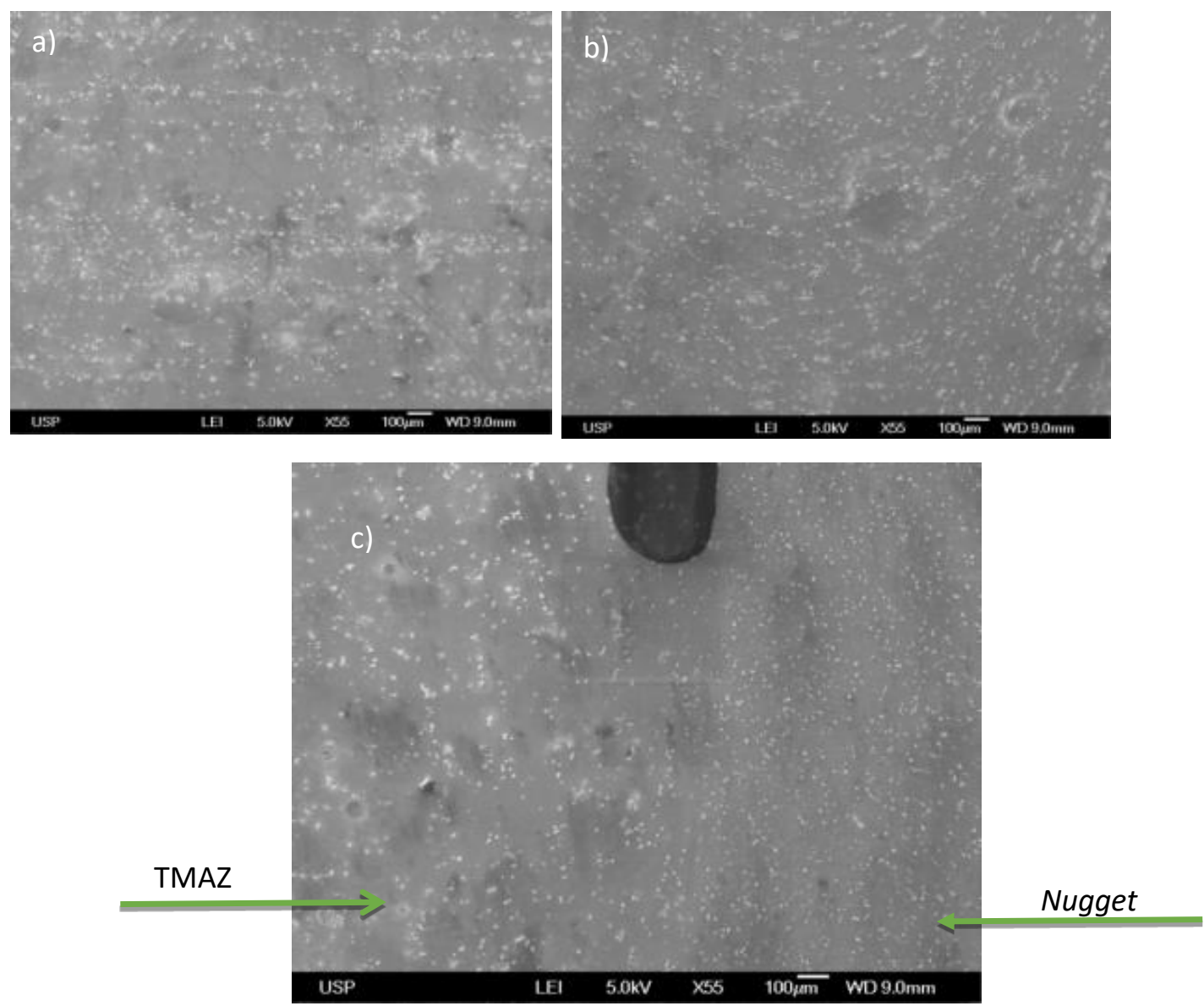

Figura 4-1: Imagens obtidas em microscópio eletrônico de varredura, da superfície da liga AA2024-T3: metal base, região não afetada pela soldagem (a), região do nugget (b) e junção TMAZ-nugget (c).

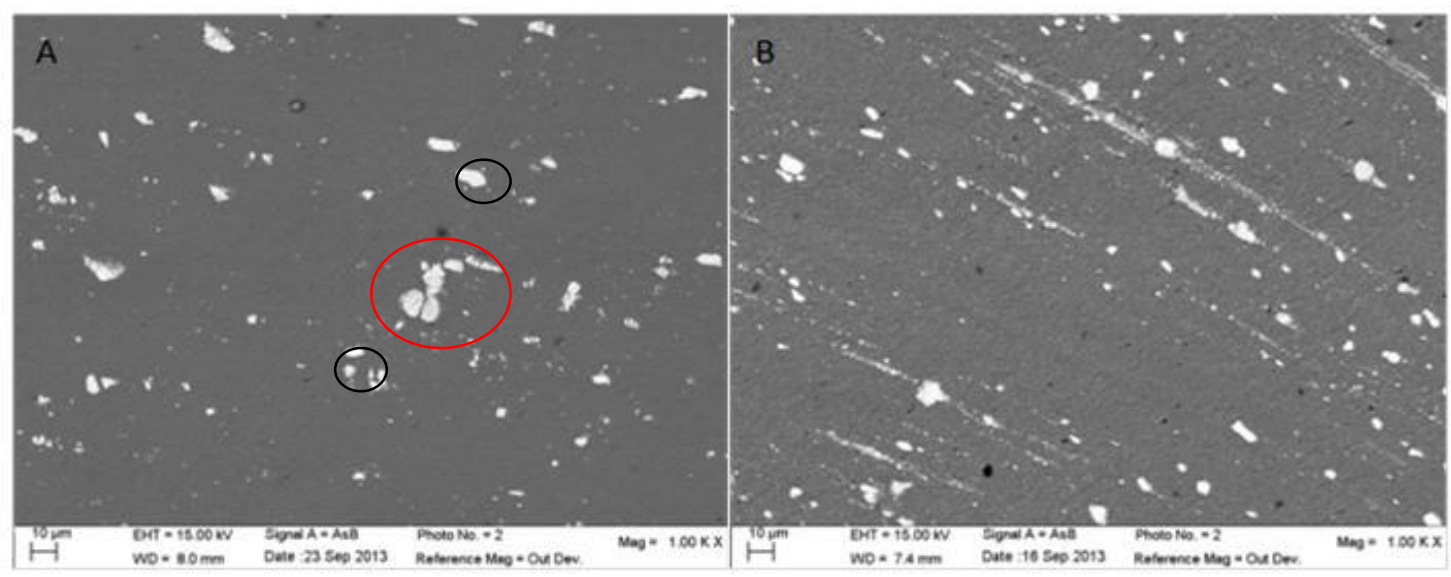

Figura 4-2: Imagens obtidas por MEV da superfície da liga AA2024: metal base (a), região do nugget (b). Círculos pretos: IMs $\mathrm{Al}-\mathrm{Cu}-\mathrm{Mg}$; círculo vermelho: grupo de IMs $\mathrm{Al}-\mathrm{Cu}-\mathrm{Fe}-\mathrm{Mn}-\mathrm{Si}$. 
A Figura 4-3 exibe uma micrografia de uma região da TMAZ contendo os diferentes tipos de IM juntamente com o mapeamento por EDS. O resultado confirma que os IMs regulares, arredondados e com menores dimensões são ricos em $\mathrm{Al}, \mathrm{Mg}$ e $\mathrm{Cu}$ e que o IM com maior dimensão e de forma irregular é rico em $\mathrm{Al}, \mathrm{Cu}, \mathrm{Fe}, \mathrm{Mn}$ e Si. Para este último tipo de IM, é importante destacar que existe uma nítida separação entre as zonas ricas em $\mathrm{Cu}$ e $\mathrm{Si}$. Na imagem por $\mathrm{MEV}$ a região enriquecida neste último elemento apresenta tonalidade ligeiramente mais escurecida, devido ao menor número atômico deste em relação ao $\mathrm{Cu}$. De acordo com Hughes et al. (2010) a presença de Si na composição deste tipo de IM provoca uma diminuição na razão $\mathrm{Cu} / \mathrm{Fe}$ tornando-o mais estável eletroquimicamente.
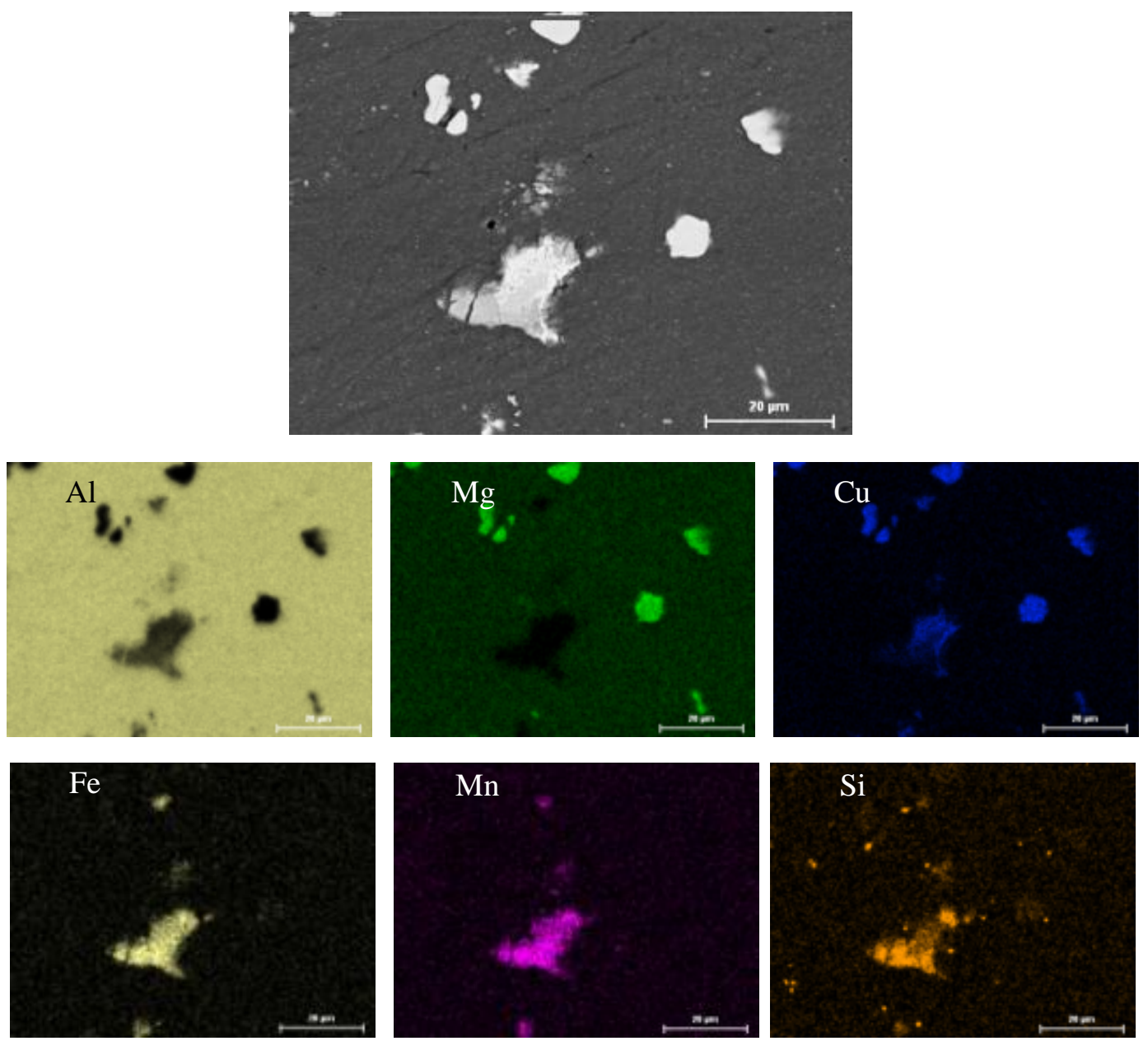

Figura 4-3: Imagem obtida em microscópio eletrônico de varredura da região TMAZ, com mapeamento EDS da região.

A micrografia de uma região do nugget juntamente com o mapeamento em EDS é apresentada na Figura 4-4. Através do mapeamento por EDS, observa-se, a presença dos dois tipos de IMs, $\mathrm{Al}-\mathrm{Cu}-\mathrm{Mg}$ e $\mathrm{Al}-\mathrm{Cu}-\mathrm{Fe}-\mathrm{Mn}-\mathrm{Si}$, com empobrecimento em $\mathrm{Cu}$ nas 
regiões ricas em Si deste último tipo de IM. A Figura evidencia também que os IMs Al$\mathrm{Cu}-\mathrm{Mg}$ permanecem relativamente intactos enquanto apenas os IMs $\mathrm{Al}-\mathrm{Cu}-\mathrm{Fe}-\mathrm{Mn}$-Si são fraturados pelo movimento de rotação da ferramenta de soldagem.

A caracterização microestrutural da região do nugget da liga de Al 2024-T3 soldada por FSW realizada por outros autores indicam a ocorrência de fratura apenas para os IMs ricos em Al-Cu-Fe-Mn (JARIYABOON, et al., 2007), ou então que também os IMs Al-Cu-Mg são fraturados (BOUSQUET, 2011a). Os resultados apresentados na Figura 4-4 indicam que para o material que está sendo estudado apenas os IMs Al-CuFe-Mn-Si são fraturados pela ação do pino da ferramenta. A diferença encontrada entre as informações disponíveis na literatura podendo ser atribuída, provavelmente, às diferentes condições de obtenção das amostras. Finalmente, destaca-se que os IMs grosseiros presentes na microestrutura da liga não são sensíveis ao aumento de temperatura, inclusive na zona de solubilização da liga (BIRBILIS \& BUCHHEIT, 2005).
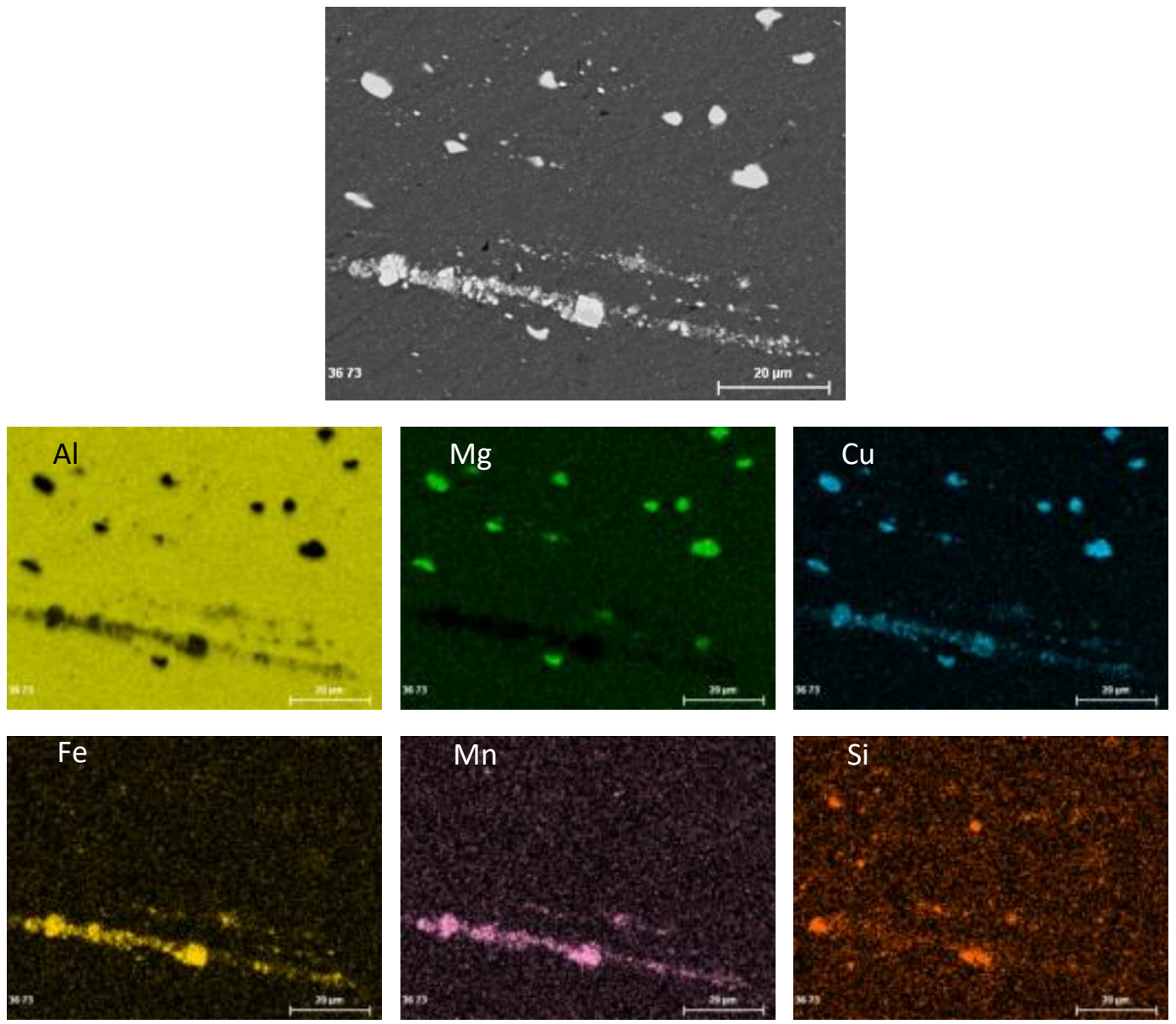

Figura 4-4: Imagem obtida em microscópio eletrônico de varredura da região do nugget, com mapeamento EDS da região. 
As ligas de Al tratáveis termicamente devem grande parte de sua resistência mecânica à presença de pequenos precipitados, de dimensões nanométricas, formados durante tratamentos térmicos anteriores (THREADGILL P. , 2009). As ligas da série 2XXX são endurecíveis por precipitação, e a têmpera T3 corresponde a uma condição onde o material é solubilizado para homogeneização, deformado a frio e, posteriormente, envelhecido naturalmente para o processo de endurecimento (HANDBOOK, 1966). De acordo com Zhang e Frankel (2003) e com Birbilis e Buchheit (2005) os nanoprecipitados presentes na microestrutura da liga 2024-T3 são as partículas dispersóides e as partículas ou precipitados de endurecimento. As primeiras são formadas durante a homogeneização e as segundas durante o envelhecimento da liga (JARIYABOON, et al., 2007). No que se refere à composição, as partículas dispersóides são $\mathrm{Al}_{20} \mathrm{Cu}_{2} \mathrm{Mn}_{3}$ (ZHANG \& FRANKEL, 2003) e os precipitados de endurecimento correspondem, principalmente, às partículas $\mathrm{Al}_{2} \mathrm{CuMg}$ formadas a partir das zonas GPB (estas não detectáveis no presente trabalho), e as partículas $\mathrm{Al}_{2} \mathrm{Cu}$, formadas a partir das zonas GP (também não detectáveis). Nas temperaturas típicas desenvolvidas durante a FSW (discutidas posteriormente neste trabalho) estas partículas podem solubilizar ou então aglomerar, provocando o seu engrossamento, o que afeta tanto as propriedades mecânicas (dureza), podendo também influir na resistência à corrosão e na incidência de algum tipo de corrosão específica como a intergranular.

A Figura 4-5 apresenta as imagens obtidas por MEV com aumento de 20000X das regiões do metal base (a), HAZ (b), TMAZ (c) e com 25000X da região do nugget (d) de uma amostra da liga 2024-T3 polida. Em todas elas é possível observar a presença de partículas com dimensões nanométricas, possivelmente aquelas descritas no parágrafo anterior. A comparação entre as micrografias das Figura 4-5 (a), (b) e (c) mostra claramente uma maior densidade de partículas na região do metal base, em relação à HAZ e à TMAZ. Isto indica, provavelmente, que nestas duas últimas regiões deve ter ocorrido a dissolução das mesmas, devido ao ciclo térmico durante o processo de soldagem. Já a região do nugget (Figura 4-5 (d)), parece apresentar uma densidade de partículas semelhante à do metal base. No entanto, observa-se uma distribuição diferente das partículas, que se encontram menos alinhadas, bem como, uma tendência de aglomeração em algumas regiões. Isto pode ser explicado por um possível fenômeno de engrossamento e também solubilização das partículas devido às elevadas temperaturas atingidas na região do nugget durante a soldagem. É importante destacar também que um importante percentual das partículas precipitadas nas regiões afetadas termicamente pode ter ocorrido 
durante o envelhecimento natural da região de solda, característico do endurecimento das ligas 2024 nesta têmpera, o que justificaria a distribuição mais aleatória destas na microestrutura da liga. Este processo pode ter ocorrido durante o armazenamento da liga no laboratório após o processo de soldagem, e, por ocorrer em regiões com microestruturas não controladas (nenhum tipo de tratamento pós-soldagem foi aplicado ao material) ocorre de modo mais heterogêneo na microestrutura.

Jariyaboon et al (2007) apresentam micrografias das regiões do nugget e da HAZ para soldas FSW produzidas com diferentes velocidades de rotação do pino. Nas micrografias apresentadas por estes autores verifica-se que a densidade de partículas na região do nugget é maior que na HAZ para soldas produzidas com menores velocidades de rotação, ou seja, quando a quantidade de calor gerada no processo é menor. Por sua vez, na maior velocidade de rotação, quando maior quantidade de calor é gerada na soldagem, esta relação se inverte. Em concordância com a literatura, trabalhos desenvolvidos no Laboratório de Processos Eletroquímicos (LPE) do Departamento de Engenharia Metalúrgica e de Materiais da EPUSP com soldas produzidas por FSW utilizando diferentes velocidades de rotação da ferramenta, evidenciaram nanoprecipitados mais grosseiros na região do nugget quando se utilizou menores velocidades de rotação da ferramenta. 


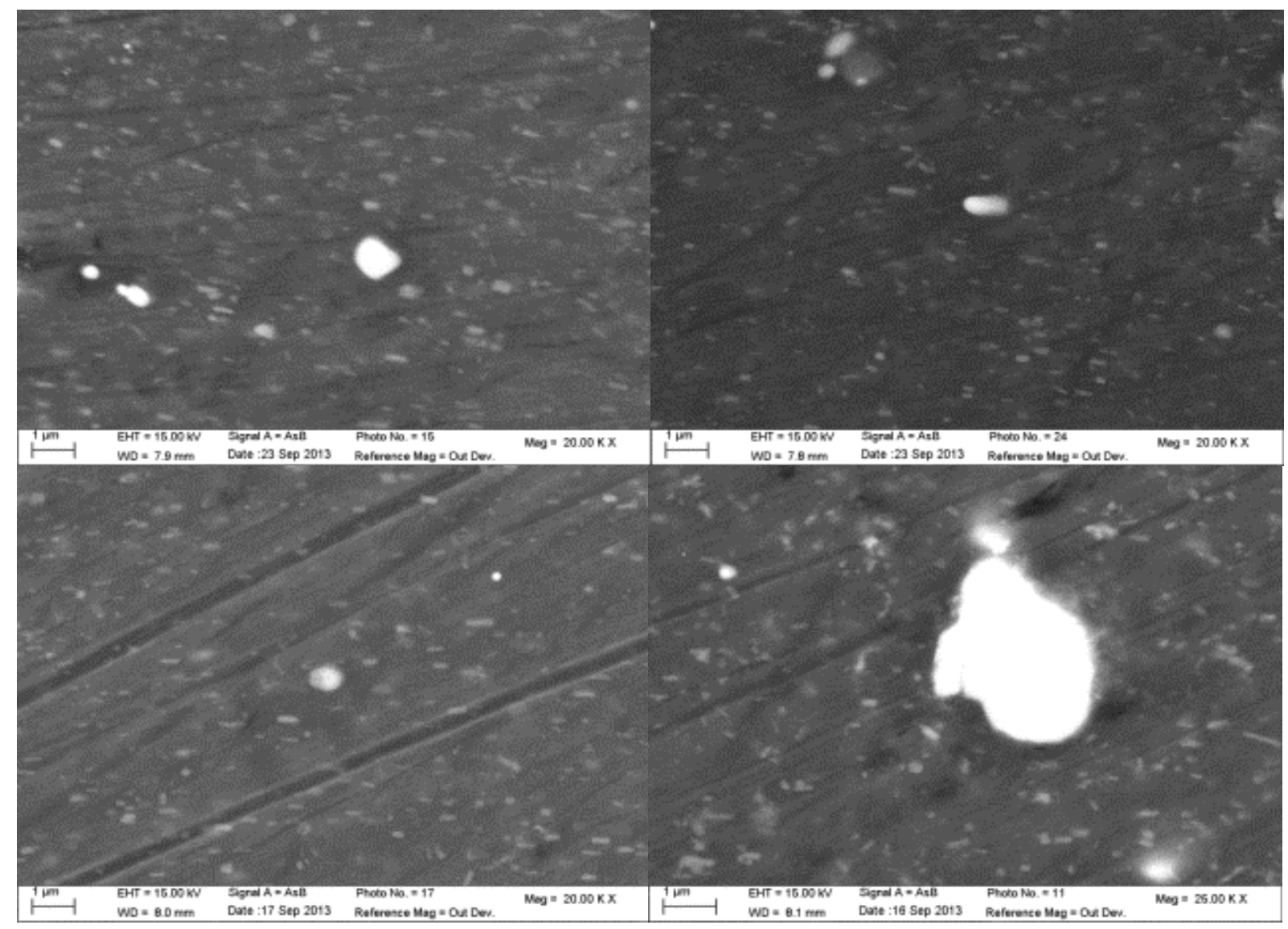

Figura 4-5: Micrografias obtidas em microscópio eletrônico de varredura da superfície da liga AA2024-T3: metal base (a), HAZ (b), TMAZ (c) e nugget (d).

\subsubsection{Caracterização por Microscopia Eletrônica de Transmissão (TEM)} das diferentes regiões geradas durante a soldagem por FSW

Com a finalidade de melhor avaliar a distribuição dos nanoprecipitados na microestrutura das diferentes regiões geradas durante a soldagem da liga por FSW, análises por TEM foram realizadas nas diferentes zonas. A Figura 4-6 apresenta micrografias representativas de cada uma destas regiões.

Observa-se no metal base a presença de precipitados intragranulares $(\sim 200 \mathrm{~nm})$ com forma de bastão uniformemente distribuídos (Figura 4-6 (a)) e o acúmulo de precipitados alinhados em algumas regiões de contorno de grão (Figura 4-6 (b)). Entretanto, é importante salientar que regiões semelhantes a esta última não foram frequentemente encontradas no metal base, indicando ser esta uma configuração de precipitação pouco comum nesta região. Na literatura, precipitados em forma de bastão têm sido associados aos dispersóides $\mathrm{Al}_{20} \mathrm{Cu}_{2} \mathrm{Mn}_{3}$ (PAREL, WANG, \& STARINK, 2010) enquanto os precipitados de endurecimento são reportados como tendo forma de ripas 
(RINGER S. , HONO, POLMEAR, \& SAKURAI, 1996) (GAO, DAVIN, WANG, CEREZO, \& STARINK, 2002), (PAREL, WANG, \& STARINK, 2010) as quais não foram encontradas em nenhuma das imagens TEM do presente trabalho, mostrando que as condições de aquisição das micrografias não foram adequadas para aquisição de imagens dos precipitados nesta configuração.

$\mathrm{Na}$ região da HAZ verifica-se a presença dos precipitados intragranulares em forma de bastão distribuídos uniformemente na microestrutura, no entanto, observa-se uma ligeira diminuição na densidade destes em relação à matriz (Figura 4-6(c)). Algumas regiões de contorno de grão apresentaram alinhamentos de precipitados (Figura 4-6 (d)), sendo este tipo de distribuição encontrado mais facilmente que no metal base, embora também não tenha sido observada com frequência. Nesta região foram encontradas também formas poligonais escurecidas como a apresentada na Figura 4-6 (e). Wang e Starink (2007) encontraram formas semelhantes à da Figura 4-5 (e) após aquecimento de uma liga AA 2324 a $270^{\circ} \mathrm{C}$, cuja análise por difração de área selecionada mostrou serem $\mathrm{Al}_{2} \mathrm{CuMg}$. Os autores argumentaram que se tratava da seção transversal da fase $\mathrm{S}$, que apresenta forma de ripa (WANG \& STARINK, 2007). Curiosamente, as dimensões da seção transversal reportadas por Wang e Starink (2007), 150 x 250 nm, são bastante semelhantes àquelas apresentadas na Figura 4-6 (e), reforçando a hipótese de que estes são de fato precipitados da fase de endurecimento $\mathrm{Al}_{2} \mathrm{CuMg}$.

Na TMAZ (Figura 4-6 (f)) observou-se mais claramente a diminuição na densidade de precipitados em relação às duas outras regiões previamente analisadas. Além do mais, nesta região, contornos de grão com partículas acumuladas foram facilmente identificáveis (Figura 4-6(g)). Na Figura 4-6 (h) são apresentadas partículas poligonais encontradas nesta região, e que são semelhantes àquelas identificadas por Wang e Starink como sendo a sessão transversal da fase S (WANG \& STARINK, 2007).

Finalmente, na região do nugget, verifica-se que os precipitados nanométricos são mais grosseiros que nas demais regiões e que estão distribuídos de forma randômica (Figura 4-6 (i)). Além do mais, partículas poligonais semelhantes às reportadas por Wang e Starink (2007) foram encontradas, e que também tinham aparência mais grosseira que nas demais regiões (Figura 4-6 (j)). Destaca-se que, nesta região específica, os precipitados nanométricos não se encontram alinhados como nas demais, apresentando orientação aleatória, o que é uma forte evidência de que grande parte destas partículas dissolveu durante a soldagem do material e que, posteriormente, precipitou de modo 
aleatório durante o envelhecimento natural. Nas regiões analisadas do nugget, não foram encontradas partículas precipitadas nos contornos de grão.

Antes de terminar este item, é importante destacar que, partículas poligonais como as apresentadas nas Figura 4-6 (e), (h) e (j) também foram observadas no metal base, porém em proporção bem inferior (em apenas uma imagem precipitados com forma semelhante foram observados). Isto indica que, provavelmente, estas partículas são formadas por engrossamento das partículas de endurecimento originais e que apresentam forma de ripa fina, como apresentado em vários trabalhos (RINGER S. , HONO, POLMEAR, \& SAKURAI, 1996) (GAO, DAVIN, WANG, CEREZO, \& STARINK, 2002) (PAREL, WANG, \& STARINK, 2010) 

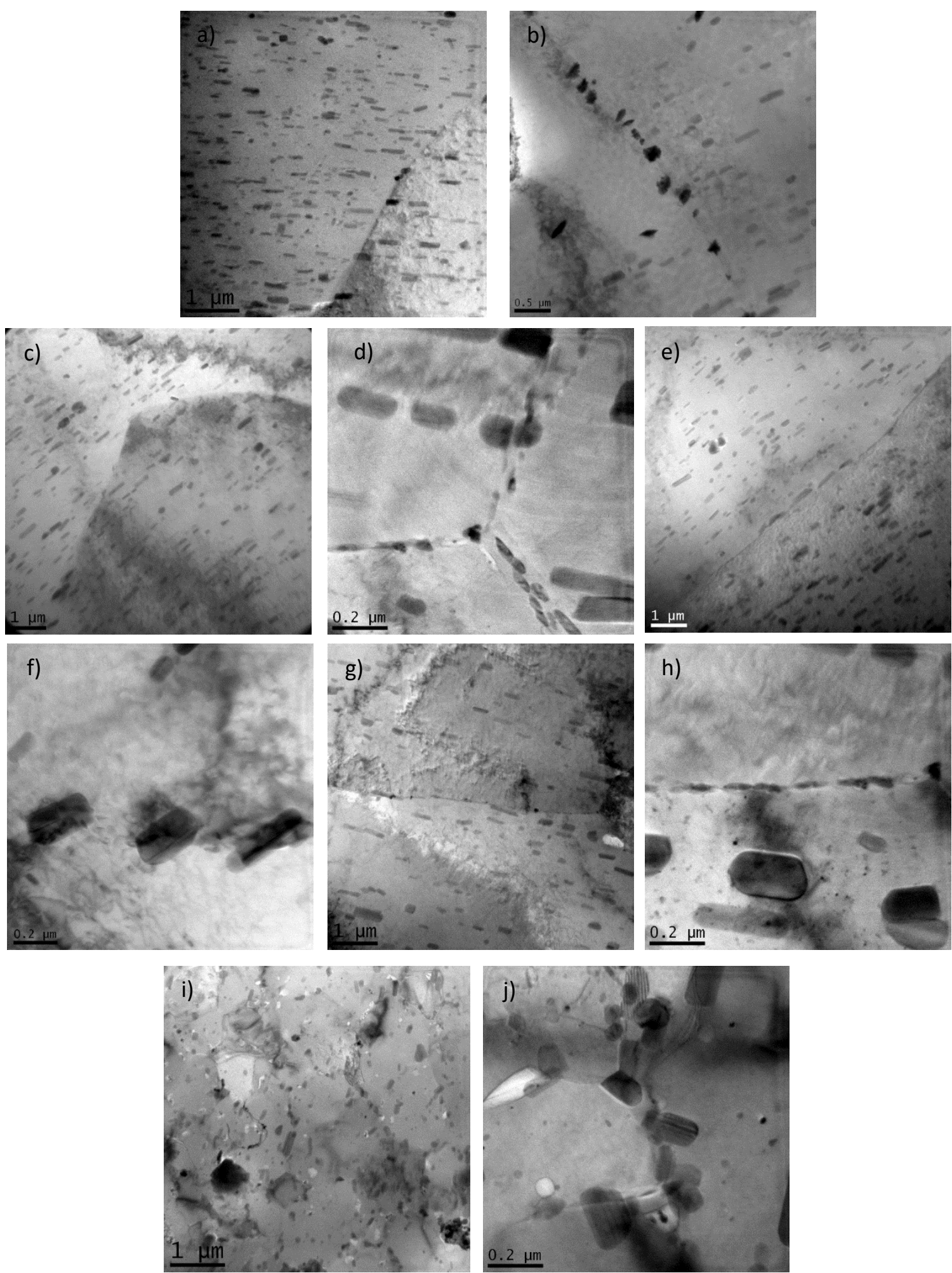

Figura 4-6: Micrografias obtidas por TEM das diferentes regiões da solda. Metal-base (a) e (b); HAZ (c), (d) e (e), TMAZ (f), (g) e (h), nugget (i) e (j). As micrografias (e), (h) e (j) mostram detalhes de precipitados poligonais atribuídos por Wang e Starink à fase $S$ (WANG \& STARINK, 2007). 


\subsubsection{Determinação da microdureza}

A dureza das ligas de alumínio de elevada resistência mecânica está profundamente associada à distribuição das partículas de endurecimento na microestrutura, e, consequentemente à resistência mecânica das mesmas. Por este motivo, diversos autores têm utilizado este tipo de determinação para avaliar o efeito da temperatura sobre a distribuição das nanopartículas na microestrutura desta classe de liga (FRIGAARD, GRONG, \& MIDLING, 2001) (GENEVOIS, DESCHAMPS, DENQUIN, \& DOISNEAU-COTTIGNIES, 2005) (JARIYABOON, et al., 2007) (STARINK, GAO, $\&$ YAN, 2004).

A Figura 4-7 apresenta o perfil de microdureza superficial, determinado com microdurômetro, através de todo o cordão de solda e da região afetada pelo calor. Observa-se que este se apresenta ligeiramente assimétrico em relação ao centro do cordão de solda, região do nugget, e que a dureza varia através das diferentes zonas afetadas pelo processo de soldagem. Além do mais, constata-se que a dureza de toda a região afetada pelo processo de soldagem é inferior à da matriz (identificada como BM na Figura).

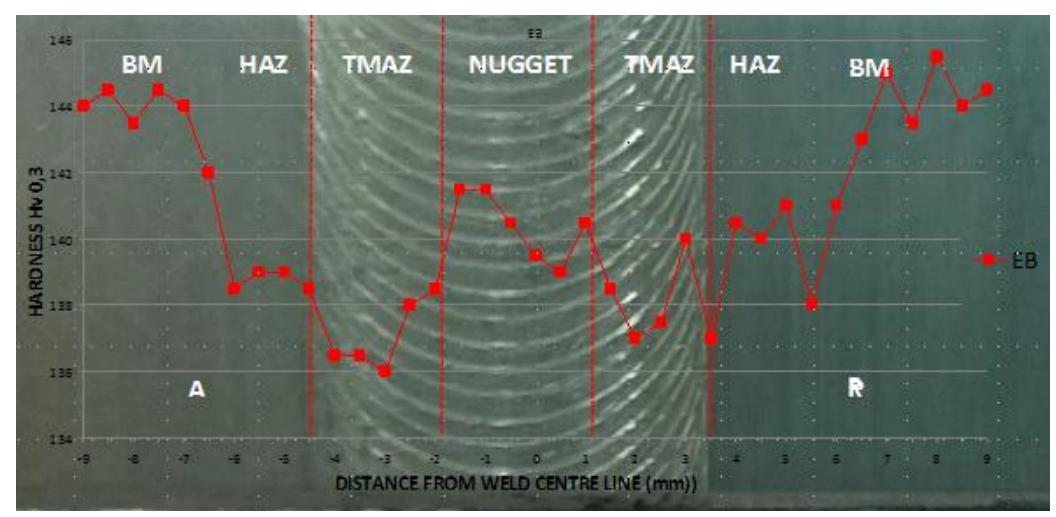

Figura 4-7: Perfil de dureza através das regiões afetadas pela soldagem por FSW.

Com relação à assimetria do perfil de dureza em relação ao centro da solda, os trabalhos consultados não comentam este aspecto específico, embora seja possível perceber que esta característica está presente em alguns dos resultados apresentados por (GENEVOIS, DESCHAMPS, DENQUIN, \& DOISNEAU-COTTIGNIES, 2005) e por (JARIYABOON, et al., 2007). Recentemente, Yau et al. (2013) investigaram a distribuição de temperatura durante a soldagem por FSW da liga de alumínio 2024-T3 e verificaram que esta era ligeiramente inferior do lado do retrocesso. Como a dureza local 
da liga é extremamente dependente da distribuição de precipitados na microestrutura da liga, a qual é função da geração de calor durante a soldagem, e esta, por sua vez, depende do movimento do metal plasticizado, que é diferente no lado do avanço e no do retrocesso (THREADGILL P. L., LEONARD, SHERCLIFF, \& WITHERS, 2009), é possível prever uma ligeira assimetria entre as durezas encontradas nos dois lados do cordão de solda.

Os resultados apresentados na Figura 4-7 mostram que, dentre as regiões afetadas pelo calor, a de maior dureza se encontra no nugget. De acordo com Sato, Kurihara, Hokawa (2011), o aumento da temperatura do nugget aumenta o tamanho dos grãos dinamicamente recristalizados o que tende a promover uma diminuição da dureza (relação de Hall-Petch). Por outro lado, as temperaturas mais elevadas desenvolvidas nesta região tendem a solubilizar mais fortemente as partículas submicrométricas coerentes e incoerentes com a matriz, levando os elementos para a solução sólida. Quando da manutenção da liga à temperatura ambiente após o processo de soldagem, estas partículas podem reprecipitar a partir da solução sólida supersaturada provocando a recuperação da dureza por envelhecimento natural. Os resultados apresentados na Figura 4-7 indicam que a reprecipitação das partículas de endurecimento é mais importante que a relação de Hall-Petch na região do nugget para determinação da dureza local na liga de alumínio 2024-T3 soldada por FSW.

Finalmente, a Figura 4-7 mostra que a região com menor dureza se encontra na TMAZ, indicando que esta zona é a mais fortemente afetada pelas mudanças microestruturais produzidas durante a soldagem.

O perfil de dureza apresentado na Figura 4-7 mostra que as diferenças nos valores deste parâmetro entre as diferentes regiões da solda e o metal base não são significativa, sendo, inclusive, inferiores àquelas verificadas em diversos dos trabalhos consultados sobre a própria liga 2024 soldada por FSW (BOUSQUET, POULON-QUINTIN, DEVOS, PUIGGALI, \& TOUZET, 2012) (GENEVOIS, DESCHAMPS, DENQUIN, \& DOISNEAU-COTTIGNIES, 2005) (JARIYABOON, et al., 2007)). Destaca-se que a liga utilizada no presente estudo foi cedida pela EMBRAER já na condição soldada, e que permaneceu vários meses no laboratório durante a realização do presente trabalho. Deste modo, deve ter ocorrido forte atenuação na diferença de dureza devido ao processo de envelhecimento natural, que, para a liga AA2024-T3, ocorre à temperatura ambiente. Frigaard, Grong e Midling (2001) mostram em seu artigo que o aumento do tempo de envelhecimento das ligas de alumínio de elevada resistência mecânica diminui de maneira considerável a diferença entre as durezas do metal base e das diferentes regiões da solda 
FSW. Supõe-se que este mesmo fenômeno tenha acontecido no material estudado no presente projeto, explicando os resultados encontrados.

\subsubsection{Caracterização por MEV de amostras polidas atacadas por Keller}

A microscopia ótica foi utilizada para identificar as diferentes regiões da solda após ataque da amostra polida com reagente de Keller, conforme apresentado na Figura 4-8. Em razão da alta condutividade térmica do Al, durante o processo de soldagem por FSW se cria um gradiente térmico no material e, desta maneira, as mudanças na microestrutura ocorrem tanto devido à deformação (TMAZ e nugget) como pelo aumento da temperatura provocadas pela ferramenta de soldagem (TMAZ e nugget), e pela dissipação do calor gerado para a chapa (HAZ). A Figura 4-8 apresenta a seção transversal da solda contendo as diferentes regiões geradas durante o processo: nugget, TMAZ (a) e (r), HAZ (a) e (r) e metal base após ataque com reagente Keller, onde (a) e (r) se referem, respectivamente, ao lado do avanço e do retrocesso. Para melhor visualizar as diferenças entre as microestruturas das várias regiões, os detalhes destas foram ampliados em 100x (Figura 4-8 (b)-(f)).
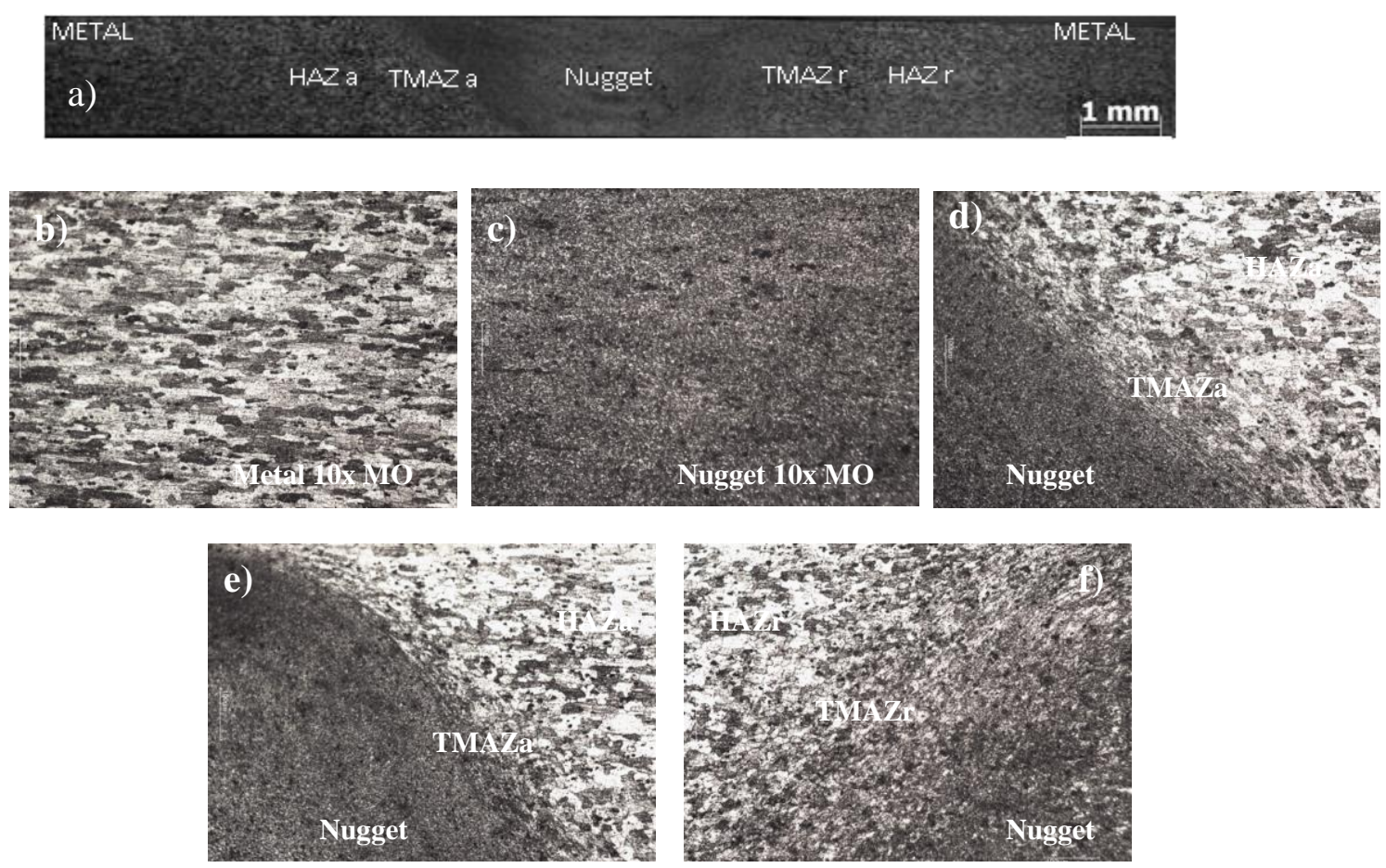

Figura 4-8: Imagem por microscopia ótica da seção transversal após ataque com reagente Keller (a). Detalhes das regiões do metal base (b); do nugget (c); do nugget e das zonas termicamente afetadas do lado do avanço (d) e (e), do nugget e das zona termomecanicamente afetadas do lado do retrocesso (f). 
Observa-se na Figura 4-8(b) que a região do metal base apresenta grãos alongados na direção de laminação da chapa, similares aos encontrados na HAZ, Figura 4-8 (d, e), onde verifica-se a descrição HAZa. A Figura 4-8 (c) apresenta a região do nugget. Observa-se uma imagem escura e homogênea, indicando a presença de grãos com menores dimensões e mais arredondados, o que é consequência das elevadas temperaturas desenvolvidas nesta região, e que modifica fortemente a estrutura dos grãos (BOUSQUET, POULON-QUINTIN, PUIGGALI, DEVOS, \& TOUZET, 2011). Na literatura, esta modificação tem sido frequentemente associada a um processo de recristalização dinâmica, embora ainda existam discussões se a microestrutura gerada não seria originada por um processo de recuperação dinâmica, já que vários experimentos mostram forte crescimento dos grãos quando a região do nugget é aquecida em temperaturas próximas a $500^{\circ} \mathrm{C}$ (THREADGILL P., LEONARD, SHERCLIFF, \& WHITERS, 2009). Nas Figura 4-8 (d) e (e), onde juntamente com o nugget são mostradas a HAZ e a TMAZ do lado do avanço, observa-se, nesta última região, que os grãos são alongados similarmente ao que ocorre no metal base e na HAZ, indicando que não ocorre recristalização dos grãos durante a soldagem. No entanto, devido à deformação plástica durante o processo, esses se tornam mais alongados e levemente rotacionados na direção de rotação da ferramenta (RHODES, MAHONEY, BINGEL, SPURLING, \& BAMPTON, 1997). Finalmente, comparando-se as Figura 4-8 (e) e (f) verifica-se que o limite entre a HAZ, a TMAZ e o nugget do lado do avanço (Figura 4-8 (e)) é mais bem definido que do lado do retrocesso (Figura 4-8 (f)), o que deve ser consequência do fato de que o arraste de material pela ferramenta durante a soldagem ocorre basicamente a partir desta última região.

A Figura 4-9 apresenta micrografias obtidas por MEV da distribuição dos precipitados submicrométricos em uma zona não afetada pelo calor do metal base após ataque com reagente de Keller. Na Figura 4-9 (a) observa-se que as partículas se encontram distribuídas de forma regular no interior dos grãos da amostra. Nesta região do metal não foi possível identificar nem tendência ao coalescimento das partículas nem precipitação preferencial ao longo dos contornos de grão, mesmo com forte aumento da imagem, como mostrado na Figura 4-9 (b). Devido às dimensões reduzidas dos precipitados não foi possível realizar análise da composição por EDS, entretanto, os estudos disponíveis na literatura indicam que as partículas responsáveis pelo endurecimento da liga de $\mathrm{Al}$ 2024-T3 é a fase $\mathrm{S}(\mathrm{S})^{\prime}$, cuja composição é $\mathrm{Al}_{2} \mathrm{CuMg}$ (BOUSQUET, POULON-QUINTIN, PUIGGALI, DEVOS, \& TOUZET, 2011), 
(GUILLAUMIN \& MANKOWSKI, 1998); (SATO, KURIHARA, \& KOKAWA, 2011). A literatura reporta que a dimensão destas partículas é da ordem da centena de nanômetros, que corresponde às dimensões visualizadas na Figura 4-9 (b). Porém não se pode descartar a hipótese de que estas partículas também incluam os dispersóides, que também possuem dimensões da mesma ordem de grandeza.
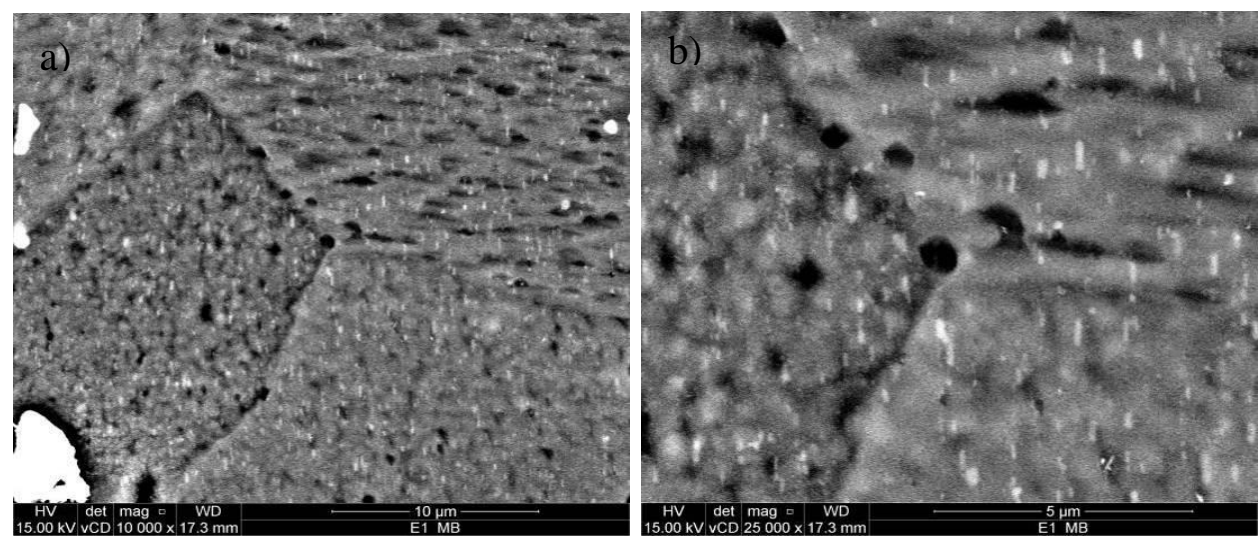

Figura 4-9: Micrografias obtidas por FE-SEM de zona não afetada pelo calor da liga AA 2024-T3 após ataque com reagente de Keller.

Na Figura 4-10 são apresentadas micrografias obtidas por MEV na região da TMAZ de uma amostra atacada com o reagente de Keller. Comparando estas imagens com aquelas apresentadas na Figura 4-9 é possível observar que os precipitados submicrométricos estão distribuídos de modo menos homogêneo nesta zona. Verifica-se também uma tendência a alinhamento na região de contornos de grão (regiões com círculos vermelhos nas Figura 4-10 (a)) e (b)) assim como uma leve tendência ao coalescimento dos precipitados. Levando-se em conta que, conforme documentado na literatura, a precipitação das partículas dispersóides ocorre em elevadas temperatura (BIRBILIS \& BUCHHEIT, 2005) (ZHANG \& FRANKEL, 2003) (ROSEN, IVES, RIDDER, BIANCANIELLO, \& MEHRABIAN, 1985) que não são atingidas na TMAZ (FRIGAARD, GRONG, \& MIDLING, 2001), e que, conforme evidenciado na Figura 4-10 (b), houve dissolução destas partículas e reprecipitação nos contornos de grão, seja durante a soldagem ou então durante envelhecimento à temperatura ambiente que aconteceu após o término do processo (as ligas ficaram armazenadas no laboratório), é possível supor que, nesta região específica dos grãos, as partículas que sofreram algum tipo de transformação se tratam dos precipitados de endurecimento. Por outro lado, o engrossamento, pode ter ocorrido tanto com os dispersóides como com as partículas de endurecimento. 

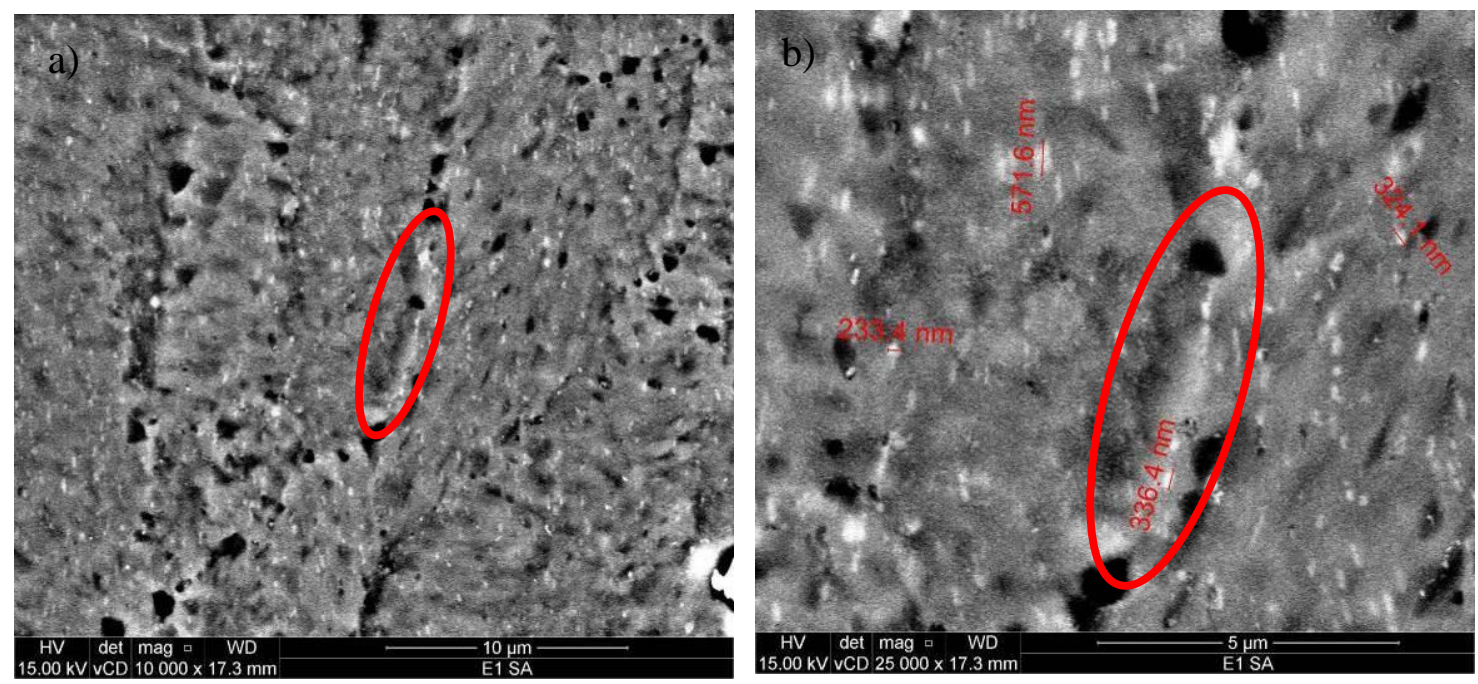

Figura 4-10: Micrografias obtidas por FE-SEM da TMAZ da liga AA 2024-T3 soldada por FSW após ataque com reagente de Keller. Em evidência, nanopartículas precipitadas ao longo dos contornos de grão.

As micrografias por FE-SEM da região do nugget após ataque com reagente de Keller estão apresentadas na Figura 4-11. Na Figura 4-11 (a) é possível observar que os grãos são arredondados, com diâmetro aproximado de $5 \mu \mathrm{m}$. Devido ao processo de recristalização dinâmica, nesta região os grãos são equiaxiais com aspecto arredondado (THREADGILL P. , 2009), com tamanhos reportados que variam entre 2 e $5 \mu \mathrm{m}$, dependendo das condições de soldagem (SATO, KURIHARA, \& KOKAWA, 2011), (SU J. , NELSON, MISHRA, \& MAHONEY, 2003), (GENEVOIS, DESCHAMPS, DENQUIN, \& DOISNEAU-COTTIGNIES, 2005) (JONE, et al., 2005), o que está de acordo com o apresentado na imagem. Entretanto a amostra apresentou-se fortemente atacada nos contornos de grão não sendo possível, portanto, definir se existe ou não a tendência para aglomeração de precipitados nesta região, embora esta tendência não tenha sido detectada nas análises por TEM (Figura 4-6). No entanto, a micrografia da Figura 4-11 (b), obtida com maior magnitude, indica que os precipitados estão distribuídos randomicamente no interior dos grãos, o que, segundo (RHODES, MAHONEY, BINGEL, SPURLING, \& BAMPTON, 1997) sugere a solubilização dos precipitados originais durante a soldagem e posterior reprecipitação, porém, aparentemente, em uma densidade menor que no metal base (Figura 4-9). 

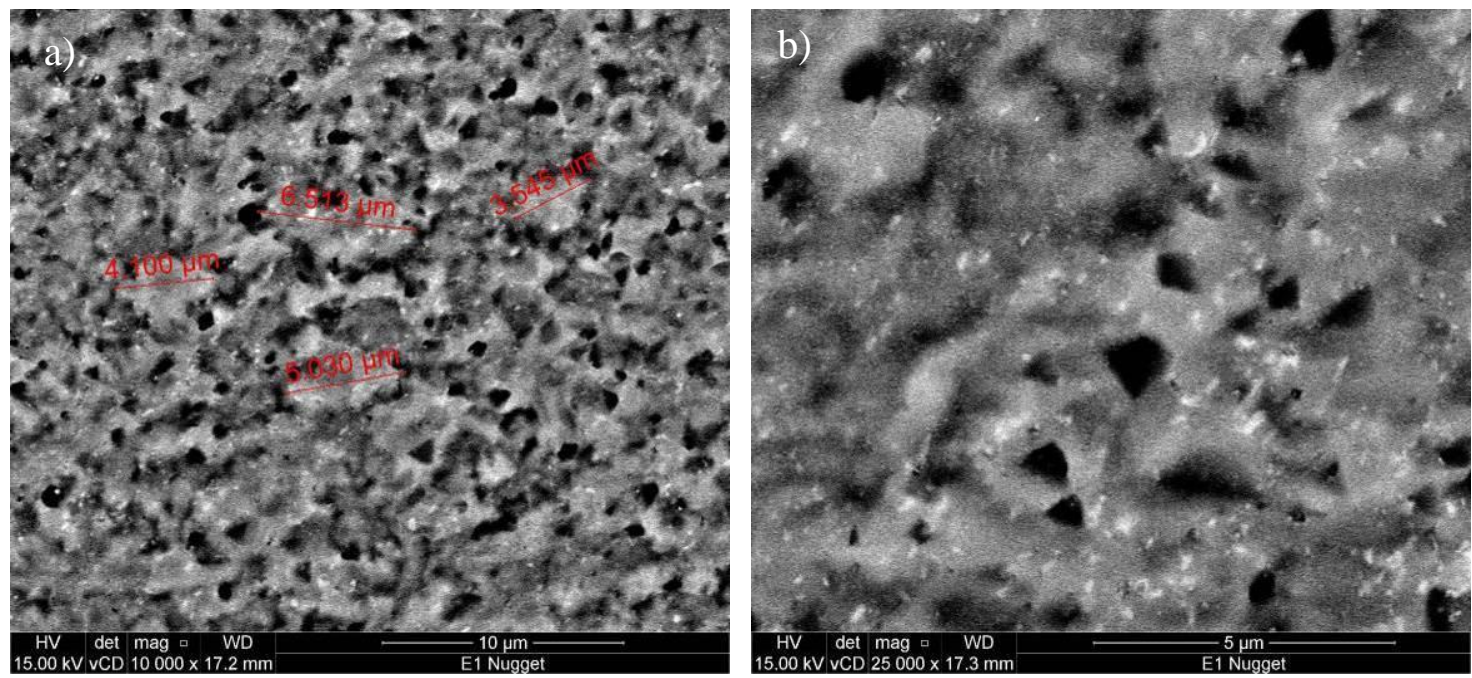

Figura 4-11: Micrografias obtidas por FE-SEM do nugget da liga AA 2024-T3 soldada por FSW após ataque com reagente de Keller.

As micrografias apresentadas nas Figura 4-9 a Figura 4-11 mostram que a distribuição de precipitados submicrométricos (PS) nas regiões afetadas pelo processo de soldagem (TMAZ e nugget) é bastante diferente do metal base. Isto ocorre porque na faixa de temperatura atingida durante a soldagem por FSW o coalescimento e a solubilização dos PS é possível, (RHODES, MAHONEY, BINGEL, SPURLING, \& BAMPTON, 1997) (ROSEN, IVES, RIDDER, BIANCANIELLO, \& MEHRABIAN, 1985) (FRIGAARD, GRONG, \& MIDLING, 2001). Outros fenômenos passíveis de acontecer são a precipitação de fases não coerentes com a matriz durante o resfriamento pós-soldagem (FRIGAARD, GRONG, \& MIDLING, 2001) e a reprecipitação de precipitados de endurecimento, que contribuem para o aumento da resistência mecânica, por envelhecimento natural da região de solda.

A título de exemplo, o diagrama esquemático da Figura 4-12, concebido para a liga de alumínio 7108-T6 submetida à soldagem por FSW (FRIGAARD, GRONG, \& MIDLING, 2001), permite interpretar de modo inequívoco os possíveis fenômenos que podem acontecer com os PS durante o ciclo térmico que ocorre durante a soldagem das ligas de alumínio em geral. Para esta liga, na faixa de temperatura entre $200-340^{\circ} \mathrm{C}$ ocorre a dissolução da fase ๆ', responsável pelo endurecimento da liga, e, ao mesmo tempo, partículas da fase $\eta$, que não contribuem para o endurecimento, crescem, estes dois processos contribuem para diminuir a resistência mecânica. Nas regiões que atingem temperaturas acima de $340^{\circ} \mathrm{C}$ ocorre dissolução de todos os PS da fase $\eta$, porém, durante o resfriamento destas regiões após a soldagem, estas partículas podem reprecipitar contribuindo para criar uma zona permanentemente macia na microestrutura da região 
afetada pelo processo. É importante relembrar que, após o término da soldagem, pode haver recuperação das propriedades mecânicas devido à precipitação por envelhecimento natural de PS ๆ', porém, normalmente, a nucleação destas fases ocorre de forma heterogênea, a menos que um tratamento térmico seja aplicado ao material, implicando que esta recuperação não ocorre de modo completo.

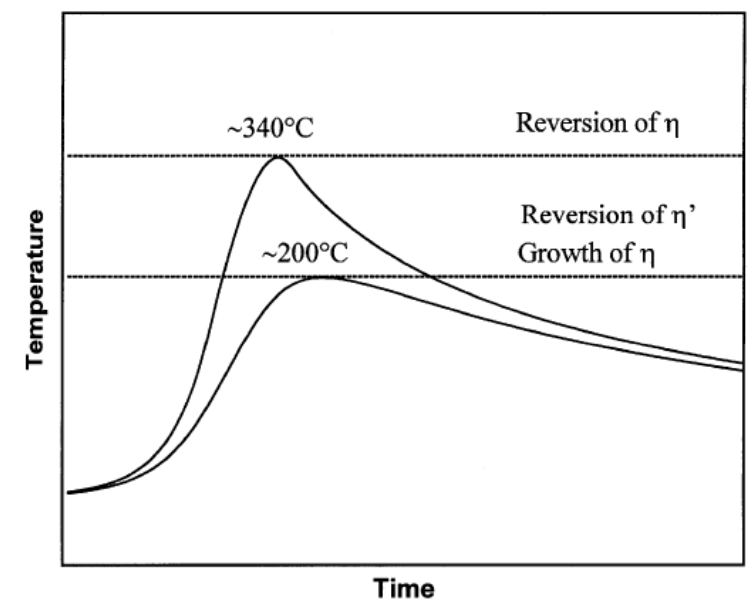

Figura 4-12: Diagrama esquemático mostrando detalhes da evolução da microestrutura na HAZ para a liga de alumínio endurecível por precipitação AA 7108-T6 (FRIGAARD, GRONG, \& MIDLING, 2001).

De acordo com a literatura consultada e amplamente documentada na revisão de literatura deste trabalho, os PS de endurecimento encontrados na microestrutura da liga AA 2024 e AA2024-T351 consistem de zonas GPB (Guinier-Preston-Bagaryatsky), homogêneas e coerentes com a matriz, e de finos precipitados da fase $\mathrm{S}\left(\mathrm{Al}_{2} \mathrm{CuMg}\right)$, com dimensões de algumas centenas de nanômetros, e que também são ou coerentes ou semicoerentes com a matriz da liga (como não foram detectados intermetálicos $\mathrm{Al}_{2} \mathrm{Cu}$, fase $\theta$, a existência da fase GP não será discutida). Estas partículas são os PS mais mencionados na literatura, embora a existência de outros tipos também seja reportada por alguns autores (ZHANG \& FRANKEL, 2003). A fase GPB e os precipitados $\mathrm{S}$ coerentes ou semicoerentes com a matriz (também denominados $S$ " e $S$ '-vide Figura 2-3. são responsáveis pelo endurecimento e consequente melhoria da resistência mecânica da liga (ROSEN, IVES, RIDDER, BIANCANIELLO, \& MEHRABIAN, 1985). Bousquet et al. (2011) reporta que as dimensões típicas das zonas GPB é de apenas algumas dezenas de nanômetros, portanto, abaixo do poder de resolução das micrografias apresentadas nas Figura 4-9 a Figura 4-11. Entretanto, mesmo utilizando a microscopia eletrônica de 
transmissão (TEM), a revisão da literatura demonstra que estas partículas são difíceis de detectar, e ainda existe larga incerteza a respeito de suas características.

Com relação às fases que contribuem para a melhoria das propriedades mecânicas da liga 2024 (GPB, S”, S'(S)), Muthu Kumaran (2012) reporta que a formação das zonas GPB começa a ocorrer em temperaturas próximas a $73^{\circ} \mathrm{C}$ com dissolução (juntamente com a fase coerente S") a $219^{\circ} \mathrm{C}$, e que a fase semi-coerente $S^{\prime}$ é formada a $284^{\circ} \mathrm{C}$. Já Genevois et al.(2005) indicam que as zonas GPB começam a dissolver em temperaturas próximas a $150^{\circ} \mathrm{C}$ e que as fases $\mathrm{S}^{\prime}(\mathrm{S})$ começam a precipitar pouco acima de $275^{\circ} \mathrm{C}$. Este último valor estando dentro da faixa de temperatura sugerida para a precipitação da fase S por Wang e Starink (2007), entre 230 e $340^{\circ}$ C, e por Starink, Gao e Yan (2004) entre 230 e $320^{\circ} \mathrm{C}$. Nestes dois últimos trabalhos é sugerido que a dissolução da fase $\mathrm{S}$ ocorre progressivamente a partir de $340^{\circ} \mathrm{C}$ (WANG \& STARINK, Two types of S phase precipitates in $\mathrm{Al}-\mathrm{Cu}-\mathrm{Mg}$ alloy, 2007) e de $330^{\circ} \mathrm{C}$ (STARINK, GAO, \& YAN, 2004). Rosen et al. (1985) reportam que para ligas de alumínio 2024 a temperatura de solubilização dos PS de fase $\mathrm{S}$ é de $495^{\circ} \mathrm{C}$, portanto, quanto mais próximo desta temperatura menor a possibilidade da existência de PS grosseiros na microestrutura. Estes mesmo autores (ROSEN, IVES, RIDDER, BIANCANIELLO, \& MEHRABIAN, 1985) reportam ainda que o aquecimento em temperaturas próximas a $350^{\circ} \mathrm{C}$ provoca o máximo coalescimento destas partículas prejudicando fortemente a dureza do material.

Com relação às temperaturas atingidas durante processos de FSW disponíveis na literatura. Para uma razão entre as velocidades de rotação e de deslocamento entre 0,9 e 5,4, Nakata et al. (2000) mostram que durante a FSW da liga 2024 a temperatura de pico pode variar entre aproximadamente $467^{\circ} \mathrm{C}$ e $557^{\circ} \mathrm{C}$, sendo que quanto maior esta razão maior a temperatura. Rhodes et al., a partir de dados retirados da literatura, sugerem que as temperaturas atingidas no nugget durante o processo atingem entre 450 e $480^{\circ} \mathrm{C}$ (RHODES, MAHONEY, BINGEL, SPURLING, \& BAMPTON, 1997), enquanto Frigaard et al.(2001) utilizando termopares colocados na parte posterior de placas de Al das ligas 6082 e 7108 durante a soldagem por FSW, na região do ombro da ferramenta, determinaram que as temperaturas máximas atingidas foram, respectivamente, de $500^{\circ} \mathrm{C}$ e $525^{\circ}$ C. Levando em conta estes valores os autores (FRIGAARD, GRONG, \& MIDLING, 2001) admitiram que a temperatura máxima atingida no nugget era de $555^{\circ}$ $\mathrm{C}$, tendo utilizado este valor para a modelagem de diversos aspectos relativos ao processo de FSW. Estes mesmos autores (FRIGAARD, GRONG, \& MIDLING, 2001), utilizando termopares posicionados na HAZ a diversas distâncias do centro do nugget, determinaram 
o perfil de temperatura durante a soldagem, procedimento semelhante ao adotado por Jariyaboon et al (2007). Alguns resultados relevantes apresentados nestes dois trabalhos estão resumidos na Tabela 4-1 apresentada a seguir.

Tabela 4-1: Temperatura de máximo em função dos parâmetros de soldagem para diferentes ligas de alumínio soldadas por FSW. Medições com termopares posicionados na HAZ. PT - posição do Termopar. $\omega$ - velocidade de rotação da ferramenta. $v$ velocidade de deslocamento da ferramenta.

\begin{tabular}{|c|c|c|c|c|c|c|c|c|c|c|c|}
\hline Fonte & \multicolumn{6}{|c|}{ Frigaard et al. $^{\text {(a) }}$} & \multicolumn{5}{|c|}{ Jariyaboon et al. $^{(\mathrm{b})}$} \\
\hline PT (mm) & \multicolumn{6}{|c|}{17,5} & \multicolumn{5}{|c|}{16,0} \\
\hline LIGA & \multicolumn{3}{|c|}{ AA 6082} & \multicolumn{3}{|c|}{ AA 7108} & \multicolumn{5}{|c|}{ AA 2024-T3 } \\
\hline$\omega(\mathrm{rpm})$ & \multicolumn{6}{|c|}{1500} & \multicolumn{2}{|c|}{215} & 350 & \multicolumn{2}{|c|}{468} \\
\hline$v(\mathrm{~mm} / \mathrm{s})$ & 5 & 8 & 12 & 5 & 8 & 12 & 1,25 & 2,57 & 1,58 & 1,25 & 2,57 \\
\hline $\mathrm{T}_{\max }\left({ }^{\circ} \mathrm{C}\right)^{(\mathrm{c})}$ & 330 & 275 & 240 & 375 & 290 & 255 & 260 & 250 & 310 & 330 & 275 \\
\hline
\end{tabular}

(a) Ø. FRIGAARD, Ø. GRONG, O.T. MIDLING A Process Model for Friction Stir Welding of Age Hardening Aluminum Alloys. METALLURGICAL AND MATERIALS TRANSACTIONS A, VOLUME 32A, MAY, pp. 1189-1200 (2001)

(b) M. Jariyaboon, A.J. Davenport, R. Ambat, B.J. Connolly,S.W. Williams, D.A. Price The effect of welding parameters on the corrosion behaviour of friction stir welded AA2024-T351. Corrosion Science 49 (2007) 877-909

(c) Valores aproximados

Os valores de temperatura reportados nos parágrafos anteriores e na Tabela 4-1 confirmam que durante os ciclos térmicos da soldagem por FSW modificações microestruturais importantes podem acontecer nas chapas soldadas, e que as mesmas são dependentes da distância em relação ao centro da solda. Corroborando para as análises de microscopia apresentadas anteriormente. 


\subsection{ENSAIOS DE CORROSÃO}

\subsubsection{Ensaio de imersão}

A Figura 4-13 apresenta micrografias obtidas por MEV das regiões do metal base e do nugget da peça soldada, após imersão durante 3 horas de uma peça completa (contendo o metal base e todas as regiões de solda) em solução de $\mathrm{NaCl} 0,1 \mathrm{~mol} \mathrm{~L}^{-1}$. Como documentado para a liga de alumínio 2024-T3, nas duas regiões analisadas, a atividade de corrosão localizada está concentrada em torno dos IMs (Blanc et al., 1997). Este processo tem sua origem na diferença de potencial existente entre estes IMs e a matriz da liga (Buchheit, 1995), e é caracterizado pela formação de trincheiras na matriz em torno dos IMs (Hughes et al., 2010). É amplamente aceito na literatura que o processo de corrosão local da liga de AA 2024 é iniciado pelo desligamento (dealloying) das partículas de fase $\mathrm{S}$ (IMs $\mathrm{Al}-\mathrm{Cu}-\mathrm{Mg}$ ), que têm seus componentes mais ativos ( $\mathrm{Al}$ e $\mathrm{Mg}$ ) seletivamente atacados, deixando um remanescente rico em $\mathrm{Cu}$, que se torna catódico em relação à matriz, este mecanismo foi inicialmente proposto por Buchheit et al. (1997). De acordo com o documentado por Hughes et al., (2010), este fenômeno tem seu início apenas alguns minutos após a imersão da liga em solução de $\mathrm{NaCl} \mathrm{0,1} \mathrm{mol} \mathrm{L}^{-1}$. Entretanto, com o aumento do tempo de imersão, o processo também se estende para os IMs Al-CuFe-Mn-(Si), que são menos ativos eletroquimicamente (Hughes et al., 2010; Queiroz et al., 2008). A Figura 4-14 mostra que, para o tempo de imersão utilizado no teste, a corrosão ocorre tanto no entorno nos IMs Al-Cu-Mg (fase S) como dos Al-Cu-Fe-Mn(Si). Entretanto, a comparação entre as Figuras 4-14 (a) e (b) indica que o ataque local da liga em torno dos IMs é mais uniforme na região do nugget (quase todos os IMs estão ativados), sendo particularmente acentuado no entorno dos IMs Al-Cu-Fe-Mn-(Si), que foram fraturados pela ação rotatória do pino da ferramenta (Figura-4-14). 

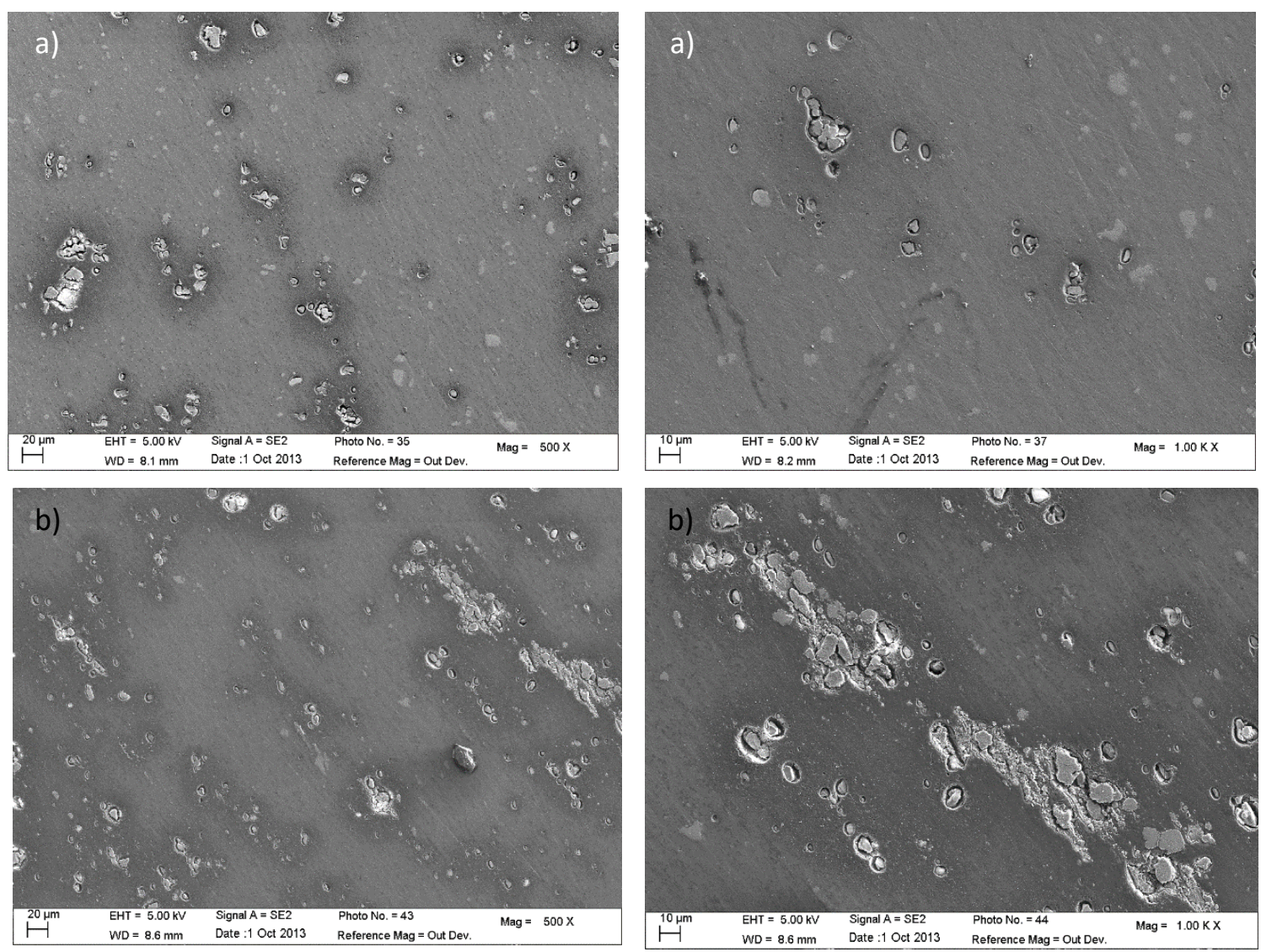

Figura 4-13: Imagens obtidas por microscopia eletrônica de varredura da região do metal base (a) e do nugget (b) após 3 horas de imersão em solução de $\mathrm{NaCl}$ 0,1 mol L ${ }^{-1}$. Imagens obtidas sobre um mesmo corpo de prova contendo toda a região de solda.
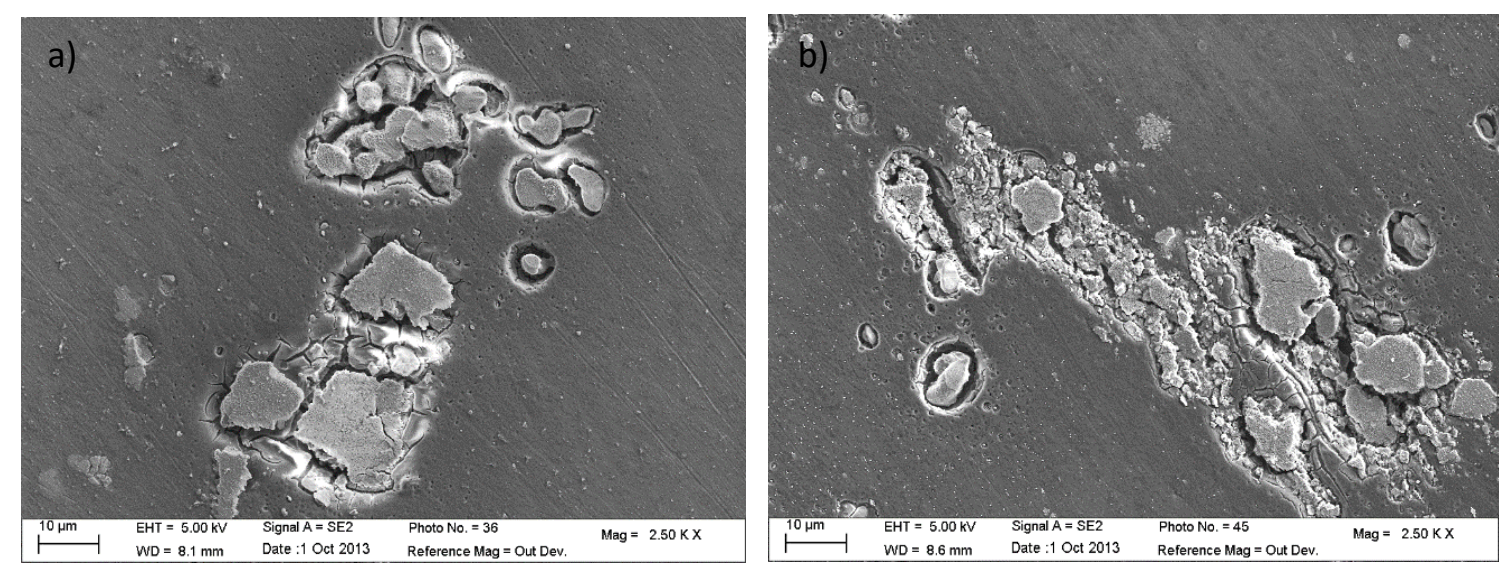

Figura 4-14: Detalhe da corrosão de um IM Al-Cu-Fe-Mn-(Si) no metal base (a) e no nugget (b). Imagens obtidas em um mesmo corpo de prova contendo toda a região de solda. 


\subsubsection{Ensaio em solução de $\mathrm{NaCl} 0,7 \mathrm{~mol} \mathrm{~L}^{-1}$ contendo ágar-ágar e indicador universal de pH (teste de visualização com gel)}

Com a finalidade de identificar macroscopicamente a região mais suscetível à corrosão, amostras da liga soldada foram recobertas com uma camada de solução contendo $0,7 \mathrm{~mol} \mathrm{~L}^{-1}$ de $\mathrm{NaCl}$ e 2,5 $\mathrm{g} \mathrm{L}^{-1}$ de ágar-ágar e $7 \mathrm{ml}$ de indicador universal de pH. Em estudos anteriores este teste havia sido utilizado por (JARIYABOON, et al., 2007) e por (PROTON, et al., 2011) para visualizar a corrosão em juntas de ligas de alumínio soldadas por FSW, com a diferença de que estes autores realizaram os testes utilizando o ágar-ágar no estado sólido (gel), enquanto no presente estudo o procedimento foi realizado com o meio em estado líquido, que foi solidificando gradualmente durante o teste. As imagens apresentadas nestes trabalhos mostram claramente que a resistência à corrosão através do cordão de solda é heterogênea.

No teste empregado, as regiões anódica e catódica são indicadas pelas alterações de pH. As áreas com coloração entre amarela e laranja indicam a presença de zonas ácidas, que correspondem a sítios anódicos (áreas de corrosão) resultantes da oxidação do alumínio (Equação 4.1) seguida da sua reação de hidrólise (Equação 4.2). As áreas verde-azuladas indicam regiões básicas (sítios catódicos) resultantes da reação de redução do oxigênio (Equação 4.3) ou mesmo da redução do íon $\mathrm{H}^{+}$(Equação 4.4).

$$
\begin{array}{lr}
\mathrm{Al}_{(\mathrm{s})} \rightarrow \mathrm{Al}^{3+}{ }_{(\mathrm{aq})}+3 \mathrm{e}- & 4-1 \\
\mathrm{Al}^{3+}{ }_{(\mathrm{aq})}+\mathrm{H}_{2} \mathrm{O}_{(\mathrm{l})} \rightarrow \mathrm{AlOH}^{2+}{ }_{(\mathrm{aq})}+\mathrm{H}^{+}{ }_{(\mathrm{aq})} & 4-2 \\
\mathrm{O}_{2(\mathrm{aq})}+2 \mathrm{H}_{2} \mathrm{O}_{(\mathrm{l})}+4 \mathrm{e}-\rightarrow 4 \mathrm{OH}^{-}{ }_{(\mathrm{aq})} & 4-3 \\
2 \mathrm{H}^{+}{ }_{(\mathrm{aq})}+2 \mathrm{e}-\mathrm{H}_{2(\mathrm{~g})} & 4-4
\end{array}
$$

A Figura 4-15 apresenta a evolução da corrosão para a liga soldada por FSW em função do tempo de ensaio. Verifica-se que após alguns minutos a atividade anódica começa a se desenvolver na região entre a HAZ e a TMAZ, no lado do avanço, logo se estendendo para a região do nugget (20 minutos). Finalmente, após três horas de ensaio, o processo corrosivo se estende para toda a região afetada pelo processo de soldagem. Durante todo o processo o metal base se comportou como região catódica. Os resultados obtidos neste teste indicam claramente que a região de solda é mais eletroquimicamente que o metal base, o que está de acordo com diversos trabalhos publicados na literatura e que a reatividade é heterogênea através do cordão de solda, como verificado por 
(JARIYABOON, et al., 2007) e (PROTON, et al., 2011) em testes realizados com metodologia semelhante.

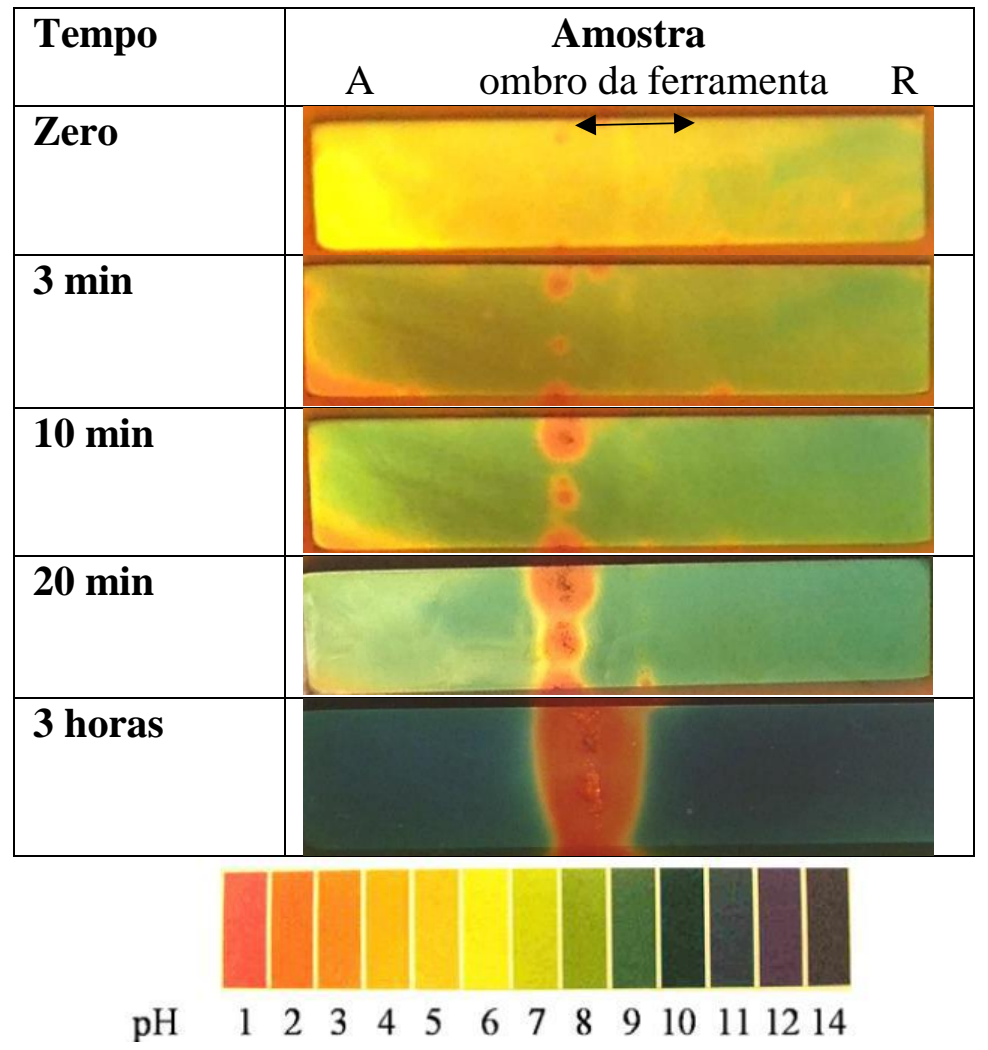

Figura 4-15: Resultado do teste de corrosão em solução de $\mathrm{NaCl} 0,7 \mathrm{~mol} \mathrm{~L}^{-1}$ contendo ágar-ágar e indicador universal de pH sobre a superfície da liga de alumínio 2024-T3 soldada por FSW "A" e "R" se referem, respectivamente, ao lado do avanço e do retrocesso.

\subsubsection{Ensaio de corrosão por esfoliação (ASTM G-34)}

A Figura 4-16 apresenta os resultados do ensaio de corrosão por esfoliação da liga de Al 2024 soldada por FSW, e que foi realizado de acordo com o recomendado pela norma ASTM G-34. Observa-se uma grande quantidade de produtos de corrosão sobre toda a superfície da amostra. Entretanto, o ataque mais intenso acontece na região da solda, na qual uma região contínua de ataque mais acentuado se desenvolve na divisão entre o nugget e a TMAZ, na região que fica sob o ombro da ferramenta, no lado do avanço (indicada pela seta vermelha na Figura 4-16).

A seção transversal da amostra ensaiada também foi avaliada após remoção dos produtos de corrosão e embutimento (Figura 4-17) para aferir a profundidade do ataque. Observa-se, inicialmente, que toda a região afetada pelo processo de soldagem (HAZ, TMAZ e nugget) foi mais fortemente atacada do que a matriz da liga. Na região da TMAZ 
do lado do avanço (Figura 4-17(a)) a profundidade da esfoliação foi mais intensa em relação à TMAZ do lado retrocesso (Figura 4-17(b)) Estes resultados, além de confirmarem a heterogeneidade de reatividade ao longo da região afetada pela soldagem, estão em completo acordo com o verificado no teste de visualização com gel, que indicou ser esta região a mais suscetível ao processo corrosivo. Além do mais, as análises por MEV (Figura 4-2) e por TEM (Figura 4-6) mostraram que a precipitação de precipitados submicrométricos na região do contorno de grão era mais frequente na TMAZ, o que facilita a progressão deste tipo de corrosão.

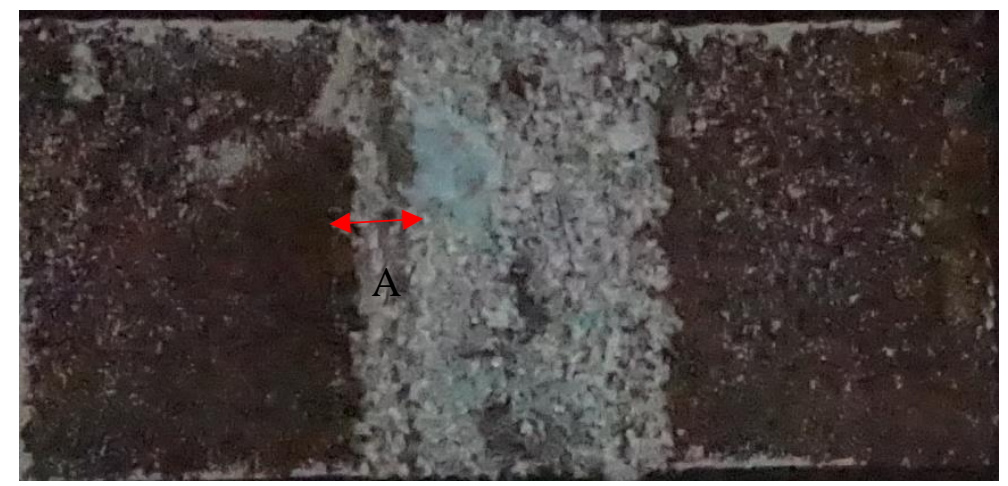

Figura 4-16: Imagem de topo por microscopia ótica da superfície da liga AA 2024-T3 soldada por FSW após o término do ensaio de corrosão por esfoliação.
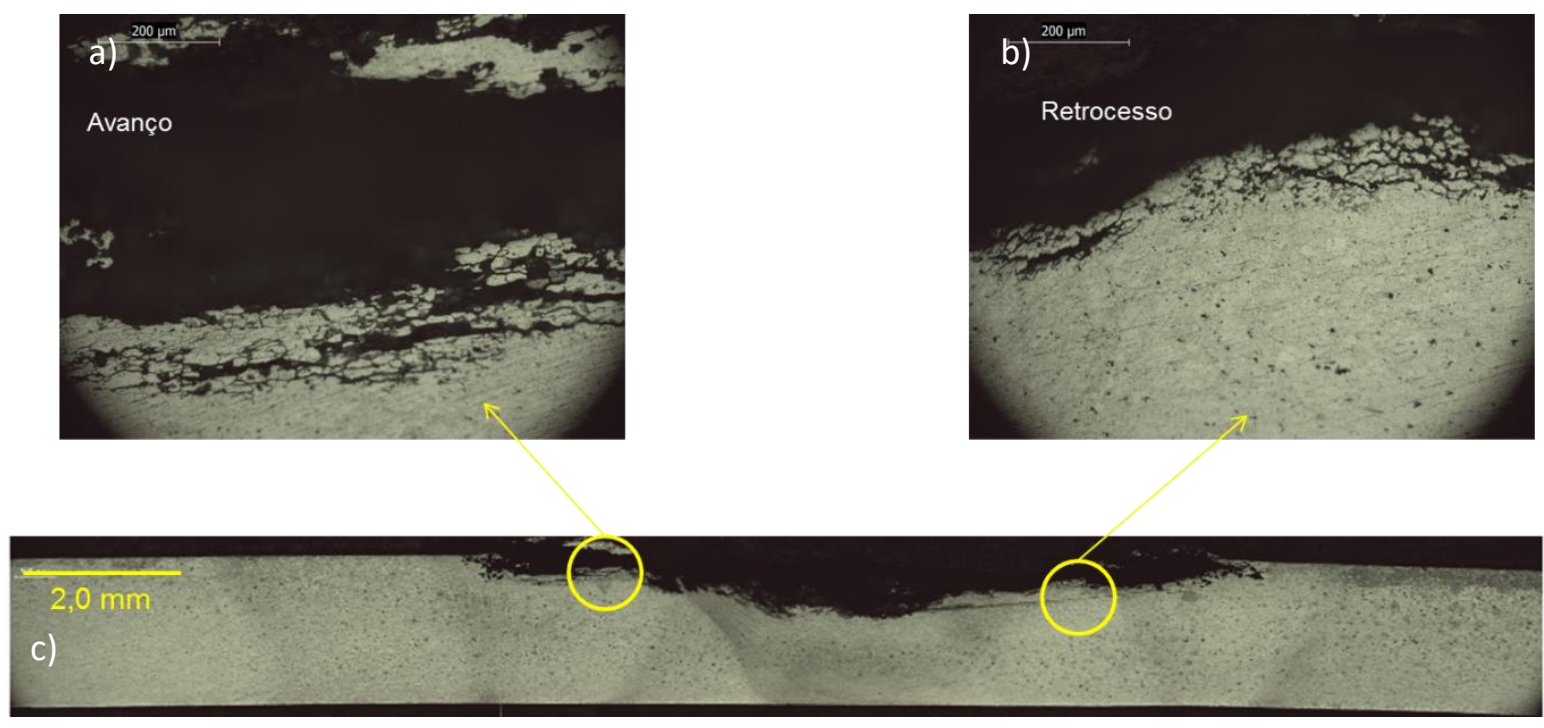

Figura 4-17: Imagem por microscopia ótica da seção transversal da liga de Al 2024 soldada por FSW após ensaio de corrosão por esfoliação realizado de acordo com a norma ASTM G-34 e limpeza dos produtos de corrosão. Detalhes do: lado do avanço (a)) e lado do retrocesso (b). 
Poucos trabalhos estão disponíveis na literatura onde testes de corrosão por esfoliação foram aplicados para avaliar a resistência à corrosão de ligas de alumínio de elevada resistência mecânica soldadas por FSW. Zucchi, Trabanelli e Grassi (2001) utilizaram a solução EXCO e verificaram que a resistência à exfoliação da região de solda da liga AA5083 soldada por FSW era superior à da matriz, o que foi atribuído à recristalização da zona do nugget, que forneceria uma distribuição mais uniforme de intermetálicos em comparação com a liga trabalhada a frio, que apresenta grãos orientados na direção de laminação. Curiosamente, apesar de mencionarem a redistribuição dos IMs na microestrutura da liga como sendo um fator importante no aumento da resistência à esfoliação, os autores não apresentam caracterização microestrutural que justifiquem tal hipótese (ZUCCHI, TRABANELLI, \& GRASSI, 2001). Entretanto, Mishra e Ma (2005) em revisão de literatura sobre FSW, mencionam alguns artigos publicados em anais de congressos onde foi relatado que a resistência à esfoliação da região de solda de ligas de alumínio da série 7XXX soldadas por FSW é inferior à da matriz quando testada em solução EXCO modificada, cuja composição é apresentada no artigo 


\subsubsection{Ensaio de corrosão intergranular (ASTM-G110)}

A Figura 4-18 apresenta as micrografias obtidas com microscópio ótico da seção transversal de uma amostra da região de solda que foi submetida ao ensaio de corrosão intergranular de acordo com o procedimento recomendado na norma ASTM G110-97.

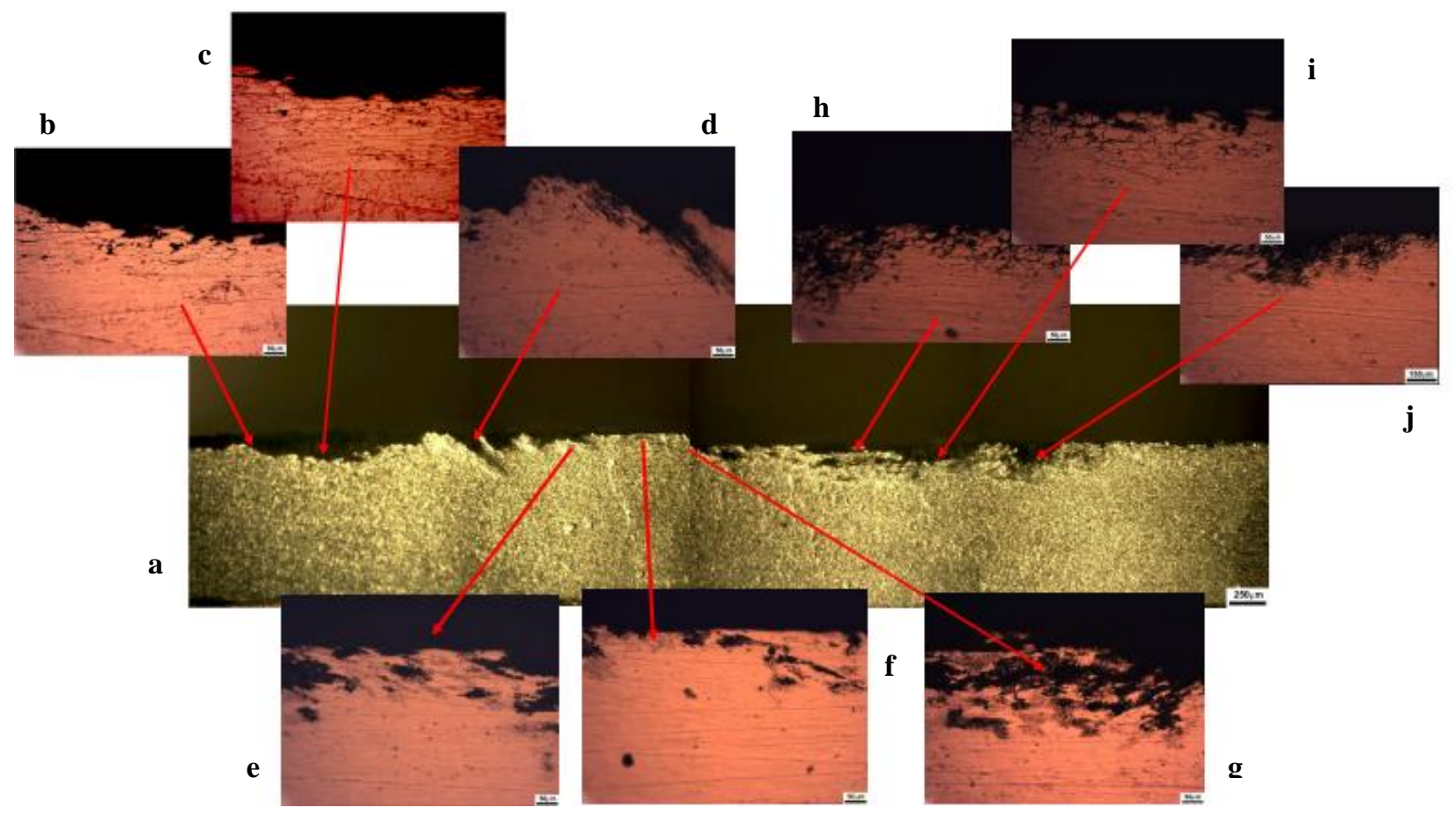

Figura 4-18: Micrografia ótica da seção transversal da região de solda após ensaio de corrosão intergranular de acordo com a norma ASTM G11097 (a). Detalhes com maiores aumentos: das regiões HAZ-TMAZ (avanço) (b), (c), (d); da região do nugget (e), (f), (g); das regiões TMAZ-HAZ (retrocesso) (h), (i), (j) 
Na Figura 4-19 está apresentado um detalhe da seção transversal do metal base, submetido ao mesmo teste, onde se verifica que este não sofreu corrosão intergranular durante o período de realização do experimento.

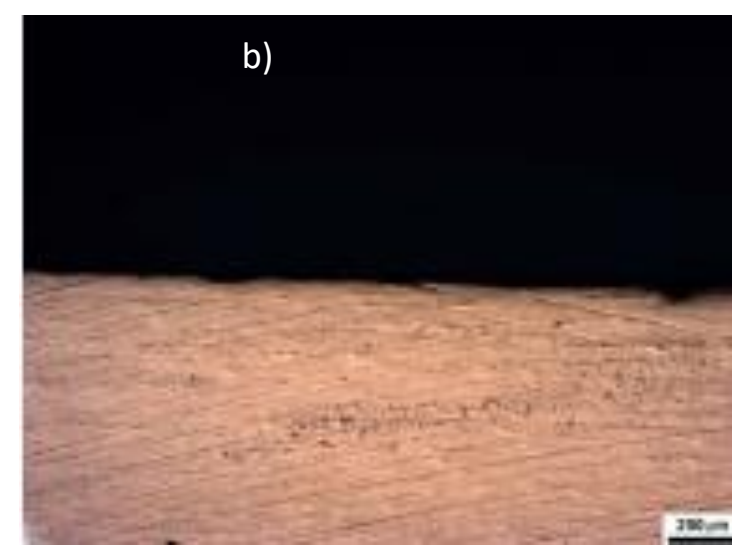

Figura 4-19: Seção transversal do metal base após ensaio de corrosão intergranular de acordo com os procedimentos da norma ASTM G110-97

A análise da seção transversal de toda a peça (Figura 4-18 (a)) mostra uma intensa perda de espessura nas partes laterais da mesma, e uma pequena elevação na parte central. As zonas laterais correspondem à HAZ e à TMAZ do lado do avanço (à esquerda) e do retrocesso (à direita), enquanto a parte em central, em relevo, corresponde ao nugget.

As Figura 4-18 (b), (c) e (d) apresentam detalhes das regiões HAZ e TMAZ do lado do avanço. Observa-se nestas imagens, além da perda de massa, uma intensa corrosão intergranular se desenvolvendo em profundidade na seção transversal do metal. A ocorrência deste tipo de corrosão indica que a perda de massa deve ter ocorrido por destacamento dos grãos, o que corresponde a um mecanismo clássico deste tipo de corrosão. $\mathrm{O}$ mesmo processo ocorreu nas zonas TMAZ-HAZ no lado no retrocesso (Figura 4-18 (h) (i) e (j)), mas, aparentemente, de modo ligeiramente menos intenso, já que a perda de espessura parece ter sido menor, e vários grãos superficiais ainda permanecem aderidos à matriz, apesar do progresso visível da corrosão intergranular (Figura 4-18 (h) e (i)).

As imagens detalhadas na região do nugget (Figura 4-18 (e), (f) e (g)) mostram uma situação diferente. Aqui, não foi verificada a progressão da corrosão intergranular (não foi identificada a penetração da solução entre os grãos), mas alguns vazios foram formados na seção transversal do material, como se, em algumas regiões, parte do material tivesse sido arrancada ou preferencialmente corroída. 
Está amplamente documentado na literatura que o início da corrosão localizada em ligas de alumínio de elevada resistência mecânica está fortemente associado à presença de intermetálicos com potencial eletroquímico diferente da matriz (BUCHHEIT, GRANT, HLAVA, MCKENZIE, \& ZENDER, 1997); (QUEIROZ, MAGNANI, COSTA, \& deMELO, 2008) (BOAG, et al., 2010), sendo que a fase $\mathrm{S}\left(\mathrm{Al}_{2} \mathrm{CuMg}\right)$ é particularmente reativa (QUEIROZ, MAGNANI, COSTA, \& deMELO, 2008) (BLANC, LAVELLE, \& MANKOWSKI, 1997; BLANC, et al., 2010). Em trabalho recente, Zhuo et al.(2012) demonstraram que pites estáveis se desenvolvem principalmente a partir de sítios onde agrupamentos de IMs da fase $\mathrm{S}$ existem, os quais se encontram enterrados sob a superfície metálica, e apresentam uma intersecção com esta no ponto onde o processo corrosivo tem seu início. A corrosão destas partículas em profundidade ofereceria um caminho para o eletrólito penetrar no material produzindo íons Al na região confinada, cuja hidrólise provocaria acidificação local da solução na região de propagação da corrosão, a qual também é rica em cloretos (2012).

Por sua vez, a ocorrência da corrosão intergranular está associada à natureza mais reativa dos contornos de grão, à qual é potencializada quando ocorre precipitação de partículas de segunda fase anódicas ou catódicas nesta região, o que pode acarretar a formação de pilhas e de regiões de depleção em elementos de liga. A ocorrência de precipitação de nanopartículas nos contornos de grão das regiões afetadas pelo processo de FSW tem sido documentada por diversos autores para diferentes ligas de alumínio (JARIYABOON, et al., 2007) (PROTON, et al., 2013) (PAGLIA \& BUCHHEIT, 2006) (BOUSQUET, POULON-QUINTIN, PUIGGALI, DEVOS, \& TOUZET, 2011) (SU J.Q. , NELSON, MISHRA, \& MAHONEY, 2003) tendo sido também identificada no presente trabalho por MEV e TEM, principalmente na HAZ e na TMAZ. Frequentemente a ocorrência desta precipitação no contorno de grãos tem sido utilizada para justificar o aumento da incidência da corrosão intergranular em regiões específicas de ligas de alumínio soldadas por FSW (JARIYABOON, et al., 2007); (PROTON, et al., 2013) (BOUSQUET, POULON-QUINTIN, PUIGGALI, DEVOS, \& TOUZET, 2011); (PROTON, et al., 2011), o que também parece ser o caso no presente estudo.

Em trabalho recente, Zhuo et al. demonstrou uma forte correlação entre o desenvolvimento da corrosão intergranular e a nucleação e crescimento de pites estáveis (ZHOU, LUO, HASHIMOTO, HUGHES, \& THOMPSON, 2012). De acordo com estes autores, o estabelecimento de pites estáveis a partir do ataque eletroquímico a agrupamentos de IMs da fase $\mathrm{S}$ gera uma região confinada com baixo $\mathrm{pH}$ (gerado pela 
hidrólise dos íons $\mathrm{Al}$ ), e que possui geometria adequada para que seja estabelecido um front de corrosão que permite a atuação de um gradiente de concentração entre esta região, que também seria rica em cloretos, e a superfície da liga. De acordo com os autores, quando este front de corrosão encontra um contorno de grão a corrosão intergranular é iniciada (ZHOU, LUO, HASHIMOTO, HUGHES, \& THOMPSON, 2012). Assim na TMAZ e na HAZ o efeito de precipitação das nanopartículas (de endurecimento ou dispersóides) nos contornos de grão tende a acelerar a corrosão intergranular, pois gera regiões mais suscetíveis a este processo, como verificado nos resultados experimentais exibidos na Figura 4-18. A presença de agrupamentos de IMs na microestrutura da liga 2024, não evidenciado no presente trabalho, mas amplamente documentado na literatura (ZHOU, LUO, HASHIMOTO, HUGHES, \& THOMPSON, 2012) (BOAG, et al., 2009) (CHEN, GAO, \& WEI, 1996), contribuiria para acelerar o desenvolvimento deste tipo de corrosão, conforme o mecanismo proposto por Zhuo et al. (2012).

A ausência de corrosão intergranular na região do nugget pode ser atribuída a dois fenômenos: inicialmente, as análises por TEM e MEV não mostraram a precipitação de nanoprecipitados nos contornos de grão nesta região, consequentemente, esta região deve ser menos reativa no nugget que na HAZ e na TMAZ, como o é também na matriz da liga (Figura 4-19). Um outro fator que pode ter relevância é o efeito de mistura da liga nesta região por ação do pino da ferramenta, que diminuiria a incidência de agrupamentos de IMs e o desenvolvimento de pites estáveis com progressão para corrosão intergranular, conforme o mecanismo proposto por Zhuo et al. (2012).

Um último aspecto a ser esclarecido é a forma particular de corrosão verificada na região do nugget, visível nas micrografias óticas das Figura 4-18 (e), (f) e (g). O tipo de ataque identificado nestas Figuras é semelhante ao observado por Zhang e Frankel em estudo sobre a transição entre corrosão por pites e intergranular na liga de alumínio 2024, e que foi denominado por estes autores como ataque granular seletivo, não caracterizando, portanto, nem a ocorrência de corrosão por pites nem intergranular (ZHANG \& FRANKEL, 2003). No estudo desenvolvido por estes autores (ZHANG \& FRANKEL, 2003) este tipo de ataque ocorreu quando a liga 2024 foi imersa em solução de $\mathrm{NaCl} 1 \mathrm{~mol} \mathrm{~L}^{-1}$ após ter sido submetida aos tratamentos térmicos T8 e T8+ (tratamento em forno a $190^{\circ} \mathrm{C}$ por $12 \mathrm{~h}$ e $36 \mathrm{~h}$, respectivamente, seguido de resfriamento ao ar). $\mathrm{O}$ ataque preferencial ocorreu ao longo dos grãos alongados, em um mecanismo completamente diferente do verificado nas corrosões por pites e intergranular. A hipótese levantada por Zhang e Frankel (2003) para explicar este tipo de corrosão foi de que o tratamento térmico de envelhecimento aplicado à liga torna a matriz pobre 
em $\mathrm{Cu}$, o que a tornaria mais suscetível à quebra da película passiva que os contornos de grão e a zona com depleção de soluto. Para explicar porque a corrosão não se espalha para os grãos adjacentes, os autores propõem que os contornos de grão podem ficar protegidos pela deposição de $\mathrm{Cu}$ proveniente da corrosão da matriz da liga nestes grãos específicos (ZHANG \& FRANKEL, 2003). Este tipo de argumento (enriquecimento em $\mathrm{Cu}$ das paredes da fresta formada durante a corrosão intergranular) também foi utilizado por Zhou et al.(2012) para explicar porque a corrosão intergranular não progride para o interior dos grãos, mantendo o ataque concentrado nos contornos de grão. De acordo com estes autores (ZHOU, LUO, HASHIMOTO, HUGHES, \& THOMPSON, 2012), durante a corrosão do Al, ocorre a formação de uma fina camada enriquecida em $\mathrm{Cu}$ na superfície, com alguns nanômetros de espessura, porque a energia livre de Gibbs por equivalente-grama (- $\Delta \mathrm{G} \%$ eq) para a formação de óxidos de cobre é menos negativa que para a formação da alumina. Isto tornaria a parede da fresta catódica em relação ao front de propagação da corrosão intergranular, evitando a progressão para o interior dos grãos, e também explicaria porque, frequentemente, a evolução de hidrogênio é observada nas proximidades das regiões anódicas durante a corrosão do $\mathrm{Al}$ (ZHOU, LUO, HASHIMOTO, HUGHES, \& THOMPSON, 2012)

\subsection{ENSAIOS ELETROQUÍMICOS GLOBAIS}

Inicialmente, ensaios clássicos de corrosão foram realizados utilizando amostras das diferentes regiões da solda recortadas e embutidas em baquelite. A variação do potencial de circuito aberto (PCA) em função do tempo das regiões do metal base, nugget e HAZ em solução de $\mathrm{NaCl}$ 0,1 mol.L $\mathrm{L}^{-1}$ está apresentada na Figura 4.20. Observa-se, para todos os corpos de prova, uma rápida estabilização do PCA, e que os PCAs da HAZ e do metal base apresentam oscilações típicas de uma superfície que está passando por um processo de corrosão por pites, com nucleação e repassivação. Por sua vez, o PCA da região nugget, tende a se estabilizar em um valor menos nobre que as demais regiões, e praticamente não apresenta essas oscilações típicas da corrosão por pites. Entretanto, a diferença entre os PCA das diferentes regiões é de apenas $50 \mathrm{mV}$, indicando que o efeito de polarização quando do acoplamento das diferentes regiões de solda e entre estas e o metal base não deve ser acentuado. 


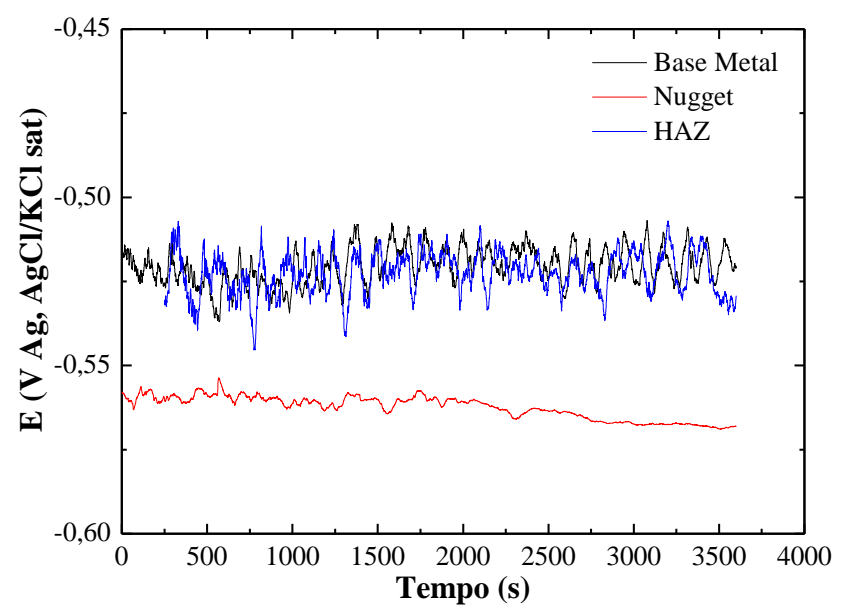

Figura 4-20: Monitoramento do potencial de circuito aberto para as regiões do metal base, $\mathrm{HAZ}$ e nugget em solução de $\mathrm{NaCl} 0,1$ mol.L $\mathrm{L}^{-1}$ durante 1 hora.

A variação do PCA da região nugget pode ser correlacionada com as modificações que ocorrem na microestrutura durante o processo de soldagem. Nesta região atinge-se as temperaturas mais elevadas do processo de soldagem, fazendo com que ocorra uma recristalização dinâmica induzida pela deformação mecânica (JARIYABOON et al, 2007; CRUZ,2009; THREADGILL,2009). Este processo pode ser considerado como sendo semelhante a uma solubilização, onde ocorre uma homogeneização da microestrutura da liga com a introdução do máximo teor de solvente na microestrutura da mesma (ZHANG \&. FRANKEL, 2003), podendo ocorrer também a dissolução de partículas de dimensões nanométricas, responsáveis pelo endurecimento e resistência mecânica da matriz, como já discutido anteriormente. Nesta região as deformações introduzidas pelo trabalho a frio da liga também são aliviadas, sendo documentado que a mesma possui baixa densidade de discordâncias (MAHONEY, 1964), o que pode diminuir a ocorrência de áreas potencialmente ativas para a ocorrência de fenômenos corrosivos na matriz da liga. A diminuição da quantidade de oscilações nos diagramas de PCA quando comparada com as outras regiões ensaiadas, indica uma maior estabilidade da camada de óxido formada sobre o Al na região do nugget confirmando esta possibilidade.

A Figura 4-21 apresenta as curvas de polarização anódica para as diferentes regiões de solda em soluções de $\mathrm{NaCl}$ 0,1 mol.L $\mathrm{L}^{-1}$. É importante destacar que da TMAZ apenas a região dinamicamente recristalizada, representada pelo nugget, está apresentada. Em concordância com as tendências observadas nas curvas de PCA, verifica-se que o potencial de corrosão da região do nugget é inferior ao das outras duas regiões analisadas, 
exibindo também um menor valor de densidade de corrente de corrosão, indicando maior estabilidade. A região do nugget apresenta também uma pequena região passiva, enquanto às demais exibem comportamento ativo, nesta Figura os potenciais de corrosão do metal base e da HAZ coincidem com o potencial de pites determinado para o nugget.

A Figura 4.22 apresenta as curvas de polarização catódica para as diferentes regiões de solda em soluções de $\mathrm{NaCl} 0,1$ mol. $\mathrm{L}^{-1}$ onde observa-se uma menor densidade de corrente para a região do nugget, confirmando a menor atividade eletroquímica para esta região. Por sua vez, maiores densidades de corrente foram determinadas para a HAZ, quando comparada com as demais condições, o que pode ser consequência da formação de partículas mais grosseiras na microestrutura desta região, e que são formadas pelos ciclos térmicos.

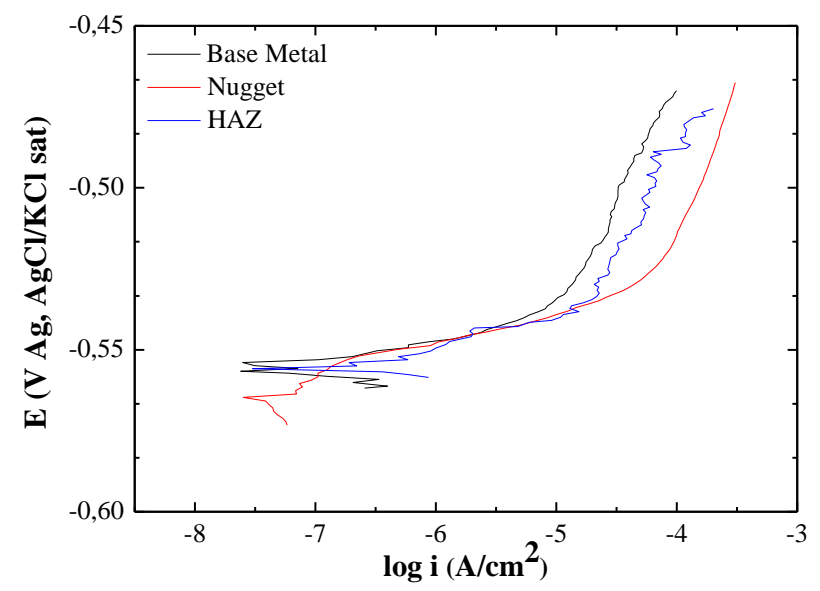

Figura 4-21: Curvas de polarização potenciodinâmica anódica em meio de $\mathrm{NaCl} 0,1$ mol.L ${ }^{-1}$ das regiões da liga de alumínio 2024-T3 soldada por FSW: metal base, HAZ e nugget. 


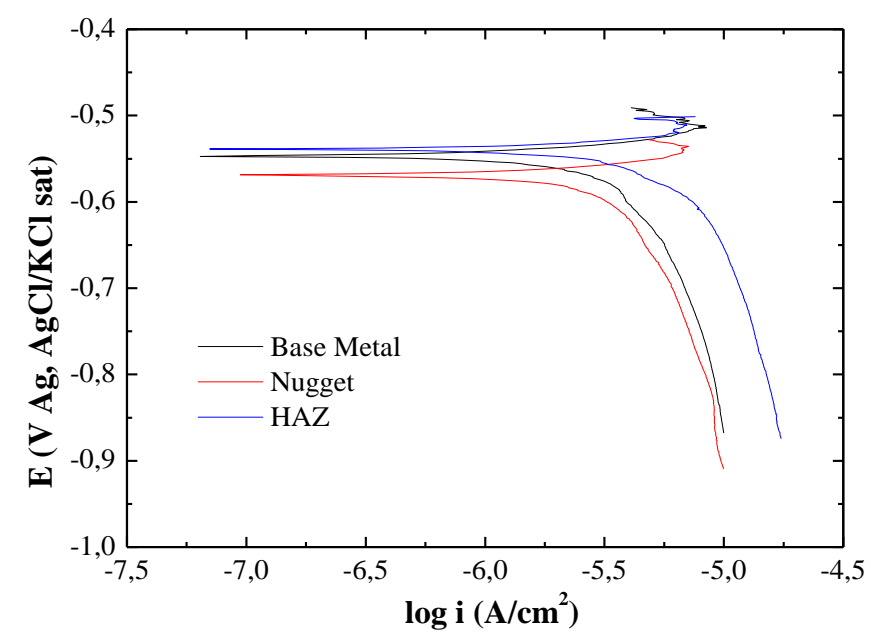

Figura 4-22: Curvas de polarização potenciodinâmica catódica em meio de $\mathrm{NaCl} 0,1$ mol. $\mathrm{L}^{-1}$ das regiões da liga de alumínio 2024-T3 soldada por FSW: metal base, HAZ e nugget.

Os diagramas de impedância para as diferentes regiões da solda da liga AA2024T3 em solução de $\mathrm{NaCl}$ 0,1 mol.L $\mathrm{L}^{-1}$ após uma hora de imersão são apresentados na Figura 4-23. Todos os diagramas são compostos por duas constantes de tempo bem definidas. A constante de tempo em altas frequências pode ser atribuída à resposta mista da fina camada de óxido presente na superfície da liga em série com a resistência de transferência de cargas (AOKI, et al., 2001)) enquanto as constantes de tempo em baixas frequências correspondem à resposta das reações de corrosão na interface. A impedância associada à HAZ é nitidamente inferior às demais, e a região do metal base apresentou a melhor resposta de impedância, em concordância com a menor reatividade detectada nos ensaios de corrosão macroscópicos discutidos anteriormente

A Figura 4-24 apresenta os diagramas de impedância para amostras constituídas pelo metal base acoplado à região de solda (nugget + TMAZ + HAZ) em diferentes proporções: 1:1 e 2:1, para efeito de comparação os diagramas apenas do metal base e também da região de solda constituída pelo nugget + TMAZ também são apresentados. Os resultados mostram que os módulos da impedância para as diferentes configurações do eletrodo de trabalho são semelhantes entre si, indicando que o acoplamento entre o metal base e a região de solda não provoca aceleração substanciais dos processos interfaciais devido a efeitos de polarização, como indicado pelas curvas de PCA apresentadas na Figura 4-20. 

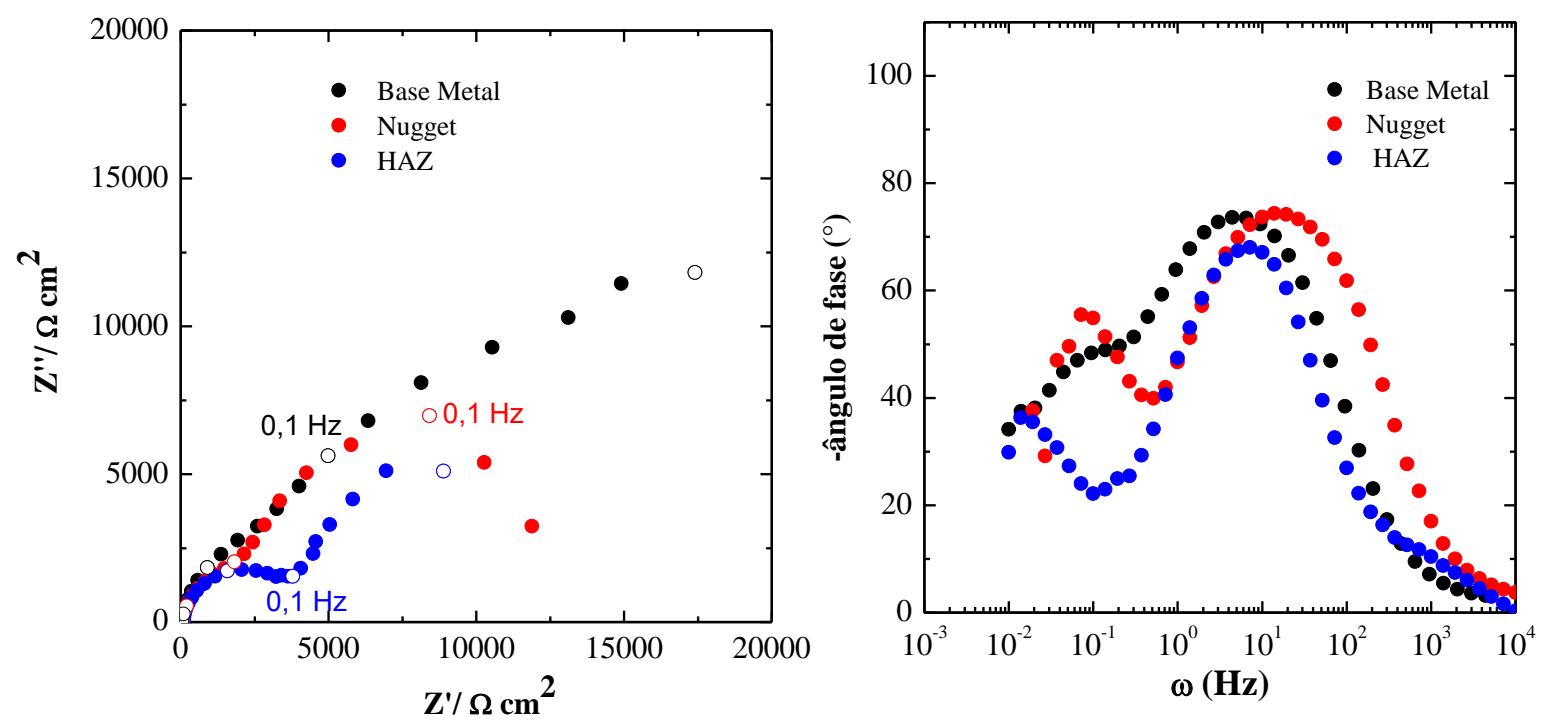

Figura 4-23: Diagramas de impedância em meio de $\mathrm{NaCl} 0,1$ mol.L $\mathrm{L}^{-1}$ para Liga de alumínio 2024 soldada por FSW (a) Diagrama de Nyquist e (b) Diagramas de Bode

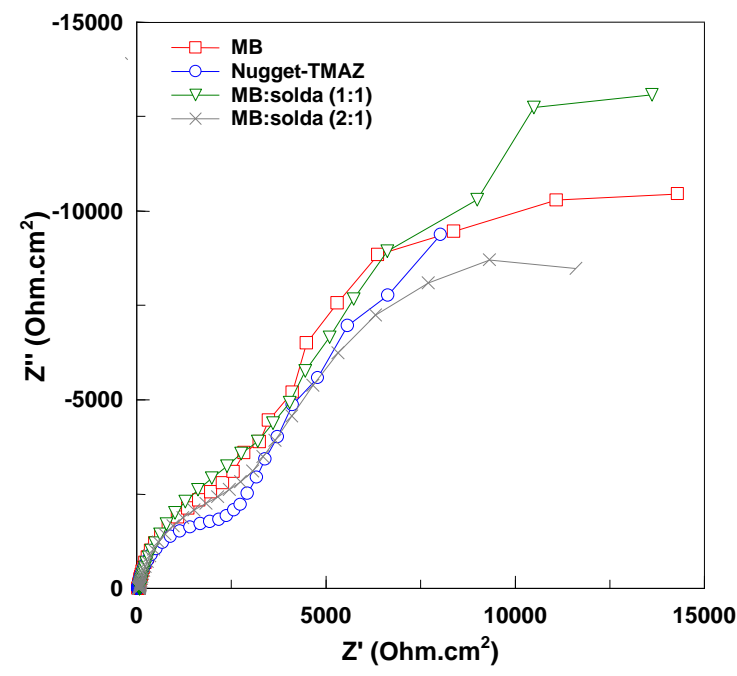

(a)

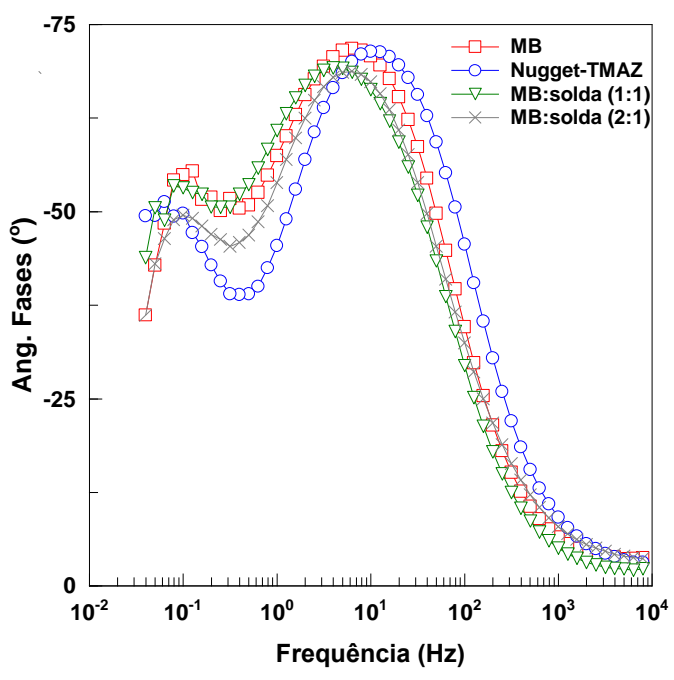

(b)

Figura 4-24: Diagramas de Nyquist (a) e de ângulo de fases (b) para a liga AA2024-T3 soldada por FSW. 


\subsection{ENSAIOS ELETROQUÍMICOS UTILIZANDO A MICROCÉLULA}

Para avaliar o comportamento eletroquímico de cada uma das diferentes regiões originadas durante o processo de soldagem foi construída uma microcélula. No início optou-se por separar cada uma das regiões de solda individualmente e construir eletrodos a partir destas, porém, devido às pequenas dimensões das mesmas, o trabalho mecânico não permite separá-las, principalmente no que concerne às regiões do nugget e da TMAZ. Por isto, durante o período, foi desenvolvida uma microcélula para isolar cada uma das regiões das peças e estudar seus comportamentos eletroquímicos individuais. Esta metodologia, além de permitir uma fácil separação de cada uma das regiões, também elimina os efeitos de borda presentes em eletrodos embutidos, e que são particularmente problemáticos quando estes apresentam pequenas dimensões. Além do mais, sob o ponto de vista estatístico, pode-se realizar diversas medidas sobre diferentes regiões de uma mesma peça para avaliar a reprodutibilidade.

Alguns autores utilizaram microcélulas para a avaliação do comportamento eletroquímico das diferentes regiões de solda geradas durante o processo de FSW de ligas de alumínio. Jariyaboon et al. (2007) empregaram esta metodologia para obter curvas de polarização e registrar a variação do potencial de circuito aberto da liga de alumínio 2024T3 soldada por FSW sob diferentes condições. Este mesmo autor (Jariyaboon et al., 2009) usou uma microcélula para avaliar o efeito de um tratamento criogênico aplicado durante a soldagem no comportamento de corrosão das diferentes regiões da solda. Bousquet et al. (2011b, 2012) utilizaram uma microcélula para obter o potencial de corrosão das diferentes regiões de solda, comparando-os com os resultados de medidas de microdureza. Que seja de nosso conhecimento, a espectroscopia de impedância eletroquímica utilizando uma microcélula ainda não foi empregada para a avaliação do comportamento eletroquímico das diferentes regiões de uma solda produzida por FSW em ligas alumínio.

A microcélula desenvolvida, de área $0,031 \mathrm{~cm}^{2}$, foi empregada utilizando eletrodos de referência (microeletrodo de $\mathrm{Ag} / \mathrm{AgCl}$ fabricado no laboratório) e contraeletrodo constituído por uma fina lâmina de Pt. Para a construção do microeletrodo (Figura 4-25.) foi utilizado um fio de prata com aproximadamente $1 \mathrm{~mm}$ de diâmetro. Inicialmente, o fio foi polido com lixa d'água até 1200 (óxido de silício). Em seguida foi depositado $\mathrm{AgCl}$ sobre o mesmo, mantendo-se um potencial constante de 1,3 V (Ag/AgCl) por um período de tempo de 400 segundos em uma solução de $\mathrm{KCl}$ saturada. A deposição foi realizada 
utilizando uma célula convencional de três eletrodos: eletrodo de referência de $\mathrm{Ag} / \mathrm{AgCl}$, contraeletrodo de Pt e o fio de prata como eletrodo de trabalho. Em seguida da deposição, o fio foi introduzido em uma ponta de pipeta plástica na qual havia sido previamente fixado, sob pressão, um pedaço de separador de bateria com o objetivo de permitir o contato eletrolítico.

O bom funcionamento do microeletrodo de referência foi verificado registrandose voltamogramas para a $\mathrm{Pt}$ em solução de $\mathrm{K}_{3}\left[\mathrm{Fe}(\mathrm{CN})_{6}\right]$ e comparando-os com voltamogramas obtidos com eletrodo de referência comercial. Exemplos de voltamogramas obtidos são apresentados na Figura 4-26.

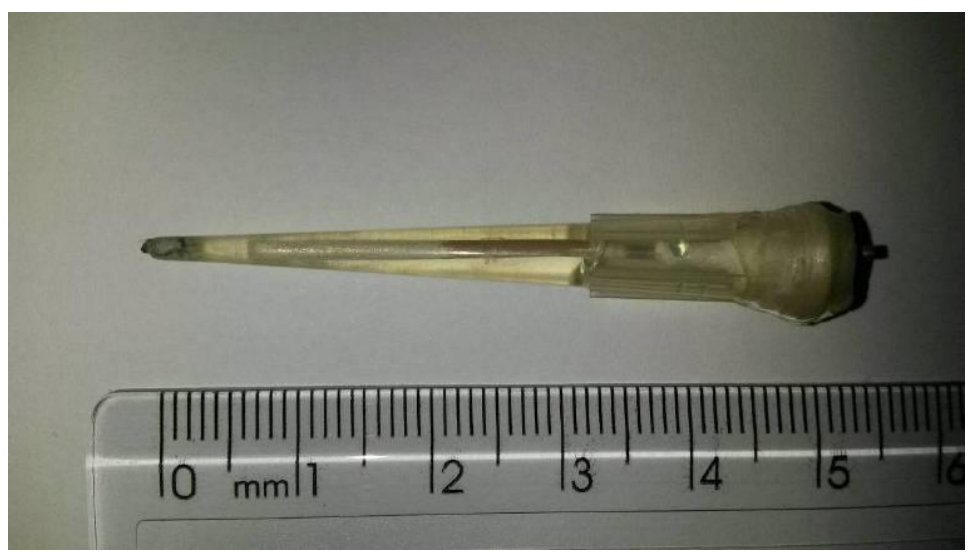

Figura 4-25: Fotografia do microeletrodo de referência de $\mathrm{Ag} / \mathrm{AgCl}_{\text {sat }}$.

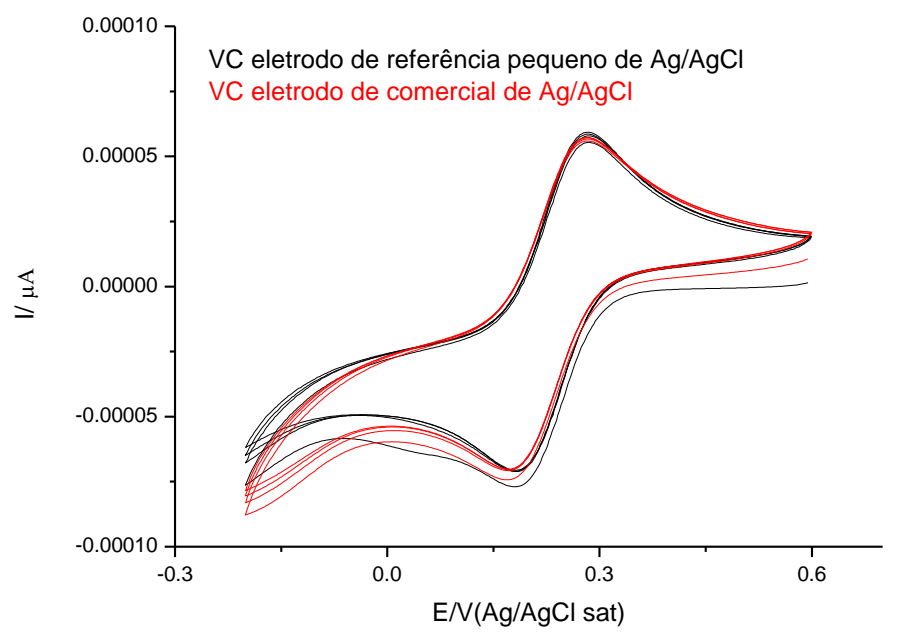

Figura 4-26: Comparação entre voltamogramas obtidos com o microeletrodo de referência de $\mathrm{Ag} / \mathrm{AgCl}$ e eletrodo comercial de $\mathrm{Ag} / \mathrm{AgCl}$. Pt em solução de $\mathrm{K}_{3}\left[\mathrm{Fe}(\mathrm{CN})_{6}\right]$. 
A variação do PCA em solução de $\mathrm{NaCl} 0,1$ mol.L ${ }^{-1}$ para o metal base e para as diferentes regiões da solda produzidas estão apresentados na Figura 4-27. Os potenciais de corrosão das diferentes regiões de solda foram semelhantes e inferiores ao do metal base em aproximadamente $50 \mathrm{mV}$, entretanto, estes apresentaram fortes oscilações, típicas de uma superfície que está passando por processo de corrosão por pites, com nucleação e repassivação. Em virtude disto os experimentos de EIS, apresentados a seguir, tiveram sua frequência limitada a $100 \mathrm{mHz}$, de modo a garantir a estacionaridade. As oscilações no potencial devem ser consequências do pequeno volume de solução no interior da microcélula, tornando o meio mais agressivo.

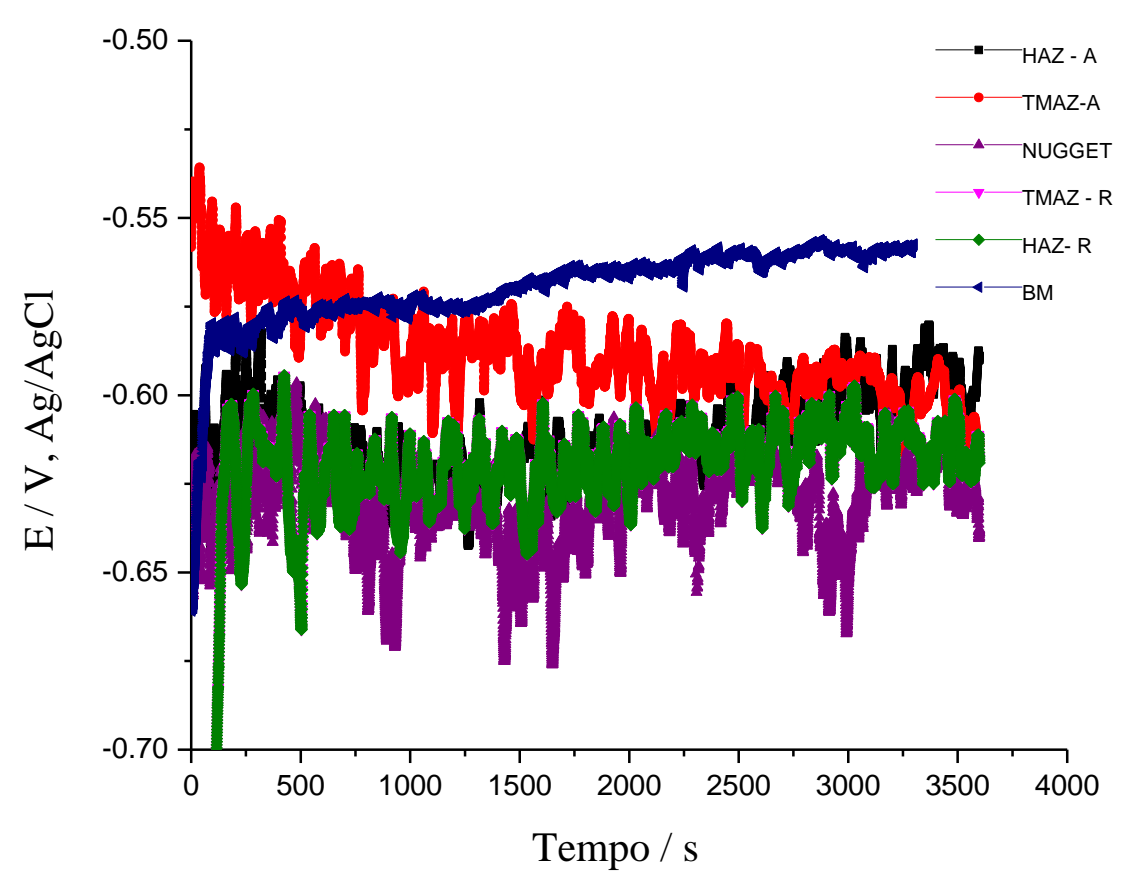

Figura 4-27: Monitoramento do potencial de circuito aberto em solução de $\mathrm{NaCl} 0,1$ mol. $L^{-1}$ para as diferentes regiões de solda da liga de alumínio 2024-T3 soldada por FSW. BM - base metálica; HAZ - A - zona termicamente afetada no lado do avanço; TMAZ A - zona termomecanicamente afetada lado do avanço; nugget; TMAZ - $\mathrm{R}$ zona termomecanicamente afetada no lado do retrocesso; HAZ - R - zona termicamente afetada no lado do retrocesso.

Os diagramas de impedância após uma hora de imersão em solução de $\mathrm{NaCl}$ 0,1 mol. $L^{-1}$ para o metal base e para as diferentes regiões da solda da liga de alumínio 2024T3 são apresentados na Figura 4-28. Os módulos de impedância das regiões de solda foram diferentes entre si e em relação ao metal base, confirmando a reatividade heterogênea através da zona afetada pelo processo, o que está de acordo não só com os 
testes de corrosão realizados anteriormente como com a maioria dos trabalhos consultados na literatura. Os diagramas de Nyquist associados tanto ao metal base como às diferentes regiões de solda são constituídos por apenas um arco capacitivo achatado, e os diagramas de ângulo de fases apresentaram-se bastante deformados, indicando a sobreposição de constantes de tempo. A resposta de impedância do metal base foi superior à de todas as regiões de solda, e, dentre estas, o nugget apresentou o maior valor de impedância, o que está de acordo com os ensaios globais apresentados anteriormente. Os resultados mostram também que as regiões com menores valores de impedância, e, portanto, menos resistentes à corrosão, encontram-se nas zonas afetadas pelo calor, HAZ e TMAZ, do lado do avanço, o que está de acordo com os testes de visualização com ágar-ágar, e com os testes de esfoliação e de resistência intergranular. A maior reatividade da HAZ e da TMAZ também está de acordo com os resultados reportados por Jariyaboon et al. (2009) para uma liga 2024-T351, embora estes autores não tenham identificado se a região mais reativa se encontrava do lado do avanço ou do retrocesso. Por sua vez, no trabalho de Bousquet et al. (2011) a região de menor resistência à corrosão se situou entre a HAZ e a TMAZ, portanto com localização semelhante ao obtido no presente estudo, mas, aparentemente, do lado do retrocesso. Entretanto, é importante destacar que resultados encontrados no LPE (PMT-EPUSP) e também por outros autores (JARIYABOON, et al., 2007) mostram que a posição da região mais reativa varia com as condições de soldagem. A Tabela 4 do artigo de Threadgill at al. (2009) mostra claramente esta variabilidade, o que deve ser consequência tanto do histórico termomecânico dos diferentes materiais, como também das condições de soldagem.

Os resultados dos ensaios de EIS revelam uma forte correlação com os ensaios de microdureza apresentados na Figura 4-28. Assim, o metal base seguido do nugget apresentaram os maiores módulos de impedância, sendo esta também a sequência para as microdurezas. Por sua vez, as zonas mais macias do cordão de solda se situaram do lado do avanço (HAZ e TMAZ), sendo estas as que exibiram os menores de valores de impedância. Ressalta-se ainda, que como consolidado no parágrafo anterior, nos ensaios de corrosão macroscópicos estas duas zonas também exibiram maior suscetibilidade à corrosão.

Diversos autores têm realizado medidas de microdureza em estudos de corrosão de ligas de alumínio soldadas por FSW com a finalidade mapear as mudanças microestruturais resultantes do processo (PAGLIA \& BUCHHEIT, 2006) (PROTON, et al., 2011), (JARIYABOON, et al., 2007), (BOUSQUET, POULON-QUINTIN, 
PUIGGALI, DEVOS, \& TOUZET, 2011). Isto não é surpreendente, uma vez que, como amplamente documentado na literatura, existe uma forte correlação entre medidas de dureza e as mudanças que ocorrem na microestrutura das ligas de alumínio de elevada resistência mecânica em função do envelhecimento/aquecimento (RINGER \& HONO, 2000); (SILCOK, 1960-1961) (GENEVOIS, DESCHAMPS, DENQUIN, \& DOISNEAU-COTTIGNIES, 2005). Enquanto nos trabalhos consultados, claramente, a região de solda apresenta menor dureza que o metal base, não foi possível estabelecer uma correlação direta entre dureza e resistência à corrosão. Assim, nos estudos realizados por Proton et al.(2011) e por Paglia e Buchheit (2006), desenvolvidos, respectivamente, com ligas $\mathrm{Al}-\mathrm{Cu}-\mathrm{Li}$ (tratada termicamente) e $\mathrm{Al}-\mathrm{Cu}$, verificou-se que a região de solda apresentava menor dureza e maior resistência à corrosão. Por sua vez, no trabalho de Bousquet et al. (2011), realizado com uma liga 2024-T351, a zona mais suscetível à corrosão foi a HAZ próxima à TMAZ, aparentemente do lado do retrocesso, onde os autores observaram um forte gradiente de dureza. Finalmente, no estudo de Jariyaboon et al. (2007), também desenvolvido com a liga 2024-T351 e onde se investigou o efeito dos parâmetros de soldagem sobre a resistência à corrosão da liga soldada, verificou-se que, para algumas das condições de soldagem empregadas, a região menos resistente à corrosão correspondeu àquela com menor dureza, enquanto para outras isto não foi observado. Assim, os diferentes autores correlacionam a alteração na resistência à corrosão à redistribuição dos precipitados de endurecimento (alinhamento em contornos de grão e engrossamento) na microestrutura da liga, sendo as análises fortemente apoiadas em micrografias obtidas por MEV e TEM.

No presente trabalho verificou-se que, em todas as regiões de solda, ocorreu uma diminuição na densidade de nanoprecipitados em relação à matriz, o que justifica a menor dureza encontrada nas mesmas (análises por MEV e por TEM). Além do mais, nas regiões mais suscetíveis à corrosão (HAZ e TMAZ) verificou-se, além do engrossamento dos nanoprecipitados, tendência para a precipitação nos contornos de grão (análises por MEV e TEM). Finalmente, no nugget, apesar de ter sido observado tendência para o engrossamento das nanopartículas, não foi observada a precipitação nos contornos de grão, o que justifica a maior resistência à corrosão verificada nesta região em relação às demais regiões de solda, e também o fato da mesma não ter apresentado tendência à corrosão intergranular. 

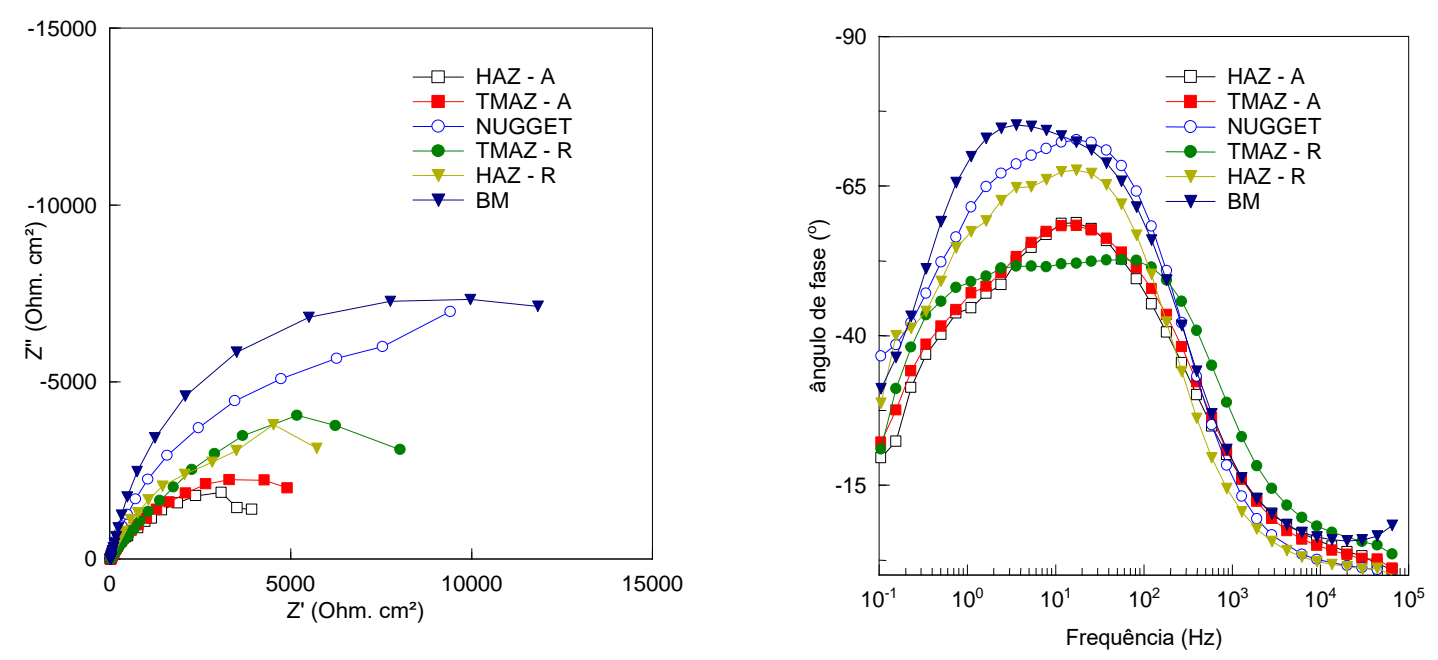

Figura 4-28: Diagramas de impedância em solução de $\mathrm{NaCl} 0,1$ mol.L $\mathrm{L}^{-1}$ para as diferentes regiões de solda da liga de alumínio 2024-T3 soldada por FSW. BM - base metálica; HAZ - A - zona termicamente afetada no lado do avanço; TMAZ - A - zona termomecanicamente afetada lado do avanço; nugget; TMAZ - $\mathrm{R}$ zona termomecanicamente afetada no lado do retrocesso; HAZ - R - zona termicamente afetada no lado do retrocesso.

\section{(SVET)}

\subsection{ENSAIOS COM ELETRODO VIBRATÓRIO DE VARREDURA}

Nos mapas de SVET, as intensidades de corrente anódica são representadas pelos valores positivos (cor vermelha) e as catódicas pelos valores negativos (cor azul). Os mapas de corrente associados às imagens do eletrodo composto pelo nugget e pelas zonas TMAZ do lado do avanço e do retrocesso obtidos após 0h, 3h, 6h de imersão em solução de $\mathrm{NaCl}$ 0,05 mol.L ${ }^{-1}$, estão apresentados na Figura 4-29. Esta Figura mostra que desde os instantes iniciais da imersão (zero hora- Figura 4-29 (a)), uma atividade anódica se desenvolve no lado avanço da região da TMAZ enquanto na região do nugget e do lado retrocesso observa-se atividade catódica. A observação de atividade eletroquímica de forma tão imediata está de acordo com o relatado por Hughes et al. (2010) que verificaram a ocorrência de corrosão localizada associada aos IMs apenas alguns minutos após a imersão da liga 2024 em solução de $\mathrm{NaCl} 0,1 \mathrm{~mol} \mathrm{~L}^{-1}$, este processo estaria associado à ativação de IMs isolados, particularmente a fase $\mathrm{S}\left(\mathrm{Al}_{2} \mathrm{CuMg}\right)$. Após 3 horas de imersão as densidades de correntes anódicas aumentam na região do avanço, enquanto observa-se também um aumento das regiões catódicas na região do retrocesso. Após 6 horas de imersão (9 (b)) as densidades de correntes anódicas continuam aumentando na região do avanço, enquanto observa-se também um aumento das regiões catódicas acompanhada de 
um início de atividade anódica, na região do retrocesso. Estas regiões permanecem fixas, indicando o desenvolvimento de pites estáveis.

Após 12 horas de imersão (Figura 4-30(a)) observa-se uma diminuição nas densidades de correntes anódicas na região do avanço, no entanto, a região anódica, nesta região, passa a se propagar para a uma região mais próxima do nugget, enquanto aumentase a densidade de corrente catódica na parte superior da região do avanço. Este processo pode estar associado à formação de produtos de corrosão sobre os pites estáveis, impedindo a detecção da corrente em sua superfície, destaca-se que a atividade corrosiva pode continuar a ocorrer em profundidade através da microestrutura da liga. A formação de domos de produtos de corrosão sobre regiões anódicas tem sido reportada na literatura (HUGHES, et al., 2010) (HUGHES, et al., Corrosion of AA2024-T3 Part II, 2011). Na região do retrocesso a densidade de corrente catódica apresenta-se estável. Após 20 horas de imersão (Figura 4-30(b)) as densidades de correntes catódicas na região do retrocesso continuam a diminuir e verifica-se o início de correntes anódicas nesta região. Após 24 horas de imersão (Figura 4-30(c)) observa-se o retorno da estabilidade das correntes catódicas na parte de cima da região do nugget e a estabilidade das correntes anódicas nas regiões tanto do avanço quanto do retrocesso.

Os resultados apresentados nas Figuras 4-29 e 4-30 estão em concordância com os demais ensaios de corrosão apresentados anteriormente, que mostraram que a região do avanço é mais sensível que à região do retrocesso. 
a)
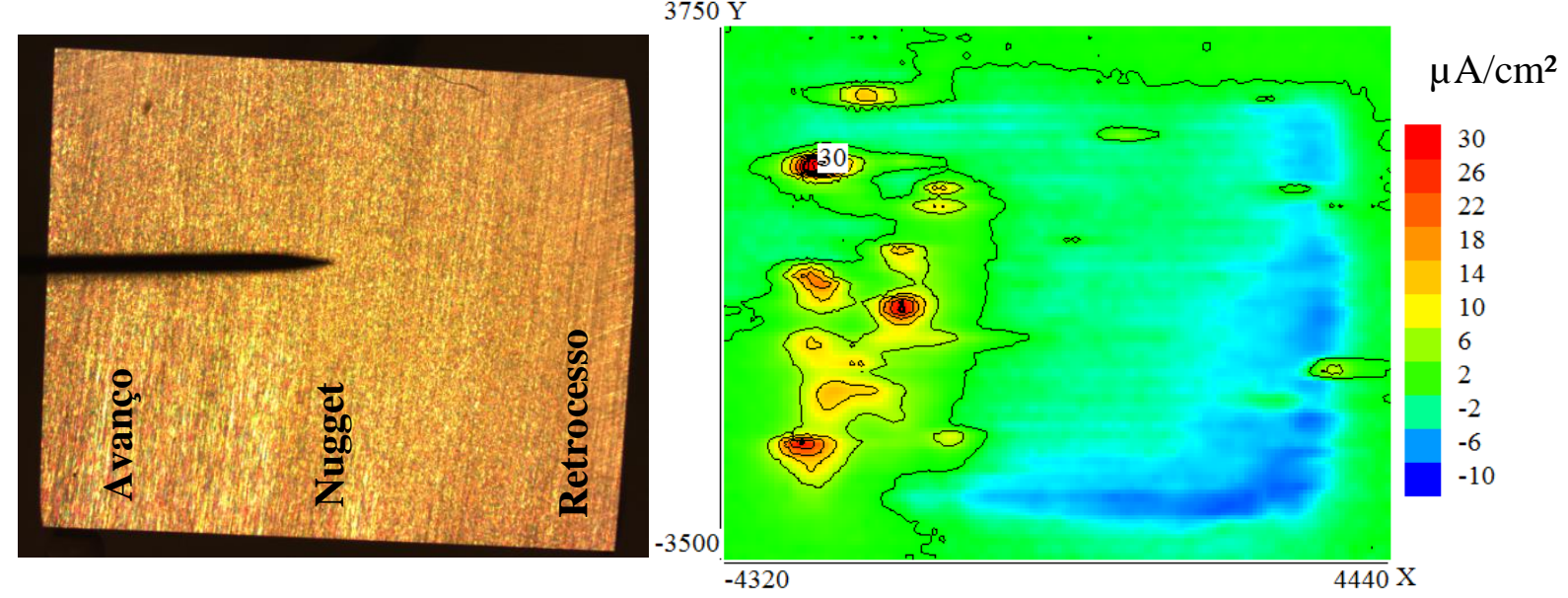

b)

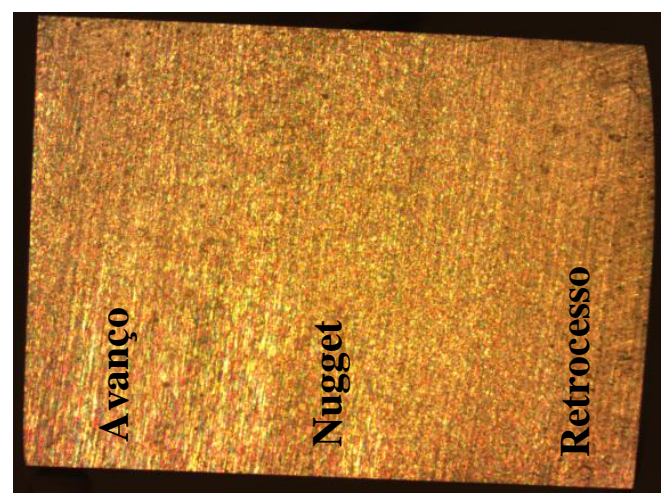

$3750 \mathrm{Y}$

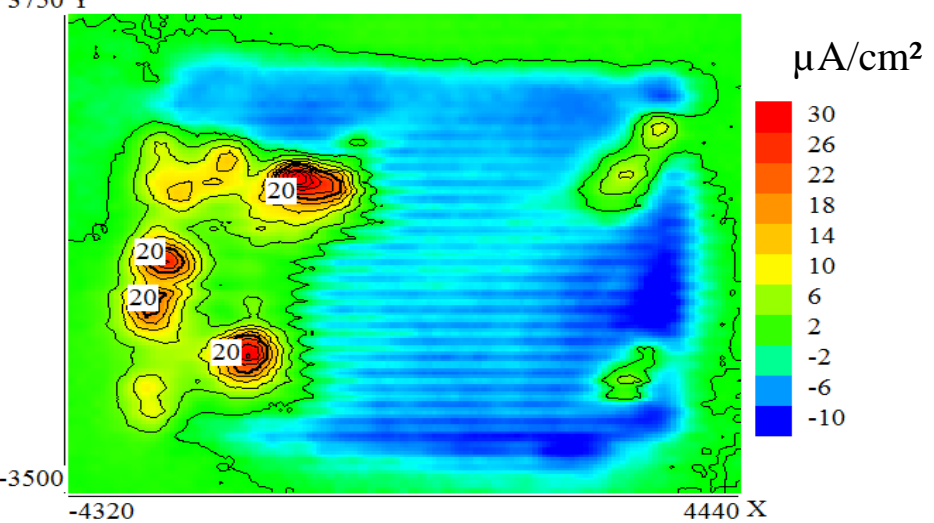

c)

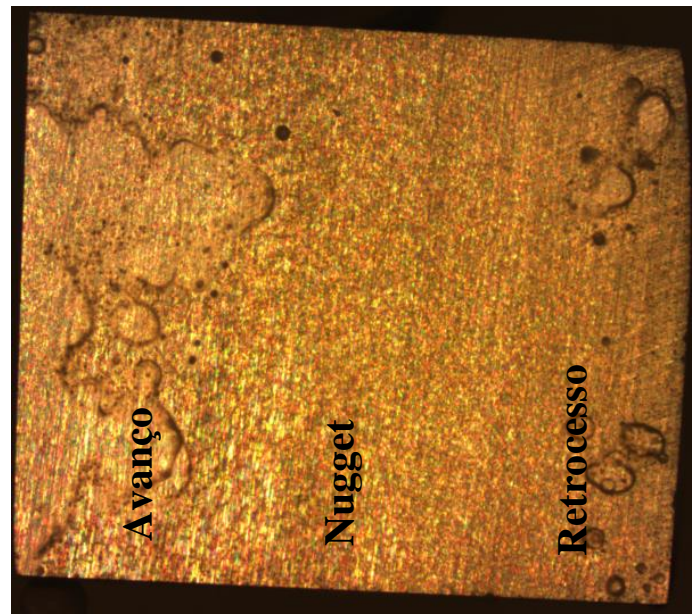

$3750 \mathrm{Y}$

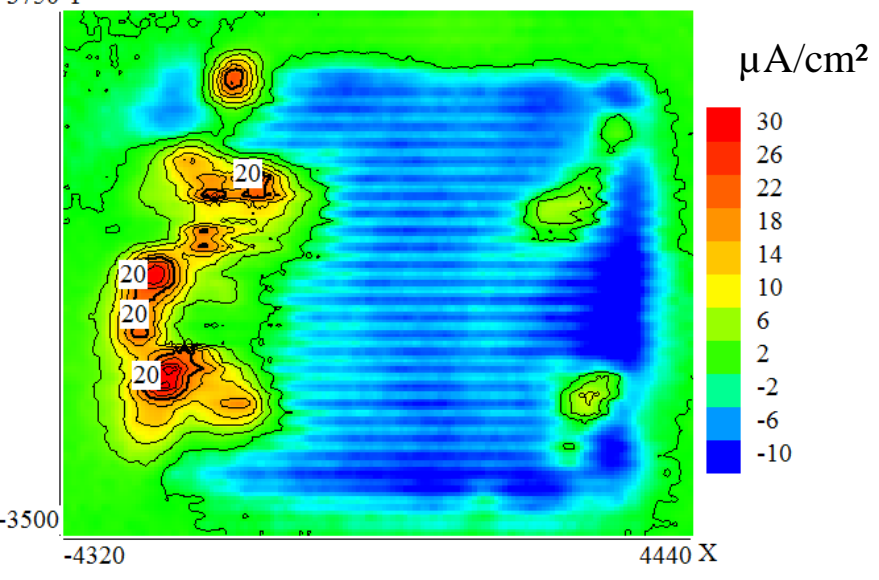

Figura 4-29: Mapas de densidade corrente, obtidos por SVET com as imagens do eletrodo de trabalho (Nugget) após $0 \mathrm{~h}(\mathrm{a}), 3 \mathrm{~h}$ (b), $6 \mathrm{~h}$ (c), de imersão em $\mathrm{NaCl}$ 0,05 mol.L ${ }^{-}$ 1 . 
a)
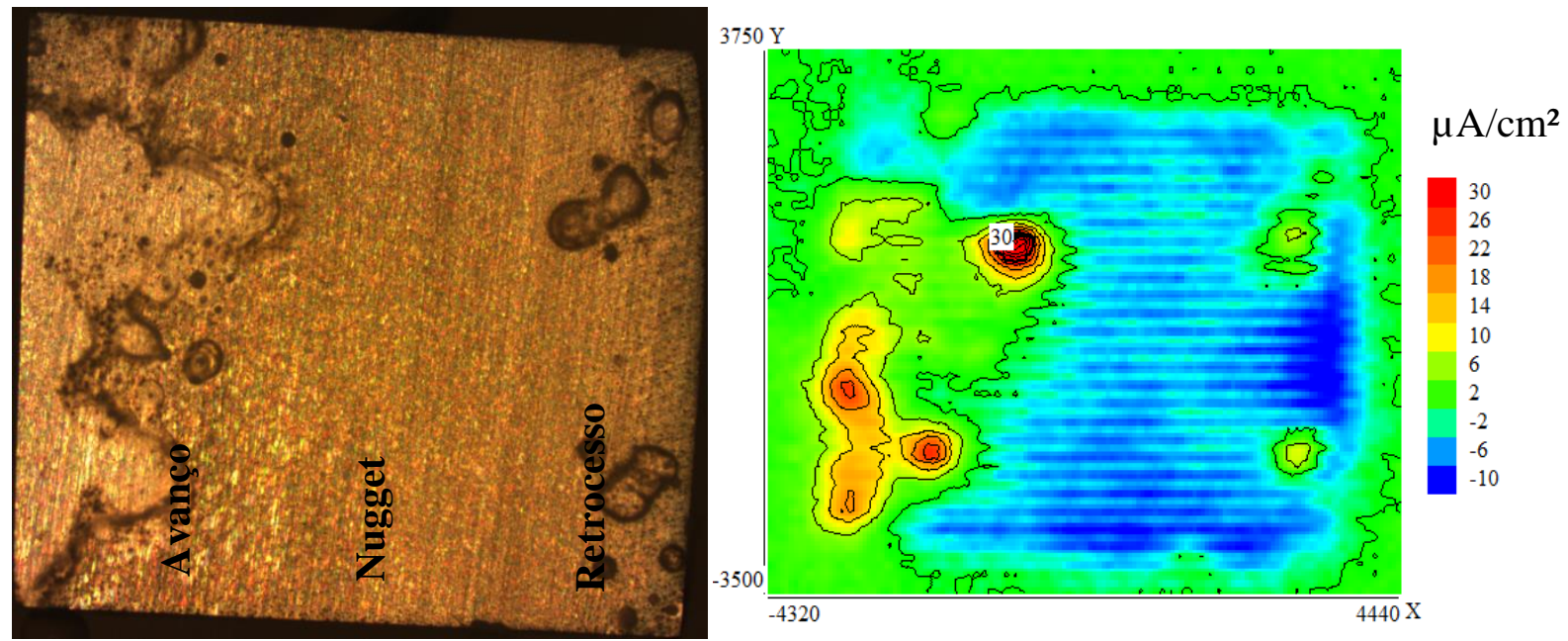

b)

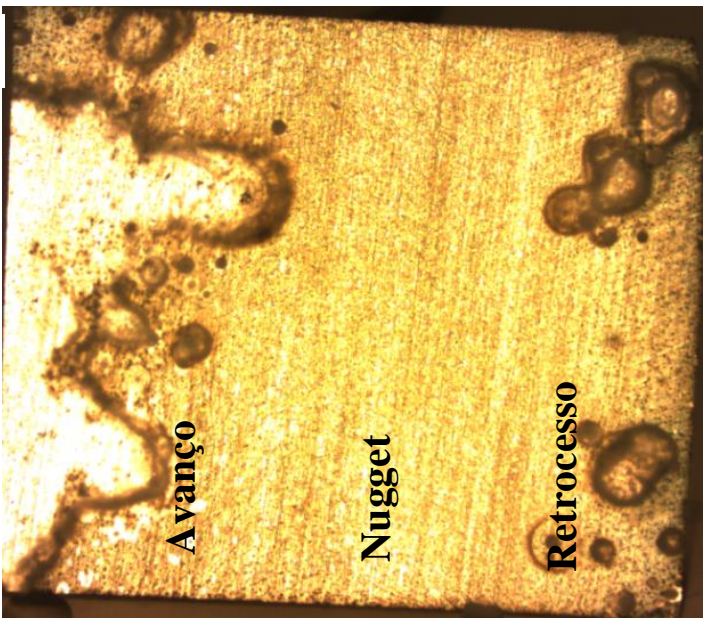

$3750 \mathrm{Y}$

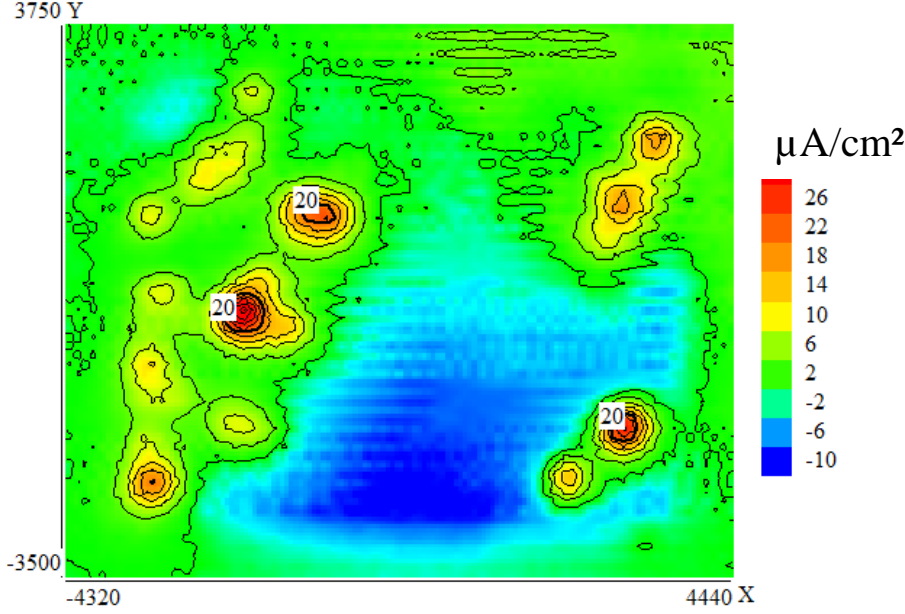

c)

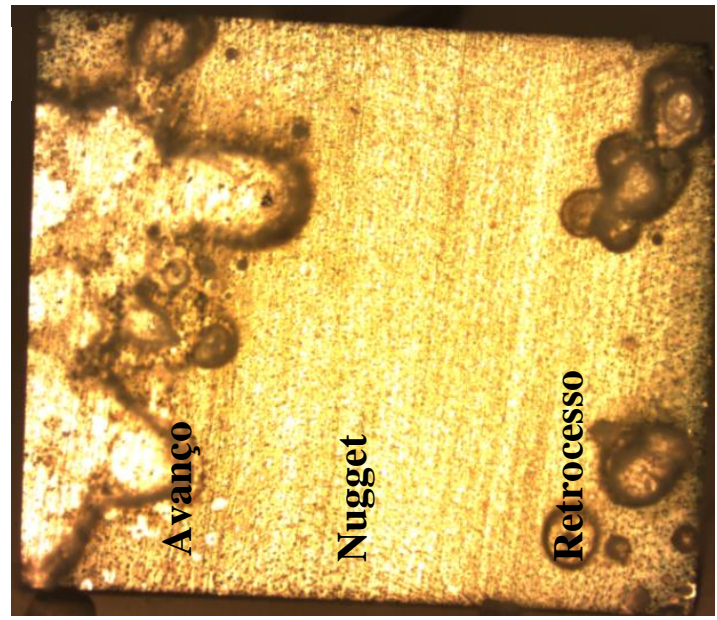

$3750 \mathrm{Y}$

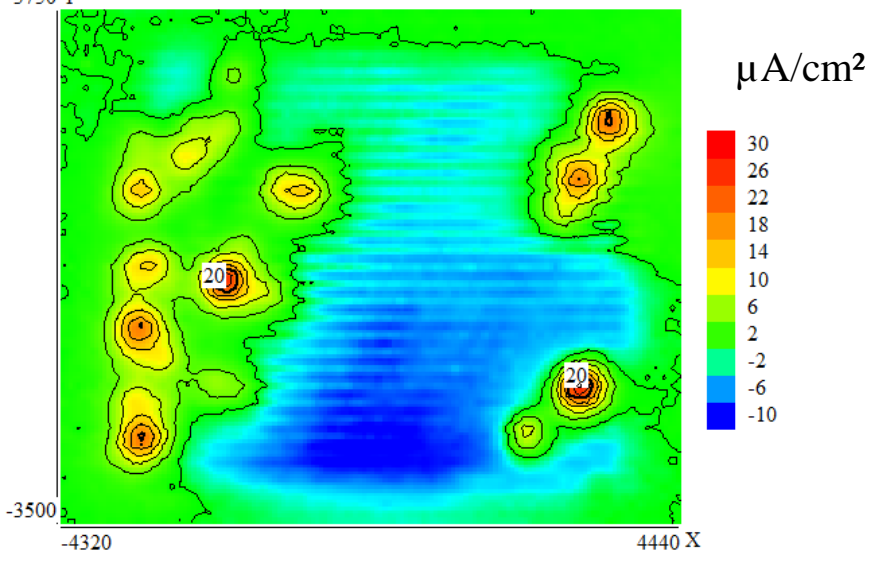

Figura 4-30: Mapas de densidade corrente, obtidos por SVET com as imagens do eletrodo de trabalho (Nugget) após 12h (a), 20h (b) e 24h (c) de imersão em $\mathrm{NaCl}$ 0,05 mol. $\mathrm{L}^{-1}$.

Os mapas de corrente, associados à imagem do eletrodo composto pelas regiões da HAZ, TMAZr e do nugget, foram obtidos após 0h (Figura 4-31 (a)), 3h (Figura 4-31 (b)) e 24h (Figura 4-31 (c)), em solução de $\mathrm{NaCl}$ 0,05mol.L-1 . A Figura 4-31 mostra que 
nos instantes iniciais da imersão (zero hora - (Figura 4-31 (a)), uma atividade anódica se desenvolve na região central da amostra, que corresponde lado do retrocesso da TMAZr. Esta região permanece como ativa durante todo o período de ensaio, entretanto, após 24 horas de imersão (Figura 4-31 (c)) observa-se claramente a diminuição na intensidade da densidade de corrente o que, como já discutido anteriormente, pode ser consequência da precipitação de produtos de corrosão sobre as regiões anódicas.

a)
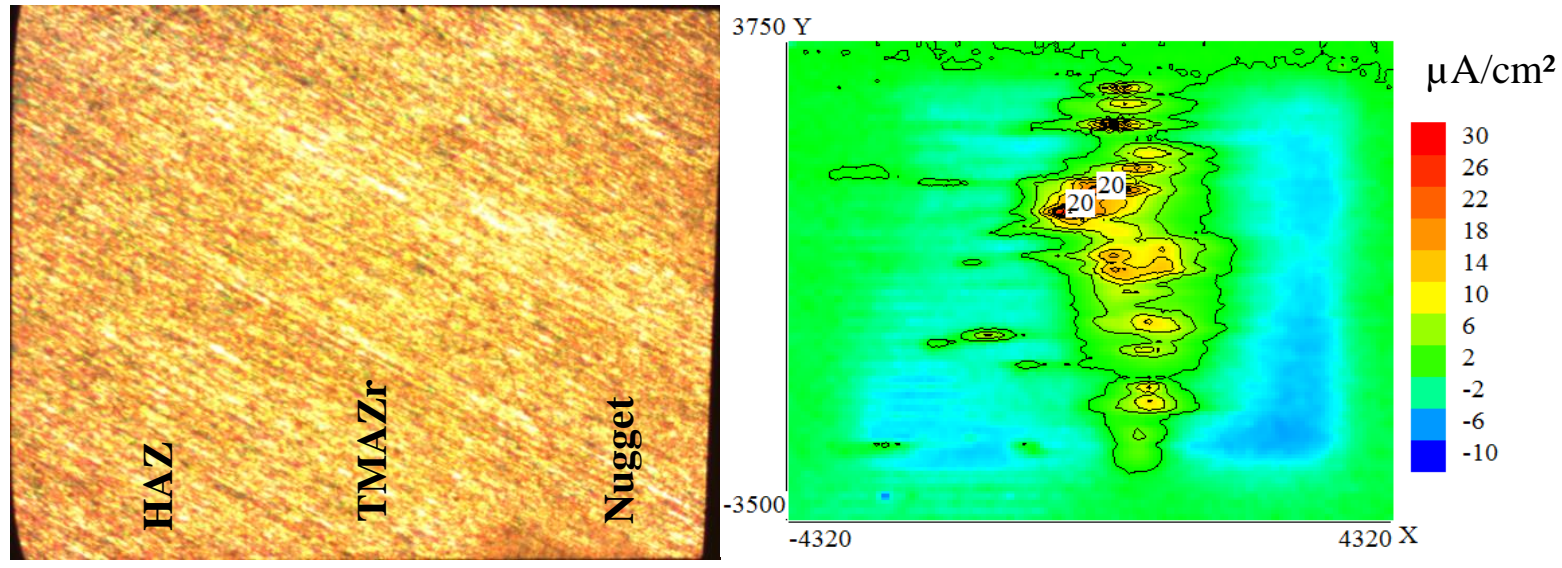

b)
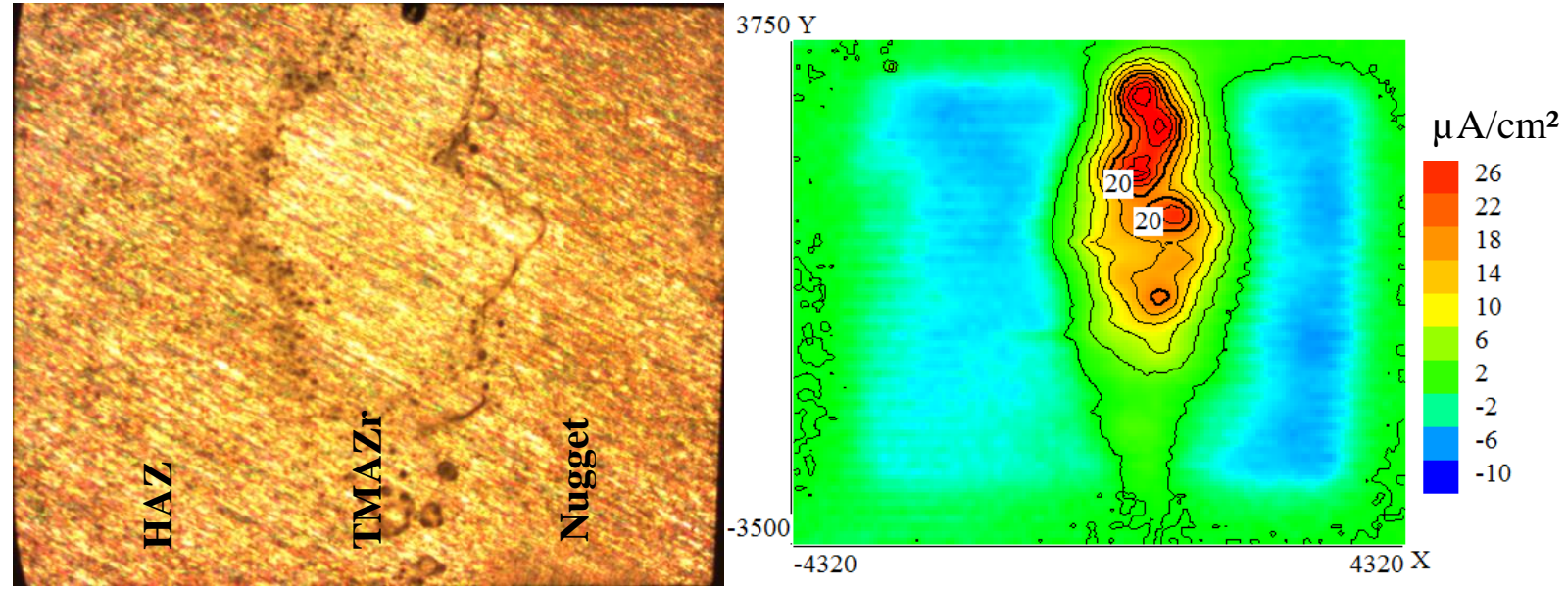

c)
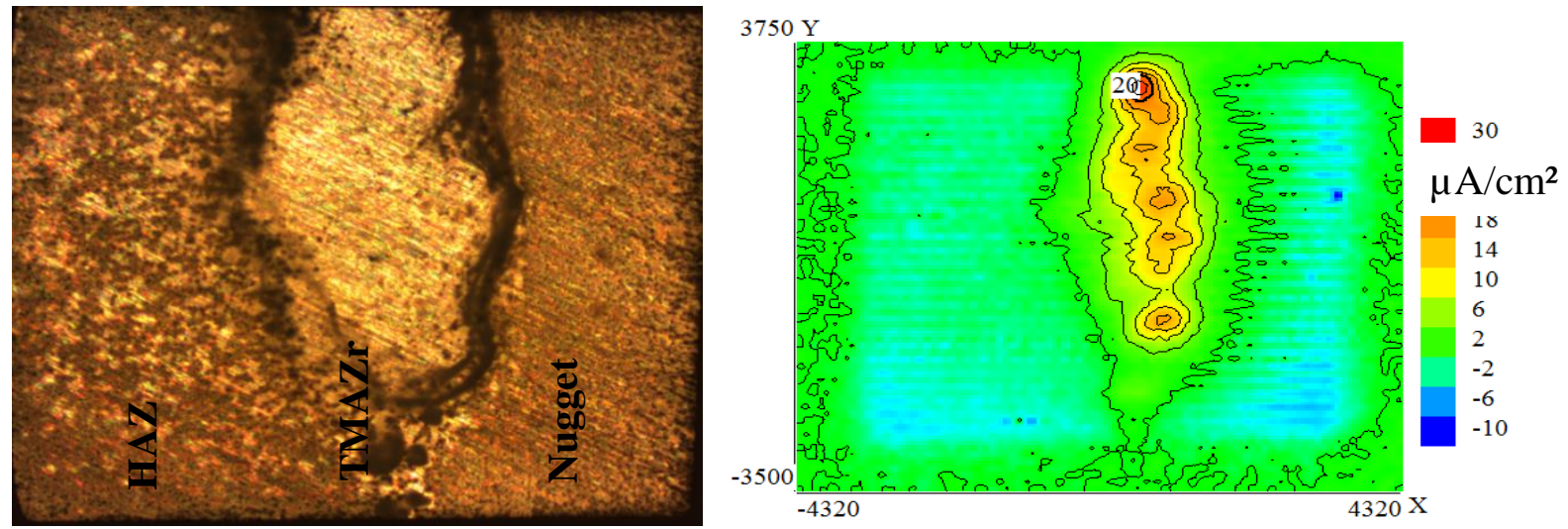

Figura 4-31: Mapas de densidade de corrente, obtidos por SVET com as imagens do eletrodo de trabalho (HAZ, TMAZr e do nugget) após 0h (a), 3h (b) e 24h (c) de imersão em $\mathrm{NaCl}$ 0,05 mol.L $\mathrm{L}^{-1}$. 
A Figura 4-32 apresenta os mapas de SVET obtidos para o eletrodo constituído pelo HAZ, TMAZ e nugget do lado do avanço, eles guardam as mesmas características já discutidas com relação à Figura 4-31: a zona mais sensível à corrosão é a TMAZ e a intensidade da densidade de corrente local diminui para tempos mais longos de ensaio. Entretanto, a comparação das intensidades das densidades de corrente desenvolvidas nesta amostra, com aquelas da Figura 4-31 (regiões similares mas do lado do retrocesso), mostra que os valores são mais elevados, mais uma vez corroborando com as observações dos ensaios anteriores que demonstraram que a região do retrocesso é mais suscetível à corrosão que a região do avanço.

a)
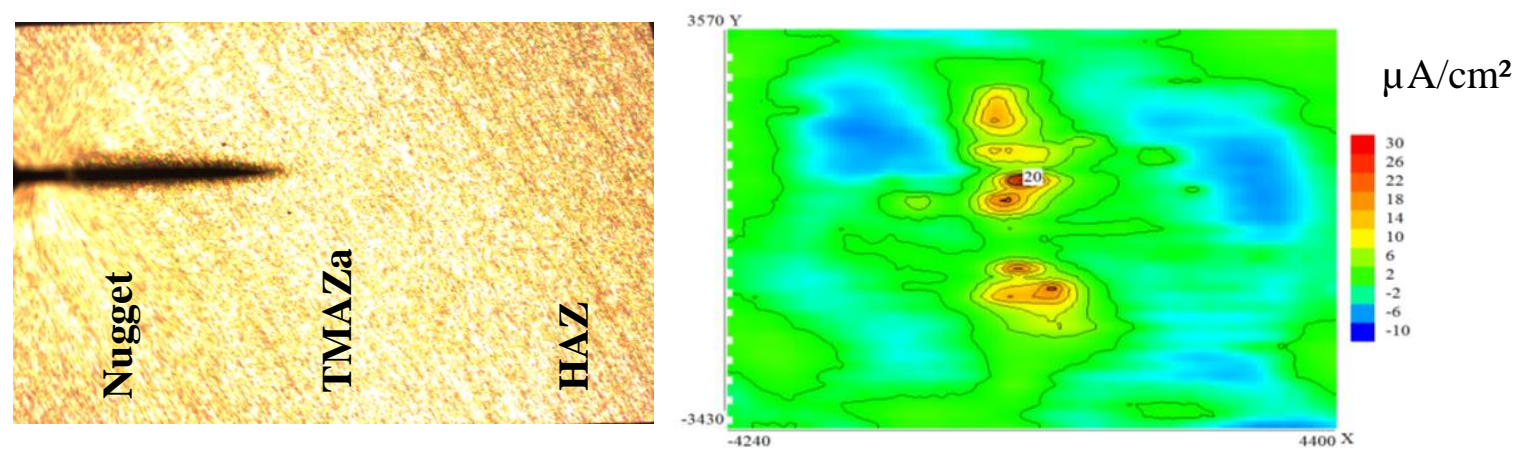

b)
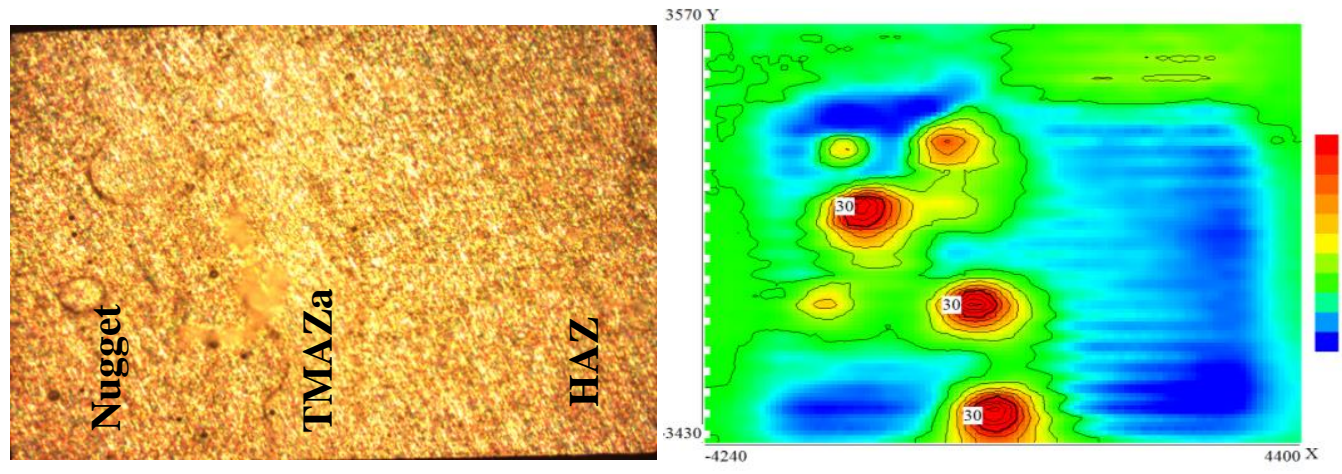

c)
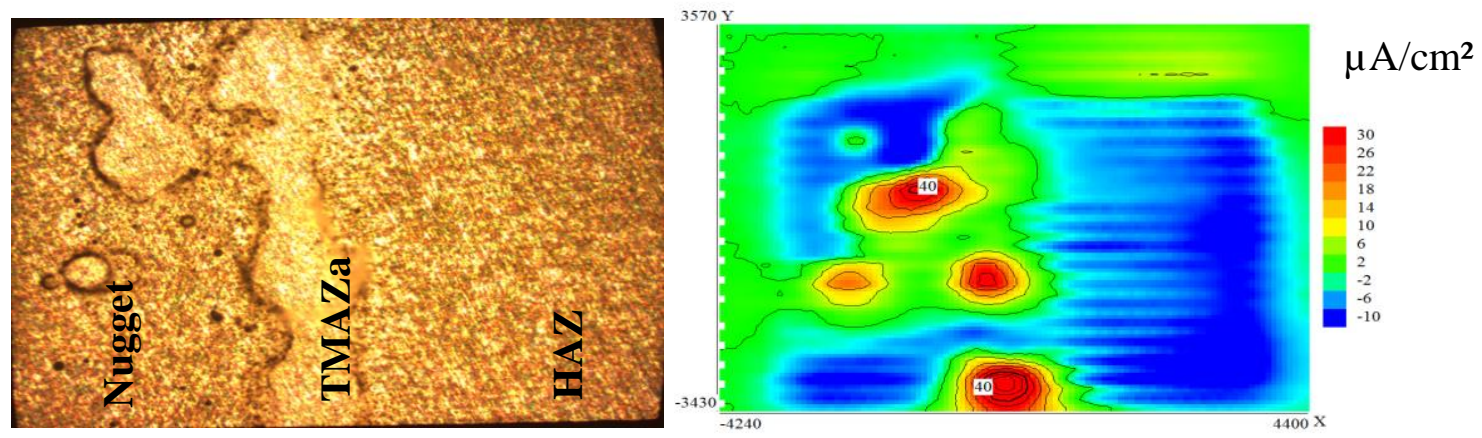

Figura 4-32: Mapas de densidade de corrente, obtidos por SVET com as imagens do eletrodo de trabalho (HAZ, TMAZa e do nugget) após 0h (a), 3h (b) e 24h (c) de imersão em $\mathrm{NaCl} 0,05$ mol.L ${ }^{-1}$. 


\subsection{ESPECTROSCOPIA DE IMPEDÂNCIA LOCAL (LEIS)}

As medidas de LEIS foram realizadas em meio $\mathrm{NaCl} 0,1$ mol.L $\mathrm{L}^{-1}$ sobre amostras da liga AA 2024-T3 contendo a região soldada por FSW e também o metal base, e teve por objetivo tanto avaliar, dentre as regiões geradas pela solda, qual é a mais susceptível à corrosão, bem como verificar se a formação de pares galvânico entre as diferentes regiões influencia no comportamento de impedância local das diferentes regiões. Os diagramas foram obtidos depois de imersão do eletrodo de trabalho no eletrólito teste. A Figura 4-33 (a) apresenta os diagramas de impedância global registrados durante a realização dos ensaios locais, já que a montagem utilizada permite o registro simultâneo das duas impedâncias. Observa-se que estes exibem as mesmas características dos apresentados anteriormente (Figura 4-23 e Figura 4-24), sendo constituídos de dois arcos capacitivos, cujas possíveis origens já foram discutidas.

Os diagramas de impedância local (Figura 4-33(b)) apresentam as mesmas características dos globais na região de altas para médias frequências, com um arco capacitivo com impedância da mesma ordem de grandeza, confirmando a adequabilidade da montagem para aquisição dos dados. Entretanto, devido à dispersão, o limite de frequências utilizado para a aquisição dos dados em BF foi de aproximadamente $10 \mathrm{mHz}$, não permitindo verificar a existência de diferenças entre os módulos de impedância das diferentes regiões de solda, de modo a poder classifica-las como mais ou menos resistentes à corrosão, como feito nos ensaios realizados com a microcélula e como verificado nos ensaios macroscópicos de corrosão.

A Figura 4-33(c) apresenta um aumento da região indicada por um quadrado nos diagramas de impedância local da Figura 4-33(b). Observa-se a presença de componentes imaginárias na região de altas frequências, que, no presente estudo, são constituídas por linhas paralelas que se deslocam progressivamente à medida que o bieletrodo é deslocado sobre a superfície da amostra a partir do metal base, passando por toda a região da solda e terminando mais uma vez sobre o metal base. Trabalhos realizados por Huang et al.(2007a) Huang et al.(2007b) e Huang et al.(2007c) demonstraram que a resposta imaginária na região em altas frequências nos diagramas de impedância local está associada à impedância ôhmica local. Esta corresponde a uma relação entre a diferença de potencial entre um eletrodo de referência situado imediatamente no exterior da dupla camada difusa e um outro eletrodo de referência posicionado idealmente no infinito e a corrente local, esta última determinada a partir da diferença de potencial medida pelas 
duas sondas do bieletrodo (Equação 3-2) estando incluída na medida de impedância local (HUANG et al.,2007a) (FERRARI, 2011) Este tipo de resposta AF já havia sido observado no primeiro trabalho sobre espectroscopia de impedância eletroquímica local realizado utilizando um sistema de cinco eletrodos e publicado por Lillard, Moran e Isaacs (LILLARD, MOARAN, \& ISAACS, 1992 ) sem que, no entanto, tenha sido explicada a origem.
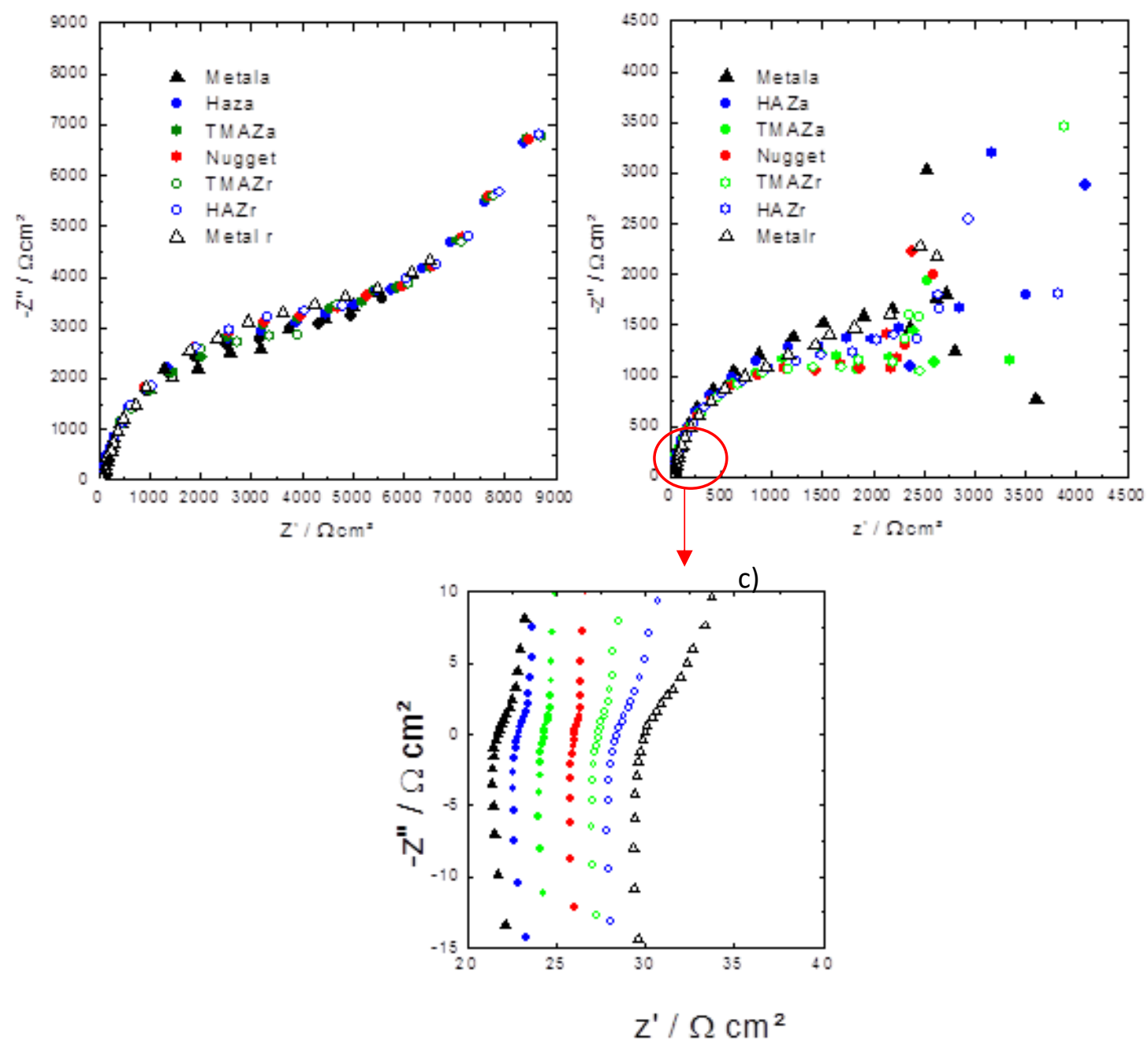

Figura 4-33: Diagramas de Nyquist das medidas de impedância global (a), local (b), realizadas sobre AA 2024-T3 soldada por $\mathrm{FSW}$ em meio $\mathrm{NaCl} 0,1$ mol.L $\mathrm{L}^{-1}$ e a região em AF da impedância local (c)

Nos trabalhos inicialmente desenvolvidos por Huang et al.(2007a) Huang et al.(2007b) e Huang et al.(2007c), a dispersão observada em altas frequências nos diagramas de impedância local foi atribuída à geometria do eletrodo embutido, que impõe uma distribuição não uniforme de potencial e de corrente sobre a superfície, como 
proposto inicialmente por Newman ( (NEWMAN, Resistance for Flow of Current to a Disk, 1966).

Posteriormente Vivier, com diferentes colaboradores, partindo do princípio de que o potencial na solução nas proximidades do eletrodo obedece à equação de Laplace, simulou a distribuição de potencial e corrente sobre eletrodos modelos de $\mathrm{Al} / \mathrm{Cu}$ (JORCIN et al, 2008) e Al/Mg (LACROIX et al, 2009). Foi verificado que o acoplamento galvânico induz uma distribuição não uniforme de potencial e de corrente sobre a superfície de cada um dos eletrodos acoplados, a qual é consequência da distorção das linhas equipotenciais provocada pelo acoplamento galvânico, como representado na Figura 4-34. Os autores demonstraram que quando a contribuição da corrente radial para a densidade de corrente local não pode ser desprezada, sendo distribuída ao longo do raio do eletrodo, a distribuição de potencial sobre a superfície do eletrodo em questão é não uniforme, por outro lado, quando a contribuição da corrente radial para a densidade de corrente local é zero ocorre uma distribuição da componente normal da corrente local ao longo do raio do eletrodo, fazendo com que a distribuição de potencial seja uniforme. Posteriormente foi verificado experimentalmente por LEIS que a existência de uma distribuição da componente radial da densidade de corrente local sobre a superfície de um eletrodo acoplado galvanicamente (condição na qual ocorre uma distribuição de potencial) provoca o aparecimento de arcos indutivos característicos na região AF dos diagramas de impedância local, e que são sensíveis (variam de diâmetro e de posição no diagrama de impedância) à posição radial do bieletrodo sobre a superfície da amostra (BLANC, et. al., 2010) (LACROIX et al, 2012). Por outro lado, quando ocorre distribuição da componente normal da densidade de corrente local (situação na qual o potencial permanece constante), a região AF dos diagramas de impedância local é insensível ao posicionamento radial do bieletrodo, permanecendo constante.

As regiões em altas frequências dos diagramas de impedância local apresentadas na Figura 4-33(c) não apresentam o arco indutivo característico da situação de acoplamento galvânico relatado nos diversos trabalhos publicados na literatura (BLANC, et. al., 2010) (LACROIX et al, 2012) (DE LINA NETO et al, 2008, apresentando apenas um deslocamento sequenciado em paralelo à medida que o bieletrodo foi deslocado sobre a superfície da amostra, sem qualquer correlação aparente com as regiões afetadas pelo processo de soldagem. Deste modo, é possível concluir que a distribuição observada na região AF não se deve ao acoplamento galvânico entre as diferentes regiões, mas sim a fatores geométricos conforme sugerido por Newman (NEWMAN, 1996a) (NEWMAN, 
1966b), podendo ainda estar relacionada ao fato de que o eletrodo de referência não está efetivamente posicionado no infinito (HUANG et al, 2007b)

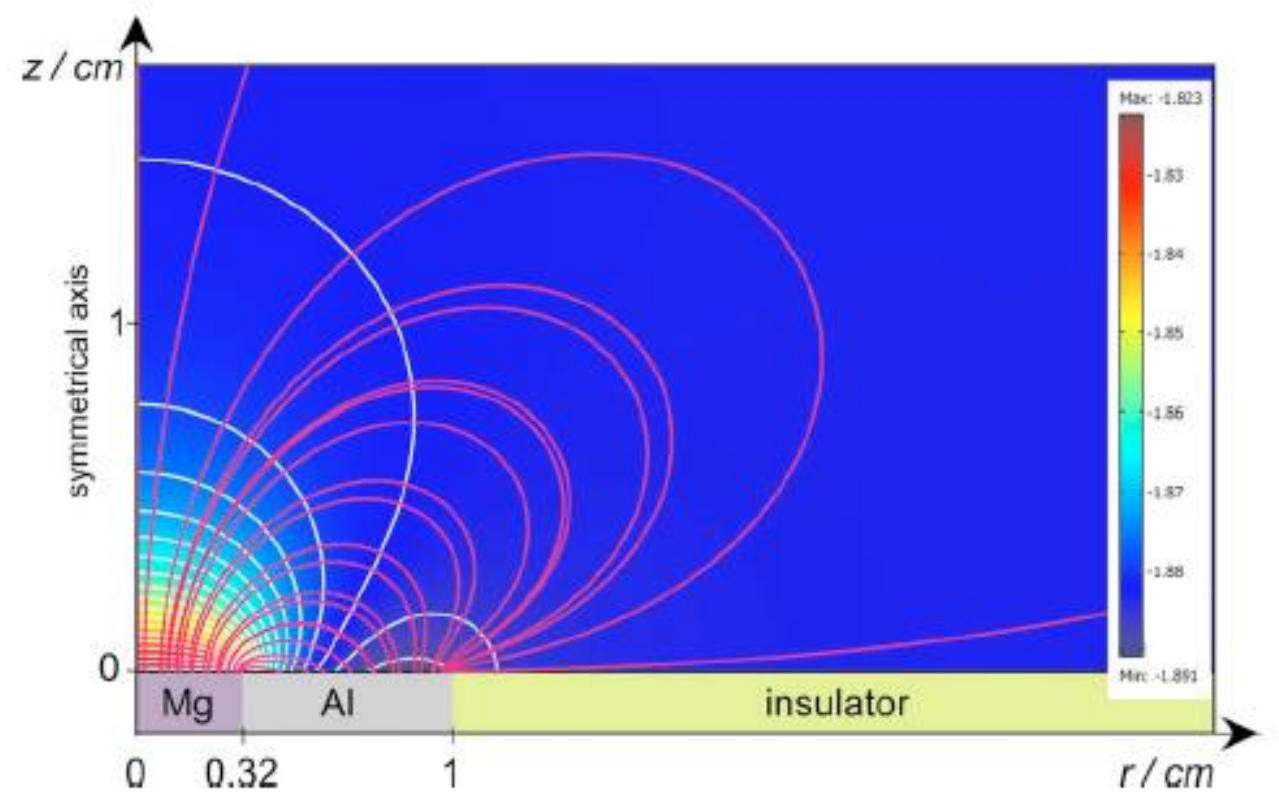

Figura 4-34:Distribuições de potencial e corrente na solução devido ao acoplamento galvânico entre eletrodos modelos de $\mathrm{Al}$ e $\mathrm{Mg}$. Em branco as linhas equipotenciais e em vermelho a distribuição de corrente em solução. Adaptado de Lacroix et al (2009)

\subsection{ACOPLAMENTO EIS/ÂNGULO DE CONTATO}

\subsubsection{Modelização das linhas de corrente e potencial em uma gota}

\subsubsection{Descrição do sistema de desenvolvimento das equações}

Para simplificação, a célula gota foi modelada assumindo um sistema de dois eletrodos nos quais, ER (Eletrodo de Referência) e CE (Contra-eletrodo) são conectados juntos (possuem formalmente o mesmo potencial elétrico). Do ponto de vista prático, isto se justifica porque na montagem experimental o RE e o CE estão muito próximos um do outro na célula gota.

As duas configurações que foram investigadas com simulação numérica estão apresentadas na Figura 4-35. Na primeira configuração (Figura 4-35 a) a interface sólidolíquido tem diâmetro de 2,4 mm, correspondendo ao ET, e o CE é um bastão com 0,2mm de diâmetro, formando uma calota esférica. Na segunda configuração (Figura 4-35 b), o 
diâmetro do CE e cinco vezes maior e o diâmetro do ET é 3,4mm, formando uma elipsóide.

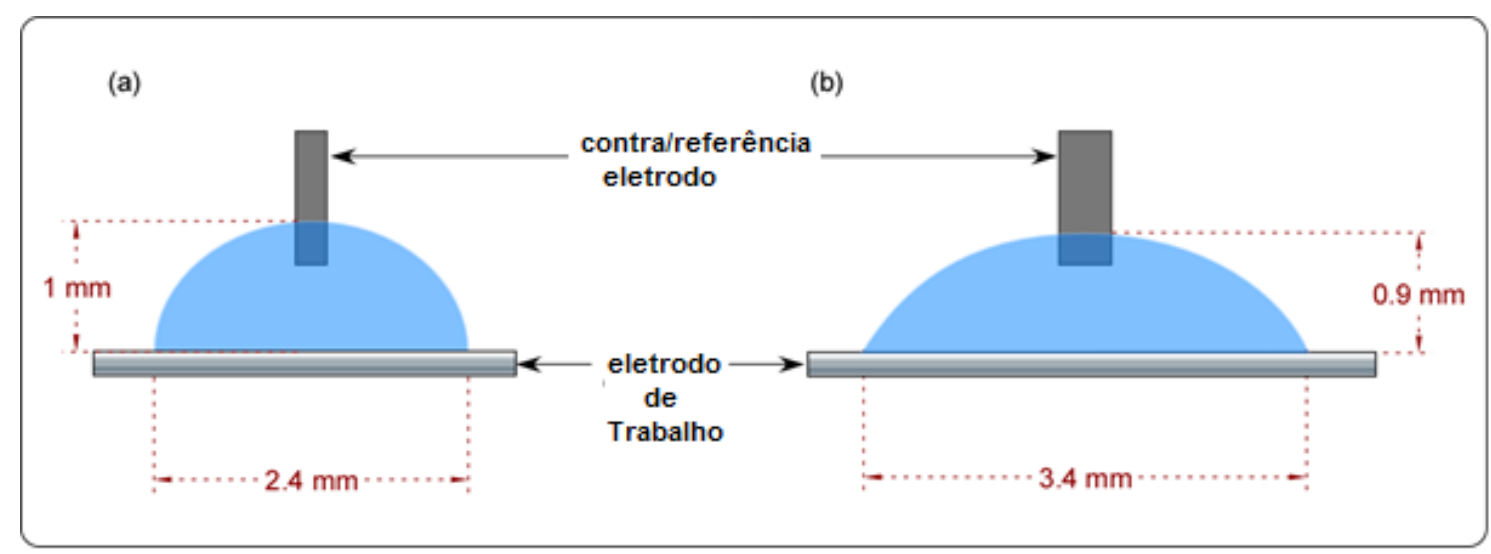

Figura 4-35: Esboços das configurações utilizadas para modelagem numérica

Foi considerada uma reação de transferência de elétrons envolvendo espécies solúveis, representada pela equação 1 :

$O x+e^{-} \rightleftharpoons \operatorname{Red}$

Assumindo que a velocidade da reação eletroquímica segue a cinética de ButlerVolmer, esta pode ser expressa conforme equação 4-6.

$v=k^{0}\left(C_{o x} e^{\left(\frac{-\alpha F}{R T}\left(E-E^{0}\right)\right)}-C_{r e d} e^{\left(\frac{(1-\alpha) F}{R T}\left(E-E^{0}\right)\right)}\right)$

Deste modo, a equação da corrente é representada pela equação 4-7:

$I=-F A k^{0}\left(C_{o x} e^{\left(\frac{-\alpha F}{R T}\left(E-E^{0}\right)\right)}-C_{r e d} e^{\left(\frac{(1-\alpha) F}{R T}\left(E-E^{0}\right)\right)}\right)$

onde $C_{\mathrm{ox}}$ e $C_{\text {red }}$ são as concentrações das espécies eletroativas, $\alpha$ é o coeficiente de transferência de carga, $k^{0}$ é a constante de velocidade padrão, $E^{0}$ o potencial padrão de redução, $A$ a área do eletrodo, $E$ o potencial aplicado, com os demais parâmetros com seus significados habituais.

A fim de investigar a influência da geometria da célula gota, três diferentes contribuições devem ser levadas em conta para o cálculo da impedância eletroquímica: o gradiente de concentração devido à polarização (DC) da interface, a qual leva a um comportamento de estado estacionário, o gradiente de concentração devido à perturbação 
senoidal (ou seja, a contribuição oscilatória utilizada para a medida da impedância eletroquímica), e as distribuições de corrente e de potencial no interior do pequeno volume formado pela gota.

$\mathrm{Na}$ presença de eletrólito de suporte, a migração pode ser negligenciada, e admitindo que a célula gota é livre de convecção, o fluxo de espécies eletroativas na interface segue a segunda lei de Fick, que pode ser expressa em coordenadas cilíndricas pela equação 4-8.

$D_{k}\left(\frac{\partial^{2} C_{k}}{\partial r^{2}}+\frac{1}{r} \frac{\partial C_{k}}{\partial r}+\frac{\partial^{2} C_{k}}{\partial z^{2}}\right)=0$

Onde $k$ representa $\mathrm{Ox}$ ou Red, $D_{\mathrm{k}}$ é o coeficiente de difusão da espécie $k, r$ é a coordenada radial medida a partir do centro do eletrodo, e $z$ é a coordenada normal à superfície do eletrodo.

As condições de contorno na superfície do eletrodo são dadas por uma condição de contorno de Neumann, correspondendo a um fluxo constante determinado pela velocidade da reação eletroquímica (negativa para a redução e positiva para a oxidação), conforme equação 4-9.

$$
D_{k} \frac{\partial C_{k}}{\partial t}= \pm v
$$

Sobre o CE, um potencial também é aplicado, permitindo calcular a concentração de cada espécie eletroativa. Curiosamente, devido ao tamanho da gota (a distância entre o CE e WE é ao menos cinco vezes maior que a camada de difusão - observar Figura 435), o sistema se comporta de modo semelhante quando uma concentração constante é aplicada no CE para a simulação numérica.

Quando a perturbação senoidal é sobreposta, a lei de Fick pode ser escrita no domínio da frequência como representado na equação 4-10 (GABRIELLI, et al., 2006).

$j \omega \tilde{C}_{k}=D_{k}\left(\frac{\partial^{2} \tilde{C}_{k}}{\partial r^{2}}+\frac{1}{r} \frac{\partial \tilde{C}_{k}}{\partial r}+\frac{\partial^{2} \tilde{C}_{k}}{\partial z^{2}}\right)$

E a condição de contorno na superfície do eletrodo é obtida a partir da linearização da velocidade da reação (Eq. 4-6) como já descrito em (MICHEL, MONTELLA, VERDIER, \& DIARD, 2010)

A impedância faradaica é então calculada a partir da integração do fluxo na superfície do eletrodo. É importante mencionar que o tamanho da camada de difusão, o 
qual é controlado em um experimento tanto pela frequência da onda senoidal como pela convecção natural, é limitado pela sua extensão no interior da gota. Assim, nenhum comportamento da camada fina é esperado, sendo possível supor um comportamento de difusão semi-infinito, como geralmente observado para sistemas eletroquímicos milimétricos, uma vez que o intervalo de frequência utilizado tanto para as simulações como para os experimentos limita o amortecimento da onda de concentração a uma distância menor do que o tamanho da gota. Além disso, a utilização de uma solução equimolar para ambas as espécies redox supera o consumo de uma delas no ET durante a medida, sendo este processo compensado pela sua formação no contraeletrodo, permitindo que seja evitada qualquer depleção no interior da gota, especialmente quando experimentos de longa duração são realizados. Além do mais, o consumo de oxigênio foi descartado na análise dos dados e na simulação, uma vez que a concentração das espécies eletroativas utilizadas neste trabalho é muito maior do que a concentração usual de oxigênio dissolvido.

As distribuições de corrente e potencial no interior da gota foram calculadas simultaneamente com o gradiente de concentração utilizando a lei de Laplace, conforme equação 4-11.

$\frac{\partial^{2} \phi}{\partial r^{2}}+\frac{1}{r} \frac{\partial \phi}{\partial r}+\frac{\partial^{2} \phi}{\partial z^{2}}=0$

onde $\phi$ é o potencial da solução $(\phi=E$ no ET).

$\mathrm{Na}$ solução, as condições de contorno controlam a queda ôhmica devida à condutividade do eletrólito $(\sigma)$ (equação 4-12):

$\vec{\nabla} \cdot(\sigma \vec{\nabla} \phi)=0$

Enquanto, na superfície do eletrodo, o fluxo, $\vec{J}$, é controlado pela impedância faradaica, $Z_{f}$, calculada a partir do gradiente de concentração, e pela capacitância da dupla camada elétrica $C_{d l}$ (equação 4-13):

$\vec{n} \cdot \vec{J}=j \omega C_{d l}+\frac{1}{Z_{f}}$ 
Onde $\vec{n}$ é o vetor normal à superfície do eletrodo.

\subsubsection{Resultados das simulações}

Diferentes parâmetros físico químicos (tais como a condutividade do eletrólito e a constante de velocidade de transferência eletrônica heterogênea) ou geométricos (a distância entre o CE e o ET ( $\left.d_{C E-E T}\right)$, o tamanho do eletrodo) da célula gota descrita na Figura 4-3 (a) foram variados. Para simplificar, os cálculos numéricos foram realizados para um par redox com as mesmas concentrações $\left(C_{\mathrm{ox}}=C_{\text {red }}=5 \times 10^{-6} \mathrm{~mol} \mathrm{~cm}^{-3}\right)$, um coeficiente de transferência de cargas $\alpha=0,5$, e com o mesmo coeficiente de difusão $\left(D_{\text {ox }}=D_{\text {red }}=D=5 \times 10^{-6} \mathrm{~cm}^{2} s^{-1}\right)$. O valor da capacitância da dupla camada elétrica na interface sólido-solução foi assumido como sendo $10 \mu \mathrm{F} \mathrm{cm}^{-2}$.

A validade da simulação numérica foi verificada inicialmente realizando o cálculo da impedância eletroquímica para uma configuração de célula com 3 eletrodos, considerando que o RE e o CE se encontravam bem próximos, com um WE com $5 \mathrm{~mm}$ de diâmetro e um grande CE a uma distância 20 vezes maior que o tamanho do WE. Como esperado, os resultados apresentados na Figura 4-36: Diagrama de Nyquist da simulação FEM (círculos abertos) para um eletrodo de $5 \mathrm{~mm}$ de diâmetro em uma célula convencional de 3 eletrodos. A linha sólida foi obtida a partir da expressão analítica (Eq. 10) correspondendo ao circuito Randles. As simulações foram feitas com $\mathrm{k} 0=10-3 \mathrm{~cm}$ $\mathrm{s}-1, \mathrm{D}=510-6 \mathrm{~cm} 2 \mathrm{~s}-1, \alpha=0,5, \sigma=10 \mathrm{mS} \mathrm{cm}-1$. (símbolos abertos) mostram uma constante de tempo em alta frequência $(\mathrm{HF})$, correspondente à resistência de transferência de carga em paralelo com a capacitância de dupla camada, e um domínio linear, com inclinação de $45^{\circ}$, em baixas frequências, atribuído à difusão de Warburg. Curiosamente, os dados de impedância calculados por FEM corroboram com o circuito equivalente Randles (Equação 4-14), no qual a contribuição de difusão, impedância de Warburg, reflete a solução da equação de Fick em 1D, como apresentado pelos resultados na Figura 4-36.

$$
Z(\omega)=R_{e l}+\frac{1}{j \omega C_{d l}+R_{c t}\left(1+\frac{\lambda}{\sqrt{j \omega}}\right)}
$$


com

$$
\lambda=\frac{2 k^{0}}{\sqrt{D}}
$$

onde $R_{e l}$ e $R_{c t}$ são as resistências do eletrólito e de transferência de carga, respectivamente.

Os valores de capacitância da dupla camada e da resistência de transferência de carga obtidos tanto com a simulação por FEM como pelo ajuste com a equação 10 apresentaram boa concordância entre si. Além do mais, um fator $\lambda=0,87 \mathrm{~s}^{1 / 2}$, correspondente à contribuição difusional, foi obtido, o qual foi coerente com o valor esperado $\left(0,89 \mathrm{~s}^{1 / 2}\right)$. Também deve ser mencionado que o desvio em baixas frequências (abaixo de $10 \mathrm{mHz}$ ) entre os valores plotado e teórico pode ser atribuído ao fato de que a expressão usual da impedância de Warburg foi concebida para difusão em 1D e um CE com tamanho infinito posicionado no infinito, ao passo que as simulações em FEM foram realizadas para difusão 2D (ou seja, levando em consideração os efeitos de borda do WE) e um tamanho finito para a célula eletroquímica. Um exame detalhado da região HF (f > $5 \mathrm{kHz}$-valores não mostrados) mostra a influência das distribuições de corrente e de potencial descrita primeiramente por Newman, no caso de um eletrodo bloqueado ou na presença de reações faradaicas (NEWMAN, Frequency dispersion in capacity measurements at a disk electrode, 1970)

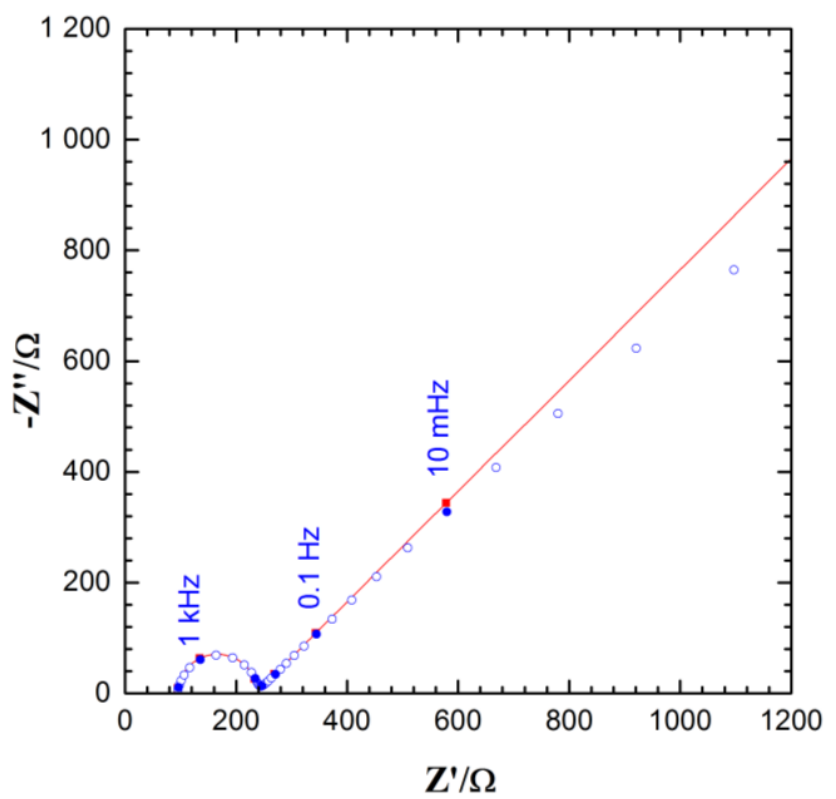

Figura 4-36: Diagrama de Nyquist da simulação FEM (círculos abertos) para um eletrodo de $5 \mathrm{~mm}$ de diâmetro em uma célula convencional de 3 eletrodos. A linha sólida foi obtida a partir da expressão analítica (Eq. 10) correspondendo ao circuito Randles. As simulações foram feitas com $\mathrm{k}_{0}=10^{-3} \mathrm{~cm} \mathrm{~s}^{-1}, \mathrm{D}=510^{-6} \mathrm{~cm}^{2} \mathrm{~s}^{-1}, \alpha=0,5, \sigma=10 \mathrm{mS} \mathrm{cm}^{-1}$. 
Em uma segunda etapa, foi considerada a geometria da célula gota com as duas configurações previamente descritas. Para a geometria da célula apresentada na Figura 434 (a), a condutividade do eletrólito foi fixada em $62 \mathrm{mS} \mathrm{cm}^{-1}$, o diâmetro do ET em 2,4 mm e a distância entre o ET e o CE em $200 \mu$ m. A impedância eletroquímica foi calculada por FEM utilizando dois valores de $k^{0}\left(10^{-2}\right.$ e $\left.10^{-3} \mathrm{~cm} \mathrm{~s}^{-1}\right)$. A primeira avaliação da Figura 4-36 demonstra que o volume confinado da célula gota resulta em diagramas similares aos obtidos em condições com volumes maiores, em condições clássicas, isto é, o limite em HF do diagrama correspondendo à resistência do eletrólito, o arco capacitivo referente à relaxação da resistência de transferência de carga e a capacitância da dupla camada elétrica e a difusão de Warburg em baixas frequências. Os valores tanto da resistência de transferência de carga como do parâmetro $\lambda$ ficaram de acordo com os valores fornecidos para $k^{0}$ e para o coeficiente de difusão. É interessante observar que, mesmo no domínio de baixa frequência, a expressão analítica que corresponde ao circuito de Randles concorda bastante bem com a simulação FEM (Figura 4-37) diferentemente dos resultados apresentados para a configuração clássica (Figura 4-36). Isto pode ser explicado pela geometria da célula gota, para a qual as bordas do ET são delimitadas pela forma da gota, o que resulta numa difusão 1D eficaz. Além do mais, a distância de amortecimento da onda de concentração é $(D / \omega)^{1 / 2}$, correspondendo a aproximadamente $100 \mu \mathrm{m}$ para uma frequência de $10 \mathrm{mHz}$ e um coeficiente de difusão de $510^{-6} \mathrm{~cm}^{2} \mathrm{~s}^{-1}$. Como resultado, o tamanho da célula é visto como um domínio infinito quando comparado com a espessura da camada de difusão, ou seja, um comportamento tipo Warburg é observado para frequências maiores que $D / L^{2} \cong 1 \mathrm{mHz}$ (onde $L$ é a dimensão característica da célula gota). 

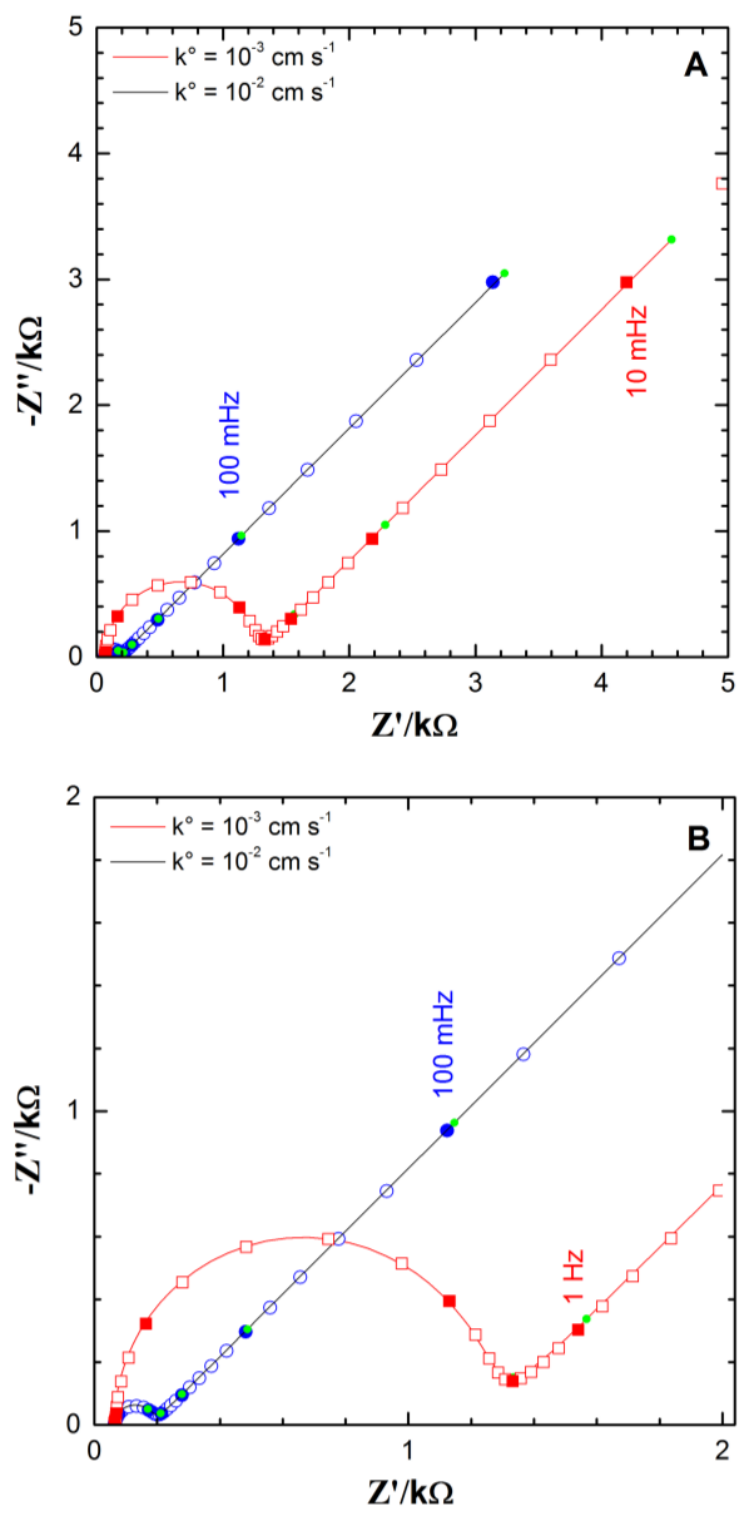

Figura 4-37: A. Diagramas de Nyquist obtidos por simulação FEM (círculos abertos) para uma célula gota (configuração a). A linha sólida foi calculada com a expressão analítica (Eq. 10) correspondendo ao circuito Randles. Os detalhes para altas frequências são apresentados na figura $B$. As simulações foram feitas com $D=510^{-6} \mathrm{~cm}^{2} \mathrm{~s}^{-1}, \alpha=0,5$, $\sigma=62 \mathrm{mS} \mathrm{cm}^{-1}$.

Para a segunda geometria de célula eletroquímica, apresentada na Figura 4-35 (b), a condutividade do eletrólito foi de $10 \mathrm{mS} \mathrm{cm}^{-1}$, o tamanho do CE foi maior que para a célula apresentada na Figura 4-34 (a), mas ainda continuou menor que o ET, e a distância entre o ET e o CE foi fixada em $200 \mu \mathrm{m}$. Com esta configuração, os efeitos dos vários parâmetros eletroquímicos na resposta da impedância foram investigados. Da mesma forma que para a primeira configuração, foram considerados dois valores de $k^{0}\left(10^{-3}\right.$ e 2 $10^{-2} \mathrm{~cm} \mathrm{~s}^{-1}$ ). Os resultados dos espectros de impedância simulados estão representados na Figura 4-37 na representação de Nyquist. 
$\mathrm{O}$ aspecto geral do diagrama continua similar aos apresentados na Figura 4-37 para um eletrólito com alta condutividade. Entretanto, no domínio HF, verificou-se uma distorção significativa para a resposta de EIS (Figura 4-377 (B)) para o menor valor de $k^{0}$ (ou seja, alta resistência de transferência de carga), isto é, na faixa de frequência dominada pela capacitância. Em outras palavras, quanto menor $k^{0}$, maior $R_{c t}$ e maior o produto $R_{c t} C_{d l}$. Assim, o menor valor de $k^{0}$ resulta em um menor valor da constante de tempo (proporcional a $1 / R_{c t} C_{d l}$ ). Assim, a dispersão de frequência devida às distribuições de corrente e potencial pode ser distinguida da resposta faradaica. Por outro lado, um valor de $k^{0}$ elevado resulta em valores elevados para a constante de tempo. Neste caso, pode-se supor que a resposta faradaica impede, pelo menos parcialmente, a distribuição de corrente, o que significa que esta última contribuição ainda existe, mas não pode ser distinguida como uma única constante de tempo.

Este comportamento foi confirmado para o sistema com a velocidade de transferência de carga heterogênea mais baixa, para o qual o efeito da condutividade do eletrólito foi investigado, como apresentado na Figura 4-38. A distorção em HF depende claramente da condutividade do eletrólito, que controla o gradiente de potencial na vizinhança do eletrodo. Tal comportamento pode ser atribuído a uma dispersão de frequência correspondente à distribuição de corrente e potencial em um sistema resistivo e confinado. Do ponto de vista prático, pode também resultar numa incerteza na determinação da resistência de transferência de carga e da resistência do eletrólito. Assim, o ajuste desses espectros de impedância simulados com o circuito equivalente de Randles conduz a resultados diferentes, como apresentados na Figura 4-389 e na Tabela 4-2, dependendo do peso dado para o domínio em alta frequência. Então duas abordagens foram desenvolvidas para apresentação dos resultados na Figura 4-389. Nas Figura 4-389 e A Figura 4-389.(C), os resultados de impedância de todo o intervalo de frequência (100 $\mathrm{kHz}-10 \mathrm{mHz}$ ) foram levados em conta para o ajuste, enquanto somente uma pequena faixa de frequência $(1,6 \mathrm{kHz}-10 \mathrm{mHz})$ foi considerada (descartando as frequências mais elevadas) para simular os ajustes nas Figura 4-389 (B) e Figura 4-389 (D). Esses resultados demonstraram que a dispersão no domínio HF pode ser minimizada utilizando um eletrólito com condutividade adequada. 

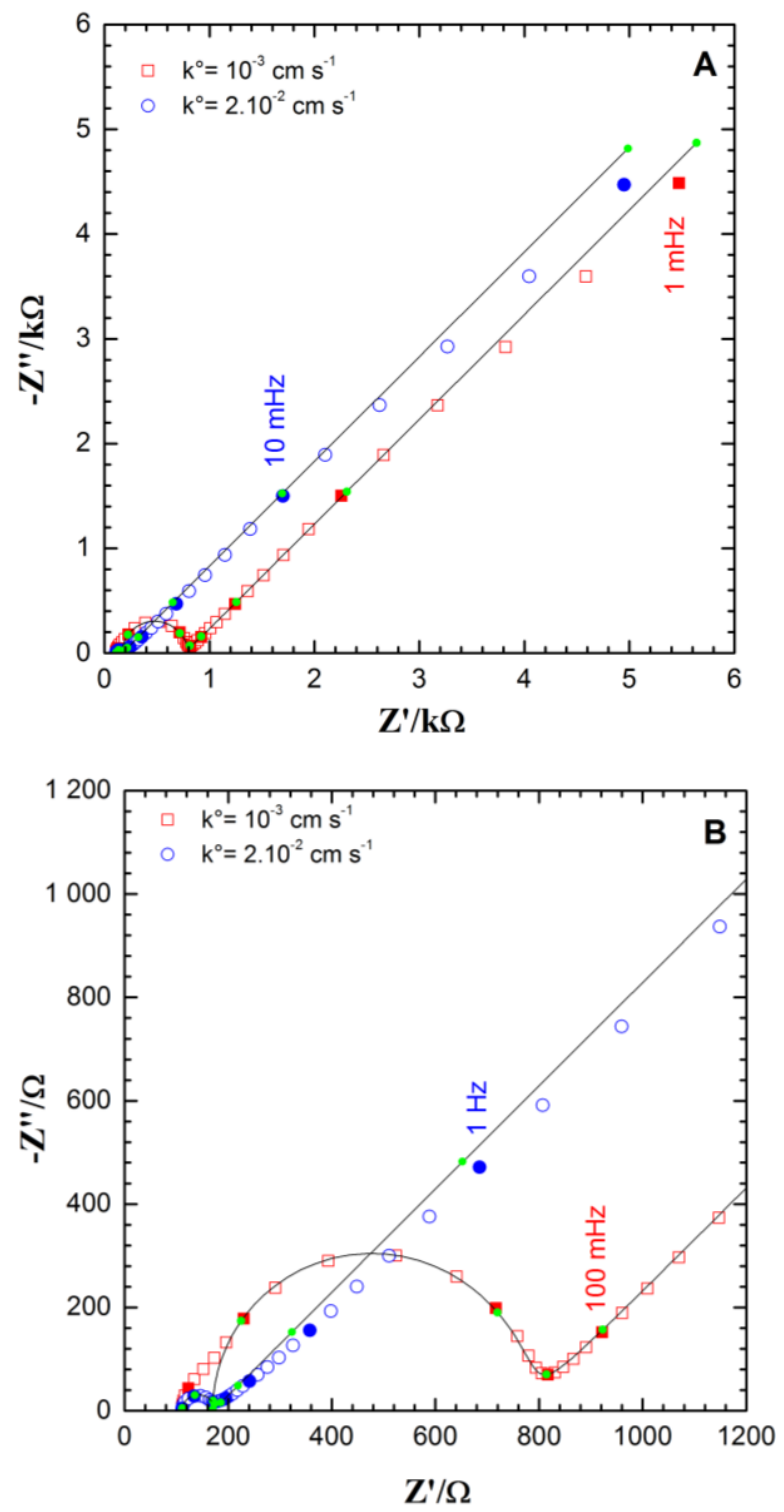

Figura 4-38: Diagramas de Nyquist obtidos por simulação FEM (círculos abertos) para uma célula gota (configuração b). A linha sólida foi calculada com a expressão analítica (Eq. 10) correspondendo ao circuito Randles. Os detalhes para a alta frequência são apresentados na figura $B$. As simulações foram conduzidas com $D=510^{-6} \mathrm{~cm}^{2} \mathrm{~s}^{-1}, \alpha=$ $0,5, \sigma=10 \mathrm{mS} \mathrm{cm}^{-1}$. 

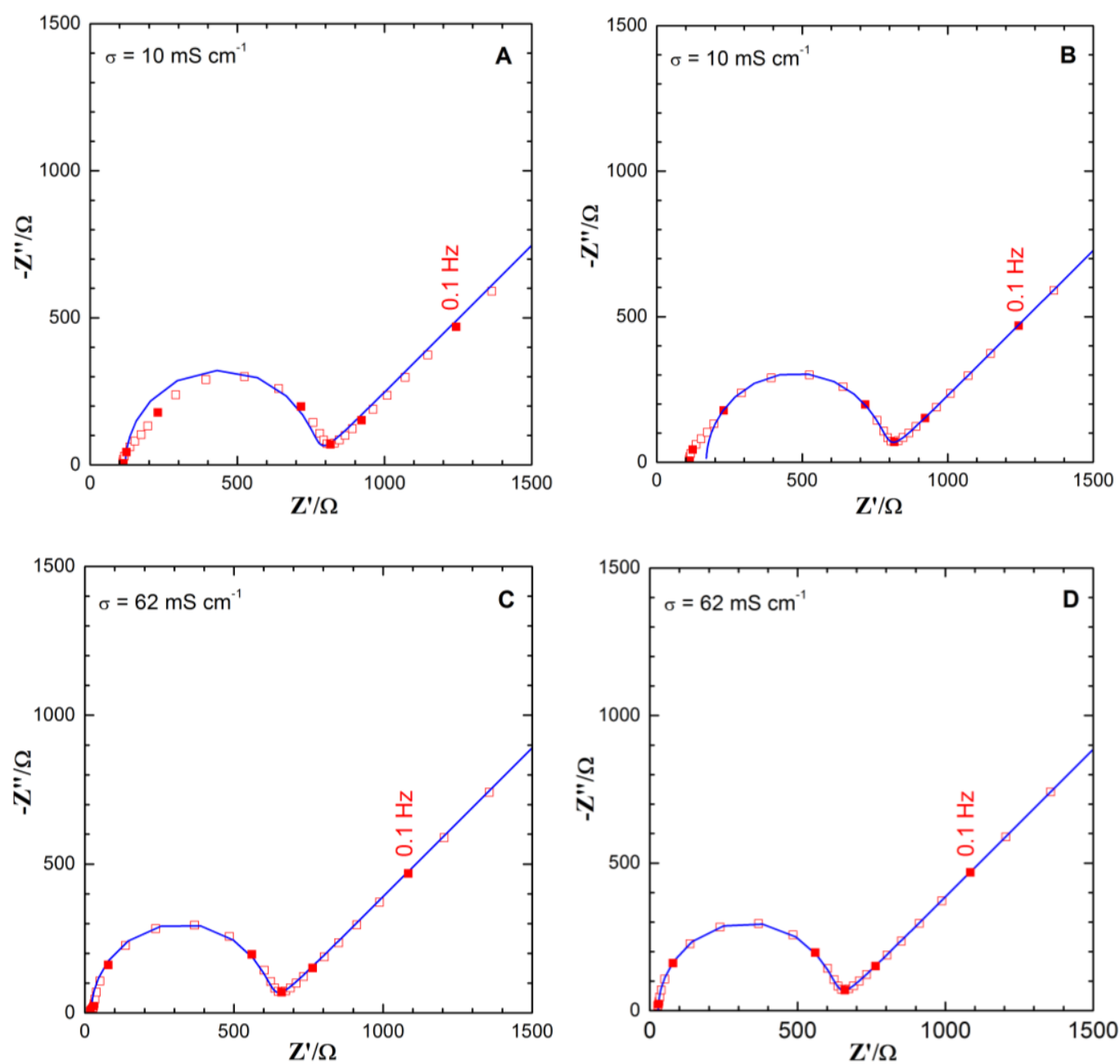

Figura 4-39:Diagramas de Nyquist obtidos por simulação FEM (círculos abertos) para uma célula gota (configuração b). A linha sólida foi calculada com a expressão analítica (Eq. 10) correspondendo ao circuito de Randles. As simulações foram realizadas com $\mathrm{k}_{0}$ $=10^{-3} \mathrm{~cm} \mathrm{~s}^{-1}, \mathrm{D}=510^{-6} \mathrm{~cm}^{2} \mathrm{~s}^{-1}, \alpha=0,5$, (A) e (C) foram plotadas usando todos os valores de frequência $(100 \mathrm{kHz}-10 \mathrm{mHz})$; Figuras (B) e (D) com um intervalo menor $(1,6 \mathrm{kHz}$ $-10 \mathrm{mHz}$ )

Tabela 4-2: Parâmetros dos ajustes obtidos com o circuito Randles para a configuração b da célula eletroquímica e para os dados apresentados na Figura 4-37

\begin{tabular}{|l|l|l|l|l|}
\hline & $\sigma\left(\mathrm{mS} \mathrm{cm}^{-1}\right)$ & $\mathrm{R}_{\mathrm{e}}(\Omega)$ & $\mathrm{R}_{\mathrm{ct}}(\Omega)$ & $\mathrm{C}_{\mathrm{d}}(\mu \mathrm{F})$ \\
\hline Fig. 4-36A & 10 & 120 & 634 & 0,63 \\
\hline Fig. 4-36B & 10 & 170 & 603 & 0,82 \\
\hline Fig. 4-36C & 62 & 22 & 589 & 0,82 \\
\hline Fig. 4-36D & 62 & 28 & 587 & 0,86 \\
\hline
\end{tabular}


A distância entre o ET e a relação CE/RE é também um parâmetro importante como mostrado na Figura 4-40. Como esperado, esta distância controla os valores da resistência do eletrólito: quanto maior a distância, maior a resistência do eletrólito, que parece variar linearmente. Embora a geometria dessa célula possa ser modelada por um cone truncado, esta relação não é simples, uma vez que o campo elétrico não é constante ao longo do comprimento do cone. Para um sistema com uma cinética mais lenta, a distorção do arco da transferência de carga em frequências mais elevadas é menos pronunciada (Figura 4-40 (A)) quando a distância dCE-ET aumenta, o que pode ser explicado por um deslocamento da frequência característica com o inverso da resistência do eletrólito (HUANG, VIVIER, ORAZEM, PEVERE, \& TRIBOLLET, 2007). Por outro lado, para o sistema com maior velocidade de transferência eletrônica heterogênea o aumento da distância $\mathrm{d}_{\mathrm{CE}-\mathrm{WE}}$ parece afetar apenas a resistência do eletrólito (Figura 4-40 (B)), indicando assim que a dispersão de frequências no domínio HF é dificultada pela contribuição faradaica da impedância. 

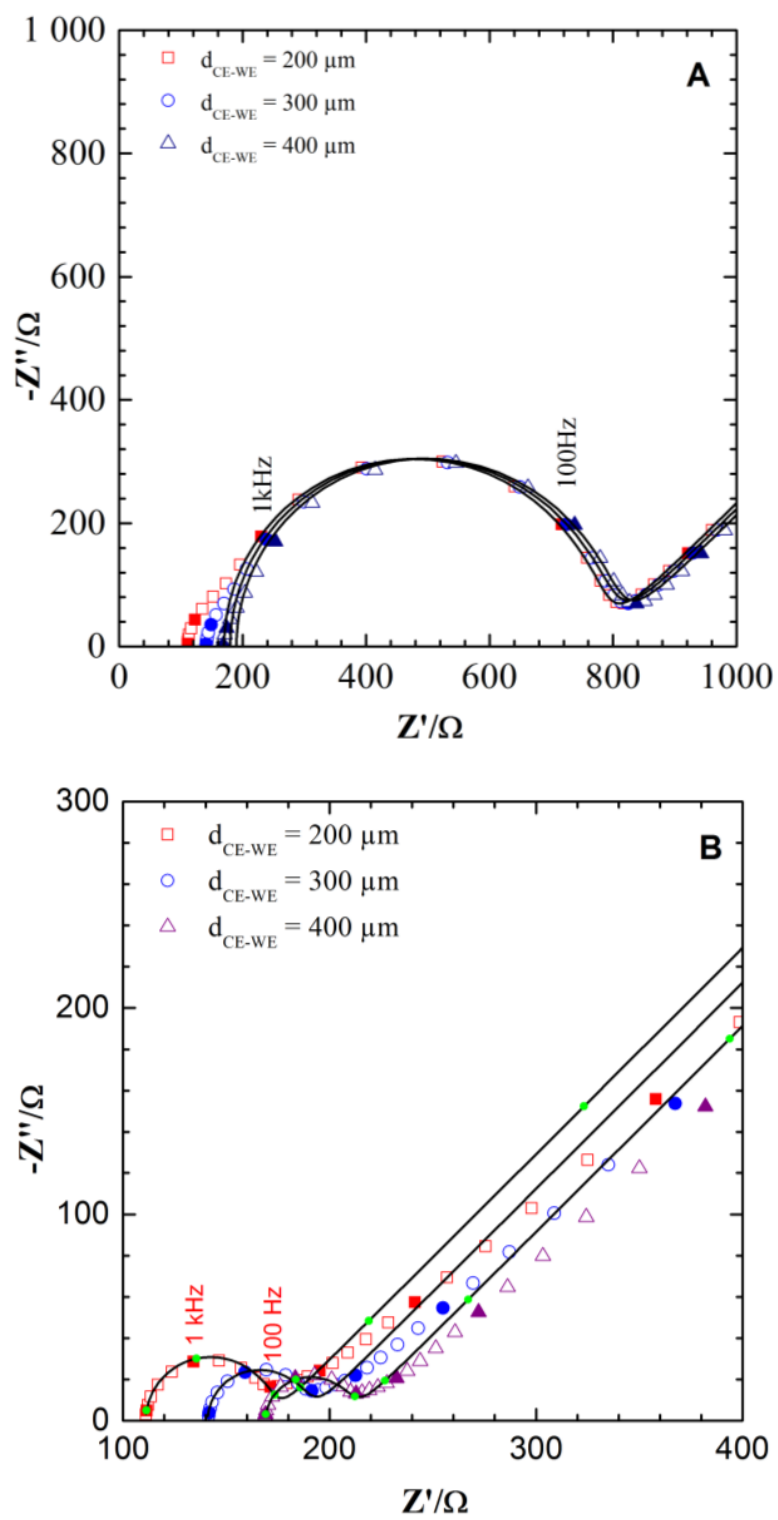

Figura 4-40: Diagramas de Nyquist obtidos por simulação FEM (símbolos abertos) para uma célula gota (configuração b) em função da distância entre o ET e da relação RE/CE. A linha sólida foi calculada com a expressão analítica (Eq. 10) correspondendo ao circuito de Randles cujos parâmetros foram obtidos por ajuste descartando os resultados nas frequências mais elevadas. A simulação foi feita com $D=510^{-6} \mathrm{~cm}^{2} \mathrm{~s}^{-1}, \alpha=0,5$, e (7A) $\mathrm{k}^{0}=10^{-3} \mathrm{~cm} \mathrm{~s}^{-1}$ ou (7B) $\mathrm{k}^{0}=210^{-2} \mathrm{~cm} \mathrm{~s}^{-1}$.

\subsubsection{Medidas de impedância em uma gota}

Foram investigadas duas configurações de célula gota com configuração de 3 eletrodos com CE de platina com diferentes tamanhos. No caso de experimentos reais, é difícil de controlar com precisão a superfície da interface ET-eletrólito. Mesmo que seja colocado o mesmo volume de solução eletrolítica, a cobertura do ET e, 
consequentemente, sua área depende da textura da superfície. No entanto, a área pode ser facilmente medida por análise das imagens captadas com uma câmara CCD.

Os resultados obtidos com as configurações da gota foram comparados com os obtidos com a célula eletroquímica clássica (configuração onde o ET é imerso em uma célula convencional de 3 eletrodos). A fim de tornar mais fácil esta comparação, os diagramas de Nyquist foram plotados com a correção da resistência do eletrólito (Figura 4-41.). Como esperado, qualquer que seja o tamanho do CE, a resistência do eletrólito aumenta com a distância d $\mathrm{CE}_{\mathrm{CE}} \mathrm{WE}$ (Tabela 4-3).

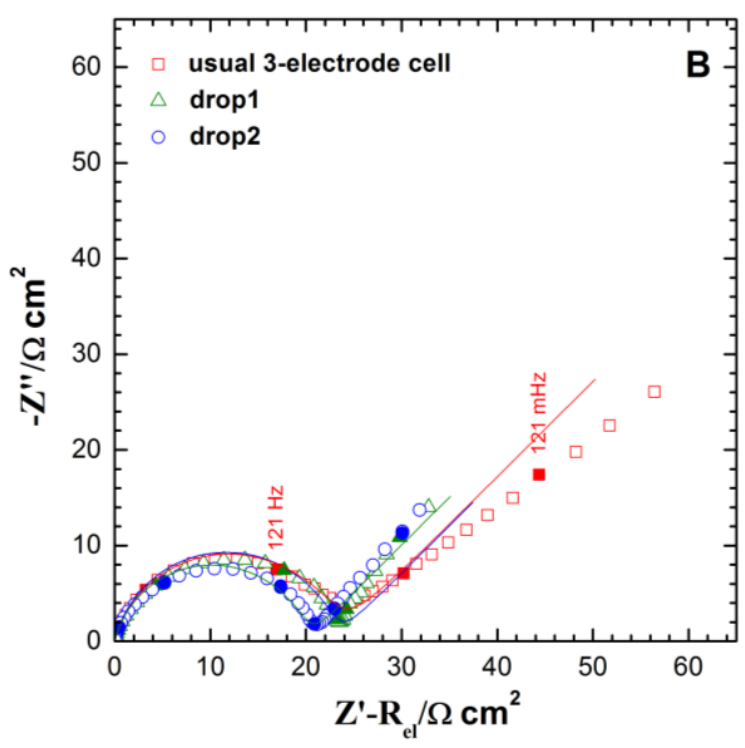

Figura 4-41: Comparação dos diagramas de Nyquist obtidos com a célula eletroquímica convencional de 3 eletrodos e com a célula gota com configuração para dois tamanhos do CE (A) 0,1 mm e (B) 0,2 mm de diâmetro. As linhas sólidas correspondem ao ajuste utilizando circuito de Randles com as características especificadas na Tabela 2.

Tabela 4-3: Parâmetros geométricos e ajustados dos resultados experimentais apresentados na Figura 4-39.

\begin{tabular}{lllllllll}
\hline & $\begin{array}{l}\phi_{C E} \\
(\mathrm{~mm})\end{array}$ & $\begin{array}{l}d_{C E-W E} \\
(\mathrm{~mm})\end{array}$ & $\begin{array}{l}S_{W E} \\
\left(\mathrm{~cm}^{2}\right)\end{array}$ & $\begin{array}{l}R_{e l} \\
\left(\Omega \mathrm{cm}^{2}\right)\end{array}$ & $\begin{array}{l}R_{c t} \\
\left(\Omega \mathrm{cm}^{2}\right)\end{array}$ & $\begin{array}{l}Q \\
\mu \mathrm{F} \mathrm{s}{ }^{-(1-\alpha)} \mathrm{cm}^{-}\end{array}$ & $\begin{array}{l}\alpha) \\
2\end{array}$ & $\begin{array}{l}C_{o} \\
\left(\mu \mathrm{F} \mathrm{cm} \mathrm{cm}^{-2}\right)\end{array}$ \\
\hline Pt_bulk & $\infty$ & $\infty$ & 0,2 & 19 & 23 & 68 & 0,87 & 23 \\
Pt1 gota 1 & 0,1 & 0,28 & 0,057 & 3 & 22 & 60 & 0,86 & 14 \\
Pt1 gota2 & 0,1 & 0,42 & 0,071 & 4.5 & 23 & 59 & 0,86 & 15 \\
Pt2 gota1 & 0,2 & 0,21 & 0,064 & 5 & 20 & 57 & 0,85 & 13 \\
Pt2 gota2 & 0,2 & 0,4 & 0,057 & 6 & 23 & 62 & 0,86 & 16 \\
\hline
\end{tabular}

Como apresentado na Figura 4-41, as medidas realizadas com a célula gota são similares às medidas obtidas com a célula clássica. $\mathrm{O}$ ajuste com o circuito de Randles permitiu determinar a resistência de transferência de carga. Os resultados apresentados 
na Tabela 4-3 mostram que $R_{c t}$ é independente do tipo de célula eletroquímica utilizado para sua determinação, e as pequenas discrepâncias entre todos os valores medidos devem ser atribuídos às características da superfície do eletrodo de platina e não à influência da geometria da célula eletroquímica. Além do mais, as pequenas discrepâncias observadas para todas as constantes cinéticas (ou resistências de transferência de carga) são menores que $10 \%$, e podem ser influenciadas por pequenas incertezas na determinação da área ativa. Também deve ser mencionado que a constante de tempo HF apresenta-se achatada e é melhor descrita por um elemento de fase constante (CPE) definido por $Q$ e $\alpha$, que correspondem ao parâmetro da CPE e seu expoente, respectivamente, ao invés de um capacitor puro, o que é normal, mesmo quando se utiliza um mediador redox simples com um eletrodo de disco de Pt. A capacitância característica $C_{o}$, como introduzida por Brug et al.(1984) para um sistema com reações faradaicas com resistência de transferência de carga, foi calculada de acordo com a equação 4-16.

$$
C_{o}=\left[Q\left(\frac{1}{R_{e l}}+\frac{1}{R_{c t}}\right)^{\alpha-1}\right]^{1 / \alpha}
$$

Além disso, as grandes diferenças na resistência dos eletrólitos devem ser atribuídas apenas à geometria da célula. A resposta em baixa frequência com uma pequena célula gota dá origem a uma maior inclinação da impedância de Warburg. Atribuiu-se este comportamento ao tamanho tanto da gota como do CE. Entretanto, como o objetivo deste trabalho é de combinar medidas de ângulo de contato e EIS, um grande CE e volume da gota entre 2-5 foram utilizados para realizar essas análises (vide infra).

Curiosamente, estes resultados corroboram com os obtidos por voltametria cíclica (Figura 4-42) com velocidade de varredura bastante baixa $\left(50 \mathrm{mV} \mathrm{s}^{-1}\right)$. Com tal velocidade de varredura, são necessários apenas 20s para explorar uma amplitude de $1 \mathrm{~V}$. Pela comparação com as medidas EIS feitas em baixas frequências $(0,1$ a 0,01 Hz), esta escala de tempo é relativamente baixa, indicando que o processo de difusão é regido por condições semi-infinitas.

Finalmente, destaca-se que esta configuração foi concebida para combinar as medidas das variações de ângulo de contato em função da polarização com a finalidade de ajustar a molhabilidade da interface utilizando a eletroquímica. Como mostrado na Figura 4-43, o ângulo de contato da gota séssil da solução de $\mathrm{Fe}(\mathrm{CN})_{6}^{4-/ 3-}$ colocada sobre a superfície da Pt pode ser medido em função do tempo mesmo na presença do contra eletrodo e do eletrodo de referência dentro da gota, observa-se uma ligeira diminuição 
deste com o tempo de ensaio em uma escala de tempo de algumas centenas de segundos. Esta variação é devida, inicialmente, à evolução do sistema para que seja atingido o equilíbrio entre a gota e a superfície. Posteriormente, existe o efeito de uma leve evaporação da água. Entretanto, estas variações podem ser minimizadas usando uma câmara fechada de umidificação desenvolvida para este dispositivo e que permite acompanhar a variação da molhabilidade da superfície do sólido a ser estudado durante a polarização, se alguma reação ou mudança química ou física ocorrer na superfície.

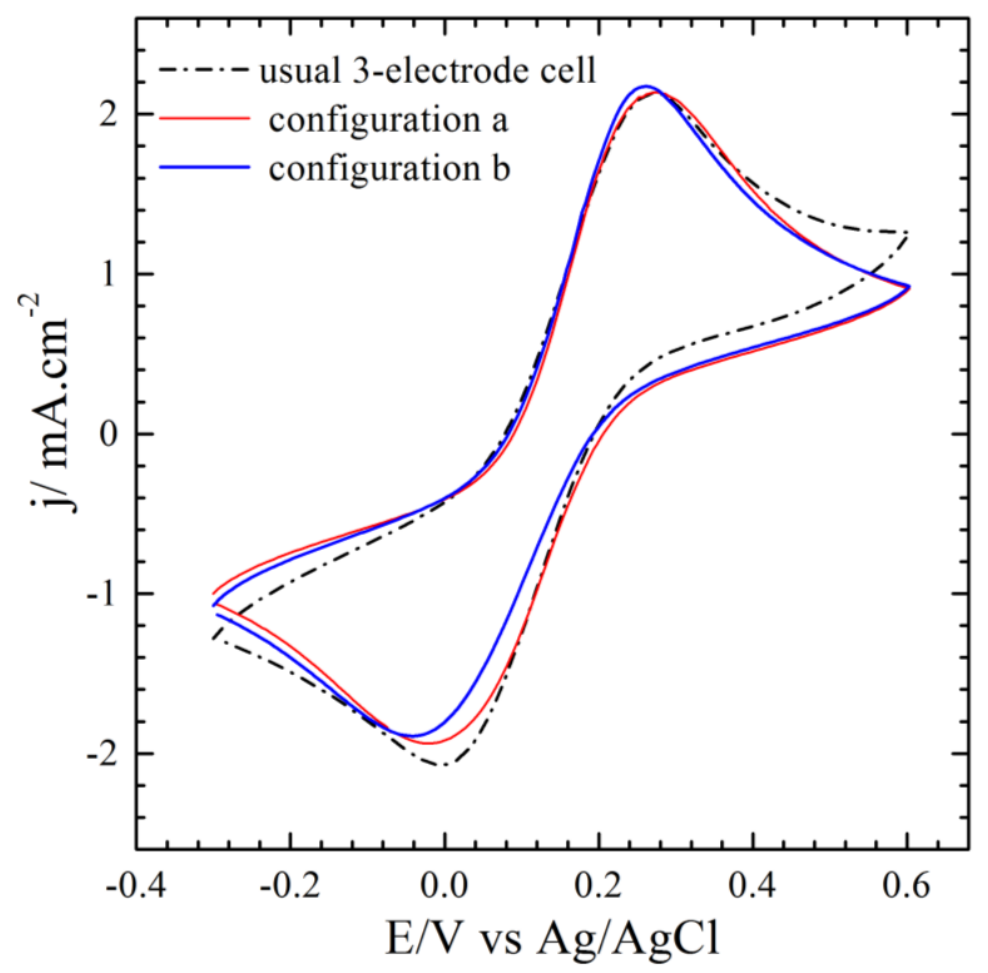

Figura 4-42: Voltamograma cíclico para as três configurações (célula eletroquímica convencional e duas células gota) a $50 \mathrm{mV} \mathrm{s}^{-1}$. 


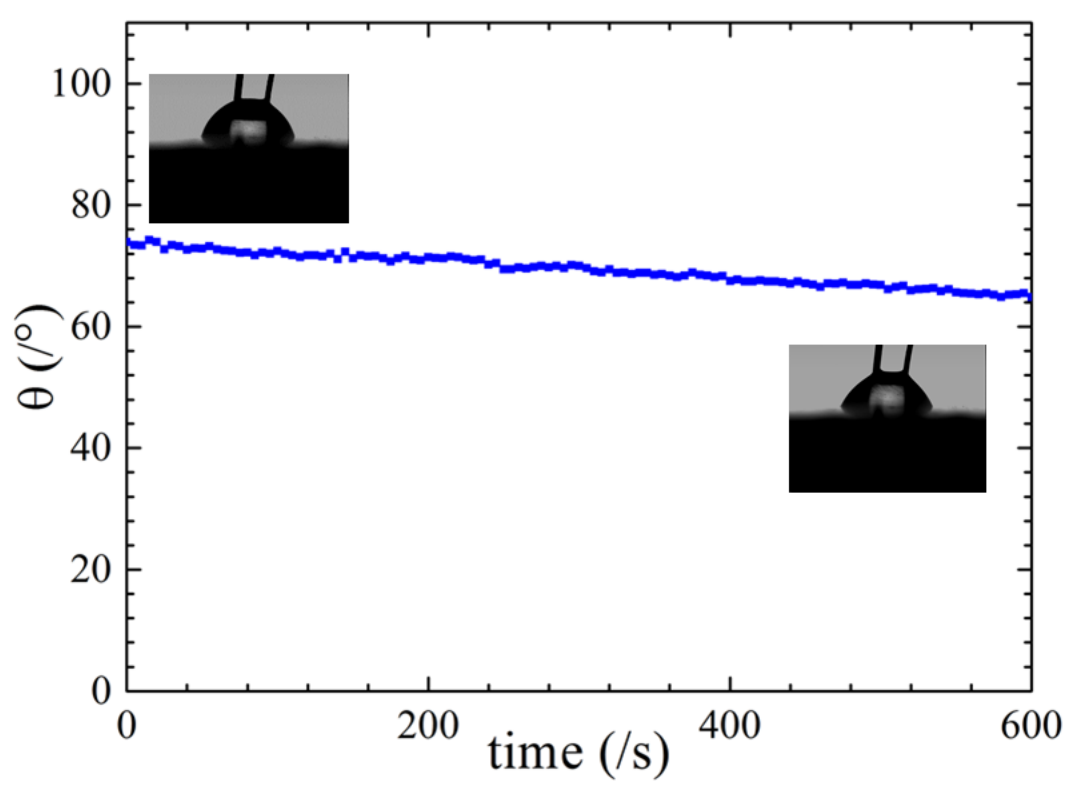

Figura 4-43: Variação do ângulo de contato da gota $\mathrm{Fe}(\mathrm{CN})_{6}{ }^{3-} / \mathrm{Fe}(\mathrm{CN})_{6}{ }^{4-}$ em $0.1 \mathrm{~mol} \mathrm{~L}^{-}$ ${ }^{1} \mathrm{KCl}$ (configuração b)durante as medidas de impedância. As variações devem-se à evaporação da água como mostrado nas figuras.

A Figura 4-44 (A) apresenta os registros da variação do potencial de circuito aberto (A) e do ângulo de contato (B) para quatro medidas diferentes realizadas em uma mesma região. Observa-se uma excelente reprodutibilidade para as medidas das duas grandezas. No que se refere à Figura 4-44 (B), as oscilações observadas no diagrama são consequência do acréscimo de água destilada à gota visando repor o volume perdido por evaporação.
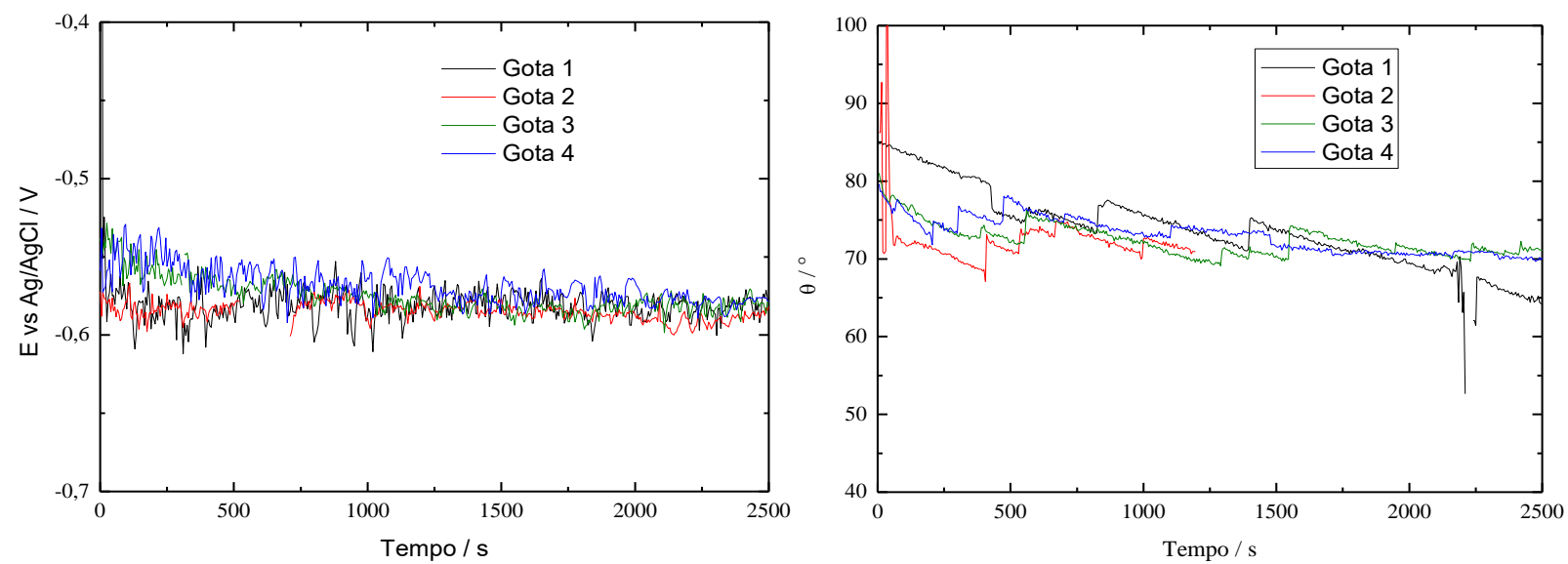

Figura 4-44: Avaliação da reprodutibilidade, com repetições de 4 gotas, acompanhando o potencial de circuito aberto em função do tempo (A) e o ângulo de contato (B) na região do metal em solução de $\mathrm{NaCl}$ 0,1 mol.L ${ }^{-1}$. 
A Figura 4-45 apresenta as medidas de OCP em função do tempo para as diferentes regiões.

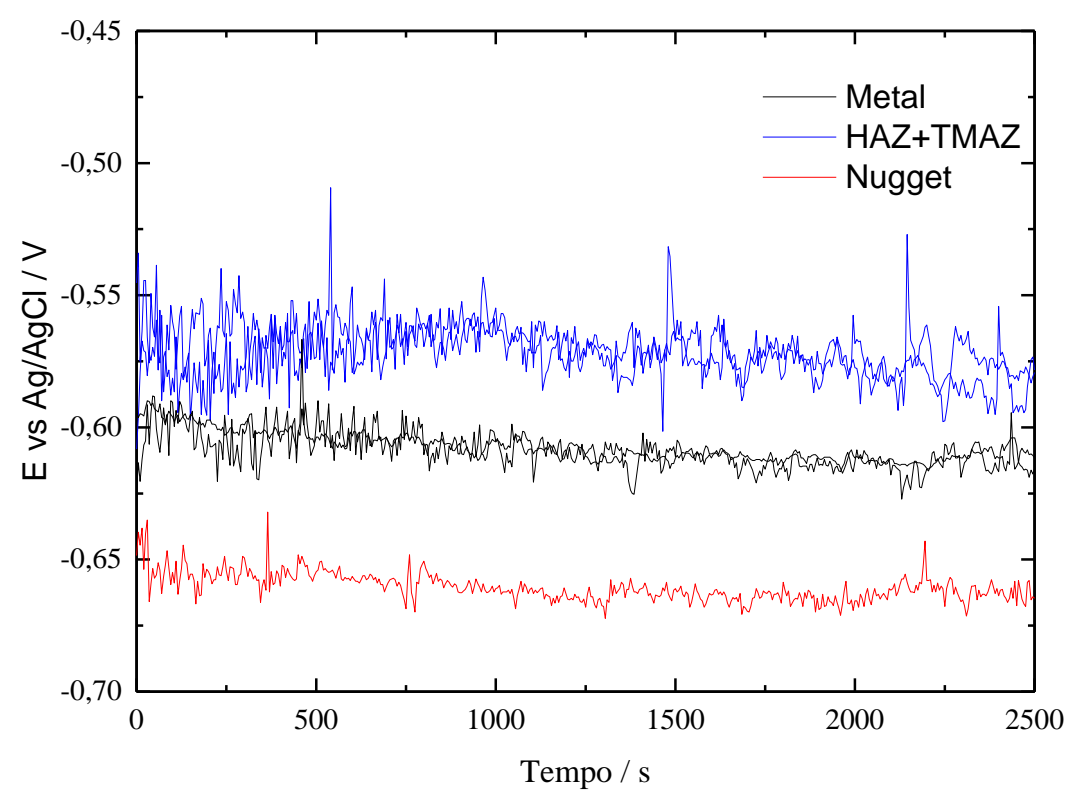

Figura 4-45: Variação do OCP para as regiões do metal base, HAZ+TMAZ e nugget em solução $\mathrm{NaCl} 0,1$ mol.L ${ }^{-1}$

Conforme apresentado pela equação 30, podemos dizer que $\mathrm{C}^{\sigma}$ é a capacitância interfacial por unidade de área que pode ser a capacitância da dupla camada elétrica em uma medida de impedância, e $\phi$ corresponde ao potencial de circuito aberto. Como todos os ensaios serão feitos acompanhando o ângulo de contato entre o metal (Al 2024) e o líquido a solução $\mathrm{NaCl}$ 0,1 mol.L ${ }^{-1}$, podemos, com isso, determinar a capacitância de dupla camada elétrica da impedância eletroquímica e determinarmos através da equação 30 o valor teórico desta, verificando assim se podemos utilizar esta equação como um modelo matemático. A Figura 4-466 apresenta como os resultados experimentais que serão interpretados a partir dos valores experimentais que poderão ser expressos como uma equação Tipo Lippman. Onde no eixo $\mathrm{Y}$ tem-se $\tau^{\mathrm{SL}}$ que é calculado a partir da equação 29. Onde $\theta$ é obtido a partir da medida de ângulo de contato em função do tempo e $\gamma^{\mathrm{LV}}=71 \mathrm{mNm}^{-1}$. Pode-se então calcular $\tau^{\mathrm{SL}}$ para os diferentes tempos da medida, pois a medida de potencial $\phi$ é feita ao mesmo tempo. Traçando então uma curva $\tau^{\mathrm{SL}} \mathrm{em}$ função de $\phi^{2}$, o coeficiente angular da curva é $-\frac{1}{2} \mathrm{C}^{\sigma}$, onde $\mathrm{C}^{\sigma}$ é expressa em $\mathrm{mF} / \mathrm{m}^{2}$. 
Pode-se então comparar este valor com a capacitância obtida pela impedância eletroquímica.

$$
\tau^{\mathrm{SL}}=\frac{(2+\cos \theta)(1-\cos \theta)}{1+\cos \theta} \gamma^{\mathrm{LV}}
$$

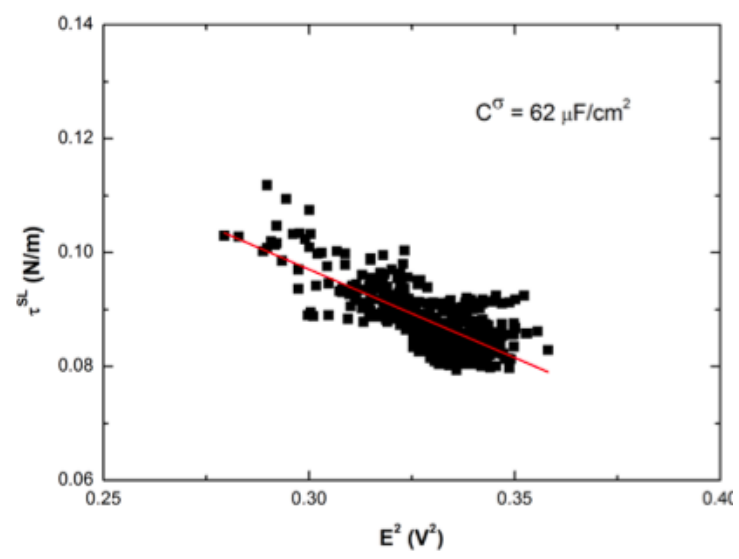

Figura 4-46: Simulação da interpretação dos dados experimentais com os valores estabelecidos pela Figura 3-11.

As medidas de EIS e ângulo de contato (Figura 4-47(A e B)) foram realizadas em meio $\mathrm{NaCl}$ 0,1 mol.L $\mathrm{L}^{-1}$ sobre amostras da liga AA 2024-T3 contendo a região soldada por FSW e também o metal base, e teve por objetivo tanto avaliar, dentre as regiões geradas pela solda, qual é a mais susceptível à corrosão, bem como avaliar a eficiência da técnica de acoplamento do ângulo de contato com EIS. Em uma mesma região, foram depositadas 3 gotas para avaliar a reprodutibilidade da técnica. Observa-se na Figura 4-47(A) que para as três gotas na mesma região da solda, as impedâncias foram semelhantes. A partir desta avaliação, as gotas foram depositadas em regiões diferentes para avaliação. A região entre TMAZ e nugget é menor do que a área da gota, em torno de $3 \mathrm{~mm}$, portanto, não foi possível avaliar esta região isoladamente.

A Figura 4-47 (B) apresenta os diagramas de impedância global registrados durante a realização dos ensaios. Os diagramas de impedância apresentam as mesmas características dos globais já apresentados, na região de altas para médias frequências, com um arco capacitivo seguido de uma difusão. 

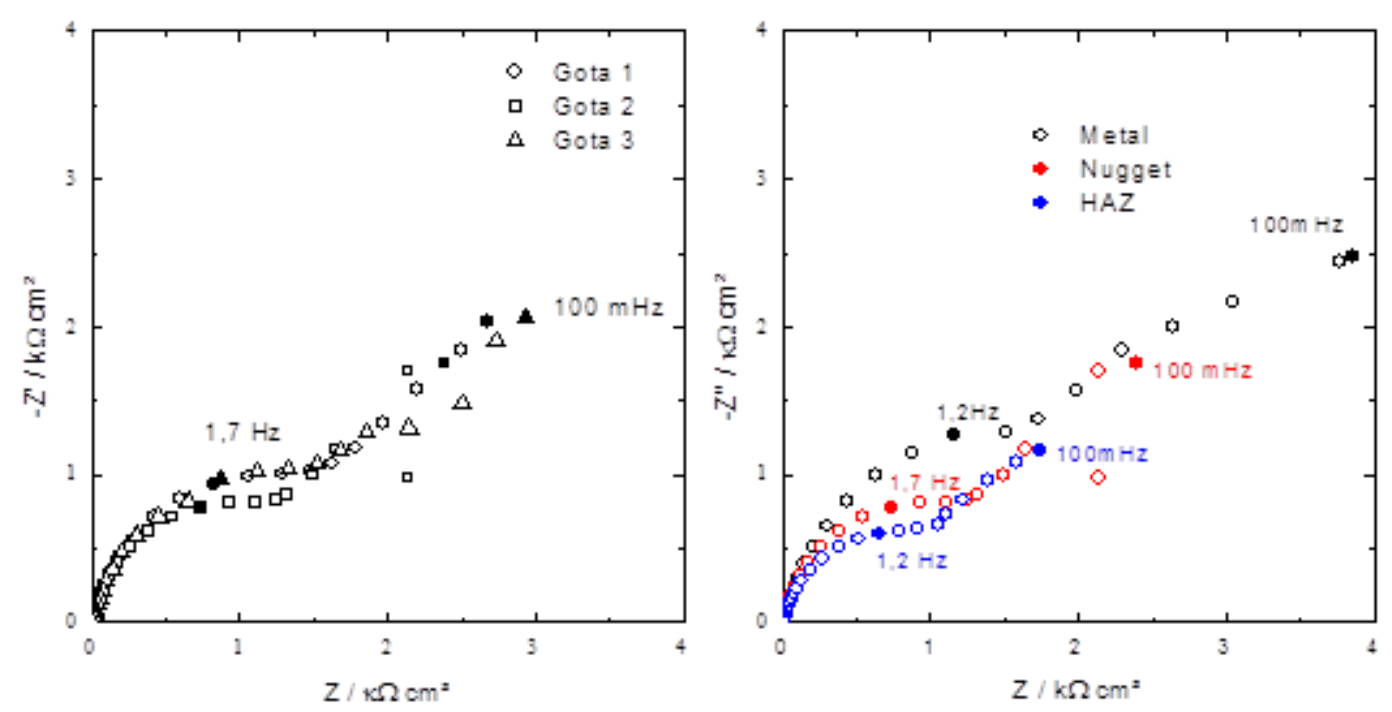

Figura 4-47: Diagramas de Nyquist das medidas de impedância sobre a gota, realizadas sobre AA 2024-T3 soldada por FSW nas diferentes regiões da solda em meio $\mathrm{NaCl} \mathrm{0,1}$ mol.L $\mathrm{L}^{-1}$.

Com objetivo de avaliar a eficiência da técnica utilizada, a capacitância foi calculada experimentalmente ( $\mathrm{C}_{\text {EIS }}$ ) e o cálculo teórico foi feito de acordo com a Figura $4.46\left(\mathrm{C}_{\mathrm{CA}}\right)$ para a capacitância, onde pode-se observar uma coerência nesses resultados concluindo que a equação de Lippman pode ser utilizada para validar a metodologia.

Tabela 4-4: Valores calculados de capacitância para a impedância e a calculada através da simulação

\begin{tabular}{ccc}
\hline & CEIS $\left(\boldsymbol{\mu F ~ \mathbf { ~ c m } ^ { - 2 } )}\right.$ & $\mathrm{C}_{\text {CA }}\left(\mu \mathbf{F ~ c m}^{-2}\right)$ \\
\hline HAZ+TMAZ & 62 & 57 \\
Metal & 58 & 62 \\
Nugget & 28 & 20 \\
\hline
\end{tabular}




\section{CONCLUSÃO}

Os resultados do presente estudo permitem concluir que:

$\mathrm{O}$ aquecimento e as deformações mecânicas provocadas pelo processo de soldagem por fricção (Friction Stir Welding - FSW) de topo da liga de alumínio 2024T3 provocam mudanças na microestrutura principalmente no que concerne à distribuição das partículas nanométricas precipitadas durante o envelhecimento da liga e que são responsáveis pelo controle da sua microestrutura e geram regiões com atividades eletroquímicas heterogêneas.

Os resultados dos ensaios de macroscópicos de corrosão (teste de visualização com gel, ensaios de exfoliação (ASTM G-34) e de corrosão intergranular (ASTM G-110) e dos ensaios eletroquímicos locais (microcélula, SVET) foram altamente concordantes entre si. Os resultados mostraram que a região do metal afetada pelo processo de soldagem possui resistência à corrosão inferior à do metal base, e que, dentre estas, as zonas termicamente afetada (Heat Affected Zone - HAZ) e termomecanicamente afetada (Thermomechanically Affected Zone- TMAZ) do lado do avanço são as mais suscetíveis à corrosão.

A espectroscopia de impedância eletroquímica (Electrochemical Impedance Spectroscopy - EIS) global não foi sensível para avaliar as modificações na resistência à corrosão da liga soldada. Assim, os resultados dos ensaios realizados com eletrodos formados por diferentes proporções do metal base e da região de solda mostraram-se similares entre si, e, por sua vez, não se diferenciaram de modo consistente dos resultados obtidos apenas com o metal base, demonstrando que o procedimento não é adequado para avaliar mudanças na resistência à corrosão de ligas de alumínio similares soldadas por FSW. Por sua vez, quando os testes foram realizados com eletrodos produzidos a partir das diferentes regiões de solda foi possível ranquear a resistência à corrosão das diferentes regiões de solda.

As dispersões na região de baixas frequências, que limitam a algumas centenas de milihertz a frequência mínima para aquisição de dados em um experimento de LEIS, não permitiram a diferenciação da reatividade local das diferentes regiões de solda utilizando esta técnica, pelo menos quando se trata da soldagem de ligas similares. Entretanto, o uso desta técnica foi importante para evidenciar que efeitos de acoplamento galvânico não 
são importantes na determinação da reatividade local das diferentes zonas afetadas pelo processo de FSW.

Através de considerações teóricas, e baseando-se na definição termodinâmica de energia de superfície e nas diferentes forças de tensão entre as interfaces formadas entre um sólido, uma gota e o ar, foi possível obter uma metodologia para cálculo da capacitância da dupla camada elétrica através de medidas de ângulo de contato e do potencial de circuito aberto em função do tempo de contato de uma gota séssil com a superfície de um eletrodo metálico. As previsões teóricas foram confirmadas através de experimentos realizados com um sistema modelo e nas diferentes regiões da liga soldada por FSW. Os valores de capacitância determinados pelo método da gota séssil mostraram um elevado grau de concordância com aqueles obtidos através de ensaios de espectroscopia de impedância eletroquímica realizados simultaneamente com a aquisição dos valores de ângulo de contato. 


\section{SUGESTÕES PARA TRABALHOS FUTUROS}

- Realizar uma caracterização microestrutural mais aprofundada das diferentes regiões afetadas pelo processo de soldagem por meio de TEM a fim de melhor avaliar a distribuição dos nanoprecipitados na microestrutura das diferentes regiões afetadas pelo processo de soldagem. $\mathrm{O}$ estudo pode ser realizado associado a ensaios de calorimetria diferencial de varredura, que, de acordo com a revisão de literatura, é uma técnica bastante sensível a mudanças na distribuição dos precipitados de endurecimento na microestrutura das ligas de alumínio de elevada resistência mecânica.

- Otimizar o sistema de acoplamento gota/EIS para possibilitar o uso de uma gota de tamanho menor permitindo assim avaliação das regiões TMAZ. Avaliar a possibilidade de usar este sistema com o eletrodo sob condições de polarização.

- Utilizar a microcélula em ligas dissimilares, bem como a técnica de LEIS para verificar e comparar os resultados de acoplamento galvânico.

- Aprimorar a construção do bieletrodo para melhorar a sua resolução quando utilizado em eletrodo de trabalho não simétrico como no eletrodo utilizado com a solda FSW.

- Avaliar a influência do posicionamento do eletrodo de referência em relação aos resultados obtidos por LEIS 


\section{REFERÊNCIA BIBLIOGRÁFICAS}

(TWI), T. W. (december de 1991). EUA Patente $N^{o} P C T / G B 92 / 02203$.

ABAL - Associação Brasileira do Alumínio. (2007). Fundamentos e aplicação do aluminio. São Paulo: ABAL.

ABNT NBR15975:2011, A. (14 de 12 de 2015). Alumínio primário e de fundição Composição química. p. 14.

AOKI, I., BERNARD, M.-C., CORDOBA DETORRESI, S., DESLOUIS, C., DE MELO, H., JOIRET, S., \& TRIBOLLET, T. (2001). Ac-impedance and Raman spectroscopy study of the electrochemical behaviour of pure aluminium in citric acid media. Electrochimica Acta, 46, pp. 1871-1.

ASM Specialty Handbook. (1993). Aluminum and aluminum alloys. 2(1). ASM International.

ASTM METALS HANDBOOK. (1990). Corrosion. Formerly 9th edition.

ATKINS, P., \& JONES, L. (2001). Princípios de Química: Questionando a vida moderna e o meio ambiente. Porto Alegre: Bookman.

BALOGH, D., TEL-VERED, R., RISKIN, M., ORBACH, R., \& WILLNER, I. (2011). Electrified au nanoparticle sponges with controlled hydrophilic/hidrophobic properties. ACS Nano, 5, pp. 299-306.

BARDAL, E. (1933). Corrosion and Protection. London: Springer.

BARIL, G., BLANC, C., KEDDAM, M., \& PÉBÈRE, N. (2003). Local Electrochemical Impedance Spectroscopy Applied to the Corrosion Behavior of an AZ91 Magnesium Alloy. Journal of Electrochemical Society, 150( 10), pp. B488-B493.

BASTOS, A., \& SIMÕES, A. (2003). Corrosion of Electrogalvanized Steel in $0.1 \mathrm{M}$ $\mathrm{NaCl}$ Studied by SVET. Portugaliae Electrochimica Acta, 21, pp. 371-387.

BASTOS, A., DIAS, S., DIAMANTINO, T., \& FERREIRA, M. (2013). Uma introdução à técnica SVET. Corrosion Protection Materials, 32, pp. 50-57.

BENAVIDES, S., LI, Y., \& MURR, L. (1999). Low-temperature friction-stir welding of 2024 aluminum. Scripta Materialia, 41, p. 809.

BERTONCELLO, J., MANHABOSCO, S., \& DICK, L. (2015). Corrosion study of the friction stir lap joint of AA7050-T76511 on AA2024-T3 using the scanning vibrating electrode technique. Corrosion Science, 94 , pp. 359-367.

BIRBILIS, N., \& BUCHHEIT, R. G. (2005). Electrochemical Characteristics of Intermetallic Phases in Aluminum Alloys. Journal of The Electrochemical Society, 152, pp. B140-B151. 
BLANC, C., LAVELLE, B., \& MANKOWSKI, G. (1997). The role of precipitates enriched with copper on the susceptibility to pitting corrosion of the 2024 aluminun alloy. Corrosion Science, 39(3), pp. 495-510.

BLANC, C., ORAZEM, M., PÉBÈRE, N., TRIBOLLET, B., VIVIER, V., \& WU, S. (2010). The origin of the complex character os the ohmic impedance. Electrochimica Acta, 55, pp. 6313-6321.

BOAG, A., HUGHES, A., WILSOM, N., TORPY, A., MACRAE, C., GLENN, A., \& MUETS, T. (2009). How complex is the microstructure of AA2024-T3. Corrosion Science, 51, pp. 1565-1568.

BOAG, A., TAYLOR, R., MUSTER, T., GOODMAN, N., MCCULLOCH, D., RYAN, C., ... HUGHES, A. (2010). Stable pit formation on AA2024-T3 in a $\mathrm{NaCl}$ environment. Corrosion Science, 52, pp. 90-103.

BOUSQUET, E. (21 de julho de 2011a). Durabilité des Assemblages Soudés par Friction Stir Welding (FSW). Tese, 254 p. Bordeaux, França,: Université de Bordeaux 1.

BOUSQUET, E., POULON-QUINTIN, A., DEVOS, O., PUIGGALI, M., \& TOUZET, M. (2012). Microstructure, Mechanical and Corrosion Behaviour of an AA2024-T3 FSW. Joint Advanced Materials Research, 409, pp. 257-262.

BOUSQUET, E., POULON-QUINTIN, A., PUIGGALI, M., DEVOS, O., \& TOUZET, M. (2011). Relationship between microstructure, microhardness and corrosion sensity of AA 2024-T3 friction stir welded joint. Corrosion Science, 53(9), 3026-3034.

BUCHHEIT, R. (1995). A Compilation of Corrosion Potentials Reported for Intermetallic Phases in Aluminum Alloys. Journal of Electrochemical Society, 142(11), pp. 3994-3996.

BUCHHEIT, R., GRANT, R., HLAVA, P., MCKENZIE, B., \& ZENDER, G. L. (1997). Local Dissolution Phenomena Associated with S Phase (Al2CuMg) Particles in Aluminum Alloy 2024-T3. Journal of the Electrochemical Society,, 144(8), pp. 26212628.

CALLISTER, J., \& WILLIAN, D. (1994). Materials Sciences an Engineering: an introduction. New York: J. Wiley \& Sons.

CAMPESTRINI, P., VAN WESTING, E., VAN ROOIJEN, H., \& de WIT, J. (2000). Relation between microstructural aspects of AA2024 and its corrosion behaviour investigated using AFM scanning potential technique. Corrosion Science, 42, pp. 18531861.

CHARAI, A., WALTHER, T., ALFONSO, C., ZAHRA, A., \& ZAHRA, C. (2000). Coexistence of Clusters, GPB Zones, S"-, S'- and S-Phases in an $\mathrm{Al} \pm 0.9 \% \mathrm{Cu} \pm 1.4 \% \mathrm{Mg}$ Alloy. Acta Materialia, 48, pp. 2751-2764.

CHEN, G., GAO, S., \& WEI, R. (1996). Microconstituent-induced pitting corrosion in aluminium alloy 2024-T3. Corrosion, 52(1), pp. 8-15. 
CORRAL, J., TRILLO, E., YING, L., \& MURR, L. (2000). Corrosion of friction-stir welded aluminum alloys 2024 and 2195. Journal of Materials Science Letters, 19, pp. $2117-2122$.

DE LIMA-NETO, P., FARIAS, J., HERCULANO, L., MIRANDA, H., ARAÚJO, W., JPRCIN, J.-B., \& PÉBÈRE, N. (2008). Determination of the sensitized zone extension in welded AISI 304 stainless steel using non-destructive electrochemical techniques. Corrosion Science, 50(4), pp. 1149-1159.

DIX, E. (1940). Acceleration of the rate of corrosion by high constant stresses. Am.Inst.Mining Met.Engrs., Inst.Metals Div., Tech.Pub., 30(1204).

DUBOIS, J., FOURNÉE, V., THIEL, P., \& BELIN-FERRÉ, E. (2008). Measurements of contact angles of water on Al-based inetrmetallic surfaces. Journal of Physics: Condensed Matter, 1-10.

DUBOIT, B., \& SAINFORT, P. (1991). Durcissement par précipitation des alliages d'aluminium - Découverte et évolution de la technique. Techniques de l'Ingénieu.

DUDZIK, K. (2011). The influence of joining method of AW-7020 aluminium alloy on corrosion properties. Journal of KONES Powertrain and Transport, 18(4), 587-591.

FERRARI, J. (2011). Estudo da corrosão localizada da liga de alumínio 7475-T761 por espectroscopia de impedância eletroquímica global e local em meio de sulfato de sódio. Universidade de São Paulo - USP, Escola Politécnica de São Paulo, São Paulo.

FONDA, R., BINGERT, J., \& COLLIGAN, K. (2004). Development of grain structure during friction stir welding. Scripta Materialia, 51(3), pp. 243-248.

FONDA, R., PAO, P., JONES, H., FENG, C., CONNOLLY, B., \& DAVENPORT, A. (2009). Microstructure, mechanical properties, and corrosion of friction stir welded Al 5456. Material Science Engineering, A 519(1-8).

FRIGAARD, Ø., GRONG, Ø., \& MIDLING, O. (Maio de 2001). A Process Model for Friction Stir Welding of Age Hardening Aluminum Alloys. METALLURGICAL AND MATERIALS TRANSACTIONS A, 32A, pp. 1189-1200 .

FRIGAARD, O., GRONG, O., \& MIDLING, O. A. (2001). Process Model for Friction Stir Welding of Age Hardening Aluminum Alloys. Metallurgical and Materials Transactions A, 32A, pp. 1189-1200.

GABRIELLI, C., KEDDAM, M., PORTAIL, N., ROUSSEAU, P., TAKENOUTI, H., \& VIVIER, V. E.-L. (2006). J Phys Chem B, 110 , pp. 20478-20485.

GALICIA, G., PÉBÈRE, N., TRIBOLLET, B., \& VIVIER, V. (2009). Local and global electrochemical impedances applied to the corrosion behaviour of an AZ91 magnesium alloy. Corrosion Science, 51, pp. 1789-1794.

GAO, N., DAVIN, L., WANG, S., CEREZO, A., \& STARINK, M. (2002).

Precipitation in stretched $\mathrm{Al}-\mathrm{Cu}-\mathrm{Mg}$ alloys with reduced alloying content studied by DSC, TEM and atom probe. Materials Science Forum, 396-402, pp. 923-28. 
GAO, N., DAVIN, L., WANG, S., CEREZO, A., \& STARINK, M. (2002).

Precipitation in stretched $\mathrm{Al}-\mathrm{Cu}-\mathrm{Mg}$ alloys with reduced alloying content studied by DSC. Materials Science Forum, 396-402, pp. 923-28.

GENEVOIS, C., DESCHAMPS, A., DENQUIN, A., \& DOISNEAU-COTTIGNIES, B. (2005). Quantitative investigation of precipitation and mechanical behaviour for AA2024 friction stir welds. Acta Materialia, 53, pp. 2447-2458.

GIBSON, B., LAMMLEIN, D., PRATER, T., LONGHURST, W., COX, C., BALLUN, M., . . . COOK, G. S. (2013). Friction Stir Welding: Process, Automation, and Control. Journal of Manufacturing Processes.

GLENN, A., MUSTER, T., LUO, C., ZHOU, X., THOMPSON, G., BOAG, A., \& HUGHES, A. (2011). Corrosion of AA2024-T3 Part III. Corrosion Science Propagation, 53 , pp. 40-50.

GLOBAL ADVISORY GROUP, G. (2011). Terms and Definitions. 1(3a. ). The Aluminum Association.

GUERRA, M., SCHIMIDT, C., MCCLURE, J., MURR, L., \& NUNES, A. (2003). Flow patterns during friction stir welding. Materials Characterization, pp. 95-101.

GUILLAUMIN, V., \& MANKOWSKI, G. (1998). Localized corrosion of 2024 T351 aluminium alloy in chloride media. Corrosion Science, 41(3), pp. 421-438.

GUILLAUMIN, V., \& MANKOWSKI, G. (1999). Localized corrosion of 1913 T240 aluminium alloy in chloride media. Corrosion Science, 41, pp. 421-438.

GUPTA, R., DAS, H., \& PAL, T. (2012). Influence of Processing Parameters on Induced Energy, Mechanical and Corrosion Properties of FSW Butt Joint of 7475 AA. Journal of Materials Engineering and Performance, 21(8), p. 1645.

HANDBOOK, M. S. (1966). Aluminum and aluminum alloys. Washington 25, D.C.: Departament Of Defense USA.

HATHERLY, F., \& HUMPHREYS, M. (1995).

http://www.sciencedirect.com/science/book/9780080441641. NY: Perganon Press.

HEINS, B., \& SKROTZKI, B. (2002). Characterization of a friction-stir-welded aluminum alloy 6013. Metallurgical and Materials Transactions B, 33(3), pp. 489-498.

HOLLY, F. (1977). Contact angle of sessile drops as an indicator of surface polarization. Journal of colloid and interface science, 435-437.

HU, W., \& MELETIS, E. (2000). Corrosion and environment-assisted cracking behaviour of friction stir welded Al2195 and Al2219 alloys. Materials Science Forum, pp. 1683-1688.

HUANG, V.-W., VIVIER, V., ORAZEM, M., PEVERE, N., \& TRIBOLLET, B. (2007). The apparent constant-phase-element behavior of an ideally polarized blocking electrode a global and local impedance analysis. J Electrochem Soc, 154, pp. C81-C88. 
HUGHES, A., BOAG, A., GLENN, A., MCCULlOCH, D., MUSTER, T., RYAN, C., . .. THOMPSON, G. (2011). Corrosion of AA2024-T3. Corrosion Science 53, pp. 2739.

HUGHES, A., BOAG, A., GLENN, A., MCCULlOCH, D., MUSTER, T., RYAN, C., . .. THOMPSON, G. (2011). Corrosion of AA2024-T3 Part II. Corrosion Science 53, pp. $27-39$.

HUGHES, A., MACRAE, C., WILSON, N., TORPY, A., MUSTER, T., \& GLENN, A. (2010). Sheet AA2024-T3: a new investigation of microstructure and composition. Surface and Interface Analysis, 42, pp. 334-338.

ILEVBARE, G., SCHNEIDER, O., KELLY, R., \& SCULLY, J. (2004). In Situ Confocal Laser Scanning Microscopy of AA 2024-T3 Corrosion Metrology. I. Localized Corrosion of Particles. Journal of The Electrochemical Society, 151 (8).

ISAACS, H. (1987). The use of the scanning vibrating electrode technique for detecting defects in ion vapor-deposited aluminum on steel. Corrosion, 43(10), pp. 594-598.

ISAACS, H. (1988). The measurement of the galvanic corrosion of soldered copper using the scanning vibrating electrode technique. Corrosion Science, 28(6), pp. 547558.

ISAACS, H., \& KEDING, M. (1980). Determination of surface inhomogeneities using a scanning probe impedance technique,. Corrosion, 36(6), pp. 269-273.

ISAACS, H., \& KISSEL, G. (1972). Surface preparation and pit propagation in stainless steels. Journal of the Electrochemical Society, 119(12), p. 1628.

ISAACS, H., ALDYKIEWICZ, A., THIERRY, D., \& SYMPSON, T. (1996).

Measurements of corrosion at defects in painted zinc and zinc alloy coated steels using current density mapping. Corrosion, 52(3), pp. 163-168.

JARIYABOON, M., DAVENPORT, A. J., AMBAT, R., CONNOLLY, B. J., WILLIANS, S. W., \& PRICE, D. A. (2007). The effect of welding parameters on the corrosion behaviour of friction stir welded AA2024-T351. Corrosion Science, pp. 877909.

JARIYABOON, M., DAVENPORT, A. J., AMBAT, R., CONNOLLY, B. J., WILLIANS, S. W., \& PRICE, D. A. (2009). The effect of cryogenic CO2 cooling on corrosion behaviour of friction stir welded AA2024-T351 . Corrosion Engineering, Science and Technology, 425.

JATA, K., \& SEMIATIN, S. (2000). Continuous dynamic recrystallization during friction stir welding of high strength aluminum alloys. Scripata Materialia, 43, pp. 743749 .

JONE, M., HEURTIER, P., DESRAYAUD, C., MONTHEILLET, F., ALLEHAUX, D., \& DRIVER, J. (2005). Correlation between microstructure and microhardness in a friction stir welded 2024 aluminium alloy. Scripta Materialia, 52, pp. 693-697. 
KANYANEE, T., FUEKHAD, P., \& GRUDPAN, K. (2013). Micro coulometric titration in a liquid drop. Talanta, 115, pp. 258-262.

KAUFMAN, J., \& ROOY, E. (2004). Aluminum alloy casting properties, processo and applications. ASM International.

KOVARIK, L., COURT, S., Fraser, H., \& Mills, M. (2008). GPB zones and composite GPB/GPBII zones in Al-Cu-Mg alloys. Acta Materialia, 56, pp. 4804-4815.

KRAWIEC, H., VIGNAL, V., AMAR, H., \& PEYRE, P. (2011). Local electrochemical impedance spectroscopy study of the influence of ageing in air and laser shock processing on the micro-electrochemical behaviour of AA2050-T8 aluminium alloy. Electrochim. Acta, 56, p. 958.

KWON, Y., \& SAITO, N. I. (2002). Friction stir process as a new manufacturing tech,Nique of ultrafine grained aluminum alloy. Journal of Materials Science Letters, 21, pp. 1473-1476.

LACROIX, L., BLANC, C., PÉBÈRE, N., THOMPSON, G., TRIBOLLET, B., \& VIVIER, V. (2012). Simulating the galvanic coupling between S-A12CuMg phase particlesand the matrix of 2024 aerospace aluminium alloy. Corrosion Science, 64 , pp. 213-221.

LI, Y., MURR, L., \& MCCLURE, J. (1999). Flow visualization and residual microstructures associated with the friction-stir welding of 2024 aluminum to 6061 aluminum. Materials Science and Engineering. A 271, pp. 213-223.

LIAO, C., OLIVE, J., GAO, M., \& WEI, R. (1988). In-situ monitoring of pitting corrosion in aluminum alloy 2024. Corrosion, 54(6), pp. 451-458.

LILLARD, R., KRUGER, J., TAIT, W., \& MORAN, P. (1995). USING LOCAL ELECTROCHEMICAL IMPEDANCE SPECTROSCOPY TO EXAMINE COATING FAILURE. CORROSION , 51(4), pp. 251-259.

LILLARD, R., MOARAN, P., \& ISAACS, H. (1992 ). A Novel Method for Generating Quantitative Local Electrochemical Impedance Spectroscopy. Journal of Electrochemical Society, 139(4), pp. 1007-1012.

LIU, G., MURR, L., NIOU, C., MCCLURE, J., \& VEGA, F. (1997). Microstructural aspects of the friction-stir welding of 6061-T6 aluminum. Scripta Materialia, 37(3), pp. 355-361.

LUO, C., ZHANG, X., ZHOU, X., SUN, Z., ZHANG, X., TANG, Z., . . THOMPSON, G. (maio de 2016). Characterization of Localized Corrosion in an Al-Cu-Li Alloy. Journal of Materials Engineering and Performance, 25(5), pp. 1811-1819.

LUO, C., ZHOU, X., THOMPSON, G., \& HUGHES, A. (2012). Observations of intergranular corrosion in AA2024-T351: The influence of grain stored energy. pp. 3544.

M.W. MAHONEY, C. R. (1998). Properties of friction-stir-welded 7075 T651 aluminum . Metallurgical and Materials Transactions A, 1955-1964. 
MATSUBARA, E., \& COHEN, J. B. (1983). Local atomic arrangements in the solid solution of Al-1,7 at. \% Cu at 793K. Acta Metallurgica, 31, pp. 2129-2135.

MENNUCCI, M., SANCHEZ-MORENO, M., AOKI, I., BERNARD, M., MELO, H., JOIRET, S., \& VIVIER, V. (2012). Local electrochemical investigation of copper patina. J. Solid State Electrochem., 16, pp. 109-116.

MICHEL, R., MONTELLA, C., VERDIER, C., \& DIARD, J. (2010). Numerical computation of the Faradaic impedance of inlaid microdisk electrodes using a finite element method with anisotropic mesh adaptation. Electrochim Acta, 55 , pp. 62636273 .

MIKHAYLIN, S., \& BAZINET, L. (2016). Fouling on ion-exchange membranes: Classification, characterization and strategies of prevention and control. Advances in colloid and interface science, 229, pp. 34-56.

Milani, M., \& Cardoso, A. (2003). Construction and performance of a drop cell for the nephelometric determination of sulfur dioxide. Microchemical Journal, 74, pp. 75-82.

MILANI, M., \& CARDOSO, A. (2003). Construction and performance of a drop cell for the nephelometric determination of sulfer dioxide. Microchemical Journal, 74, pp. $75-82$.

MISHRA, R., \& MA, Z. (2005). Friction stir welding and processing. Materials Science and Engineering: R: Reports., 50, pp. 1-78.

MISHRA, R., \& MA.Z.Y. (2005). Friction stir welding and processing. Materials Science and Engineering: R: Reports. , 50, pp. 1-78.

MOHAMMADTAHERI, M., HADDAD_SABZEVAR, M., MAZINANI, M., \& BAHRAMI MOTLAGH, E. (2013). The Effect of Base Metal Conditions on the Final Microstructure and Hardness of 2024 Aluminum Alloy Friction-Stir Welds. Metallurgical and materials transactions B, 738 .

MOROZ, I., ALCÂNTARA, N., \& SANTOS, J. (2012). Caracterização Microestrutural e Propriedades Mecânicas da Liga de Alumínio 2198-T851 em Configuração Tailored Blank Soldada por FSW - Friction Stir Welding. Soldagem e Inspeção, 019-025.

MOUANGAA, M., PUIGGAlli, M., TRIBOLlet, B., VIVIER, V., PÉBÈRE, N., \& DEVOS, O. (2013). Galvanic corrosion between zinc and carbon steel investigated by local electrochemical impedance spectroscopy. Electrochimica Acta, 88, pp. 6-14.

MURR, L., LI, Y., FLORES, R., \& TRILLO, E. (1998). Intercalation vortices and related microstructural features in the friction-stir welding of dissimilar metals. Material Research Innovations, 2, pp. 150-63.

MURR, L., TRILLO, E., FLORES, R., \& MCCLURE, J. (1998a). Microstructures in friction stir welded metals. Journal of Materials Processing and Manufacturing Science, 7(2), pp. 145-161. 
MUTHU KUMARAN, S. (2012). Identification of high temperature precipitation reactions in $2024 \mathrm{Al}-\mathrm{Cu}-\mathrm{Mg}$ alloy through ultrasonic parameters. Journal of Alloys and Compounds, 539, pp. 179-183.

NAKAT, S., KIM, Y., USHIO, M., HASHIMOTO, T., \& JYOGAN, S. (2000). Weldability of high strength aluminum alloys by friction stir welding. ISIJ International, 40(S15-S19).

NANDAN, R., DEBROY, T., \& BHADESHIA, H. K. (2008). Recent advances in friction-stir welding - Process, weldment structure and properties. Progress in Material Science, 53, pp. 980-1023.

NEWMAN, J. (1966). Resistance for Flow of Current to a Disk. Journal of electrochemical Society, 113, pp. 1235-1241.

NEWMAN, J. (1970). Frequency dispersion in capacity measurements at a disk electrode. J Electrochem Soc, 117 , pp. 198-203.

O'CONNELL, M., SNOWDEN, M., MCKELVEY, K., GAYET, F., SHIRLEY, I., HADDLETON, D., \& UNWIN, P. (2014). Positionable vertical microfluidic cell based on electromigration in a theta pipet. Langmuir, 30, pp. 10011-10018.

PAGLIA, C., \& BUCHHEIT, R. (2006). Microstructure, microchemistry and environmental cracking susceptibility of friction stir welded 2219-T87. Material Science and Engineering A, 429, pp. 107-114.

PAGLIA, C., \& BUCHHEIT, R. (2008). A look in the corrosion of aluminum alloy friction stir welds. Scripta Materialia, 58(5), pp. 383-387.

PALOMINO, L. (2007). Caracterização microestrutural e eletroquímica de revestimentos ambientalmente amigáveis aplicados sobre a liga de Al 2024-T3. Universidade de São Paulo - USP, Escola Politécnica, São Paulo.

PAREL, T., WANG, S., \& STARINK, M. (2010). Hardening of an Al-Cu-Mg alloy containing Types I and II S phase precipitates. Materials and Design, 31(S2-S5).

PAREL, T., WANG, S., \& STARINK, M. (2010). Hardening of an Al-Cu-Mg alloy containing Types I and II S phase precipitates. Materials and Design, 31, pp. S2-S5.

PAREL, T., WANG, S., \& STARINK, M. (2010). Hardening of an Al-Cu-Mg alloy containing Types I and II S phase precipitates. Materials and Design, 31, pp. S2-S5.

PATEL, A., COLLIGNON, M., O'CONNEL, M., HUNG, W., MCKELVEY, A., MACPHERSON, J., \& UNWIN, P. (2012). A new view of electrochemistry at highly oriented pyrolytic graphite. J Am Chem Soc, 134, pp. 20117-20130.

PATIL, H., \& SOMAN, S. (2013). Effect of weld parameter on mechanical and metallurgical properties of dissimilar joints AA6082-AA6061 in T6 condition produced by FSW. Frattura ed Integrità Strutturale, 24, pp. 151-160.

PILASKI, M., HAMELMANN, T., MOEHRING, A., \& LOHRENGEL, M. (2004). Impedance spectroscopy in micro systems. Electrochim. Acta., 49, pp. 2863-2870. 
PROTON, V., ALEXIS, J., ANDRIEU, E., BLANC, C., DELFOSSE, J., LACROIX, L., \& ODEMER, G. (2011). Influence of Post-Welding Heat Treatment on the Corrosion Friction Stir Welding Joint Behavior of a 2050-T3 Aluminum-CopperLithium Alloy. Journal of The Electrochemical Society, 139-147.

PROTON, V., ALEXIS, J., ANDRIEU, E., DELFOSSE, J., LAFONT, M.-C., \& BLANC, C. (2013). Characterisation and understanding of the corrosion behaviour of the nugget in a 2050 aluminium alloy Friction Stir Welding joint. Corrosion Science, 73, pp. 130-142.

QUEIROZ, F., MAGNANI, M., COSTA, I., \& de MELO, H. (2008). Investigation of the corrosion behaviour of AA 2024-T3 in low concentrated chloride media. Corrosion Science, 50, pp. 2646-2657).

QUEIROZ, F., MAGNANI, M., COSTA, I., \& DE MELO, H. (2008). Investigation of the corrosion behaviour of AA 2024-T3 in low concentrated chloride media. Corrosion Science, 50 (9), pp. 2646-2657.

QUEIROZ, F., MAGNANI, M., COSTA, I., \& deMELO, H. (2008). Investigation of the corrosion behaviour of AA 2024-T3 in low concentrated chloride media. Corrosion Scienc, 50, pp. 2646-2657.

RABBOW, T., TRAMPERT, M., POKORNY, P., BINDER, P., \& WHITEHEAD, A. (2015). Variability within a single type of polyacrylonitrile-based graphite felt after thermal treatment. Electrochimica Acta, 173, pp. 17-23.

RADISAVLJEVIC, I., ZIVKOVIC, A., RADOVIC, N., \& GRABULOV, V. (2013). Influence of FSW parameters on formation quality andmechanical properties of $\mathrm{Al}$ 2024-T351 butt welded joints. Transactions of Nonferrous Metals Society of China, pp. 3525-3539.

RHODES, C., MAHONEY, M., BINGEL, W., SPURLING, R., \& BAMPTON, C. (1997). Effects of friction stir welding on microstructure of 7075 aluminum. Scripta Materialia, 36, pp. 69-75.

RINGER, S. P., \& HONO, K. (2000). Microstructural Evolution and Age Hardening in Aluminium Alloys: Atom Probe Field-Ion Microscopy and Transmission Electron Microscopy Studies. Materials Characterization, 44, pp. 101-131 .

RINGER, S. P., HONO, K., SAKSAI, T., \& POLMEAR, I. J. (1997). CLUSTER HARDENING IN AN AGED Al-Cu-Mg ALLOY. Scripta Materialia, 36(5), pp. 517521.

RINGER, S., HONO, K., POLMEAR, I., \& SAKURAI, T. (1996). Precipitation processes during the early stages of ageing in A1-Cu-Mg alloys. Applied Surface Science, 94/95, pp. 253-260.

RINGER, S., HONO, K., POLMEAR, I., \& SAKURAI, T. (1996). Precipitation processes during the early stages of ageing in A1-Cu-Mg alloys. Applied Surface Science, 94/95, pp. 253-260. 
ROSEN, M., IVES, L., RIDDER, S., BIANCANIELLO, F., \& MEHRABIAN, R. (1985). Correlation between Ultrasonic and Hardness Measurements in Aged Aluminum Alloy 2024. Materials Science and Engineering, 74, pp. 1-10.

ROSEN, M., IVES, L., RIDDER, S., BIANCANIELLO, F., \& MEHRABIAN, R. (1985). Correlation between Ultrasonic and Hardness Measurements in Aged Aluminum Alloy 2024. Materials Science and Engineering, 74, pp. 1-10.

SÁNCHEZ, M., AOUINA, N., ROSE, D., ROUSSEAU, P., TAKENOUTI, H., \& VIVIER, V. (2012). Assessment of the electrochemical microcell geometry by local electrochemical impedance spectroscopy of copper corrosion. Electrochimica Acta, 62, pp. 276-281.

SATO, Y., KURIHARA, S., \& KOKAWA, H. (2011). Systematic examination of precipitation phenomena associated with hardness and corrosion properties in friction stir welded aluminium alloy 2024. Welding in the World, 55(11-12), pp. 39-47.

SCHNEIDER J., B. R. (2006). Interfacial sticking and slipping in the friction stir welding process. Materials Science and Engineering A, 297-304.

SCHREDER, M. (1999). Work of adhesion of a sessile drop to a clean surface. Journal of colloid and interface science, 602-605.

SHAO, M., FU, Y., HU, F., \& LIN, C. (2003). A study on pitting corrosion of aluminum alloy 2024-T3 by scanning microreference electrode technique. Materials Science and Engineering: A, 344(1-2,), pp. 323-327.

SIDANE, D., BOUSQUET, E., DEVOS, O., PUIGGALI, M., TOUZET, M., VIVIER, V., \& POULON-QUINTIN, A. (2015). Local electrochemical study of friction stir welded aluminum alloy. Journal of Electroanalytical Chemistry, 737 , pp. 206-211.

SILCOCK, J. (1960-1961). The structural ageing characteristics of Al-Cu-Mg alloys with copper-magnesium ratios of 7-1 and 2.2-1. Journal of the Institute of Metals, 89(6), pp. 203-210.

SILCOK, J. (1960-1961). The structural ageing characteristics of Al-Cu-Mg alloys with copper-magnesium ratios of 7-1 and 2.2-1. Journal of the Institute of Metals, 89(6), pp. 203-210.

STARINK, M., GAO, N., \& YAN, J. (2004). The origins of room temperature hardening of Al-Cu-Mg alloys. Materials Science and Engineering A, pp. 222-226.

STARINK, M., GAO, N., \& YAN, J. (2004). The origins of room temperature hardening of Al-Cu-Mg alloys. Materials Science and Engineering A, pp. 387-389.

STARKE, E. A., \& STALEY, J. T. (1996). Application of modern aluminum alloys to aircraft. Prog. Aerospace Sci., 32, pp. 131-172.

SU, J., NELSON, T., MISHRA, R., \& MAHONEY, M. (2003). Microstructural investigation of friction stir welded 7050-T651 aluminium. Acta Materialia, 51, pp. 713-729. 
SU, J.-Q., NELSON, T., MISHRA, R., \& MAHONEY, M. (2003). Microstructural investigation of friction stir welded 7050- T651 aluminium. Acta Materialia, 51, pp. 713-729.

TEL-VERED, R., KAHN, J., \& WILLNER, I. (2016). Layered Metal Nanoparticle Structures on Electrodes for Sensing, Switchable Controlled Uptake/Release, and Photo-electrochemical Applications. Small, 12, pp. 51-75.

THREADGILL, P. (2009). Friction stir welding of aluminium alloys. International Materials Reviews, 49-93.

THREADGILL, P. L., LEONARD, A., SHERCLIFF, H., \& WITHERS, P. (2009). Friction stir welding of aluminium alloys. International Materials Reviews, 54(2), 4993.

THREADGILL, P., LEONARD, A., SHERCLIFF, H., \& WHITERS, P. (2009). Friction stir welding of aluminium alloys. International Materials Reviews, 54(2), pp. 49-93.

TOBER, G., \& SCHILLER, D. (2000). NDT in Aerospace - State of Art. 15th World Conference on Non-Destructive Testing, (p. Technical Programme). Roma. Fonte: EADS Airbus GmbH: http://www.ndt.net/article/wcndt00/papers/idn904/idn904.htm

TRUJILLO, M. (2015). Análise de defeitos de anodização em peça de liga de alumínio 6262-T6 extrudada e usinada. São Paulo.

VARGEL, C. (1999). Corrosion d'aluminium. Dunod.

WANG, S., \& STARINK T, M. (2004). The assessment of GPB2/S" structures in Al$\mathrm{Cu}-\mathrm{Mg}$ alloys. Materials Science and Engineering A, pp. 156-163.

WANG, S., \& STARINK, M. (2007). Two types of S phase precipitates in Al-Cu-Mg alloy. Acta Materialia, 55, pp. 933-941.

WANG, W., \& MURRAY, R. (2007). Electrochemistry and contact angles of an ionic liquid sessile droplet on films of monolayer protected Au Nanoparticles. Anal. Chem., 79, pp. 1213-1220.

WILMANN, K., \& MURRAY, R. (1983). Contact angle between water and a poly (vinylferrocene) film on a potential controlled platinum electrode. Analytical Chemistry, 55, pp. 1139-1142.

WILSON, R., \& PARTRIDGE, P. (1965). The Nucleation and Growth of OF S' Precipitates in an Aluminium-2.5\% Copper-1.2 \% Magnesium Alloy. Acta Metallurgica, 13, pp. 1321-1327.

ZAHRA, A.-M. Z., \& ZAHRA, C. (2001). Comment on 'Positron lifetime study of an Al-1.7 at.\%Mg-1.1 at.\%Cu alloy'. Philosophical Magazine Letters, 88(1), pp. 9-12.

ZHANG, W., \& FRANKEL, G. (2003). Transitions between pitting and intergranular corrosion in AA2024 . Electrochimica Acta, 1193-1210. 
ZHOU, X., LUO, C., HASHIMOTO, T., HUGHES, A., \& THOMPSON, G. (2012). Study of localized corrosion in AA2024 aluminium alloy using electron tomography. Corrosion Science, 58, pp. 299-306.

ZOU, F., \& THIERRY, D. (1997). Localized electrochemical impedance spectroscopy for studying the degradation of organic coatings. Electrochimica Acta, 42(20-22), pp. 3293-330.

ZUCCHI, F., TRABANELLI, G., \& GRASSI, V. (2001). Pitting and stress corrosion cracking resistance of friction stir welded AA5083. Materials and Corrosion, 52, pp. 853-859. 